\title{
THE DOC
}

UC-NRLF

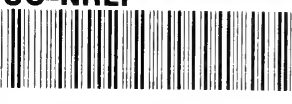

\$B 33 96 4

\section{BY WESLEY MILLS, M. D.}

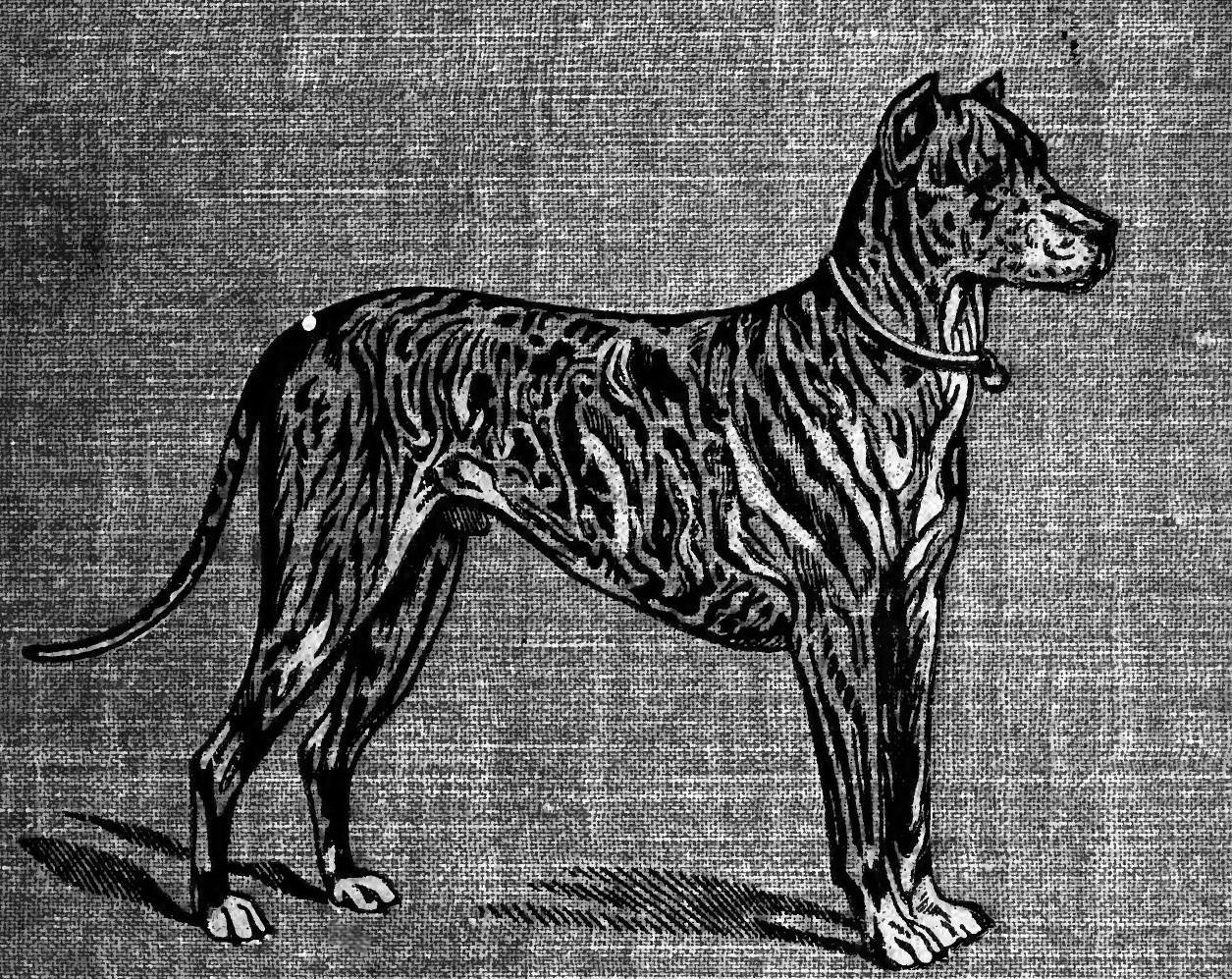




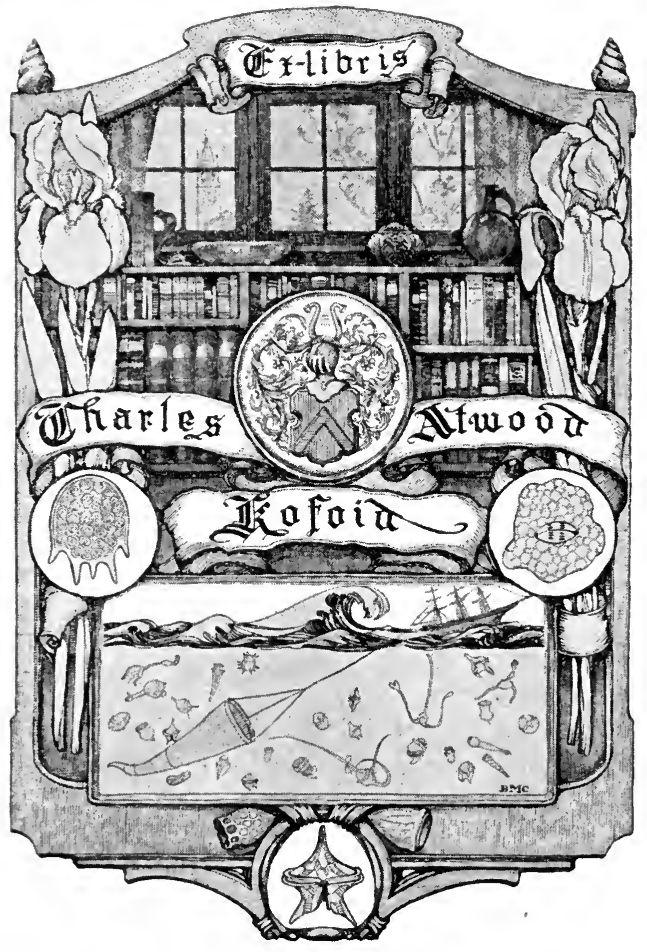




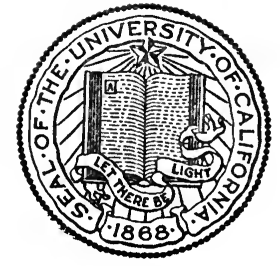

THE LIBRARY OF

\section{THE UNIVERSITY OF CALIFORNIA}

PRESENTED BY

PROF. CHARLES A. KOFOID AND

MRS. PRUDENCE W. KOFOID 




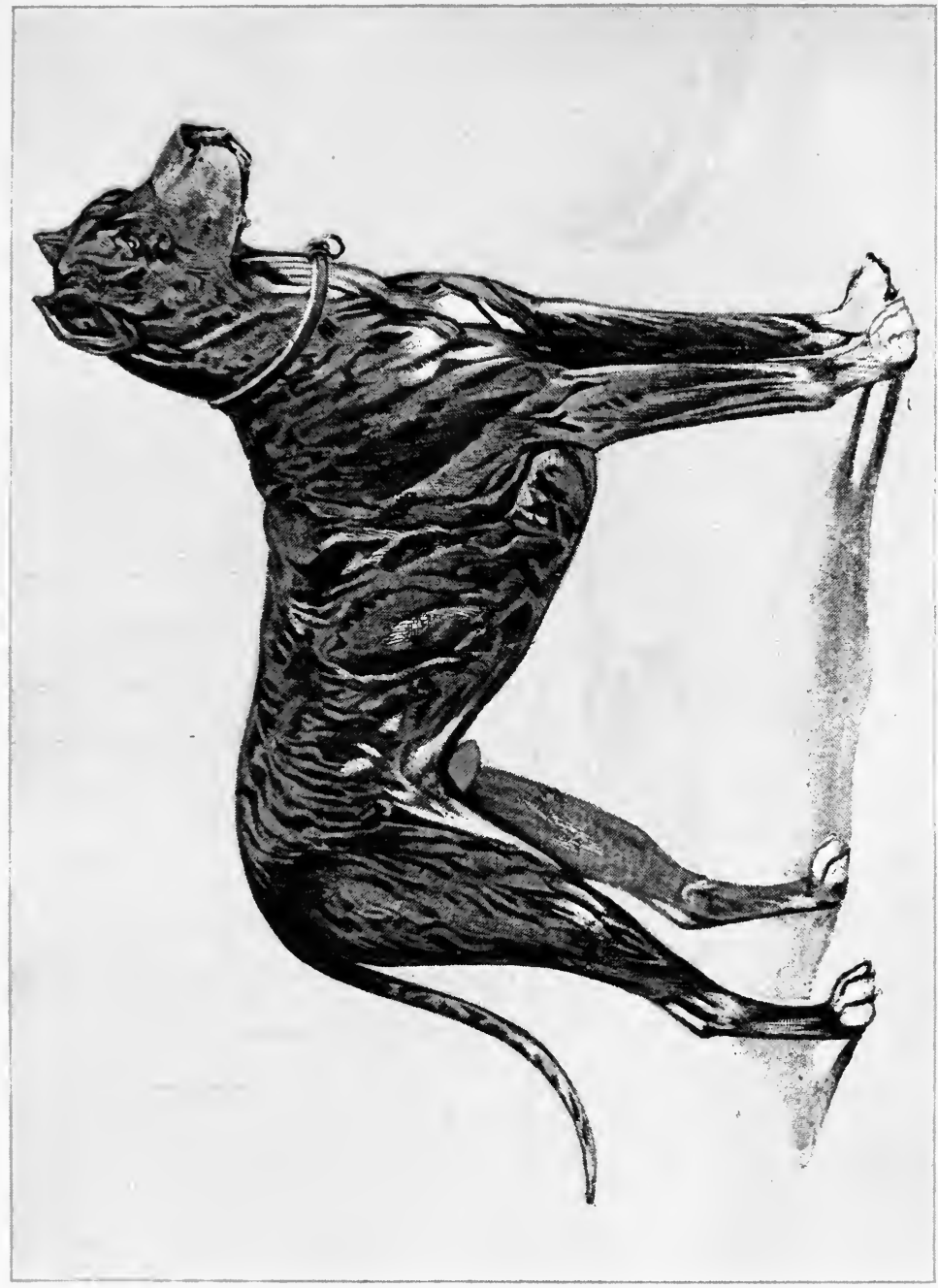

Nิ
ก
ले

$\infty$

is

j

$\dot{ }$

a

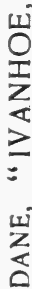

1

(I)

$\frac{\alpha}{0}$

돝 


\title{
THE DOG
}

\section{IN HEALTH AND IN DISEASE}

\author{
INCLUDING
}

HIS ORIGIN, HISTORY, VARIETIES, BREEDING, EDUCATION, AND GENERAL MANAGEMENT IN HEALTH, AND HIS TREATMENT IN DISEASE

BY

WESLEY MILLS, M. A., M. D., D. V. S., Etc.

PROFESSOR OF PHYSIOLOGY IN THE FACULTY OF HUMAN MEDICINE AND IN THE FACULTY OF COMPARATIVE MEDICINE AND VETERINARY SCIENCE OF MC GILL UNIVERSITY, MONTREAL ;

LECTURER ON CYNOLOGY IN THE LATTER FACULTY ; AUTHOR OF ANIMAL PHYSIOLOGY, COMPARATIVE PHYSIOLOGY, HOW TO KEEP A DOG IN THE CITY, ETC.

WITH FORTY-THREE FULLPAGE COTS, ONE COLORED PLATE AND NUMEROUS OTHER ILLUSTRATIONS

SECOND EDITION, REVISED AND ENLARGED

NE W YOR K

D. A P PLETON A N D COM PA N Y 
Copyright, 1892, 1895,

BX D. APPLETON AND COMPANY.

All rights reserved. 


\section{SF 427 $M 55$ 1895}

\section{PREFACE TO THE SECOND EDITION.}

That a second edition of this work has been called for in so short a time the author takes to be evidence that it meets a want. That it has been so kindly received by the press, the general public, and the veterinary profession, has encouraged him to do his best to bring this second edition up to date in even the smallest details. The author has seen no reason to change the general plan of the work, which he still deems the best because in accordance with the laws of the mind, viz., that the normal should be studied before the abnormal or diseased; and he is as fully as ever convinced that if the veterinarian is to secure the confidence of the public as regards canine medicine, he must give evidence of a knowledge of dogs as dogs-i. e., their nature and varieties, as well as their diseased conditions. In other words, the reterinarian must be a cynologist.

Some of the changes in this edition have been made in deference to the views of those whose authority carries weight in regard to the subjects of which they speak; others have been necessitated by the extraordi- 
nary advance in the science of medicine even since the date of publication of the first edition.

In addition to the usual corrections, revisions, etc., a glossary of terms in common use by dog fanciers has been introduced.

An effort has been made to maintain the reputation the work has won on account of the high character and abundance of its illustrations, by a few substitutions of more modern specimens and the addition of several fullpage cuts of breeds of dogs not illustrated in the first edition. For the originals of these the author is indebted to several persons who kindly allowed the use of cuts for the first edition, and also to Mr. James L. Little, of Brookline, Mass.; Mr. H. B. Donovan, editor of the Canadian Kennel Gazette, Toronto; Mr. L. A. Klein, of Black Lake; Mr. MacHaffie, of Cornwall, and others.

The index has also been rendered more complete, so that it is believed that the work will be found thoroughly accurate and up to date in all respects.

The author is led to hope that the book will be found worthy of the confidence of the general reader and of students and practitioners of veterinary medicine in the future as it has in the past.

The Author.

McGill University, Montreal, September, 1895. 


\section{PREFACE.}

W Iтн none of our friends and helpers among the lower animals would we part so reluctantly as with the dog. No speechless associate of man has ever so entwined itself around the very roots of our domestic life as the dog; none has won so much admiration, confidence, and affection; none has appealed to so large a number of mankind of every condition, age, and sex. It will therefore be conceded that so noble, so intelligent, and so faithful an animal as the dog is entitled to the most complete un. derstanding and the best usage of which we are capable.

The professional treatment of the dog in disease natu. rally falls to the veterinarian; but inasmuch as this animal is very different in his nature from the horse and other herbivora which engage the chief attention of the veterinary profession, it follows that if the $\operatorname{dog}$ is to be treated on a rational basis, he must be made a subject of special study by the veterinarian. A knowledge of equine medicine goes but a little way to qualify a man to treat the dog, and the sooner this is recognized by the profession of comparative (veterinary) medicine, the better will it be for both the profession and our canine friends. If the veterinarian hopes to largely acquire the confidence of the 
public as regards dogs, he must show not only that he has some grasp of medicine as medicine, but a special knowledge of the nature, varieties, and peculiarities of dogs. The dog must be understood in health before his ailments can be well appreciated and treated, and the more intelligent body of breeders and owners of dogs thoroughly realize this. The consciousness that there was no book treating of the dog in disease that recognized adequately the principles just set forth; a strong desire to better the condition of this noble animal, that for the greater part of the writer's life he has studied with pleasure and profit to his own nature; and an intimate knowledge of the condition and needs of the veterinary profession, explains the origin of this book, so far as the latter is concerned. The writer's experience as a teacher of canine medicine-or rather of the nature of the dog in both health and disease, for which the term cynology is an appropriate one-has convinced him that the study of the dog in disease should for veterinary students, as others, be preceded by his study in health, with as much thoroughness as circumstances will permit; hence the large amount of space given to the subject of the first part of this work.

But the book is by no means intended for students and practitioners of veterinary science alone. It is meant for all intelligent persons who breed, keep, or in any way take a special interest in the dog. Their number is very large, and is constantly increasing. While, therefore, the whole work has a scientific foundation, it has been kept as free from technicalities as possible, and will, it is hoped, be readily comprehensible by every intelligent person. 
It has been the aim constantly to set forth the principles that underlie the management of the dog in health and his treatment in disease, as by this course the individual reader is left free to exercise his own judgment while guided by a sort of mariner's compass the construction of which is based on the well-ascertained laws of life. It has further been the writer's aim to bring the book thoroughly up to date in all respects-hence the illustrations represent noted dogs of the day; and the medical principles and practice are modern and adapted to the real nature of the dog himself, and not to that of some other animal unlike him, as the horse, etc.

At the same time it has been thought well, so far as drugs are concerned, to avoid reference to such medicines as are now on trial merely, and with the virtues and dangers of which we are as yet but indifferently acquainted as regards man, much less the dog. This applies especially to that now large class known as antipyretics. They should be carefully tried on the dog by the expert; but to recommend them explicitly in a work of this kind seemed to the author hazardous.

But, leaving out of account the second part of the work, the first part will, it is thought, be in itself a valuable treatise on a new basis-i. e., a more rational basis - on the $\operatorname{dog}$ as he exists to-day. It has been the writer's constant endeavor to give the reason for every procedure.

Being deeply convinced that a work on the dog without good illustrations is of comparatively little value, especial pains have been taken to furnish models for judging the various breeds of dogs in the full-page plates, 
representing the best specimens as they exist at the present time. In selecting these, only one thing has been kept in view-viz., choosing those that seemed the very best, irrespective of every other consideration. Most of them have never appeared in any book on the dog before, but have been culled from the leading journals devoted to canine interests in Great Britain and America, such as the " $\mathrm{Ca}$ nine World," from which the colored plate and several others are borrowed; the "English Stock-keeper," and in America the "American Kennel Gazette," which has furnished the illustrations of the pointer "Bracket," the mastiff "Beaufort," etc., the artist of this periodical being Mr. G. Muss-Arnolt.

The sources of the cuts in the text are acknowledged by the way.

While the author has endeavored to produce a book founded on experience, with a thoroughly sound and scientific basis, in every way up to date and on a somewhat new plan, he realizes that there is much yet to learn about the $\mathrm{dog}$, and will receive with gratitude suggestions from any one who has true and accurate observations to communicate.

This, like every work and every man, has no doubt its shortcomings, but the kind way in which much that the author has written for various journals devoted to dogs has been received, and also his little book, "How to keep a Dog in the City" (William R. Jenkins, New York, and the Editor of the "Canadian Kennel Gazette," Toronto, publishers), leads him to hope for a generous reception of this work by the veterinary profession, breeders of dogs, and the public in general. 
In conclusion, the writer wishes to express his appreciation of the successful efforts of the publishers in the production of the work, including the illustrations, in such admirable form.

The Author.

Montreal, November, 1891. 



\section{CONTENTS.}

\section{Part I. The Dog in Health.}

The Oriaty and History of THe Dog.

The Zoölogical Position of tile Dog . • • • • • • 6

Anatomy of the Dog • . . . . . . . . 6

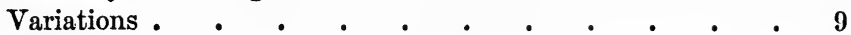

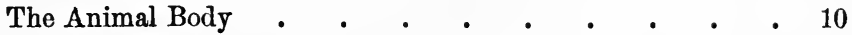

Psychic Characteristics of the Dog . . . . . . 15

Classification of Dogs . . . . . . . . . 18

Crass I.-Wild and Half-Reclaimed Dogs, ete. - • . 19

Standards • • • • • • • • • • • 21

Standards further considered • • . • • • $\quad$ • 25

Cuass II.-Dogs hunting chiefly by the Eye, etc. • • $\quad 34$

The English Greyhound . . . . . . • 34

The Deerhound . • • • . • • . • 36

The Russian Wolfhound or Barzoi • . • . • $\quad 37$

Class III.-Domesticated Dogs, hunting by Scent, which both

find and kill their Game $\quad$ • . . . . 38

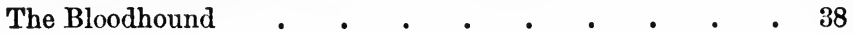

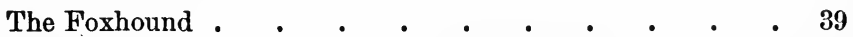

The Harrier . . . . . . . . . 41

The Beagle.$\quad$. $\quad . \quad$. $\quad . \quad$. 41

The Otterhound . . . . . . • . 42

The Bassethound ..$\quad$. . . . . 43

The Dachshund . • . . . . • . • 43

The Great Dane . . . . . . . . . . 43

The Terriers $\quad . \quad$ • $\quad$ •

The Fox-terrier . $\quad$ • $\quad$ •

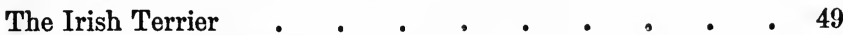

The Black-and-tan Terrier $\dot{x i}$ - . $\quad$ - $\quad 50$ 
The Yorkshire Terrier . . . . . $\quad 52$

The Scotch Terriers . . . . . . . . 53

The Bull Terrier . . . . . . . . 55

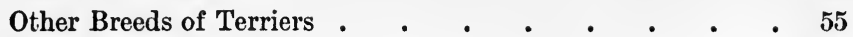

The Welsh Terrier . • . . . . . . 56

The Airedale Terrier •.$\quad$ • . . . . 56

The Dandie Dinmont Terrier • • • • • • 56

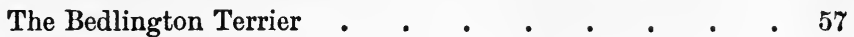

The Paisley Terrier . . . . . . . . 58

The Clydesdale Terrier $\quad$ • $\quad$ • $\quad$ • $\quad . \quad 58$

The Maltese Terrier • • • • • • • . 58

Class IV.-Domesticated Dogs, finding their Game by Scent

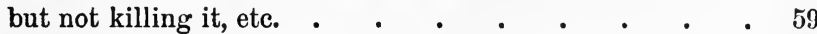

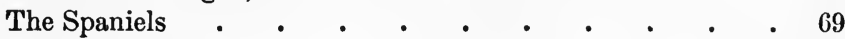

The Cocker Spaniel . $\quad . \quad$. $\quad$ • . . 69

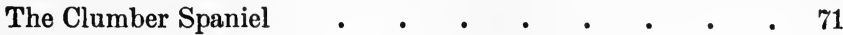

The Irish Water Spaniel . . . . . . . 72

The Retrievers . . . . . . . . . . 73

Differences between the Breeds . . . . . 73

The Chesapeake Bay Dog • . . . . . . . 74

The Dalmatian . • • • . . . • • . 74

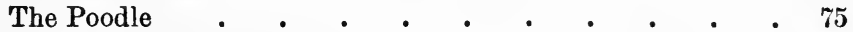

Class V.-Pastoral Dogs, etc. . . . . . . $\quad 76$

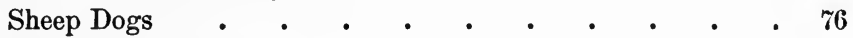

The Rough Collie . . . . . . . . $\quad$. 77

The Smooth Collie . . . . . . . . 57

The Bob-tailed Sheep Dog . . . • • . 78

The Pomeranian, Spitz, or Loup-Loup . • • • 78

The Black Newfoundland . . . . . . . 78

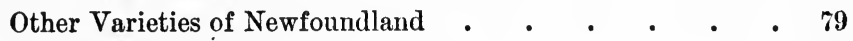

The Esquimau Dog . . • • • • . . 80

Class VI.-Watch-Dogs and House-Dogs . . . . $\quad$. 80

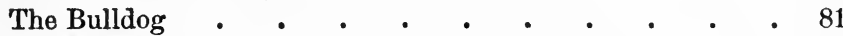

The Mastiff . . . . . . . . . 83

The St. Bernard . • . . . . . . . 86

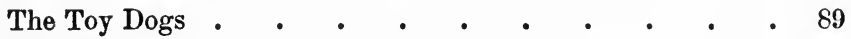

The Pug . • • . . . . . . . 90

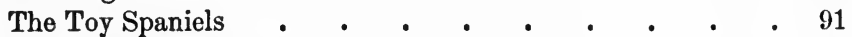

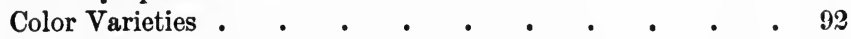

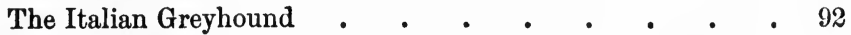

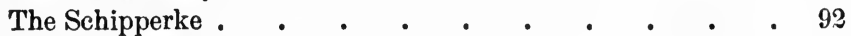

The Whippet . . . . . . . . . 93

The Mexican Hairless Dog. . . . . . . 93 
The Management of Dogs in Health

PAGE

\section{The Housing of Dogs}

Feeding

Exercise and Occupation

'The Care of the Dog's Skin

BREEDING .

Mating

The Care of the Stud Dog.

The Care of the Brood Bitch

WhelpiNG .

Choice of Puppies .

The Foster-Mother

The Rearing of Puppies . . . . . . . . . . 150

The Care of the Brood Bitch after Whelping • . . 148

Weaning Puppies . • • • . • . . • • • . 152

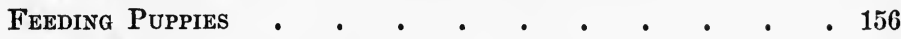

Other Management of Puppies . . . . . . . . 158

Exercise and Training of Puppies . . . . . . . 161

Retrieving • • • • • • • • • • • 167

Gun-shyness . . • . . . . . . . 168

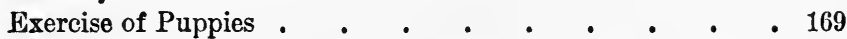

The Development of the Dog; Determination of Age • . 171

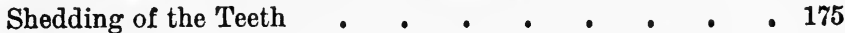

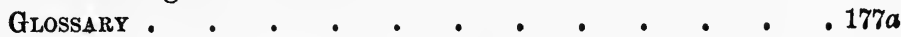

Part II. The Dog in Disease.

General Principles $. \quad . \quad . \quad . \quad . \quad . \quad . \quad . \quad .178$

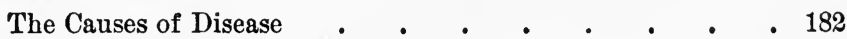

Normal Temperature of the Dog . . . . . . . 184

Fever • • • • • • • • • • • . 187

The Pulse . . . . . . . . . . . . . 187

The Methods of studying the Dog in Disease . . . 189

Remedies ANd their Mode of Use . . . . . . . 192

Drugs and their Administration . . . . . . . 193

Diet and Care of the Sick . . . . . . . . 198

Disinfection . . . . . . . . . . . 200

Autopsies and Morbid Anatomy . . . . . . . 201

Descriptions of Disease, Relative Prevalence, etc. • . 206

Diseases of the Respiratory Organs . . . • . . 209

Influenza $\cdot+\cdot \bullet^{\circ} \cdot \bullet^{\circ} \cdot \bullet^{\circ} 215$

Acute Laryngitis $\quad$ • . . . . . . . . 216

Pleurisy . . . . . . . . . . . 217

Bronchitis . . . . . . . . . . . . 221 
Pneumonia.

Asthma

Tuberculosis

Local Affections of the Nasal Passages.

Nasal Catarrh

Ozæna

Diseases of the Blood and Circulatory System Blood Diseases

Anæmia

Plethora

HearT-Disease .

Hypertrophy

Diseases of THE Blood-Vessels

Aneurism

Diseases of Veins

Diseases of Lymphatics and of Certain Glands

Bronchocele or Goitre

Diseases of the Alimentary Tract

Affections of the Mouth

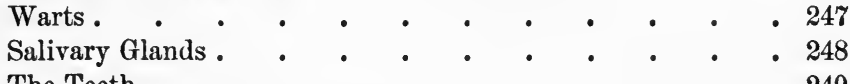

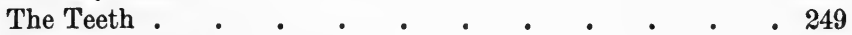

Inflammation of the Tongue $\quad . \quad$. $\quad . \quad$. $\quad$. 250

Blain • • . . . . . . . . . . 250

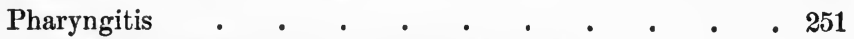

Functional Disorders of the Digestive Organs . . . 251

Salivation • • • • • • • • • • . 251

Vomiting . . . . . . . . . . . . . 251

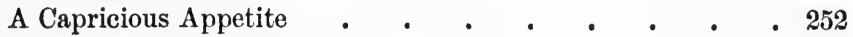

Irregularities of the Bowels $\quad . \quad$. $\quad . \quad$. $\quad . \quad$. 253

Obstruction . . . . . . . . . . . . 254

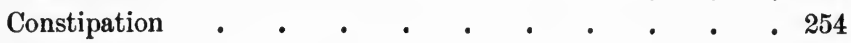

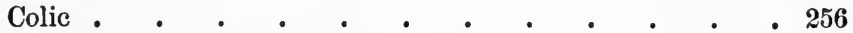

Inflammatory Affections of the Digestive Organs • . 257

Functional Disease of the Liver • • • • • • 266

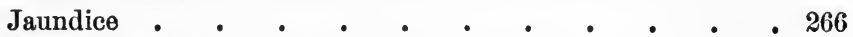

Organic Affections of the Liver • • • • • • . 267

Hepatitis . . . . . . . . . . . 267

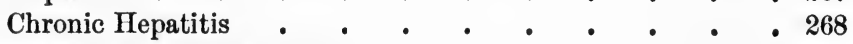

Degeneration of the Liver . • . . . • • . . 268

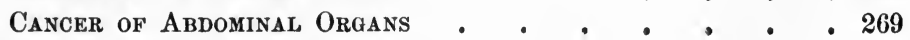

Intestinal Obstruction . • • • • • • • • 270

Diseased Conditions around tile Anus . . . . . . 271 
PAGE

Prolapse of the Rectum . . . . . . . . 271

Piles . • • . • . . . . . . . 272

Growths around the Anus. . . . . . . . 274

Perineal Abscess and Fistula in ano. . . . . . 274

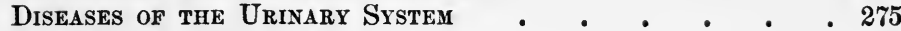

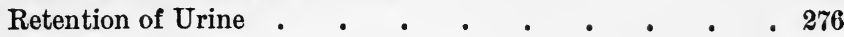

Acute Cystitis . . . . . . . . . . 278

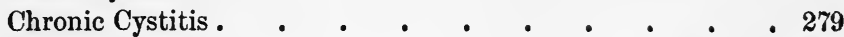

Nephritis • • • • • • • • • • • • 277

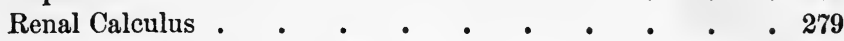

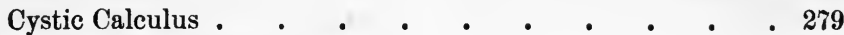

Diseases of the Genital Organs $\quad$ • . . . . . 280

Balanitis . . . . . . . . . . . 281

Morbid Growths • • . . . . . . 284

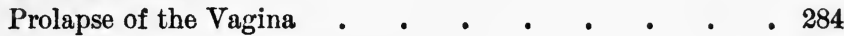

Metritis . . . . . . . . . . . . 285

Complications Incident to Parturition . • • . . 288

Malpresentations • • • • • • • • • 289

Post-partum Fever . . . . . . . . . 291

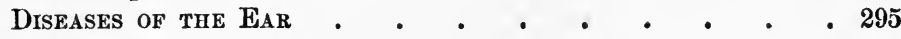

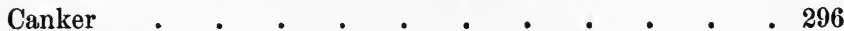

Otitis Media . . . . . . . . . . $\quad$. 300

Deafness . . . . . . . . . . . . 301

Polypus . . . . . . . . . . . . . . 301

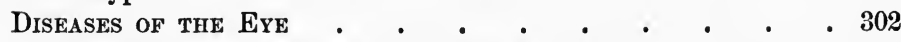

Diseases of the Protective Apparatus of the Eye . . . 305

Inflammation and Abscess of the Lachrymal Gland . . 306

The Lachrymal Ducts . . . . . . . . 306

Conjunctivitis . . . . . . . . . . . 306

Ophthalmia . . . . . . . . . . . . . 307

Ulcers of the Cornea . $\quad . \quad$. $\quad . \quad$. $\quad$. $\quad$. $\quad$. 309

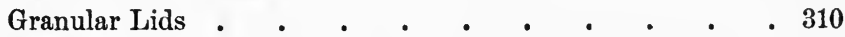

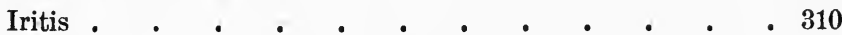

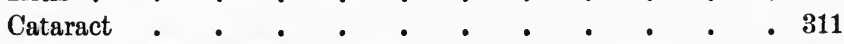

Amaurosis and Amblyopia $\quad . \quad$. $\quad$. $\quad . \quad$. 311

Dislocation . . . . . . . . . . . 312

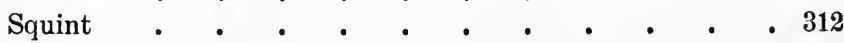

Diseases of the Nervous System • • • • • • • 312

Rabies (Hydrophobia) . $\quad . \quad$. $\quad . \quad$. $\quad . \quad$. $\quad .313$

Convulsions, Epilepsy, Fits, Apoplexy . 318

Epileptiform Convulsions . . . . . . . . . 319

Vertigo • . . . . . . . . . . 321

Apoplexy • . . . . . . . . . . . 321 
Paralysis

Meningitis

Hydrocephalus

Tetanus

Chorea

Injuries to the Brain .

Affections of the Nerves

Neuralgia

Diseases of the Skin

Ringworm .

Follicular Mange

Sarcoptic Mange

Eczema

Internal Parasites or Worms . . . . . . • . 345

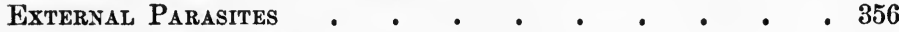

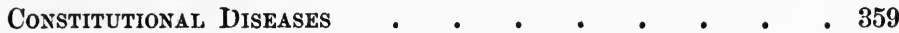

Erysipelas • • . • • • • • • • • • . 359

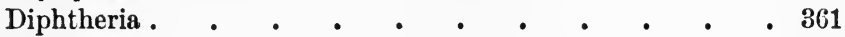

Dropsy • • • • • • • • • • . 362

Rickets . . . . . . . . . . . . .

Rheumatism • . • • • . • • • • . 365

Distemper • • . • • • • • • • •

Surgery of The DoG

Anæsthesia . . . • • . . • • . . . 381

Antisepsis . . . • • • • • • • • . 382

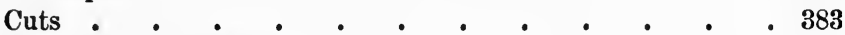

Sprains and Bruises . $\quad . \quad$. $\quad . \quad$. $\quad . \quad$. $\quad . \quad 384$

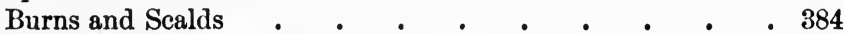

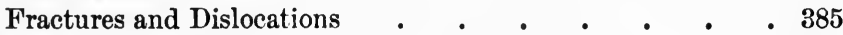

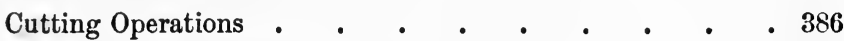

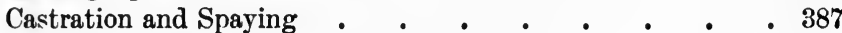

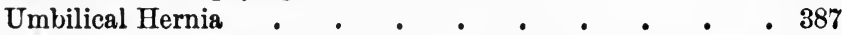

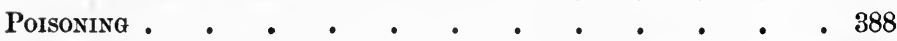

Stings. • . . . . . . . . . . . 392

Sanitary and Medical Aspects of Dog Shows . • . 393

Table of Doses of the Principal Druas . • • • • 396 


\section{FULL-PAGE ILLUSTRATIONS.}

Colored plate of the great Dane Itanhoe - Frontispiece The Greybound Fullerton . • • • • • • • . 10 The Scottish deerhound Rona III • • • • • 16 The Irish wolfhound Sheelah . • • • . . 24 The Russian wolfhound Krilutt • • • • • . 32 The bloodhound champion Cromwell . • • • • 40 The beagle champion Ringwood • • • • • • 48 The bassethound champion Chopette • • • • • . 52 The German Dachshund Isolani-Franconia • • • 56 The rough English Dachshund Woolsack. • • • 60 The SMOOTh-COATED FoX-TERRIER ChaMpion Blemton Victor II . 64 The rough-coAted fox-terriers $J_{\text {ACK }}$ St. Leger and Jigger .72 The Irish terrier Pilgrim • • • • • • • 80 The white English terrier Eclipse • • • • • 88 The Yorkshire terrier champion Ted • . • • 96 The Scottish terrier Argyle • . . . . . . 104 The Skye terrier Thurkill . • . • • • . . 120 The bull-terrier. Streatham Monarch • • • • . 136 The Boston terrier Prince Walnut . • • • • . 140 The Welsh terrier Brynhir Pardon. • • • • • 144

The Airedale terriers champion Newbold Test and champion VIXEN III • • • • • • • • • • • • 152 The Bedington terrier champion Humbledon Blue Box • 160 The polnter champion Bracket • • • • • • • 176 The English setter champion Dad Wilson • • • 184 
The Irish setter Geraldine II • • • • . .

The Gordon setter champion Bellmont • . • • . 208

The blaCK field SPANiel champion Buckle • • • . 216

The cocker spaniels Black Duke and Othello • . 224, 230

The Clumber spaniel Friar Boss . . . . . . 240

The Irish water spaniel champion Shaun. • • • . 256

The wavy-coated Retriever Darenth. • . • . . 264

The black-spotted Dalmatian Berolina • • • . 280

THE BLACK POOdLE ACHILles . . . . • • . . 300

The rough-coated collie Sefton Hero • • • • . 312

The bob-tail sheep dogs Grizzle Bob and Datry Maid . 320

The Newfoundland Mariner • • • • • • 328

The bulldogs The Graven Image, Holy Terror, and Bathos 344

The mastiff champion Beaufort . ‘ . . . . . 352

The rough-coated St. Bernard champion Sir Bedivere • • 368

The pug champion Loris • • • • • • • • 376

The ruby spaniel Ruby King . • • • • • • 384

The Italian greyhounds Winks and Idiom • • • 388

The Schipperkes Mia and Drieske . . . • . . 392 


\section{PAR T I. \\ THE DOG IN HEALTH.}

\section{THE ORIGIN AND HISTORY OF THE DOG.}

In order to understand an individual of any species of animals, it is important not only to know the circumstances under which it lives, but its past history; and the further and the more completely this can be traced the better, inasmuch as the particular animal under consideration may be regarded as the outcome or resultant of a vast number of forces extending back in fact to the origin of life itself.

To illustrate, suppose one finds that a certain greyhound for several successive years wins in the old-established English courses, we inquire why this particular dog has won. He may not seem superior in form of body to others that he surpasses in speed, but it is perhaps found that in his ancestry there is a long line of those that have excelled in this respect. This goes a long way to explain the pre-eminence of this dog. Then we may take up the general superiority in fleetness of this breed, and this leads to its origin and history. For ages the best and swiftest have been chosen to breed from, and in all probability, from the earliest times that man possessed the dog, this process 
of selection of the best was going on, consciously or unconsciously.

There was an ancient race of hounds not very unlike the present swift coursers in essential particulars. Is the breed used in the British Islands in any way related to the Roman hounds by descent, or have both arisen independently?

The characteristics of the greyhound, then, can not be understood apart from his history, nor from his origin. But regarding him simply as a dog, one of the large family of the Canidae, what has been as yet considered does not explain much.

Hence the necessity, if we would understand this greyhound as a dog, to inquire into the origin of the family group to which he belongs. In other words, we must seek for a more distant ancestry and learn if possible its history.

The subject has been very carefully studied by Charles Darwin, and no better treatment has been given it than may be found in his work, "Animals and Plants under Domestication." Briefly, the origin of the dog has been referred to the following sources: All the various breeds of dogs are believed by some to have descended from some single wild species of animal, while others hold that the evidence of descent from several is stronger. Some think the dog has been derived from several species, extinct and recent, more or less mingled. Some would refer the dog to the wolf, the jackal, or some unknown extinct species.

No view of the origin of the dog can be considered as proved; nevertheless, some are much more probable 
than others. Very few would now hold to a theory-at one time more acceptable-that all the principal varieties of dogs were derived from a distinct wild ancestral species.

In favor of the view that the dogs of the present and the past historical period were derived from several, or, at all events, more than one wild species, may be mentioned the following:

1. The great difference, especially in form, of the different breeds of dogs.

2. At the most anciently-known historical period several breeds existed resembling wild breeds then living.

Breeds of dogs allied to greyhounds are figured on Egyptian monuments between 3400 B. c. and 2100 B.c., though there is evidence that besides these breeds there were, thousands of years before our time, pariah dogs, greyhounds, other hounds, house-dogs, mastiffs, lap-dogs, turnspits, etc., which bear no small resemblance to the breeds of the present day; but there is not evidence to prove that these subvarieties are identical with those of the present time. But long before the historical period in Europe there is evidence that man possessed the dog. The resemblance of dogs, in different parts of the world, to wild species of animals, is suggestive of a multiple origin-i. e., an origin from several wild stocks. Considering man's sociable nature, the tendency of many wild species resembling our dogs to hunt in packs-which animals are more readily tamed-the attempt to tame the young of such species can be readily understood, and its success would be followed by fresh attempts as soon as it was perceived how useful they might be in the chase, 
which was the chief occupation of primitive and uncivilized men.

That the dogs possessed by the aborigines of North America bear a close resemblance to the various kinds of wolves found wild in these regions is a matter of frequent observation. It is further well known that the dogs of the natives breed freely with wolves, and the same remarks apply to some breeds of dogs of Europe and other parts of the world. There is equally good evidence to believe that some breeds of dogs are to be referred to the jackal. Upon the whole, it would seem probable that "the domestic dogs of the world are descended from two well-defined species of wolf (viz., Canis lupus and Canis latrans), and from two or three other doubtful species (namely, the European, Indian, and North African wolves); from at least one or two South American canine species; from several races or species of jackal; and perhaps from one or more extinct species" (Darwin).

But this origin of the dog being only probable and not demonstrable, we are entitled to ask whether it makes the nature of the dog as we know it to-day more intelligible than the theory that he is derived from some wild forms long since extinct and of which we know little or nothing. In other words, referring to our illustration, is the greyhound more readily understood as a dog and as a courser on this hypothesis of origin from some wild forms now existing? Without going into details at this time, we agree with those who think that without some such theory the chain of natural connections can not be forged, but that with it a flood of light is thrown on the whole nature of the dog, even to his minutest traits and 
habits. This is rendered clearer when the changes in the habits and instincts of the supposed wild ancestors of the dog under confinement and domestication are considered, and the corresponding change in dogs when they become feral. Thus most of the wild forms alluded to, strictly speaking, do not bark as the dog; but cases are on record that show that such wild forms may learn to bark in confinement, while dogs that have become feral lose this trait, and so with many other characteristics of the dog.

The great diversity of physical and psychic characteristics in the different breeds of dogs is to be explained by crossing, selection, and environment.

Crossing tends to modify in all respects the existing form and character, selection to fix a type, and environment to alter particularly the more transient or less permanent characteristics, and produce strains, or those combinations of form and qualities more difficult to detect and often affecting the vitality of the breed.

To illustrate the last statements : a highly-bred bulldog was crossed with a similarly well-bred greyhound, with the result that, in a few generations, the bulldog form was scarcely discernible, though the effects were manifest in the stamina and psychic characteristics for many generations. This interesting experiment is given at length in Stonehenge's work on the dog, and illustrated by cuts of the animals produced. That the greyhound is such a specialist is doubtless owing to the fact that, for a long period in Britain alone, he has been used for the sole purpose of coursing rabbits, in connection with which public competitions have been instituted, leading to choice of those best suited for breeding purposes and the great- 
est care in selection and rearing-that is, the puppies are, at a certain age, retained or rejected according to the merit they display. Long before this, Nature will have weeded out those that were feeble and unresisting; in other words, those perish that have insufficient stamina by a process of "natural selection," as opposed to the previous kind of selection by man, or "artificial selection."

By the environment is meant the whole combination of circumstances that enters into the life of the animal-as food, housing, exercise, climate, etc.-in fact, everything not implied in breeding and selection.

Even those extremes of form seen in the gigantic St. Bernard of two hundred pounds and the toy terrier of five pounds are to be explained chiefly on the above principles, though of course a possible origin from different wild forms complicates the problem. Great as is the influence of environment, greater by far are the effects of crossing and selection, as every breeder of experience knows.

The history of the different breeds of dogs is involved in so much obscurity that there is little agreement on this subject. But it is very doubtful if any people, savage or civilized, has been without the dog, while it seems equally probable that this noble animal will continue to be man's companion as long as human nature endures.

\section{THE ZOÖLOGICAL POSITION OF THE DOG.}

His Anatomy.-Whether the origin of the dog be as above described or not, his structure justifies placing him among the carnivora.

This is especially evident in the teeth, which are adapted for seizing, tearing, and cutting rather than grind- 
ing, as may be readily observed by comparing the teeth of the dog (pages 174 and 175) with those of some ruminant like the ox. Moreover, while the jaws of the ruminant have very free fore-and-aft and lateral movements, those of the dog are restricted almost wholly to the vertical plane.

Such teeth, moreover, are the principal weapons of defense and attack in the dog as in other carnivora.

The limbs have freely movable toes or digits armed with strong and sharp claws.

Mostly the carnivora are digitigrade, have a strong odor, are widely distributed, and have a two-horned uterus, all of which applies to the dog, even to the odor which is so pronounced in some breeds that in the house they are unpleasant companions, though this feature can be greatly modified by feeding, etc.

On the next page is given a cut of the skeleton of the dog and the technical names applied to its various parts.

To bring the structure of the dog into comparison with that of man we must place man on all fours, suppose his jaws greatly lengthened out, his skull much flattened and reduced in size, his chest flattened somewhat from side to side, one rib added, his clavicle or collar-bone absent, and, of course, his dentition modified to the carnivorous type.

Turning to the limbs, we must suppose him to walk on his fingers and toes (digits), which have been somewhat bent or flexed, and the nails elongated, thickened, narrowed, and pointed. It will follow that the bones between the digits and the wrist or ankle will be placed more or less vertically, while what is known as the wrist in man will become the "knee" in the dog, and the heel 


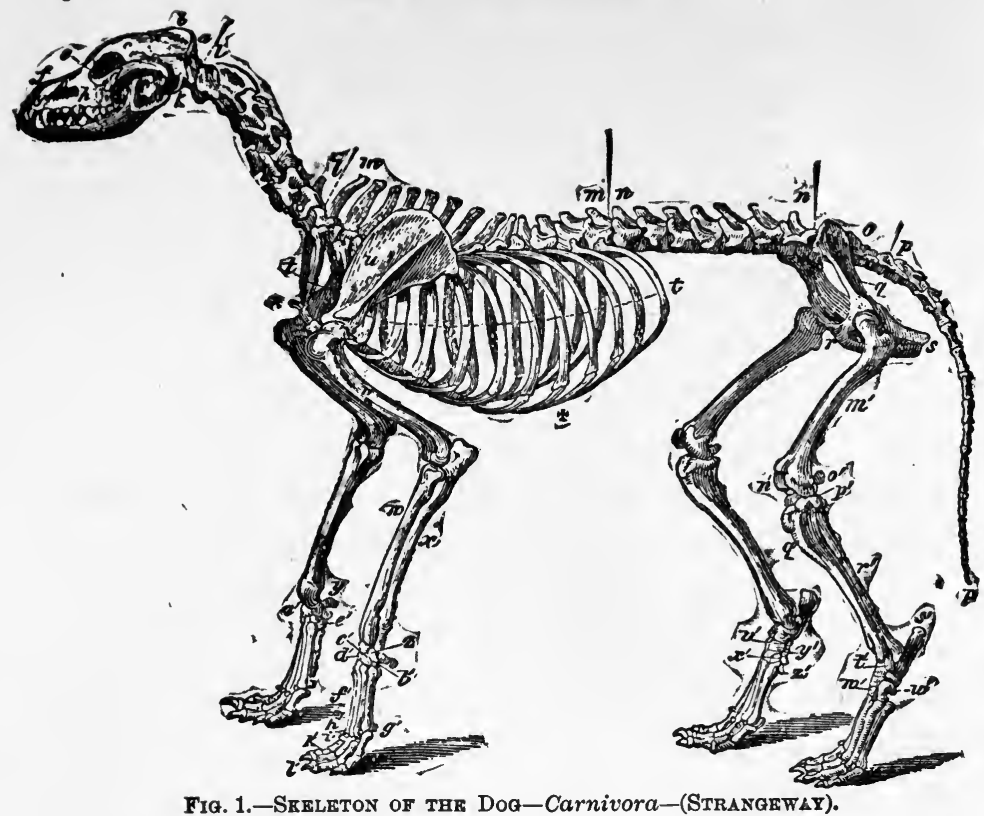

Axial Skeleton.

The Skull. Cranial Bones. $-a$, Occipital, 1; b, Parietal, 2; $c$, Frontal, 2; $k$, Temporal, 2; Sphenoid, 1; Ethmoid, 2; Auditory ossicles, 8. Facial Bones. $-f$, Nasal, 2; $e$, Lachrymal, $2 ; d$, Malar, $2 ; h$, Maxilla, $2 ; g$, Premaxilla, $2 ; i$, Inferior maxilla, 2; Palatine, 2; Pterygoid, 2; Vomer, 1; Turbinals, 4; Hyoid (segments), 9. Teeth.-Incisors, 12; Canines, 4; Molars, 26.

The Trunk. $-l l$, Cervical vertebræ, $7 ; m m$, Dorsal vertebræ, $13 ; n n$, Lumbar vertebræ, 7; $o$, Sacrum (three segments), $1 ; p p$, Coceygeal vertebræ (variable), 20 ; $t$ t, Ribs, 26 ; * Sternum (eight sternebræ), 1 ; * Costal cartilages.

\section{Appendicular Skeleton.}

Pectoral Limb. $-u$, Scapula, $2 ; v$, Humerus, $2 ; w$, Radius, $2 ; x$, Ulna. Carpus. $-y$, Trapezium, $2 ; z$, Cuneiform, $2 ; a^{\prime}$, Scaphoid, $2 ; b^{\prime}$, Unciform, $2 ; c^{\prime}$, Magnum, $2 ; d^{\prime}$, Trapezoid, $2 ; e^{\prime}$, Pisiform, 2 ; Metacarpal bones, $10 ; h^{\prime}$, Anterior sesamoids, $10 ; g^{\prime}$, Posterior sesamoids, 20. Digit.- $i^{\prime}$, Proximal phalanges, 10; $k^{\prime}$, Mesian phalanges, 8 ; $l^{\prime}$, Distal phalanges, 10 ; Small sesamoids wanting.

Pelvic Limb. Pelvis.-Os Innominatum. $-q$, Ilium, $2 ; r$, Pubis, $2 ; s$, Ischium, 2. The Limb. $-m^{\prime}$, Femur, $2 ; o^{\prime}$, Fabellæ, $4 ; n^{\prime}$, Patella, $2 ; q^{\prime}$, Tibia, $2 ; p^{\prime}$, Tibial sesamoid, $2 ; r^{\prime}$, Fibula, 2. Tarsus. $-s^{\prime}$, Calcaneum, $2 ; t^{\prime}$, Astragalus, $2 ; u^{\prime}$, Cuboid, $2 ; v^{\prime}$, Superior cuneiform, $2 ; w^{\prime}$, Ecto-cuneiforme, $2 ; x^{\prime}$, Meso-cuneiforme, $2 ; y^{\prime}$, Endo-cuneiforme, 2. Metatarsus.-Large bones, 8; $z^{\prime}$, Small bones, 2; Anterior sesamoids, 8; Posterior sesamoids, 16. Digit.-Proximal phalanges, 8; Mesian phalanges, 8; Distal phalanges, 8; Small sesamoids wanting.

\section{Visceral Skeleton.}

Os penis, 1; Rudimentary clavicle (inconstant), 2.

The bones of the Carnivore Skeleton, thus considered, are 345 . 
and ankle of man the "hock" of the dog. Usually, in the dog the innermost toe is rudimentary (dew-claw), though the feet, like other parts of this animal, vary a good deal.

Variations.-There is scarcely a physical feature in which dogs do not vary, as will be more evident after an examination of the peculiarities of different breeds. Some of these, however, are of scientific interest and worthy of notice in passing. It might almost be said that there is not a bone in the framework of this animal which does not vary in the different breeds of dogs, not to speak of differences in size, coat, carriage, and psychic traits. The shape of the head is not identical in any two breeds-a difference which generally extends to the bones composing it. Correlated with this are differences in the size and shape of the brain. Possibly also, in some cases at all events, variations in the shape, and especially the number, of the teeth are to be referred to modifications in the size and shape of the jaws. The almost entire absence of teeth, as in the Turkish dog, is to be regarded in the light of defective development, as also the lack of hair in the Mexican hairless variety. In large breeds of dogs there seems to be a tendency to the development of a fifth toe, especially behind. The extent to which the feet are webbed-i. e., the toes united by skin-is also variable and characteristic of some breeds. But, in fact, dogs vary in every possible respect, both physical and psychical, as even a moderately careful study of the different breeds will show, and this illustrates the remarkable power of animals to vary under domestication. One of the subjects of great interest in the study of this animal 
is the modification that his nature undergoes in relation to the climate and modes of life of the peoples among whom a particular breed happens to be developed.

English dogs, especially of some breeds, like Englishmen themselves, fail to adapt readily to certain climates, as those of India and Africa.

In order to understand the dog, either in health or disease, it is indispensable to know something of the way in which animals live, move, and have their being-in other words, the conditions of animal existence. From time to time this subject will be referred to in detail as it concerns the dog. In the mean time the following brief outline * may serve a good purpose, alike for those who have and those who have not studied physiology as a science:

The Animal Body.-An animal may be made up of a single cell in which each part performs much the same work; or, if there be differences in function, they are illdefined as compared with those of higher animals. The condition of things in such an animal (as $A m c e b a$ ) may be compared to a civilized community in a very crude social condition. When each individual tries to perform every office for himself, he is at once carpenter, blacksmith, shoemaker, and much more, with the natural result that he is not efficient in any one direction. A community may be judged in regard to its degree of advancement by the amount of division of labor existing within it. Thus is it with the animal body.

Looking to the existing state of things in the universe, it is plain that an animal to attain to high ends must have

* Taken, with some modifications, from the author's Comparative Physiology. D. Appleton \& Co., New York, 1890. 


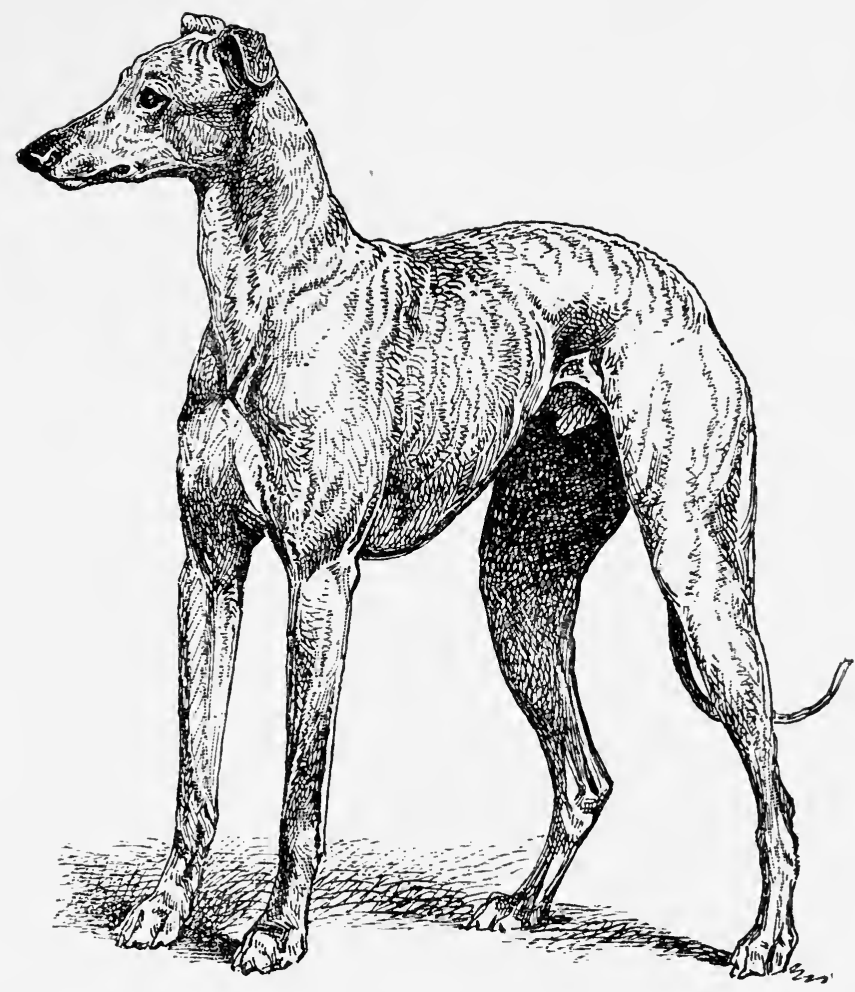

THE GREYHOUND FULLERTON.

Thrice winner of the Waterloo Cup, the most valuable of all coursing prizes.

For description, see page 31. 


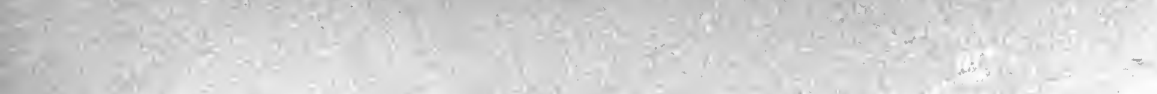

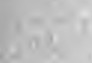

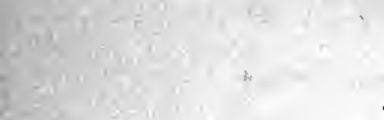

. - 
powers of rapid locomotion, capacity to perceive what makes for its interest, and ability to utilize means to attain this when perceived. These considerations demand that an animal high in the scale of being shall be provided with limbs sufficiently rigid to support its weight, moved by strong muscles, which must act in harmony. But this implies abundance of nutriment duly prepared and regularly conveyed to the bones and muscles. All this would be useless unless there was a controlling and energizing system capable both of being impressed and originating impressions. Such is found in the nerves and nervecenters. Again, in order that this mechanism be kept in good running order, the waste of its own work (metabolism), which chokes and poisons, must be got rid of-hence the need of excretory apparatus. In order that the nervous system may get sufficient information of the world around, the surface of the body must be provided with special message-receiving offices in the form of modified nerve-endings. In short, it is seen that an animal as high in the scale as a mammal must have muscular, osseous (and connective), digestive, circulatory, excretory, and nervous tissues; and to these may be added certain forms of protective tissues, as hair, nails, etc.

The whole physiological story for one of the higher animals, including the dog, may be thus told in brief :

The blood is the source of all the nourishment of the organism, including its oxygen supply, and is carried to every part of the body through elastic tubes, which, continually branching and becoming gradually smaller, terminate in vessels of hair-like fineness in which the current is very slow-a condition permitting that interchange be- 
tween the cells surrounding them and the blood which may be compared to a process of barter, the cells taking nutriment and oxygen and giving (excreting) in return waste products. From these minute vessels the blood is conveyed back toward the source whence it came by similar elastic tubes, which gradually increase in size and become fewer. The force which directly propels the blood in its onward course is a muscular pump (heart), with both a forcing and suction action, though chiefly the former. The flow of blood is maintained constant owing to the resistance in the smaller tubes on the one hand and the elastic recoil of the larger tubes on the other; while in the returning vessels the column of blood is supported by elastic double gates (valves), which so close as to prevent reflux. The oxygen of the blood is carried in disks of microscopic size, which give it up in proportion to the needs of the tissues past which they are carried.

But in reality the tissues of the body are not nourished directly by the blood, but by a fluid derived from it and resembling it greatly in most particulars. This fluid bathes the tissue-cells on all sides. It also is taken up by tubes that convey it into the blood after it has passed through little factories (lymphatic glands), in which it undergoes a regeneration. Since the tissues are impoverishing the blood by withdrawal of its constituents and adding to it what is no longer useful and is in reality poisonous, it becomes necessary that new material be added to it and the injurious components withdrawn. The former is accomplished by the absorption of the products of food digestion and the addition of a fresh supply of oxy- 
gen derived from without, while the poisonous ingredients that have found their way into the blood are got rid of through processes that may be, in general, compared to those of a sewage system of a very elaborate character. To explain this regeneration of the blood in somewhat more detail, we must first consider the fate of food from the time it enters the mouth till it leaves the tract of the body in which its preparation is carried on.

The food is in the mouth submitted to the action of a series of cutting and grinding organs worked by powerful muscles; mixed with a fluid which changes the starchy part of it into sugar, and prepares the whole to pass farther on its course. When this has been accomplished, the food is grasped and squeezed and pushed along the tube, owing to the action of its own muscular cells, into a sac (stomach), in which it is rolled about and mixed with certain fluids of peculiar chemical composition derived from cells on its inner surface, which transform the proteid part of the food into a form susceptible of ready use (absorption). When this saccular organ has done its share of the work, the food is moved on by the action of the muscles of its walls into a very long portion of the tract in which, in addition to processes carried on in the mouth and stomach, there are others which transform the food into a condition in which it can pass into the blood. Thus all of the food that is susceptible of changes of the kind described is acted upon somewhere in the long tract devoted to this task. But there is usually a remnant of indigestible material which is finally evacuated. How is the prepared material conveyed into the blood? In part, directly through the walls of the minutest blood-vessels distrib- 
uted throughout the length of this digestive tube, and in part through special vessels with appropriate cells covering them, which act as minute porters (villi).

The impure blood is carried periodically to an extensive surface (lungs), usually much folded, and there exposed in the hair-like tubes referred to before, and thus parts with its excess of carbon dioxide and takes up fresh oxygen. But all the functions described do not go on in a fixed and invariable manner, but are modified somewhat according to circumstances. The forcing-pump of the circulatory system does not always beat equally fast; the smaller blood-vessels are not always of the same size, but admit more or less blood to an organ according to its needs.

This is all accomplished in obedience to the commands carried from the brain and spinal cord along the nerves. All movements of the limbs and other parts are executed in obedience to its behests; and, in order that these may be in accordance with the best interests of each particular organ and the whole animal, the nervous centers, which may be compared to the chief officers of, say, a telegraph or railway system, are in constant receipt of information by messages carried onward along the nerves. The command issuing is always related to the information arriving.

All those parts commonly known as sense-organs-the eye, ear, nose, tongue, and the entire surface of the body -are faithful reporters of facts. They put the inner and outer worlds in communication, and without them all higher life at least must cease, for the organism, like a train directed by a conductor that disregards the dangersignals, must work its own destruction. Without going 
into further details, suffice it to say that the processes of the various cells are subordinated to the general good through the nervous system, and that susceptibility of protoplasm to stimuli of a delicate kind which enables each cell to adapt to its surroundings, including the influence of remote as well as neighboring cells. Without this there could be no marked advance in organisms, no differentiation of a pronounced character, and so none of that physiological division of labor which will be inferred from our brief description of the functions of a mammal. The whole of physiology but illustrates this division of labor.

It is hoped that the above account of the working of the animal body, brief as it is, may serve to show the connection of one part functionally with another, for it is much more important that this should be kept in mind throughout than that all the details of any one function should be known.

\section{PSYCHIC CHARACTERISTICS OF THE DOG.}

We use the term psychic in contrast with physical as implying all that relates to the mental traits and the disposition; in fact, all not purely animal or physiological. The term is of wider significance than either "mental" or "moral," and includes both.

While no doubt savages and prehistoric men early perceived that the dog possessed qualities which would aid them in accomplishing the aims of their life in the chase, etc., a little reflection will show that, apart from those characteristics which have made this animal man's closest companion of all the forms of life below him, the useful 
properties of the dog would have been of little service to the human race. Many of the wild congeners of the dog equal or excel him in hunting for game, etc., but such animals are rather the enemies than friends and helpers of man. But it is because the dog is teachable, tractable, and adaptive, as well as courageous and intelligent, that he has in all ages been one of man's most useful servants. There are, however, other reasons why all peoples and nearly all individuals have a kindly leaning toward the dog. Scarcely surpassed in intelligence by any known animal, teachable in a high degree, ready to adapt cheerfully to every condition of life, however much hardship it may involve, fitted for so wide a range of duties, forgiving without stint, meeting every wish of his owner even to whims and caprices, contented with the homeliest fare and the rudest shelter, so that he may but win his master's approbation, faithful in many instances even unto death, it is not surprising that in every age, in every clime, by the lowest savages and by men of the highest talents and attainments, the dog has been held in the greatest esteem and, after a fashion, made a member of the family circle.

The individual that can see notling to admire in the dog is surely defective either by nature or by educationin fact, a sort of human monstrosity.

The psychic characteristics of the dog have probably been more studied than those of any other animal. He has been the theme of historians, philosophers, scientists, and poets for ages, and yet the author ventures to think that, with increasing knowledge and changing views of the relations of things in the universe, the field is still open to culture and worthy of the best human abilities. 


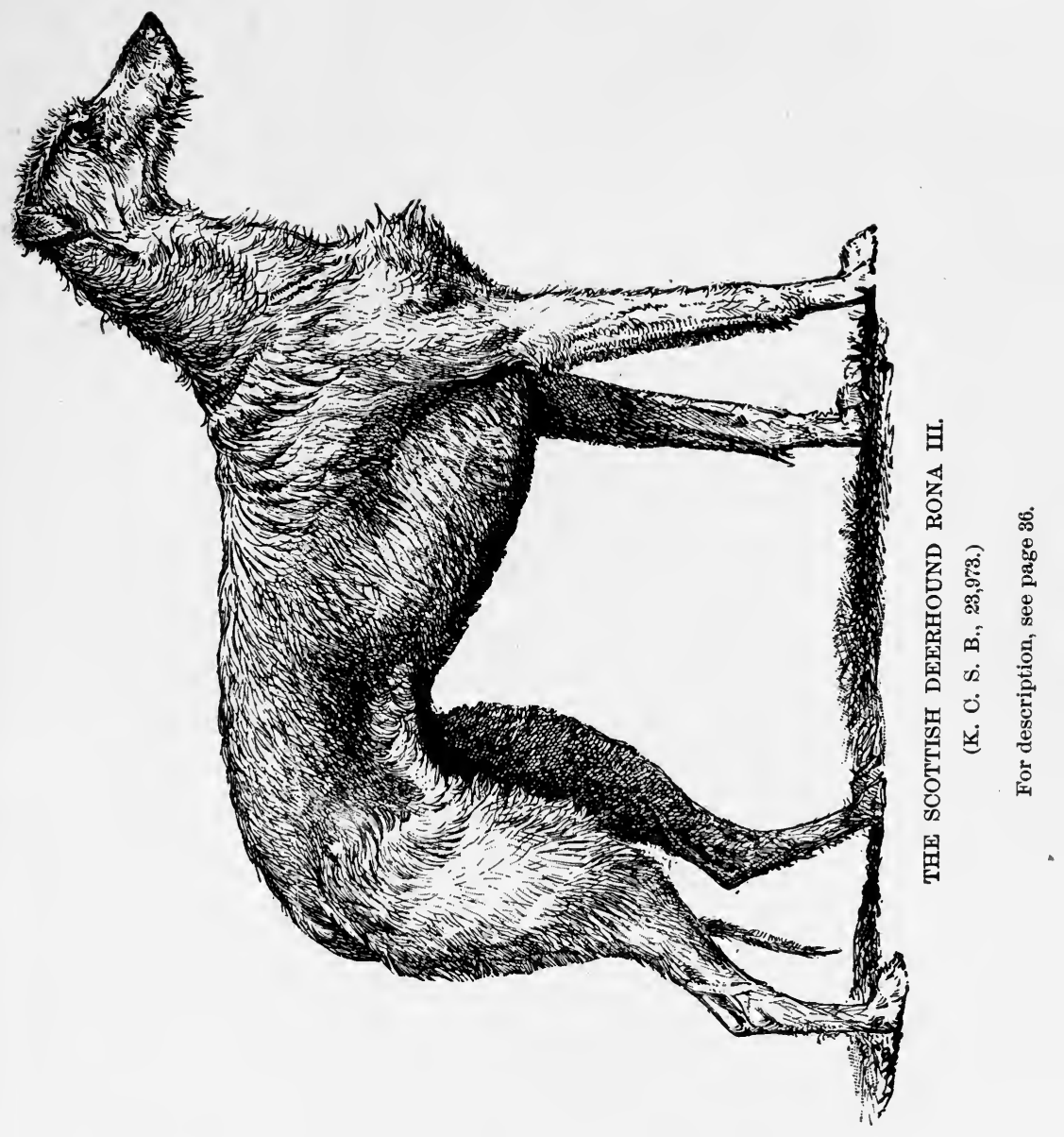


The dog is deserving of man's respect, for he seems to possess in some degree of development every mental if not also every moral faculty of man himself in so far as they can exist apart from the possession of speech. In not a few respects is the dog the superior of his master. If he can not do all that the latter can, is it not also true that there is much that he can accomplish quite impossible to man?

The author has long been impressed with the belief that in regarding the dog as very like ourselves in physical constitution, as shown by the similar action of drugs, poisons, etc., and in psychic characteristics, we are better prepared to understand this animal than on any other assumption.

While he greatly resembles the cat in some of his physical qualities, he differs from this animal in many others; and it is certain that the dog may be treated in all respects more as if he were a child than as bearing any close relationship to our other domestic animals. This will be explained more fully later; but at the present the writer wishes to impress this on the reader, whether he be a professional student or not, as he is deeply convinced that the training, general management, and medical treatment of the dog will be infinitely better carried out on this basis than any other-a view which it is a great satisfaction to know is entertained by some of our most thoughtful breeders as well as most careful students of comparative psychology and medicine.

For some time the author has been making a careful study of the entire development of puppies from birth onward, and this has greatly strengthened this conviction. 
The development of the puppy and the child are nearly parallel up to a certain stage, when the use of language begins. Previous to that the puppy, in many respects at least, surpasses the infant; after that the child is of course, on the whole, greatly in advance of the dog. As this idea of human resemblance will be the guiding principle throughout this book, it need not be further dwelt upon just now.

\section{CLASSIFICATION OF DOGS.}

There can be no doubt that the existing varieties of the dog have been produced by crossing and selection, chiefly aided by the influence of all that enters into the term "environment." Certain breeds have almost or quite disappeared, and so rapidly are the varieties known in any one country modified that the dog of to-day is in some cases so different from his ancestors of twenty years ago as to be scarcely recognizable as of the same breed, owing to the modifications produced in the way mentioned above. There is in reality no limit to the number of breeds that may be produced.

The great French naturalist, Cuvier, attempted to give dogs a scientific classification founded on the shape of the head, length of the jaws, etc., while these prominent parts were by him supposed to vary with the peculiar qualities, habits, etc., of the breed. It does not seem possible to classify dogs in this way on a strictly natural basis. As the purpose for which in the main a breed is used by man has much to do with both its form and psychic characteristics, the classification adopted by Stonehenge is at least suggestive. It is as follows : 
1. Wild and half-reclaimed dogs, hunting in packs.

2. Domesticated dogs, hunting chiefly by the eye, and killing their game for the use of man.

3. Domesticated dogs, hunting chiefly by the nose, and both finding and killing their game.

4. Domesticated dogs, finding game by scent, but not killing it; being chiefly used in aid of the gun.

5. Pastoral dogs, and those used for the purposes of draught.

6. Watch-dogs, house-dogs, and toy dogs.

7. Crossed breeds, retrievers, etc.

\section{CLASS I.}

The most important are the dingo, the dhole, the pariah, the wild $\operatorname{dog}$ of Africa, and the North and the South American dogs.

The dingo is about twenty-four inches high, and greatly resembles the fox in appearance, with a head somewhat between that of the wolf and fox, but, unlike the fox, the tail is carried curled over the hip. He may be tamed to some extent and will breed with domesticated dogs.

The dhole, or native wild dog of India, closely resembles the dingo, except that the tail is not bushy. He attacks various kinds of wild animals, including the tiger; and is of great speed and endurance.

The pariah is the name given to those dogs that abound in the villages of India, and, though without masters proper, seem ready to become the hunting companion of any one who may encourage them. They are used to hunt many varieties of game, as well as the tiger and wild boar. 
The wild African dogs (Ekia or Deab) are unclaimed, half-wild, despised animals, living on the refuse of the village streets or on wild animals they hunt on their own account. They are rather large, resemble the wolf, and are very fierce, illustrating well how usage affects the dog for evil as well as for good.

Wild American dogs are now somewhat scarce, but at one period were no doubt numerous enough.

The characteristics and mode of life of these varieties of the canine race throw much light on not a few points that are peculiar to the dog as we know him in civilization, and lend strong probability to the views as to the origin of this animal set forth in these pages.

In almost every neighborhood there are dogs that are relatively wild, and many a one, left behind to shift for himself when the family to which he belonged has moved away, has in the struggle for existence become a midnight marauder or a canine vagabond-possibly a dangerous one. The author has known of dogs that committed depredations on flocks of fowls of the neighborhoods in which they prowled about that were long attributed to foxes, till at last these vagrant animals were discovered in the act.

He has also known several dogs in the outskirts of a large city in this country take up their temporary abode in vacant lots or open fields, where a little straw or similar bedding might be found, associate with them other dogs that soon learned to be of habits more or less like their own, constituting a sort of pack that lived by visiting the barrels set out for the scavengers, such animals being a menace both to human beings and well-behaved dogs that avoided such company. This state of things has brought 
the canine race into much discredit with those who did not reflect that man is himself wholly responsible for it.

Standards.-Before proceeding to give the points, etc., of the various breeds of dogs coming under the subdivisions of the preceding classification still to be treated, it will be profitable to consider the subject of a "standard," or the description of the characteristics of any variety of the canine species. In this case again reference to the origin of standards may not be without interest. Long ago a large number of standards were printed in Stonehenge's admirable work on the dog, and these are to the present time the basis on which others have been constructed. The standard actually used, or supposed to be used, in the judging of any breed at a public exhibition of dogs is usually that adopted by the specialty club that concerns itself with the breed in question. The standards of all the leading breeds are now to be obtained in compact and cheap form in one volume, indispensable to the judge, the critic, the breeder, the exhibitor, and others. As to how far they conform to the requirements of the perfect standard may be better determined presently.

A standard of any breed should express in words the ideally perfect $\operatorname{dog}$; and it would be of the highest service to have the verbal description accompanied by an ideal illustration, for there are no perfect dogs; and if to these two were added a commentary of such a character as would render the meaning more clear and at the same time give the reasons for the various requirements of the standard, we feel certain that greater progress would be made by all concerned. While some few writers have commented on the standards of some of the 
breeds in the way suggested, it has never been done systematically or completely; nor, so far as the writer knows, have the proposed ideal cuts ever been published accompanying any set of standards. It has been customary to say little of the psychic characteristics of dogs in the standards, though surely there is no subject of higher importance. Possibly this omission is to be explained on the ground that it is impossible to learn these fully in the judging ring, etc. However, it seems to the writer that a dog of an objectionable disposition or of very defective intellect should not be encouraged in the least, as such qualities are, unless the result of bad usage, very likely to be inherited by offspring, and in fact may be in any case. To give such an animal a prize is to stamp him with approval, and it is well known that the owners of bitches often breed to prize dogs regardless of every other consideration. It should never be forgotten that the dog of every breed is meant to be the companion of his own fellows and of man himself to some extent, and in the case of some breeds very largely. It is unfortunate also that, taking the standards as a whole, they do not agree on the terms used or the subdivisions of the animal's form recognized.

Since the clubs established in the interest of each breed do now draw up and publish standards, a few words in regard to these organizations may not be out of place.

In some countries specialism in the breeding of dogs is carried so far that it is not uncommon for the admirer of one breed to feel no interest-possibly a sort of contempt or repugnance-as regards others; or it may be that his very enthusiasm may lead him to overestimate one breed 
and undervalue all others; or, again, there may be a spirit of indifference to all breeds except the favorite one. We think that the best attitude of mind for the cynologist to assume is one of calm criticism, endeavoring to see the good and the weak points of each breed and recognizing that individuals of all breeds differ greatly in merit.

The assumed object of every club is to improve the breed to which it is devoted by publishing a standard considered correct, encouraging breeding to the true typeboth physical and psychical-by giving prizes for animals bred nearest to the standard, and encouraging esprit de corps among the members.

It is also common to name certain individuals, either from among the members only or including outsiders, to act as judges at shows, believing that the true type of dog will thus be best selected.

The advantages of all this is obvious; the dangers of specialty clubs not so apparent.

The history of all specialism seems to show that narrowness and intellectual myopia are the usual pitfalls. In seeking for improvement, minor points are apt to be unduly valued and general soundness of make-up and physical and mental stamina too little considered, with also a strong tendency to go to extremes. It can not be denied, however, that without such specialism the dog would never have been advanced to the numerous distinct varieties, beautiful in form and attractive in qualities, that we find to-day. Never before were dogs, on the whole, so typical and so perfect; at all events, in such large numbers.

Without dog shows the work would have been much slower if not impossible, as they are, without doubt, the 
most rapid and effective educators of the general public and the greatest stimulus to high-class breeding. But of these again.

The dog, like most quadrupeds, may very naturally be considered as made up of the following sections or regions of the body: Head, neck, chest, shoulders, back, loins, quarters, tail, legs, and feet. Manifestly each of these is capable of subdivision, and the extent to which this is done in the different standards is very variable.

Unless standards are drawn up merely by caprice, we are entitled to ask what should be kept in mind in performing such a task? It seems to us that within the limits that Nature allows, the following should be the aims :

Primarily, the dogs of the breed in question should have such a form as is best suited to the purpose for which the animal is intended. Let this once be lost sight of, and breeders are at sea without rudder or compass.

The relative size and proportion of parts should be such as are consistent; no decided weakness anywhere; for in an animal, as in a chain, the strength of the whole is practically determined by that of the weakest part, and it is just this balance of parts, which Nature looks after so well in wild animals, that the breeder who is a specialist may be tempted to disregard. To illustrate. What matters it that a dog shall have the most perfect form in every other part if his head is so small that it can not contain the necessary amount of brain for the purposes of his work, or his loin so weak that if he has galloping work to do he must soon tire, etc. ?

But a dog may be usefully and strongly built without those refinements of proportion that we recognize in high- 


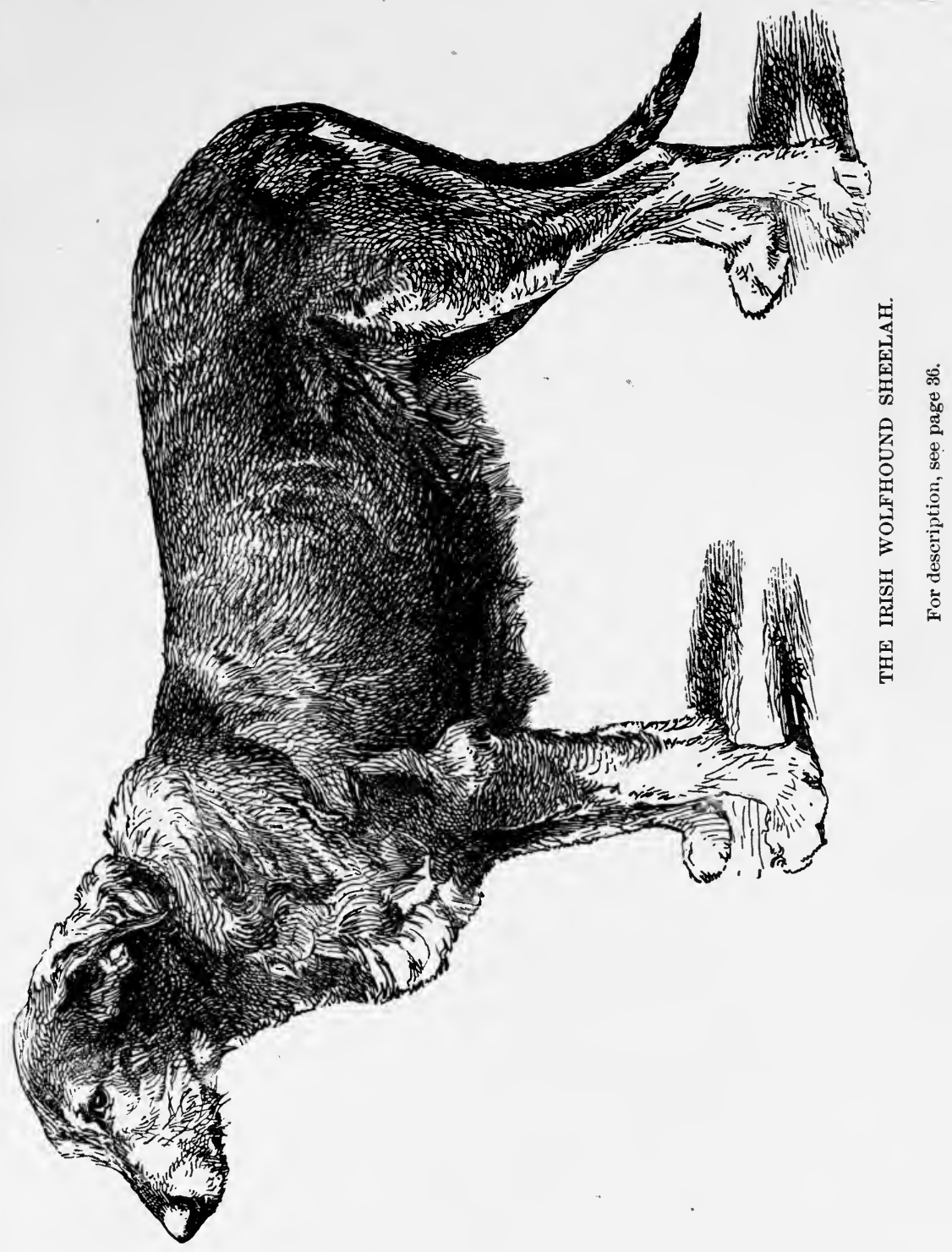


. 
class dogs. This result is in reality only the perfection of what is implied in the above. It follows almost as a corollary that all that is not of use in the formation of the animal is to be condemned, and is commonly called "lumber." Though the standards can not be so framed that the internal organs shall be taken into the account directly, they are really considered in the form of the animal. It must, however, be remembered that what is termed stamina-i. e., endurance and resisting power under unfavorable conditions-is the outcome of the working of all the cells of the body as maintained in a general balance of functions. It is well known that pure-bred dogs have not the stamina of mongrels in the sense now implied, and this is probably due to those disturbances introduced into the economy by those modifications of form, etc., for which man is responsible.

The writer's accounts of the various breeds will scarcely be full enough to constitute them complete standards. They will, however, be more comprehensive, and, it is hoped, have a special value to both the breeder and practitioner of medicine, inasmuch as they will be illustrated, and an attempt will be made to give reasons, if only briefly and by way of suggestion rather than as elaborate explanations.

The whole subject will probably be better understood if the principles stated above are applied first to the different sections of the body, without special reference to any one breed exclusively.

Standards further considered.-Certain terms have been and are used by breeders, convenient and well understood, though very difficult to define by words. Among these are "character," "quality," and " type." 
Character refers to the whole constitution of the dog, physical and psychic, in so far as the latter is evident in his appearance. A dog may be fairly correct in form, according to the standard as regards shape and proportion of parts, yet his attitude, his carriage, his facial expression, and much more that it is almost impossible to describe, yet quite easy to recognize by the experienced eye, may be so far from correct that he may be fitly said to be lacking in character; and this is a most serious, indeed, in the writer's estimation, a radical defect, and generally accompanied by psychical imperfections which, if very pronounced, render the specimen an undesirable possession.

Quality is different from character, though it may enter into the latter. It is a certain refinement arising from perfection in details of form and character. A dog of quality may be compared to a "gentleman" among human beings.

A typical animal is one that may be taken as a sort of model and is a living illustration of the standard, and inasmuch as, at the largest bench shows, such animals are to be found, these institutions become, even unconsciously, powerful educators, while the study of the best specimens with a critical eye is absolutely indispensable to the breeder, the critic, and the judge.

Returning to the subdivisions of the dog's form recognized by the standards, we shall now speak of them in a general way.

Head.-This is in reality the most important part of the animal, since it contains the brain, is the seat of most of the sense-organs, and, in consequence, deter- 
mines largely the psychic traits of the breed and the general intelligence and disposition. Apart from this, the head, more than any other feature of the animal, determines both character and quality. A dog with a head that is coarse or of wrong formation can not possibly be typical; hence in every breed great importance is attached to this part of the animal's form, though it is just possible that undue attention is often given to minute details of this region to the neglect of very important parts, as legs, feet, loin, and quarters, of so much consequence in running-dogs.

Neck.-Of this little need be said, except that it should be in harmony with the rest of the animal and free from loose skin (throatiness)-i. e., "clean" and neat.

Shoulders.-If the dog is one intended for speed, these should be sloping, clean, and distinctly marked off at the shoulder-joint proper, with wide, long blades (scapula long, wide, and obliquely placed), as seen in the greyhound, and in great perfection in the race-horse. Such conformation permits of a long and easy stride, lessens the shock when a galloping animal alights on its fore feet, and furnishes a sufficient attachment for the muscles that work the lower leg. If the withers are high, an appearance of character and quality is imparted. If the animal is not intended for speed, obliquity and length are not of such importance.

Chest.-If the chest is not deep it is plain that the shoulder-blades can not be properly placed. The dog, like the race-horse, having no collar-bone, his body is swung between his shoulder-blades, and, that there may be an easy movement of the fore-limbs, the whole chest 
should be somewhat boat-shaped. The chest must be rather narrow in front and keeled both before and behind the shoulder-joints, but, in order that abundant room be provided for both heart and lungs, there must be a limit to the narrowness in front, and the chest must be very wide above, which is insured by the ribs being well sprung, while at the same time the back ribs must be much shorter, otherwise there will be interference with the working of the hinder locomotive apparatus.

But an opposite conformation is required in the large, heavy dog destined not for speed, but strength, and answering to the heavy draught-horse, in which the chest is rather barrel-shaped.

Back.-As the shoulders cover so much of the chest in the fast animal, the back, if due proportion is to be maintained, must be short, and in most breeds it is level, and should be in all fairly muscled, and in running dogs especially so.

Loin and Quarters may well be considered together, as these parts have so much to do with the fast gallop, as witness the conformation of the greyhound, race-horse, rabbit, etc. Both leverage and muscling are to be taken into account, so that the loin should be strong, which usually implies both breadth and depth. At all events, it should measure well around. It begins at the last rib and passes into the quarters.

In bitches more depth is required than in dogs, to allow of breeding room. The exact length of the loin depends so much on the relative proportions of the animal that no rule can be laid down. If very short, there is neither strength nor freedom; and if too long, the animal 
invariably tires readily, and is frequently defective in stamina. The loin should never be absolutely flat, but should rise to a gentle curve.

The quarters must be large-i. e., both wide and deep -as here are attached the muscles that render both loin and thighs effective; and generally in very strong animals there is a more or less rugged appearance from bony prominences, which indicates a strong osseous, corresponding to a strong, muscular development.

Thighs.-The thigh-joint proper of the $\mathrm{dog}$ is inconspicuous, and what is termed the "stifle" corresponds to

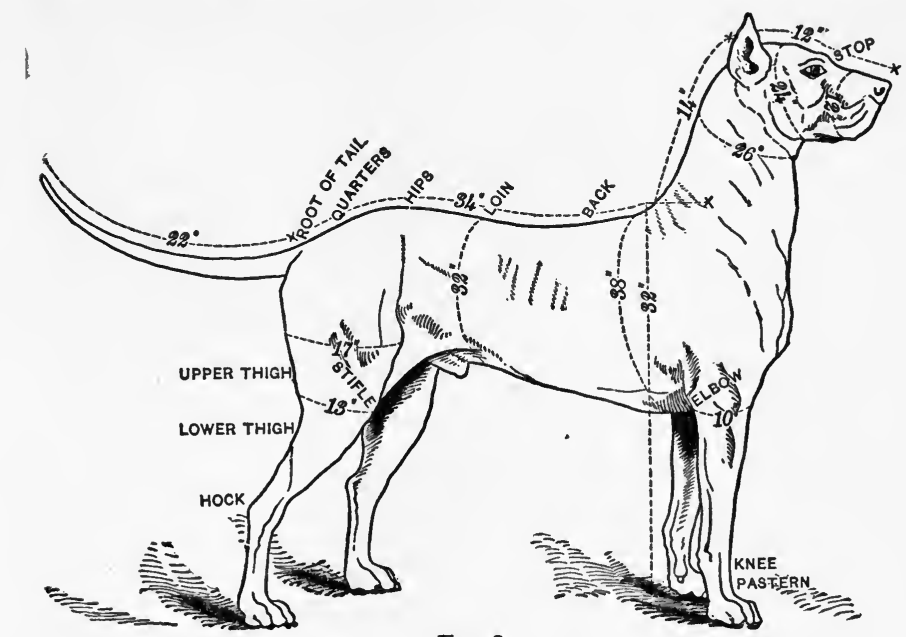

Fig. 2.

the knee of man. Upper and lower thigh (Fig. 2) are convenient terms, and both should be well developed in an animal intended for a long and rapid stride, for such implies that muscles are both thick and long. Length is of great importance for the highest speed, for it is well known that a muscle in contraction may shorten to one 
third of its length, from which its power will be evident. The stifle should be well bent for the same reason that the shoulder-blades should be oblique and should not turn in, but rather a little out, so that there may be movement free of the body.

Legs and Feet.-However good the other parts of a dog, if his legs are weak, improperly bent, or otherwise defective, he will necessarily be of little service for continuous work in hunting, etc. The upper arm (a part often too little considered) should be strong in bone and well muscled for the movement of what is commonly understood by the forearm or front leg. The leg from the elbow to the pastern or wrist (knee) should be perfectly straight, the bone large-i. e., so as to seem strong enough to support the weight of the animal and afford attachment to large muscles. The pasterns should also be strong to bear the shocks to which they are exposed in galloping, jumping, etc., and a slight obliquity in fastworking dogs is probably an advantage, though on this point there is diversity of opinion.

The elbows should be strong, but work clear of the body in every possible movement of the animal; hence they should be turned neither in nor out ("out at elbow") and placed low-i. e., low enough to be free, as indicated above.

The "knee" is really the wrist of man, and should be low placed for speed.

In the hind-legs the hock corresponds to the ankle of man. Like all joints that are called upon to bear severe strains, it should be large or prominent and well bent (well :turned)-i.e., the junction of the bones composing 
the joint should make a decided angle. It should also be low-i. e., near the ground-allowing of a longer thigh. It will be noticed that throughout a common physical principle is involved-viz., that obliquity is favorable to resistance of strain. The longer the legs above the carpal and tarsal joints (knee and hock), the more favorable for the resistance of shocks and length of leverage-i.e., speed. A dog straight in stifle or hocks has a stilty action that offends the eye as well as militates against speed.

Feet.-There are two principal types of feet-the long or hare foot, and the roundish or cat foot. The latter looks better, but it is a matter of dispute which is the more durable. It is probably a question of thickness, hardness of pads, and supply of hair between the toes, rather than of form. But the toes should be well flexed or "knuckled up," thick through, and hard on the pads for obvious reasons.

The toe-nails are of importance-more than is commonly believed. Let one be lost and it may then be learned how weak the foot concerned becomes.

The Tail.-At first sight of little importance, but having much to do with the character and quality of the animal, not to speak of its importance as an index of good breeding, it must be taken into the account. The writer believes that if animals be watched carefully it will be perceived that the dog makes great use of his tail in progression, using it as a sort of air rudder or balancing-pole -at all events, it seems to be of importance in making sharp turns, etc. This should be considered, as some breeds have the tail docked by common practice.

If the reader will now turn to the cut of the grey- 
hound he will find in it an almost perfect illustration of the embodiment of those principles that are involved in the most rapid progression. In the setter or pointer we have speed of a lower grade, but their conformation adapts them to more continuous work (p. 10).

In such a dog as the mastiff or St. Bernard all those points so important in the above-mentioned breeds and their allies are of subordinate importance, and the question in breeding such animals is simply how to get great size and strength with majesty in expression; hence a massive frame and due proportion of parts to this end is the aim. Nevertheless, attention must be paid to legs, feet, etc., so that they shall not be unduly weak or disproportioned anywhere, and at present the tendency seems to be to neglect this balance of parts which Nature when left to herself always insures, for if it does not exist in any specimen, that animal's days are generally few and it may leave no offspring. But " the survival of the fittest" as it applies to wild animals has been modified somewhat by man.

Even in toy dogs, bred exclusively to please the eye and form the household pets of their masters, this same balance must be attended to and their supporting parts (leg and feet) not wholly neglected.

To summarize the views expressed in the preceding pages and put them in language familiar to the breeder, a dog to be typical must have a correct and true form and show both quality and character.

His head must be neither coarse nor weak; his jaws even and teeth level; he must be neither overshot nor undershot (overhung, underhung; the first is also termed 


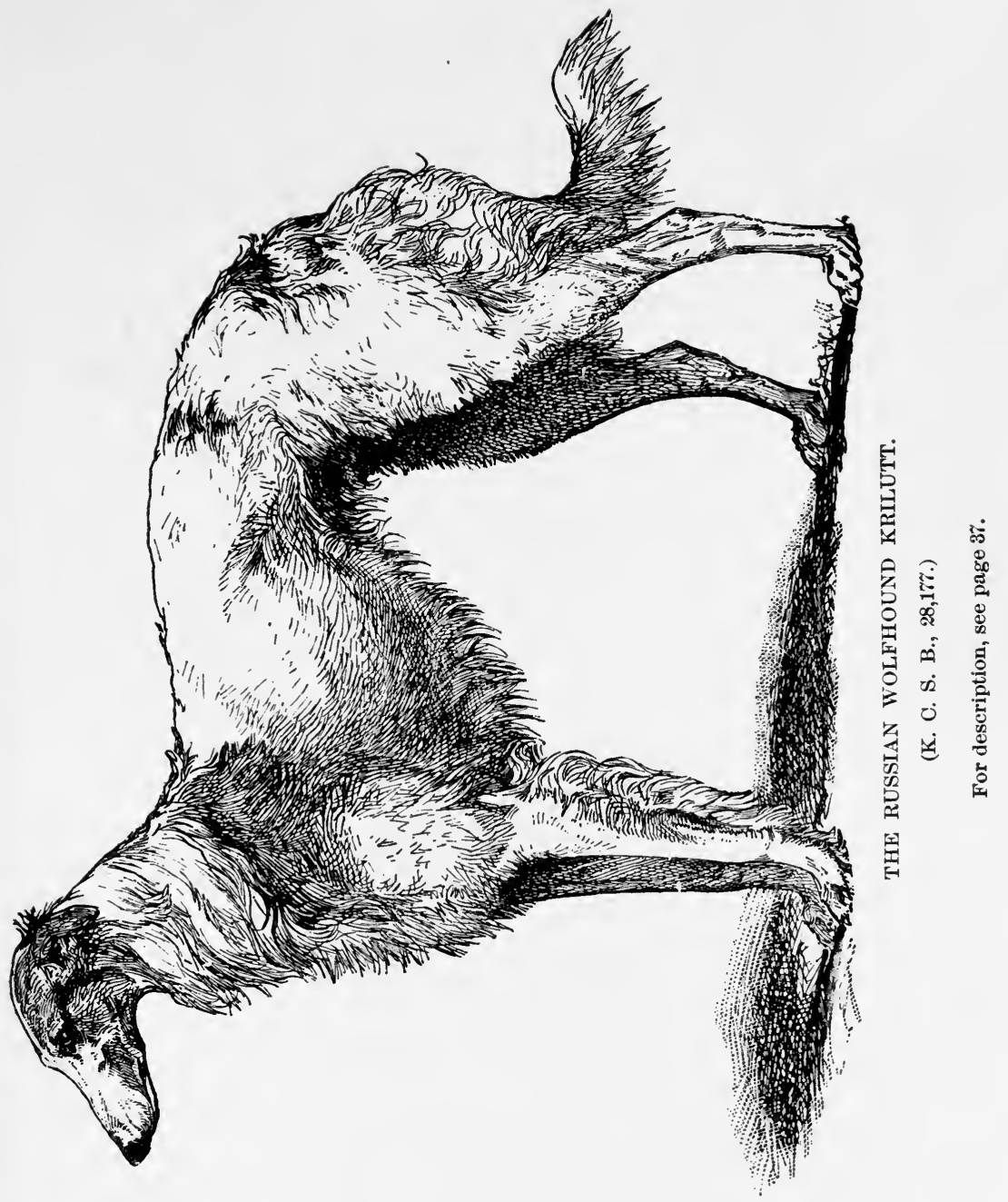


pig-jawed); his neck of due size; his chest either barrelshaped or deep and keeled according as he is intended for slow or fast work; his shoulders clean at the joints, and long and sloping if of a fast breed; his back level, short, and strong; his loin of due length and girth, strong, and not flat; the quarters in the running $d o g$ especially strong; stifles well bent; the thighs, upper and lower, muscular; the hocks strong and well bent; bones of both front and hind legs large; pasterns strong; feet thick, hard, and well-knuckled; the tail of due length, and so proportioned, etc., as not to be coarse. To put the case otherwise, the typical dog must not be snipy in muzzle, throaty, straight in shoulder-blades or loaded in shoulders, slack-backed or sway-backed, weak or flat-loined, feeble in quarters, out at elbow or tied in the elbows, stand over at the knees, weak in pasterns, straight in stifle or hock, cowhocked (turning the hocks in and very close together), ring-tailed (curl in tail), splay-footed (foot flat and toes separating), etc.

We have not alluded to coat. This should be in keeping with the work to which the breed is put. Except in toy dogs, more importance is attached to the color of nose, eyes, etc., than to that of coat, as a rule, and properly so because it is found that animals of the best strains have these well characterized. A very light-colored eye in any breed of dogs is to be avoided, as it is often associated with some pronounced psychic imperfection. Quality of coat-as hardness, softness, etc.-is also very suggestive to the experienced as to breeding, disposition, etc. 
CLASS II.

Under Stonehenge's second class, or dogs hunting chiefly by the eye and killing their game for the use of their masters, the principal breeds encouraged in England and America are the smooth English greyhound, the deerhound, the Irish wolfhound, and the Russian wolfhound or barzoi.

As the writer has taken great pains to secure the best cuts possible, the reader will find it advantageous to compare the necessarily brief descriptions compatible with the plan of this work with the illustrations. Few living specimens are to be seen as good as those represented in these illustrations, all of which are typical, and some of them almost models.

The English Greyhound.-The most perfect form that has ever existed, probably, among domesticated animals for speed. A wonderful combination of strength and grace! Since this dog is bred almost wholly for one purpose-the coursing of rabbits-he is an example of extreme specialism in breeding, and, being mostly kept exclusively in kennels and associating little with man as a companion, he is neither very intelligent nor very affectionate, as a rule, though capable of a fair development of both under more favorable circumstances (p. 10).

The greyhound may be considered as an almost perfect embodiment of those principles set forth in previous pages as constituting the fundamentals for speed. No breed of dogs could be freer from superfluous tissue or "lumber." His form is admirably adapted, even in details, for cleaving the air, while his frame is a beautiful model for the 
attachment of muscles, and these being of great length, and the bony levers also long, while the respiratory and circulatory organs are well provided for, it only remains that the bony pillars of support and the feet shall be suitable for the end to be attained.

It is manifest that when a greyhound is in "condition" the muscles should stand out distinctly and feel very hard.

The head of the greyhound should be long, lean, tapering; narrow across the skull as compared with some breeds, but of sufficient width to allow of brain room. The eyes must be rather full, clear, and bright; the ears small, lying close to the head and folded back; the jaws strong and even (not "pig-jawed"), and the teeth strong and sound to hold the hare.

The greyhound's head is an example of the flat front -i. e., the furrow between the eyes or "stop" is indifferently marked, and the brows not prominent.

The neck is long, tapering, and arched, to permit of the dog catching up the hare without stooping, and the way in which it is set into the head and shoulders or chest has much to do with determining the quality of any particular animal, especially when taken in connection with the head.

Coat.-Short, smooth, and glossy.

Color.-A matter of no great importance. A good greyhound, like a good race-horse, can not be of a "bad color," though of course a little attention must be paid to it in the show animal; but coat and color count only five in a hundred marks, according to the standard now adopted.

Tail.-Fine, nicely curved, and may indicate good 
breeding or the reverse; always carried low, except under unusual excitement.

It is scarcely necessary to speak of shoulders, chest, loin, quarters, etc., as these have been fully dealt with in the general remarks in the requirements of the fleet animal. The loin is preferred a good deal curved and the belly well tucked up.

A specially large greyhound is not to be preferred, as such have rarely excelled in coursing, and should not, therefore, have any advantage on the bench.

The Deerhound.-A coarser, larger animal than the preceding, with a rough coat, once used for hunting deer, but, like the wolfhound, not now bred for any special kind of work (p. 16).

The chief points of difference are the greater coarseness of head and neck. The head is heavier and the neck not so long or so graceful.

This breed of dog stands higher, and, being more heavily made, weighs more than the greyhound; but, though not so perfect a model of symmetry, the latter is still pronounced.

Colors.-Those most preferred are dark-blue, fawn, grizzle, and brindle, which has something of a blue tint.

Coat.-Whole body covered with a rough coat, coarser on the back than elsewhere. "Intermediate between silk and wool" is the description given by some breeders.

This variety of the greyhound tribe has been used successfully to run down the prairie wolf or coyote of North America.

The Irish Wolfhound.-The animal that was known under this name is now extinct; but a breed greatly re- 
sembling it is cultivated by a few enthusiastic admirers in Britain (p. 24).

Of the deerhound type, he is more massive and far taller, and, though more commanding in appearance, he does not compare in symmetry with either of the two preceding.

Coat.-Rough and hard.

Colors.-Much as in the preceding.

The Russian Wolfhound or Barzoi.-This breed has very recently sprung into popularity in Britain, and taken some hold in America. It is used in Russia to hunt (by sight) the wolf, etc. (p. 32).

In general appearance this dog is a combination of the greyhound and the setter, though it is not to be inferred that such has been its mode of formation. In truth, the greatest diversity of opinion is expressed about the breed in most particulars. In not a few respects the form of this animal is at variance with English and American notions of dogs, and the breed will likely be much modified if it has come to stay. The great size, the setter-like coat, and strength and elegance of form, unite to make up a most attractive whole. As to temper, intelligence, etc., we have much to learn.

This dog is very long as well as tall, and the arch of back and loin surpasses that in any other breed known, while the muscular development of these parts is very marked. 


\section{CLASS III.}

DOMESTICATED DOGS, HUNTING BY SCENT, WHICH BOTH FIND AND KILL THEIR GAME. THESE INCLUDE THE VARIOUS HOUNDS AND TERRIERS.

The Bloodhound.-The largest of existing breeds of hounds cultivated in Britain or America. In general form he greatly resembles the English foxhound; but no variety of dogs, perhaps, possesses so characteristic a head, which is more pronounced-as is usual in all its features-in the male (p. 40).

Skull very much domed and narrow across, though rather long, with very decided occipital protuberance; forehead much wrinkled. Eyes small, deep-set, with a distinct red "haw," or third eyelid. Ears long, fine in "leather," hanging close to cheeks. Muzzle long, deep, blunt at tip. Flews or angles of lips long and pendulous. Unlike most breeds, in this a "dewlap," or loose skin in front of the throat, is esteemed.

The whole expression of the animal is most peculiar and characteristic.

Coat.-Short, hard on body, but soft and silky on ears and head generally.

Colors.-Tan and black and tan; the latter much preferred, the black to predominate on the upper parts of the body.

The name of the breed is probably derived from its having been used to track wounded animals. The extent to which the bloodhound has ever been, or can be, employed to track human beings is uncertain. However, this 
subject has attracted fresh attention of late, especially in America.

The Foxhound.-The nature of the work that this animal performs has decided his form and character probably more than in any other breed of dogs after the greyhound, and the extent to which perfection has been reached is scarcely rivaled even by the latter wonderful animal form, especially if the pack, rather than the individual, be considered.

When it is remembered what fox-hunting implies, it will be realized that only a breed combining considerable speed with the greatest endurance would meet the requirements. Hence this animal's form may be considered as the model for combined speed and endurance. It is therefore a great modification of that of the greyhound, in which a burst of the highest possible speed, maintained at the most for one or two miles, is what is sought.

In few breeds have specimens been so carefully selected and the weeding-out process so rigidly carried on as in this. As individual effort must be subordinated to hunting in concert, considerable intelligence, as well as scenting powers, speed, etc., is required.

It may be instructive to consider the points of the foxhound at rather greater length than in the case of some other breeds. (See cut and description of beagle, pp. 48, 41.)

Head.-While not heavy, the skull must be large enough to accommodate a good-sized brain. Distinct but not exaggerated brows should in the male girth sixteen inches.

Muzzle.-Long (four inches and a half), wide, with open nostrils. 
Eyes.-Moderate in size, soft, and full of expression.

Ears.-Long (often "rounded" or shortened artificially), set low and lying close to cheeks.

Neck.-Long, lean, no throatiness, tapering, with convex upper outline.

Shoulders.-Long, sloping, clean at points, well muscled. True arm long and muscular.

Chest.-Large-i. e., deep-with well-sprung ribs, not so narrow as the greyhound's, and with back ribs long; shoulder girth thirty inches in a twenty-four-inch (high) hound.

Back.-Very muscular, running into loin without contracting or " nipping."

Loin.-Extremely strong and joining well into back and quarters.

Quarters.-Very strong; may even be a little rugged in appearance. Thighs strong and stifle moderately bent, as most suitable to general work and endurance.

Legs and Feet.-Elbows free, straight (neither in nor out), strong, and well let down; legs (including bone throughout, joints, etc.) of great strength. Must be the typical exemplification of legs and feet adapted to speed and endurance; hence the pasterns are so strong as to seem much as of one piece with the bone above.

The feet should be round, thick, well-knuckled, with the hardest of pads.

Stern (tail).--Slightly arched over back, tapering, and provided with a fringe of hairs below.

Coat.-Hard, short, dense, glossy.

Colors.-The "hound colors" are black, tan and white, 


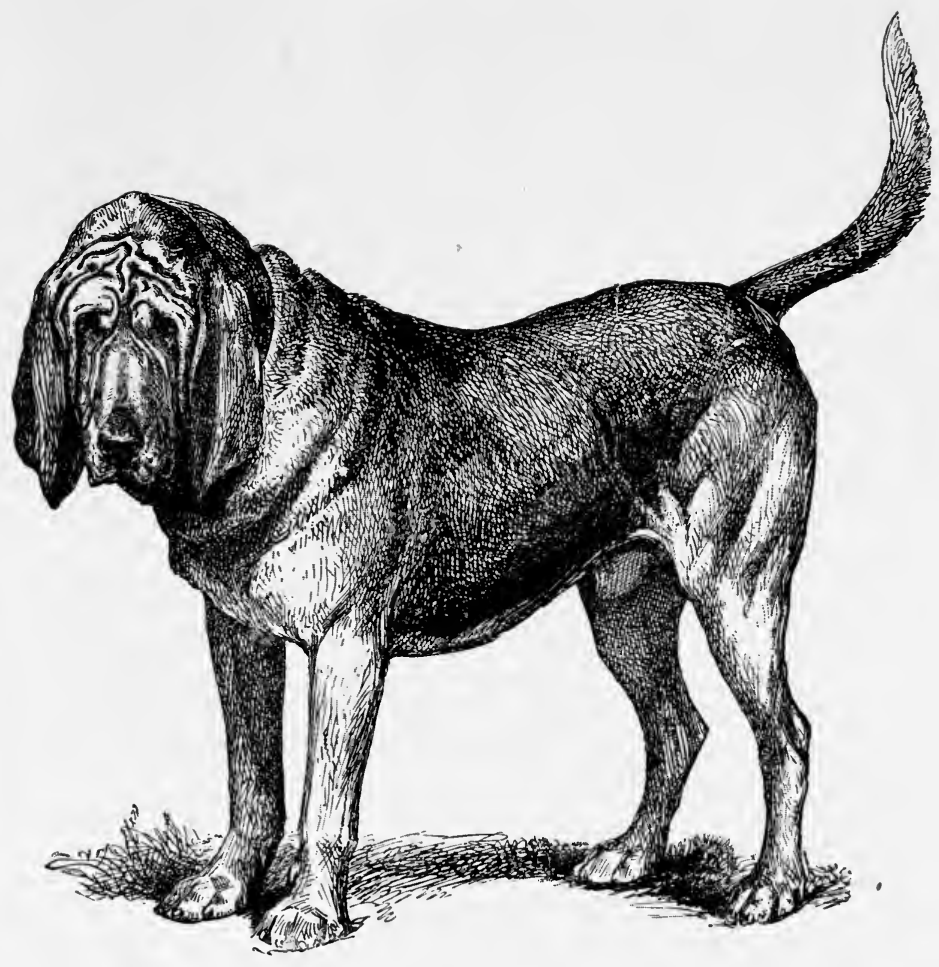

THE BLOODHOUND CHAMPION CROMWELL.

(K. C. S. B., 19,754.)

For description, see page 38. 

black and white, and the "pies"-i. e., white, with the color of hare or badger-a sort of yellow or tan.

Symmetry, quality, and character should be pronounced, especially the latter. The psychic characteristics may be inferred from preceding remarks.

Related to the foxhound are the harrier and the beagle.

The Harrier.-Said to be descended from the old Southern hound; scarcely known pure now, but mostly crossed with the foxhound. The harrier resembles the foxhound closely, the head being in some respects different. The skull is wider and heavier, and muzzle wider and longer; the ears set on rather farther back, and are not usually "rounded"; eyes softer and larger ; whole expression slightly suggestive of the bloodhound.

The harrier has probably a better nose than the foxhound, but tends to potter over the scent, and so does not push forward as fast. His voice is also more like the bloodhound's, and exceeds that of the foxhound in melody. We speak of the true harrier, not the crossed animal.

The Beagle.-A very popular breed in America, especially of late, and largely used in rabbit hunting. Being a small animal, the pack can usually be followed on foot (p. 48).

Stonehenge regards the beagle as the miniature of the Southern hound, but of greater symmetry. The standard adopted by the American-English Beagle Club describes him as "a miniature foxhound, solid and big for his inches, with the wear-and-tear look of the dog that can last in the chase and follow his quarry to the death."

In head he differs in an appreciable degree from the foxhound, and we quote from the above standard. 
Head.-Skull moderately domed at occiput; cranium broad and full; ears set on low, long and fine in texture, front edge closely framing and inturned to cheek, rather broad, rounded at tips, and with an almost entire absence of erectile power at their origin.

Eyes full, prominent, rather wide apart, soft and lustrous, brown or hazel in color; orbital processes (eyebrows) well developed; expression gentle, subdued, and pleading.

The muzzle of medium length, squarely cut, and stop well defined.

Jaws level; indentation between eyes; lips with at most only moderate flews.

Nostrils large, moist, and open.

In other parts he should resemble the foxhound, and be as strongly, perhaps even more symmetrically made with an equal development of quality and character.

Size is of importance; this dog must not exceed fifteen inches in height at the shoulder.

His voice, or "cry," is very melodious to the ears of his admirers.

The Otterhound.-Very like the bloodhound in general appearance, coat excepted, which is thick, oily, and with pily undercoat, adapting the animal to water. Open feet with plenty of web, suiting the animal to swimming, are also desirable.

In color sandy or grizzle, with black and tan more or less clearly defined.

Irritable in temper and courageous to the last degree, in consequence of contests with their quarry, they sometimes worry each other to death in the kennel. 
The Bassethound.-This breed originated in France, and is much esteemed in that country for hunting varions kinds of game, which this hound does with wonderful scenting powers and pleasing music, though slow of pace. A small pack is sufficient (p. 52).

His form is striking as a whole, with a head very like that of the bloodhound; a long body supported on strong short legs, the fore-legs being crooked, so that the toes turn out. This conformation is adopted partly by fancy and partly because of the strength it allows, and because it renders the pace slow, which is thought desirable in hunting the deer, etc., in Europe.

The Dachshund.-This breed is of German origin, and, as the name implies (badger-dog), it is used in hunting the badger, though not exclusively. A German or terrier and an English or hound type are recognized. The former is the smaller, and is unrivaled for underground work. It differs from the dog of English type in size and head, the skull being flatter, etc. They may be either smoothhaired or rough-haired (pp. 56, 60).

The head is long, narrow, with a decided occipital protuberance or "peak" in the English type; no stop; intelligent eyes; long, broad, soft, and low-set ears.

Well "crooked" fore-legs are highly esteemed.

The coat is dense and short in the smooth variety; hard and longer in the rough.

The Great Dane.-The great Dane, boarhound, Ulmer dogge, German mastiff, German dogge, etc., are all related in form and characteristics, though whether of similar or identical origin is much disputed (frontispiece).

The great Dane is the most esteemed of large dogs as a 
companion in Germany, though little, if at all, used now for boar-hunting.

Gentle with women and children, and manageable by his master, he is a desirable companion and protector, for he is both strong and courageous. $\mathrm{He}$ is valuable in America as a watch-dog, and seems to be growing in popular favor.

His strong, active form, great size, and fierce appearance render him a terror to aggressors of every kind.

As he is very suggestive of the wild beast, no dog's appearance is so fitted to inspire fear, which is a strong recommendation in a dog intended to guard a large estate, etc.

His form is about midway between that of the mastiff and the greyhound; a very muscular, upstanding, alert, active dog, combining the activity and grace of the greyhound and the strength of the mastiff in a high degree. If this be borne in mind as the ideal to be attained, the standard adopted by the Great Dane Club may be intelligently criticised.

The minimum height for dogs is 30 inches, for bitches 28 inches; the minimum weight 120 pounds and 100 pounds.

The head bears a general resemblance to that of the bull terrier, but has characteristic features of its own.

The ears are usually cropped, but, if not, should resemble in form and carriage those of the greyhound.*

The neck should be long and clean and join head and shoulders neatly. Shoulders, chest, back, loin, quarters,

* No dog of any breed born after March, 1895, can, if cropped, win a prize at a show held under the auspices of the English Kennel Club. 
legs, and feet are all in harmony with the above ideali. e., of a dog intermediate between the fleetest and the strongest breeds.

The tail is strong at the root, tapering to the end, reaching to the hock, carried slightly curved and not much if at all above the level of the back; when the animal is tranquil it is carried very low.

Coat.-Short, hard, and dense.

Colors.-Shades of gray (or blue), black, white, spotted, red, fawn, brindle or tiger-striped on a white ground, with patches of dark color. The single colors may be accompanied by markings of a darker tint about the eyes and muzzle, with a line of similar tint ("trace") along the spine. The "wall" or "china" eye seems to naturally accompany certain colors, as is also the case in sheep-dogs.

The most noticeable or common faults are too heavy or houndy a head; brows and stop too pronounced; face too broad; muzzle too light, short, or not square enough at end; ears too heavy or improperly carried; throatiness; neck too short or thick; chest too broad or too narrow; sunken or sway-back and flat loin; legs not straight; weak pasterns and cow-hocks; twisted or splayfeet; coat coarse or long; tail too heavy, too mach curved, carried too high, or curled into a sort of ring ("ring-tailed").

This, like other large breeds, is very liable to be weak in hind parts-i. e., quarters, thighs, and hocks. Many strong specimens lack symmetry, quality, and character.

Terriers.-The terriers constitute a numerous collection of breeds, and, as almost every one is in Britain encour- 
aged by a specialty club, it can be readily understood that they have been bred to great perfection, or, at all events, very near the proposed standards. It is somewhat otherwise in America, where this group, with the exception of the fox-terrier, can not be considered as very popular. But of late certain varieties, especially Irish and Scottish terriers, have made great advances in popular favor. Both breeds are hardy and courageous.

Since terriers, distinct as they are in details of form and character, have a great deal in common, it will be well to consider what may be termed terrier type.

As every breed or group of dogs must, as we have before said, be judged in reference to the work it is supposed to be able to perform, so with this one. The terrier is essentially a vermin ("varmint") dog-i. e., he is adapted to drive out, secure, or actually kill such animals chiefly as are injurious to man-as rats, foxes, etc. Such a dog must evidently be active, fast for his size, courageous, with powerful jaws and teeth, and at least not large.

Terrier character is very decided and readily recognized. The terrier must be a wiry, muscular little animal, ever on the look-out and ever ready to tackle vermin, and, if need be, to carry on the contest to the death; and if he looks this from nose to tail he has terrier character, as the term character is understood by breeders.

The bodily form is characterized as follows: Flat, more or less wedge-shaped head, with strong jaws and teeth, neat ears, dark, small, usually deep-set eyes. Teeth must be level; to be overshot or the reverse is a great fault in a terrier, as it indicates weakness where, above all, he should be strong-i. e., in holding- and killing-power. 
The neck must suit the head and body; chest, loin, quarters, legs, and feet must be those of a strong, active animal, capable of considerable speed, and hence approximating those of the great Dane, already described, which is a sort of larger terrier in form.

Tail and ears are in many breeds cut, to add, as it is thought, to terrier expression. It is to be hoped, however, that all such cruel practices will soon be abandoned, as they are plainly against nature.

The coat should, whether long or short, be hard generally and durable in all cases, so as to resist wear with work and protect the skin of the animal. It must be remembered that the terrier is frequently required to dig and to enter burrows ("go to earth "), hence the necessity of strong legs, good feet well armed with strong nails, a resisting coat, etc.

Color is variable but rarely striking, as that would discover the dog to the creatures he seeks to surprise.

The faults to be specially avoided in a terrier are a heavy, thick skull ; prominent brows ; full eyes; large, badly carried ears; weak jaws and poor teeth, not meeting in front; a cloddy form; crooked or weak legs, and splayed, soft, or thin feet; tucked-up belly; weak loin; legginess or the reverse; a broad breast, straight shoulders, or stifles; uneven back; flat sides; general deficiency of muscle; a coat lacking in quality and quantity.

If the dog has a perfect form he may still lack to the eye terrier character, in which case he will not do for the bench; and if he really is deficient in the psychical characteristics of the breed, he is, of course, useless in a degree as a vermin dog. 
The fox-terrier, the Irish terrier, the black and tar, and among toys the Yorkshire, enjoy a fair degree of popularity in America; the first is in fact a great favorite; we shall therefore call special attention to these. Although descriptions of coat will be given in referring to the various breeds of terriers, it must be seen (like the color), and in fact felt, to be appreciated thoroughly.

The Fox-terrier.-Used, as his name implies, to unearth the fox, not kill him, he should be gritty and strong, and fleet enough to keep within sight or hearing of the hounds at all events. An excellent "ratter," and ready for most kinds of small vermin, with considerable docility, affection, and intelligence, handsome, sprightly, etc., he is largely kept as a companion, even as a sort of house dog. The fox-terrier may be regarded as the young man's companion, as the poodle, the Yorkshire, or toy spaniel is that of the lady (pp. 64, 72).

Head.-Skull flat, rather narrow, sloping to muzzle; little apparent stop, viewed from the front, but showing slightly in profile; cheeks not full; ears V-shaped, small, pointing forward and lying close to cheeks; jaws strong and muscular; some chiseling below eyes; muzzle tapering to nose, which must be black; eyes and their rims dark in color, small, rather deep-set, nearly circular in shape, "full of fire, life, and intelligence"; teeth about level, but the upper may be just outside lower.

Neck.-Clean, muscular, tapering.

Shoulders.-Long, sloping, fine at points, and clearly marked off at withers.

Chest.-Deep but not broad in breast; ribs well sprung; back ribs deep. 


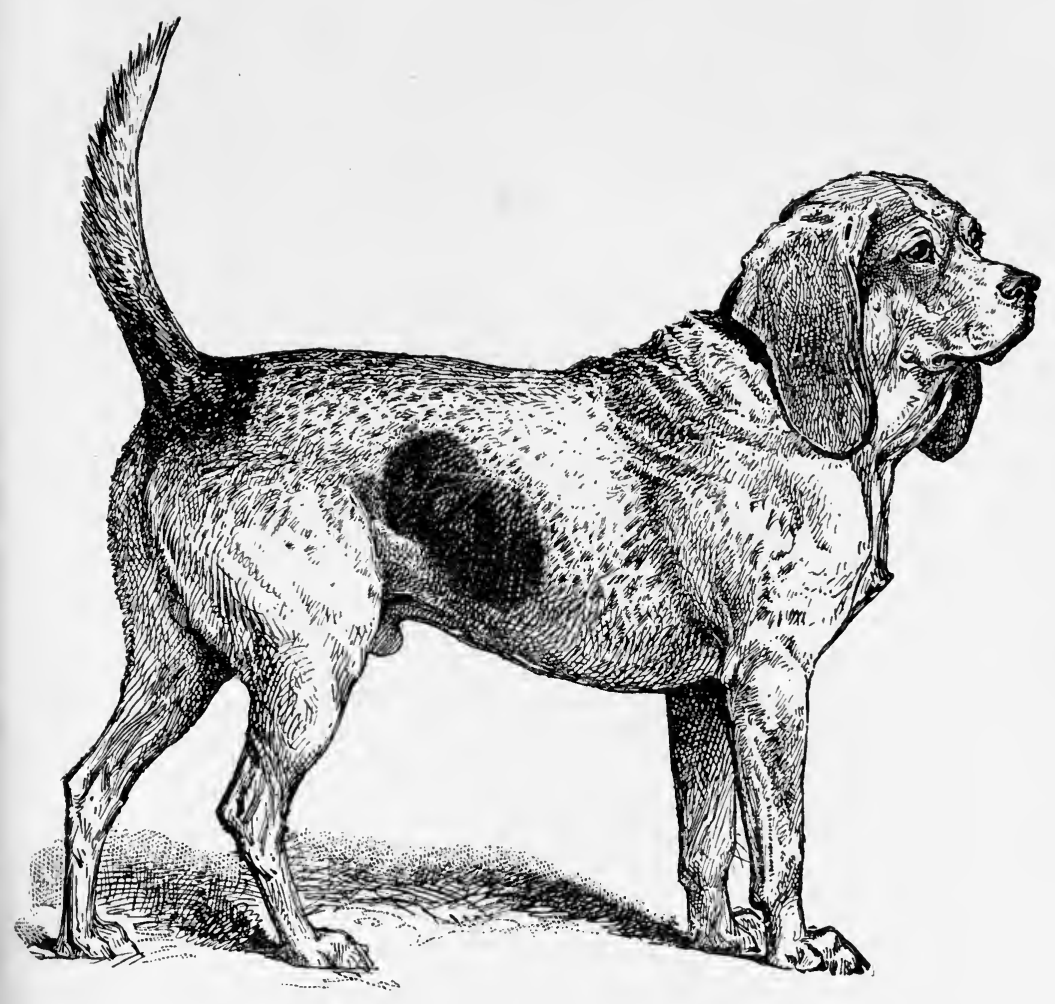

THE BEAGLE CHAMPION RINGWOOD.

(K. C. S. B., 19,846.)

For description, see page 41. 
Back.-Even, short, strong.

Loin.-Powerful, slightly arched, not tacked up in flank.

Quarters.-Strong, muscular, no droop or crouch; thighs long and powerful; hocks near ground; stifle bent as in a foxhound.

Stern (tail).-Set on high, strong, carried gayly, but not over back or curled; is usually docked.

Legs and Feet.-Much as in the foxhound.

Coat.-There are two varieties of this terrier-the smooth- and the wire-haired. In the former the hair is smooth, flat, hard, dense, abundant, tough, and should cover also the belly and inner side of thighs, though not so thickly. In the rough-haired or wire-haired breed the harder and more wiry in texture the better the coat, which is longer than in the smooth dog; but it should not give the appearance of shagginess. It must on no account be silky or woolly either to eye or hand.

Color.-White should predominate; brindle, red, or liver markings are objectionable; otherwise color is not of much importance, though black and tan on head is much liked.

The fox-terrier should show symmetry, quality, and character in a high degree.

Weight, etc.-Not either a leggy or low dog; should fall between sixteen and twenty pounds.

Irish Terrier.-This breed is very popular in Britain, and is gaining ground in America. In general appearance, except in coat and color, he somewhat resembles the fox-terrier, but is a considerably larger dog (p. 80).

Good-tempered with mankind, he is a little too ready 
for a fray with his own species, and he does not always stop to consider whether he is a match for his antagonist; but in any case he is slow to give up once he begins.

In jaws he is rather stronger than the fox-terrier. A reaction has taken place against cutting the ears of this breed, but the tail is still docked. This latter operation, when done at a very early age, as it usually is, causes very little pain. In most points the standard is similar to that for the fox-terrier, but the Irish dog is larger.

Coat.-Somewhat like that of the wire-haired foxterrier, but its true quality must be learned by feel. It should not be shaggy, but straight and flat.

Color.-Whole-colored; bright red preferred, wheaten, yellow, and gray next; brindle disqualifying. A little white on chest not so objectionable as on feet.

Weight.-Sixteen to twenty-four pounds, bitches, as in all breeds, being rather smaller.

Black-and-tan Terrier.-Formerly a white terrier identical in shape, etc., to this was much valued. This breed is now, however, rarely seen at shows in any numbers (p. 88).

The black-and-tan terrier, on account of cleanly habits, a skin free from smell, neatness, size, color, etc., is well adapted to be a house dog; but his aversion to strangers, generally manifested by a shrill, unpleasant voice, is no small drawback, though by no means confined to this breed. He is not so generally popular as the fox-terrier, not being so hardy and perhaps because of the cropping of the ears, which is not always done so as to render them presentable. They do not bear cold as well as most of the terriers. Nevertheless, he is a good vermin dog, 
being rcnowned in the rat pit. He has also many winning ways and is capable of being tanght various tricks.

In general form he is somewhat between the Italian greyhound and the fox-terrier or very small bull-terrier.

His chief peculiarities are:

Head.-Long and narrow, slight stop, tight-skinned; like a much-tapered wedge; eyes very dark (black), oblong; very bright, neither much sunken nor protruding; nose black; ears small, thin, set as close together as possible at the top of the head, lying close ("button" ear).

Chest.-Narrow between the fore-legs and deep in the brisket; ribs well sprung.

Back.-Short.

Loin.-Slightly arched and powerful; flank a little tucked up.

Quarters.-Strong and muscular.

Feet.-Compact, split up between the toes and well arched, with jet-black nails; the two middle toes of the front feet a little longer than the others; the hind-feet eat-like.

Tail.-Moderately short, set on where arch in quarters ends; thick at root, tapering gracefully, and not carried higher than loin.

Coat.-Short, close, and glossy ; not soft.

Color.-A feature of great importance in this breed. The recognized colors must not only be true but distinctly defined or sharply marked off and confined to limited regions. Black is the prevailing color, so that at a distance the dog appears black. The $\tan$ is described as a rich or warm mahogany tan, which is distributed as follows: Small spot over each eye, and another on each 
cheek, which latter must be as small as possible; lips of upper and lower jaws, extending under jaw to throat in shape of letter $\mathrm{V}$; inside of ear in part; fore-legs to knee, with black patch ("thumb-mark") between pastern and knee ; toes must have a distinct black line on each ("pencilmark"); on hind-legs up inside of thigh to a little below stifle; outside of legs must be perfectly black; tan under tail, and but sufficient to be covered by tail.

Weight.-Between fourteen and twenty-two pounds.

A dog under seven pounds is a toy, which is judged by the same standard, but is rarely so perfect, especially in head.

The Yorkshire Terrier.-Being a toy dog, he has lost a great deal of the true terrier character, though in some specimens much more is found than in others. In this breed coat is the feature of the dog, and is allowed a large proportion of the entire marks. In the words of the adopted standard, his general appearance "should be that of a long-coated pet-dog, the coat hanging quite straight and evenly down each side, a part extending from the nose to the end of the tail. The animal should be very compact and neat, the carriage being very sprightly, bearing an important air. Although the frame is hidden beneath a mantle of hair, the general outline should be such as to suggest the existence of a vigorous and well-proportioned body." In accordance with the above, uneven jaws, crooked legs, uneven back and loin can not be tolerated (p. 96).

Head.-Rather small and flat in skull, somewhat broad in muzzle, perfectly black nose; eyes of medium size, dark in color, bright, intelligent, looking straightforward, with dark-edged eyelids. 



$$
\text { . }
$$


Ears.--If not cut, they should be small, V-shaped, and carried semi-erect; if cut, quite erect.

Coat.-As long and straight (not wavy) as possible, silk-like (not woolly), extending from back of head to root of tail.

Color.-A bright steel-blue, and on no account to have any fawn, light, or dark hairs. Hair on muzzle very long and of a bright golden tan; on sides of head very long and of a little deeper tan, especially about roots of ears. Ears are covered with short hair of a deep, dark tan. Legs covered with tan hair a few shades lighter at the ends than at the roots.

Weight.-Divided usually into two classes-dogs under five pounds and over five pounds, but not to exceed twelve pounds. Sometimes classified as toy terriers under seven pounds. One of the most popular small dogs in America.

Scotch Terriers.-The hard-haired Scotch terrier and the Skye terrier are of Scotch origin, and bear the impress both of the climate of the country and of the character of the people that has such strongly pronounced national characteristics (pp. 104, 120).

These dogs, when of the best strain, are docile, courageous, affectionate, and faithful in a high degree. They are essentially vermin dogs, but to an unusual extent show also qualities which fit them for being the companions of man. Though not so popular in America as some other breeds, they are kept with pride by many a self-expatriated Scot who has not forgotten the associations of his boyhood and the canine friends of his old home.

Both the Scotch and the Skye are long, low, strongly 
made dogs, provided with a coat admirably adapted to resist wet and cold, and so fitting them for entering burrows after their quarry and facing any weather however bleak.

The Skye is an especially long dog, with an ill-defined outline owing to length of coat. A good Skye should measure in length three times its height. The Scotch is also long, but not in such proportion as the Skye. Both these breeds are more cobby in build than other terriers, and are not adapted for great speed; with their powerful limbs, however, such conformation adapts them for forcing quarry from a burrow, while their powerful jaws and teeth make their grip firm and punishing.

In weight neither breed should exceed twenty pounds; better if a little less.

Coat.-In the Scotch terrier proper it is rather short (about two inches), very dense, and extremely hard and wiry.

In the Skye the hair should be long, straight, shining, like that of a horse's tail ; silkiness, woolliness, or curl to be avoided, though on the top of the head it may approach silkiness.

Colors.-In the Scotch, steel or iron gray, black brindle, brown brindle, gray brindle, black, sandy, and wheaten; white markings undesirable and not permissible, except a little on chest.

In the Skye the colors most favored are in their order of preference-steel gray, with black tips to ears and tail; fawn, with dark-brown tips; dark slaty-blue, black, and pure fawn.

The Skyes are divided into drop-eared and prick-eared, which terms in themselves express the main difference. 
The Bull-terrier.-The strongest, heaviest, and perhaps the gamest of all the terriers (p. 136).

$\mathrm{He}$ is quick to take offence from another dog, and in fighting is very tenacious; but he is often affectionate, docile, and very companionable.

Like other all-white dogs, etc., he is liable to deafness.

General Appearance.- "The general appearance of the bull-terrier is that of a symmetrical animal, an embodiment of agility, grace, elegance, and determination."

Head.-Long, flat, wide between the ears, tapering to the nose, without cheek-muscles. There should be a slight indentation down the face, without a "stop" between the eyes; jaws long and powerful, with large black and open nostrils; eyes small and very black; lips meeting tightly without any fold; teeth regular and even in front.

Ears.-Always cropped hitherto in the show dog, and in a peculiar manner.

Chest.-Wider than in other breeds of terriers.

Feet.-More of the "hare" than of the "cat" type, but compact and well-arched. Shoulders, back, loin, legs, etc., to suit a dog of the active type.

Tail.-Set on low; thick at root and tapering to a fine point; carried at an angle of about $45^{\circ}$, without curl, and never over the back; usually ten to twelve inches long.

Color.-All white.

Coat.-Glossy, short, close, and stiff.

Weight.-From fifteen to fifty pounds.

Other Breeds of Terriers. *-The varieties of terriers

* For an illustration of the Boston terrier, see p. 140. This breed has lately become rather popular in America, and classes for them are provided at some shows. It is intermediate between the bull-dog and the bull-terrier. 
not yet referred to are but little known in America, and may be briefly described.

The Welsh Terrier.-He may be regarded as very like a black and tan, wire-haired fox-terrier, but rather larger and with a heavier head (p. 144).

The Airedale Terrier.-After the bull-terrier, the tallest and largest of this class. His form departs little from what might be termed average terrier type. He stands rather high on the leg, and the tail is usually docked (p. 152).

Coat.-Rough or broken, dense and wiry in texture, and free from curl or lock.

Color.-Dark grizzle from occiput to end of tail, extending also down sides of body, with dark markings on side of skull; rest of body a good tan, which should be darker on ears than elsewhere.

Weight.-Dogs, forty to forty-five pounds; bitches, thirty-five to forty pounds.

Dandie Dinmont Terrier.-Differing so from all other terriers in eyes, ears, general shape of head, with its topknot, and being of a somewhat unmanageable disposition when he scents "fur," it is suspected by some good authorities that a Dachshund cross occurred at some time in the history of the breed.

The skull is wide and heavy, forehead domed, powerful teeth and jaws; eyes wide apart, full, and round; ears large, pendulous, wide apart, low-set on skull. The head is covered with very soft, silky hair, forming a "topknot," but not confined to the forehead. The ears are covered with soft, straight, brown hair, and have a thin feather of lighter-colored hair like the top-knot.

Legs.-Short, straight (liable to be bandy), very strong, and set wide apart in front. 


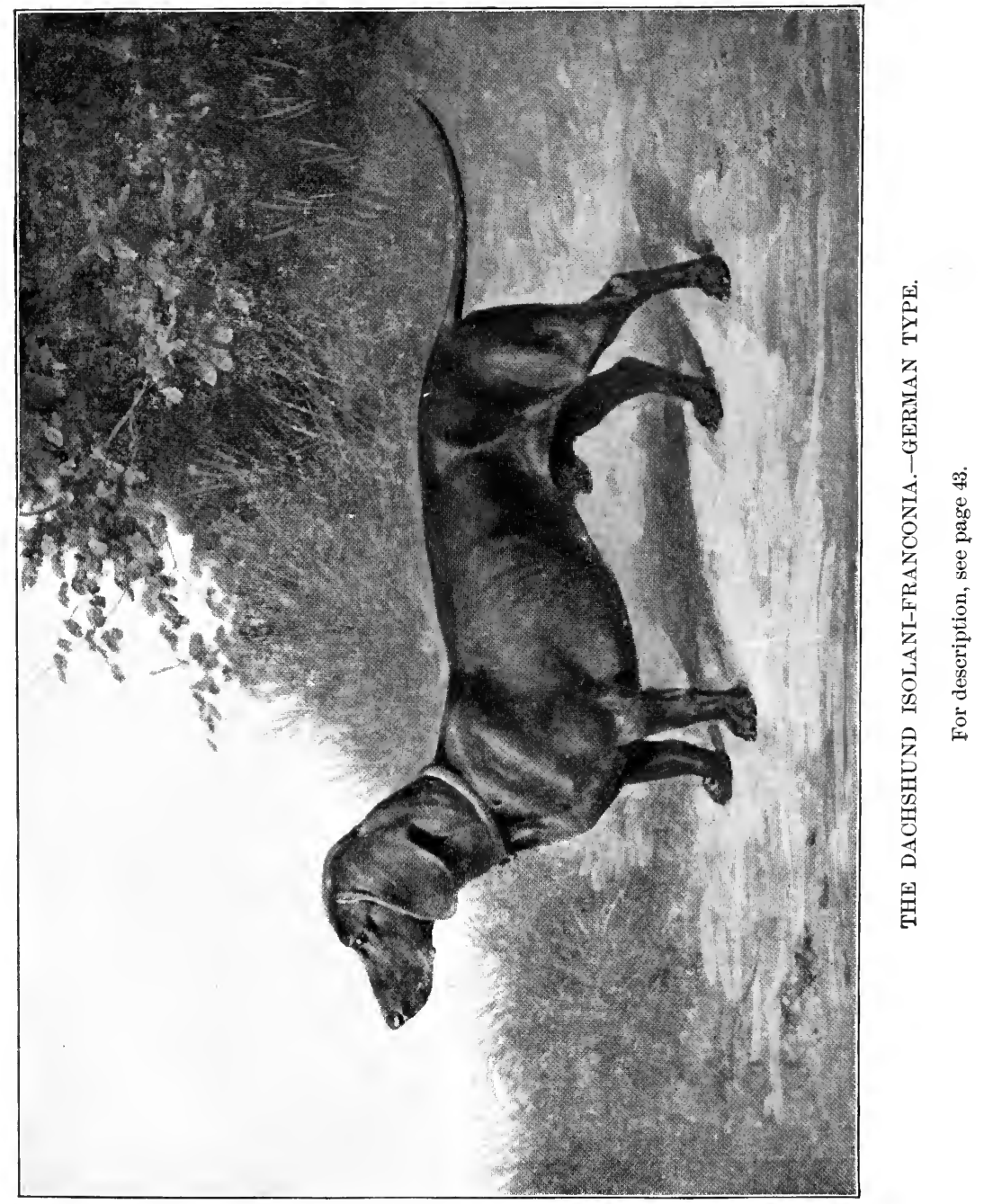



Chest.-Wider than in most terriers.

Coat.-Very difficult to secure correct in this breed. It is termed piley or penciled-i. e., a mixture of hard and soft hair, giving a crisp feel to the hand; the hard hair should be wiry, the hair on under part of body being softer, also lighter in color.

Color._"Pepper" or "mustard"-i. e., of various shades suggested by these colors but impossible of description in words.

Size and Weight.-Height at shoulder, eight to eleven inches; length not more than twice the height. Best weight, eighteen pounds.

The Bedlington Terrier.-Another peculiar-looking terrier, standing rather high on the leg, and with somewhat hound-like ears and a top-knot. $\mathrm{He}$ is a hardy, game, useful dog (p. 160).

Skull.-Narrow, deep, and rounded, high at occiput, and covered with a top-knot of silky hair.

Ears.-Rather large, filbert-shaped, well forward, lying close to cheek.

Eyes.-Small and well sunk.

Feet.-Rather long and large.

Tail.-Of characteristic shape and carriage.

Chest, etc.-Chest not wide, but deep and flat-ribbedwell "ribbed up" (deep back ribs); back rising into an arched loin; quarters rather light.

Coat.-Hard, with close bottom, and not lying flat to sides ("linty").

Color.-Dark blue, blue and tan, liver, liver and tan, sandy, sandy and tan.

Size.-Height, fifteen to sixteen inches; weight, eighteen to twenty-four pounds. 
This breed of terrier should be a light, "lathy" dog; he is apt to fail in back ribs, etc. In this breed the stifles are apt to be rather straight and the hocks placed very high.

The Paisley Terrier.-In general appearance a long, low, stoutly-built dog, with an intelligent expression, and a long, flowing, flat-lying, straight coat. The appearance of the head depends a good deal on the ears, which stand up quite straight, are set on high, covered with long hair, and well fringed.

Coat.-Long, flat, and silky; the longer and finer the better; a part extends from shoulder to tail.

Color.-Various shades of blue, dark blue preferred, but of a lighter shade on head and legs.

The Clydesdale Terrier.-A long, low dog, with a large head and a coat that resembles silk or suggests spun glass. A fancy terrier, but hardier than the Yorkshire or Maltese.

Ears.-Very characteristic, small, set on high, perfectly erect in carriage, covered with long silky hair (well feathered).

Color.-Ranging from dark blue to light fawn, the first preferred.

The Maltese Terrier.-A very small (must not be over six pounds) toy terrier, in which coat and color are of chief importance.

Coat.-Long, silky, with a slight wave; woolliness and curl are very objectionable.

Color-Pure white, suggesting spun glass; fawn patches may occur, but are highly undesirable.

Nose black; eyes full and black and not "weeping"; tail short and curled tightly over the back. 
CLASS IV.

DOMESTICATED DOGS, FINDING THEIR GAME BY SCENT, BUT NOT KILLING IT ; AND USED CHIEFLY IN AID OF THE GUN.

These include the pointer and the different kinds of setters and spaniels.

It will greatly facilitate the mastery of the points of these breeds, as well as prepare for a criticism of the adopted standards, if we first consider, according to the principles already laid down, the work or purpose for which they are intended. None of these breeds are, as a rule, employed to hunt "fur," hence the fleetness of the greyhound is not required, nor his form or characteristics in a very high degree. They are all employed to discover and indicate the whereabouts of game birds. For this purpose keen scenting powers are the primary requisite, and after that the pointing instinct. This may be regarded as an example of an acquired instinct; for, although all breeds of dogs and all the wild congeners of the dog tend to stop when prey is discovered, and in certain cases to steal upon it by cautious advances, in none of them has the actual rigid or cataleptic condition of the muscles been developed, at all events in any high degree. There is in all of these groups of animals the fundamental instinct or tendency out of which such a remarkable condition of the nervous and muscular system has been evolved, and which is now termed "pointing."

Dogs have been known to remain in this condition ("on point") for many hours, showing that it is not an act of will or a mere taught habit; though of course the 
training and selection of the dogs showing it in the highest degree for generations are the means by which so remarkable an instinct has been developed.

Indeed, the modern pointer and setter are capital examples of the process of "artificial selection," or "the survival of the fittest," or what man conceives to be the fittest. For many years both in Britain and America field trials or public competitions in actual hunting have weeded out the poorer specimens and brought the best to the front, so that breeding from these, dogs of a superior class have been produced.

While a dog deficient in nose or pointing instinct is useless, of equal or more importance are other qualities, particularly a specialized intelligence of a high order well characterized as "bird-sense" or good judgment in seeking for birds where they are most likely to be found, and so deporting himself throughout as to find the birds as soon as his nose, powers of speed, etc., will allow, all being related to economy of energy. But with these qualities of highest importance must be joined docility and tractability, and from the physical side speed and endurance.

We may say, then, that with the requisite general and special developments of the nervous system, especially of the brain and the sense of smell, there must be that physical form and constitution that enables the dog to move rapidly and to continue long at his work. If he has these qualities, symmetry and beanty are of secondary importance. However, it but rarely happens that the above exist in a high degree without a fair amount of the latter, as the relative proportion of parts must have a great deal to do with both speed and endurance. 


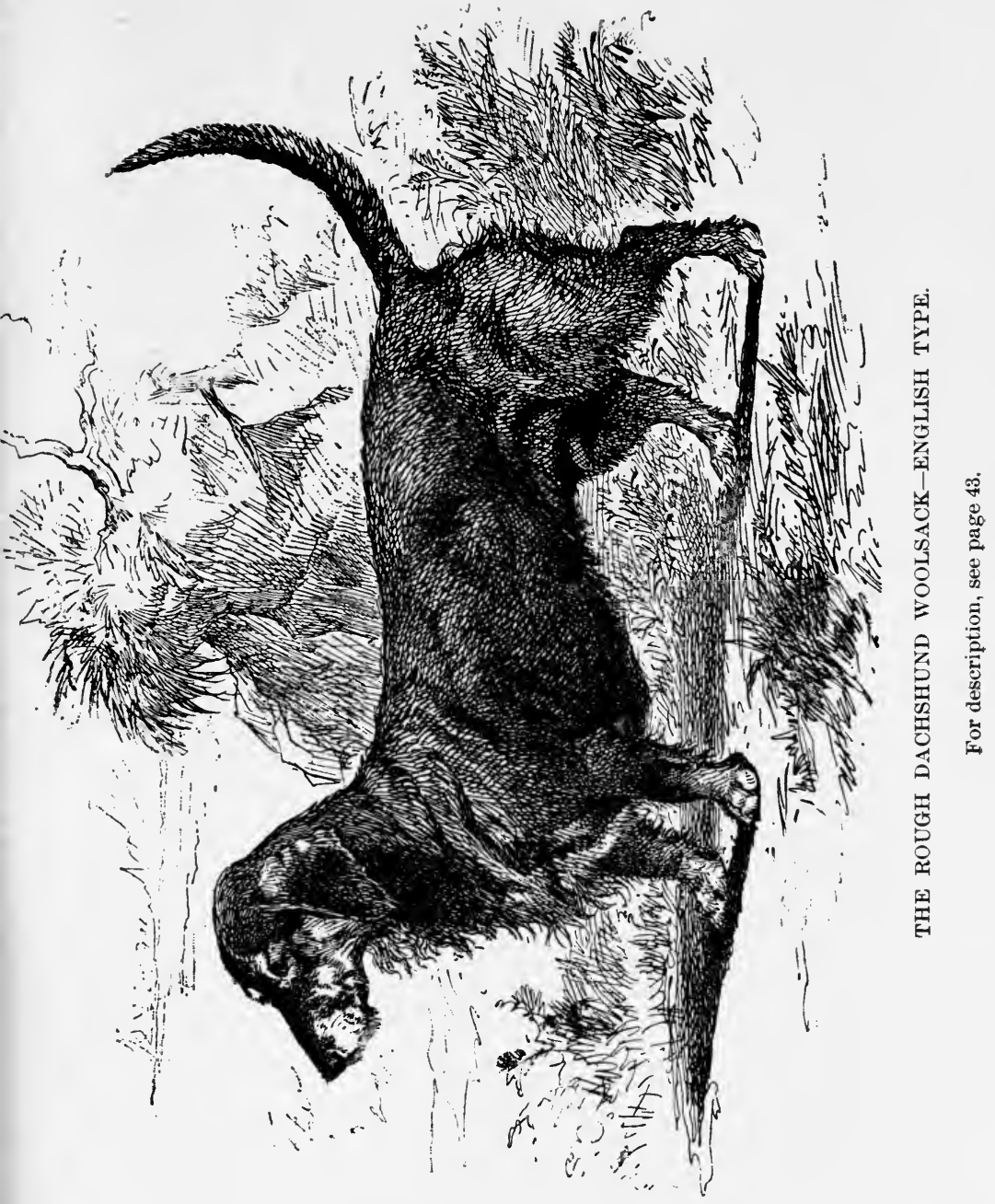



Exceptional cases occur no doubt. These do not prove that form is of no consequence, but they do seem to teach the lesson that of however great importance a strong and symmetrical form may be, a sound constitution and a welldeveloped brain and nervous system generally are much more so. The nervous system is always king in the highest classes of animals of every kind. It rarely happens that a very successful field-dog is wanting in the parts most successful in propulsion, as loins, quarters, legs, and feet, though he may be defective in head parts, neck, shoulders, back, or even chest.

But should we not endeavor as our highest ideal to combine "bench-show form" with "field form"? What meaning has the former if not related to the latter in a hunting dog? Our aim should be to discover what the latter is, and adapt bench form to field form, or, rather, make them identical.

What in a general way is "field form," or that best adapted for work in the field, should not be very difficult to determine with the greyhound, the foxhound, the racehorse, and the hunter before us. Evidently, if, as is now the custom, in consequence of the relative scarcity of game, a dog that is both fast and lasting is required, a form approaching a mean between that of the foxhound and the greyhound must be attained. And in considering this, one must not be led astray by the eminence certain strains of dogs have attained. That eminence is no doubt largely due to a specially cultivated and developed intelligence, and the subject must be studied on a wider basis than the one sometimes adopted.

The nature of the country and the climate must not be 
left out of the account. But, turning to general principles, How shall the end be attained as regards physical form so that an animal may be built up that shall, provided he has the nose and the brains, be able to put these to the most effective use?

Setter and pointer form will be first considered. It is to be remembered that these dogs must traverse all sorts of surface, pass through water often very cold, over snow and ice, crush through thorny and brambly vegetation, and all this at a very considerable speed. Such a form, combining grace and utility, experience proves is built up on the following principles, most of which have been alluded to before :

Head.-A longish skull, getting its capacity rather by length and depth than width, and suiting thus the dog's general form, more especially that of his long and not very wide but deep muzzle; eyes mild, bright, and of medium fullness, thus suggesting intelligence and docility ; ears long, low-placed, feathered, and so adapted to his general character as well as protective to eyes and inner ears ; muzzle long, deep, and fairly wide; square-cut at end, indicating that the jaws are even, with a large nose and widely open nostrils. Such a muzzle provides for a large distribution of the olfactory nerve, and such a nose readily admits air.

$N e c k$.-Clean, graceful, and long enough to admit of the dog's catching the foot-scent or reaching the ground without stooping.

Shoulders, back, loin, quarters, legs, and feet of the kind adapted for speed and endurance. The back need not have all the muscular development, the loin so much 
arch, the quarters be so wide, nor the lower thighs so developed as in the greyhound, but we must not forget that perfect model for speed while we seek to combine this quality with endurance.

The bone of the legs, the pasterns, and the feet must in strength and formation combine the features of these parts in the greyhound and the foxhound. A dog weak in these is, so to speak, weak all over-i. e., his otherwise fine powers of intellect and body are of little use. The chest is both deep and wide, but not in front or between the fore-legs; capacity is attained by depth and spring of ribs, but the chest must be keeled and in no sense barrel-shaped, though in the English and Gordon setter the back is wide; the chest must be well ribbed back (deep back-ribs.) In the setter the feet should be all that is attained in the best pointers, but, in addition, have plenty of hair between the toes as an additional protection.

Coat on all these breeds must be very abundant, especially on ears, legs, breast, and tail, where it constitutes a long fringe or "feather." This feather adds to the grace of the setter, but is of questionable advantage, inasmuch as it tends to catch all burs, etc., and must hamper as well as possibly protect. The tendency seems to be, as greater speed is sought for, to do with less feather, and, we think, wisely. The pointer's coat is short and soft, but not fine (silky, almost) as in the setter's. Very great fineness of texture of coat in either setters or pointers may indicate lack of stamina, as a coarseness may suggest bad breeding, or that the possessor is wanting in high psychical quality.

As these breeds are never required "to go to earth," there is no necessity for a hard, much less a wiry, coat. 
If the pointer were covered with a similar coat, he would, in general appearance, greatly resemble the setter. Nevertheless, there are differences the trained eye can readily discern among the various breeds of setters, and much more between them and the pointer. These points have never been very clearly defined in words, and it is doubtful if they can be, unless very full descriptions and accurate proportional measurements be given. However, they can be engraved on the memory by illustrations of the best dogs, though, of course, better still by far from seeing typical specimens of the breeds. We shall now mention some of the salient differences.

The Gordon is the largest, heaviest, and slowest of the setters; the Irish the tallest, most lightly built, but most wiry and active, perhaps; while the English is the mean between the other two (see pp. 176, 184, 192, 208).

Head.-Skull in the pointer wider from ear to ear; consists of two rounded flats separated by a furrow ; decided stop, brows, and occipital protuberance.

The whole head of the Gordon is heavier than in the other setters, but in shape much resembles that of the English. The skull of the English setter is between that of the pointer and cocker spaniel, though the tendency now is to a longer head and neck. In all these breeds the stop and brows are well marked, and there should be entire absence of "cheekiness," and both skull and muzzle should be well chiseled or clean-cut.

The Irish setter's head is long and lean, in harmony with the general build of the dog. The skull is peculiar, being oval, with a very pronounced occipital protuberance-a domed skull. The ears in all should hang close 


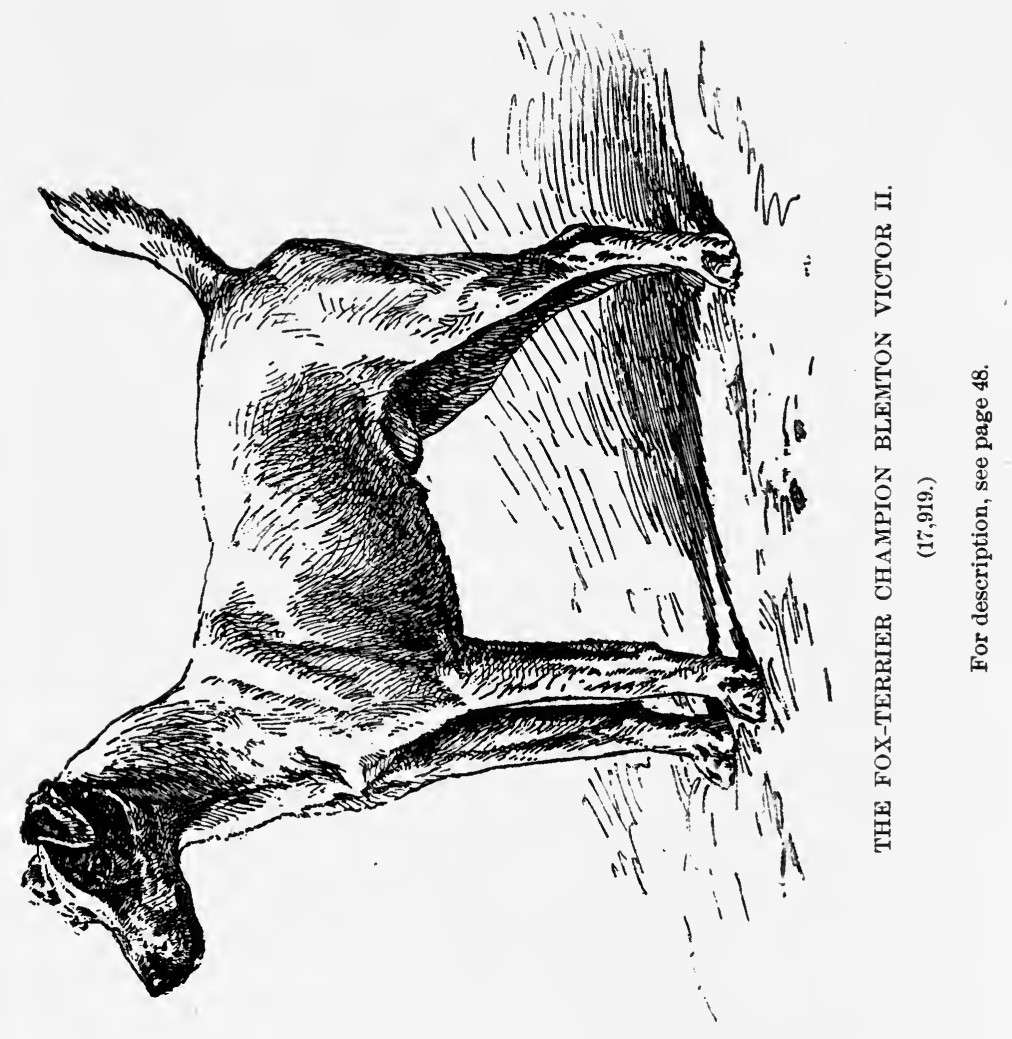




$$
1
$$


and be low-set, which applies, of course, to the pointer also.

The eyes should be dark, always having reference to the color of the dog; but there is a strong tendency for light eyes to appear, and they greatly militate against the true expression of the animal. A downright yellow eye is an abomination in any breed of dog.

In all setters the nose should be black or dark livercolor; but in lemon and white pointers and setters it may be flesh-color. In the Irish setter it is described as "dark mahogany" or " dark chocolate."

Shoulders.-The Irish setter is the most "upstanding" of all these breeds, and his shoulders should be very perfect both at joints (points) and withers. This adds greatly to the character and quality of the dog.

Loin.-The loin in all setters and the pointer should be slightly arched, but not roach-backed or "wheelbacked," as in the bulldog.

Quarters.-All should be broad and muscular here; but the Irish setter is the most ragged-looking in hips and quarters; in fact, this dog should be throughout eminently muscular and wiry; he should be entirely free from "lumber."

Feet.-The cat-foot is preferred in the pointer, and a foot with abundance of hair between the toes in the setter. This is most likely to be found in the hare-foot, though in other respects it is probably not equal to the cat-foot, and certainly does not look so well.

Tail ("flag" of setters, stern of pointers) is carried curved and nearly on a level with the back in all breeds. It should begin strong and taper to a point. A well- 
carried, "sting-like" tail is a fine feature in a pointer, and a similar carriage, with a nice feather to the tail, adds greatly to a setter's appearance. Nevertheless, it has so little to do with actual hunting ability that it should count but little in the total estimate.

Coat.-Decidedly silky in the English setter, not quite so much so in the Irish, and harder and coarser in the Gordon. In none should there be any tendency to waviness or curl; in the pointer not silky, but soft and mellow. In all these breeds the coat should be close-lying and dense.

Color.-To this, great importance is not attached in the English setter or pointer; liver and white in the latter, and black, white, and tan, and the "blue belton," or white with fine black flecks, giving a roughly ink-splashed appearance, are the most preferred now in the former. In the Irish setter the dark or mahogany-red is the choice color. In the Gordon, color, though it is set down at five per cent., is really valued higher. The same importance, though in a minor degree, is attached to the black and the tan being pure and distinct, as in the black and tan terrier; and though it is admitted that the original Gordons were black, tan, and white, the latter is now greatly objected to, except a little on the breast, which, as in the Irish setter, is of no account.

The black must be deep and pure, the tan a rich or warm mahogany-red, and confined to a spot over each eye, lips, cheeks, throat, fore-legs nearly to elbows, hindlegs to stifles, and on under side of flag, but not running into its long hair.

It will scarcely be necessary to add anything to what 
has already been said on the importance of the best of legs and feet in hunting dogs. As they have to stop sharp, "or point," when in rapid motion, there is a great strain on the ligaments and a tendency to become out at elbow, or still more to walk with the fore-feet either out or in ("pigeon-toed"), or to "knuckle over"-i. e., with the knee and pastern not in line. To avoid this, young dogs should not be exercised too much nor over too rough country, and the exercise gradually increased.

Lengthy and too often bitter controversies have raged over the respective merits of the different breeds of setters and pointers. Such discussions should be conducted in a calm, if not a scientific, spirit; but we venture the opinion that they are in general productive of little good and much harm, and lead to a great waste of energy and the engendering of bitter feeling. The best dog is that which suits his master best, and as no two men are alike, it follows that the breed best adapted to one man is not necessarily the best for another. There is room for all; and, indeed, this diversity of qualities is an advantage. The setters may be better able to resist the effects of wet, cold, briers, and rough footing, but they catch up more burs, bear heat and drought badly, as compared with the pointer, and are neither so easily trained nor so tenacious of what they learn as a class; and if pointers are not less liable to skin disease, they are more easily treated, being shorthaired dogs. The Irish setter may be faster, have more dash, vim, and endurance than the English setter, but he is not very readily broken or very easily restrained in the field; and so we might continue the discussion. But dog and man must be considered together. Besides, it 
must not be forgotten that anything to which a man has become accustomed may be better for him though not better in itself. Dogs suiting the English style of shooting must be adapted to that in vogue in America before they can use their powers to advantage, and the reverse.

Two strains of English setters have been famous in modern times, the Laverack and the Llewellin.

The latter was formed by a cross of the former with the Duke-Rhæbe blood. These strains were named from the gentlemen in whose hands they were formed or became renowned.

The Laverack is heavier in the shoulders and chest, more feathered, and perhaps more symmetrical.

The Llewellins have attained great eminence in field trials in America, one dog, Gladstone, but recently dead, having become a "name to conjure by."

We have devoted a good deal of space to the setter and the pointer on account of their great popularity in America, where they have reached a degree of perfection perhaps not yet equaled elsewhere-at all events as regards setters, whether the field or the show bench be considered.

The author has just one more remark to make in regard to these breeds. The setter is unquestionably one of the most beautiful breeds of dogs ever seen, and it is to be hoped that no temporary craze or mere fad will lead to the production of dogs so small or so spaniellike in form that we shall lose what has been the admiration and the result of the work of generations of gentleman sportsmen and earnest breeders; and it is further to be hoped that bench-show judges will not 
neglect to examine into the muscular development and condition of the dogs that came before them in some such way as is customary with the greyhound, for a dog that has not plenty of muscle and in hard condition is not fit for work; and a dog with a make-up that is unsuited for the intended purpose should not win, or judging will become a farce and bench-shows a hindrance rather than a help to the production of good animals.

The Spaniels.-The spaniels do not point, but are taught to keep within a short distance of the gun, and give tongue when game is discovered by the nose. The Clumber spaniel, however, hunts mute.

In Britain the breeds most in favor are the Clumber, the field, the cocker, the Irish water spaniel, and the English water spaniel. In America the only one of the spaniels that is thoroughly popular is the cocker, and even he is more of a companion or a house dog than a worker, hence the tendency at present to breed very small specimens. Excepting the water spaniels, the breeds agree in being long, stoutly made, low dogs, with a profusion of coat of soft texture.

All the spaniels should be of an eminently docile and sweet disposition. Those of the opposite characteristics should be discarded.

The Cocker and the Field Spaniels. - The former an active, merry little dog, strong but not clumsy, and perhaps the most symmetrical of all the short-legged group (pp. 216, 224, 230).

Long, low, heavy-boned, and cobby in build, but a small dog (between eighteen and twenty-eight pounds).

He differs from the field spaniel in size, relative length, 
and head. The head of the cocker, as a whole, is not so heavy, nor the muzzle so square throughout. The dome of the skull of the cocker should correspond nearly with the segment of a circle. Ears in both low set, but more so in the field spaniel, in which they are also larger.

The eyes should not be either full or sunken, and in color correspond with the coat. They are apt to be too light, which spoils the expression. The correct amount of stop and cleanness of chiseling, with correct eyes, has much to do with quality in both breeds-in fact, in any breed of dogs.

In the rest of the form the field spaniel and the cocker differ but little from each other.

The neck should be long enough to allow the nose to reach the ground, but free from throatiness; shoulders muscular and sloping; chest fairly wide and deep; ribs well sprung and extending back, so that the coupling shall be short; the loin strong, and the flank not tucked up.

Legs and Feet are parts which, in spaniels as in all other very long and low dogs, are apt to be wrong. Legs should be strong in bone, to support weight and enable the animal to push through thick coverts; forelegs short and straight (not bandy); elbows free, and neither in nor out; hind-legs strong, with well-bent stifle and good hocks, turning neither in nor out. Feet of moderate size, thick; toes well arched, pads hard, and plenty of hair between the toes.

Length.-It is still agreed that the field spaniel should be very long and low; but in America there is now a reaction against cocker dogs as long as those high in favor in England. The standard in vogue says of the cocker: 
"From tip of nose to root of tail, about twice the height at shoulder, rather more than less."

Coat.-Abundant, soft, and silky, straight or wavy, but not curly; chest, legs, ears, and tail well feathered.

Color.-Black preferred; liver, black, and white, and various shades of red.

Tail.-Usually docked; carried nearly level with the back; lower when at work and in rapid movement.

The Clumber Spaniel._- "A long, low, heavy-looking dog, of a very thoughtful expression, betokening intelligence. Should have the appearance of great power. Sedate in all movements, but not elumsy. Weight of dogs, between fifty-five pounds and sixty-five pounds; bitches, from thirty-five pounds to fifty pounds" (Standard). (P. 240.)

Head.-Very characteristic, being massive in all dimensions, round above eyes, flat on top, with a furrow running from between eyes up center of skull; stop and occipital protuberance pronounced; jaw long, broad, and deep; muzzle not square, but powerful-looking; nostrils large, open, and flesh-eolored, sometimes cherry-colored; eyes soft, large, deep-set, and showing haw, hazel in color, with dignified and intelligent expression; ears long and broad at top, turned over on front edge, vine-shaped, lowset, and close, slightly feathered on front edge only, with straight, short, silky hair.

Length.-About two and a half times height at shoulder.

Coat.-Silky, straight, very dense, but not very long ; feather both profuse and long.

Color.-Lemon and white, and orange and white; fewer markings on, body the better. Solid lemon or 
orange ears, evenly marked head and eyes, muzzle and legs ticked, constitute perfection of marking.

Stern.-Usually docked, set on level, and carried low.

The Norfolk and the Sussex spaniel are almost unknown in America.

The Irish Water Spaniel.-The Irish water spaniel has a good many admirers, but does not enjoy the same popularity in America as in Britain (p. 256).

No dog is more adapted for retrieving from water or being the duck-shooter's companion, unless it be the very homely Chesapeake Bay dog. He is very intelligent, but not always equally good-tempered. His general appearance is that of a handsome, strong, rather leggy dog, with very striking physical characteristics.

Head.-Skull of medium length, rather broad, with but a slight stop; muzzle long and broad to the end; eyes dark-brown and with an intelligent expression; ears long and covered with curls.

Chest.-Deep rather than wide. Loin somewhat arched.

Stifles rather straight; hocks well let down.

Stern.-Strong at root, tapering to a fine point; hair on it very short, straight, and close-lying.

Legs and Feet.-Legs long, but strong in bone; feet somewhat large.

Coat.-All over, except on face and tail, little curls, hard and not woolly. On forehead a top-knot of long hair, falling over eyes in a peak. Legs to have as little feather as possible.

Color.-A rich dark-liver, free from white, though a little of the latter on breast or toes should not disqualify. 


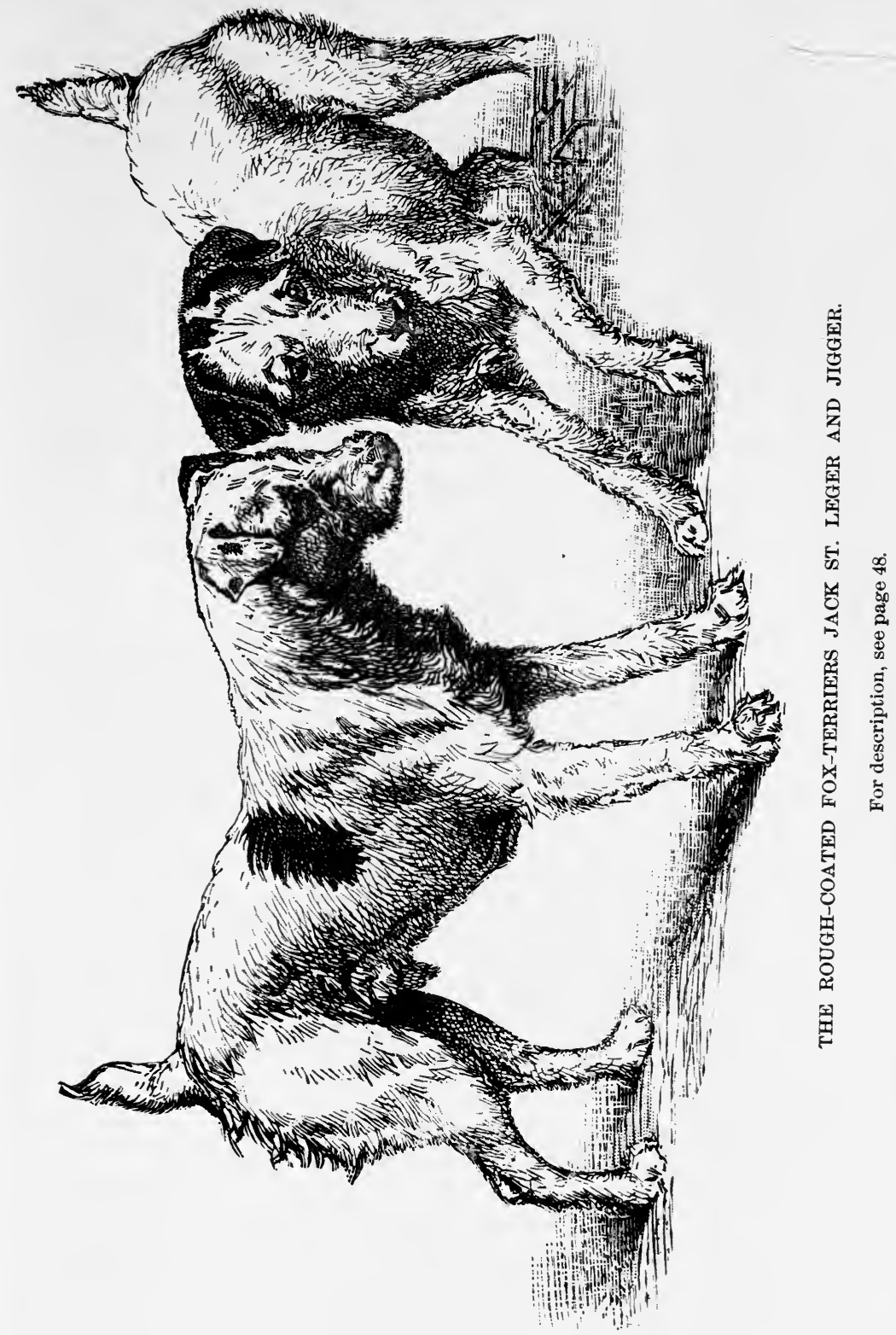



The English water spaniel, which also has a curly coat and is a useful dog, is but little known in America.

The Retrievers.-A dog kept purposely to retrieve dead and wounded birds on land is not employed in America, as setters, pointers, and spaniels are expected to do this; but in Britain a special breed for this purpose is highly esteemed (p. 264).

They are divided into two classes-the wavy-coated and the curly-coated black retriever. Both are large dogs of about eighty pounds, and standing twenty-five to twenty-six inches in height.

These breeds, which resemble each other greatly except in coat, have been formed, in all probability, by a cross between the Newfoundland and the spaniel (Irish) or the setter, or most likely both.

In general, the form is that which admits of considerable speed, endurance, and stooping power; hence a long neck is indispensable, as the dog must follow the footscent to seek out the wounded bird. Scenting powers of the highest quality are essential, as well as docility and a desire to work so as to please his master. A bad-tempered dog must not be tolerated on the bench or in the field.

Differences between the Breeds.-Tail.-In the wavycoated it may be bushy, but in the curly-coated the hair should be short and curly, and bare of curls toward the tip.

Coat.-Texture of coat and bareness of face constitute the chief difference between the breeds. The coat in the curly dog is intermediate between wool and hair, and very oily. On the whole face up to nearly middle of 
ears, coat should be quite short and without the slightest waviness.

In the wavy dog the coat is short, but not so short as in the hound or pointer, set close, slightly wavy, and glossy.

The Chesapeake Bay Dog.-This breed comprises large dogs, highly esteemed in duck shooting, and originated, as their name imports, on the shores of the Chesapeake Bay, in the United States. Their coat is adapted to resist water, some being curly and others straight-haired. The type is not very well marked, nor are they handsome dogs. They seem to be intermediate in form between the Newfoundland and Irish water spaniel, and might be called the American retriever. They are of a tawny sedge-color or red-brown.

The Dalmatian.-The Dalmatian, or coach dog, may be included under the present group, as in his native country he is employed as the pointer is with us. Upon the whole he greatly resembles the modern pointer, though his ears are shorter, his carriage of tail higher, and his general bearing in movement a good deal different to the experienced eye (p. 280).

The dog is used chiefly to follow a carriage, making a part of the general turn-out. Accordingly, he should be a dog adapted for a long journey on a hard road, being generally muscular, though not heavily built, and with good legs and the best of feet.

His chief attraction resides in the markings, which, by the standard of the club, count 40 per cent. These black spots on a white ground should be between the size of an English shilling and a half-crown, being smaller on the 
head and tail. There must be nowhere any black patches, and as few "flecks" or "freckles" as possible. Liver may be substituted for black, but is not so popular a marking. The spots should also be so close that there will not seem to be patches of white.

The Poodle.-On the Continent of Europe the poodle is used in fowling, both on land and water, an occupation for which his high intelligence and resisting coat admirably adapt him. In Britain and America he occupies the rôle of ladies' companion and house-dog chiefly. Of all dogs he excels in learning tricks, and his general intelligence is very high, as might be suspected from his large, well-chiseled skull, and the significant expression of his eyes (p. 300).

Coat and color count 50 per cent. of the total number of marks.

Head.-Skull broad and large generally; head carried high.

Muzzle.-Long and not snipy; somewhat shorter and thicker in the German breed; in the French dog, nose is a clear pink, and in the black breed jet black; roof of mouth also black.

Eyes.-Dark hazel, clear, and should look direct into the face of the one addressing the dog.

Ears.-Long, and thickly covered with long, silky hair.

Chest.-Broad and fairly deep.

Tail.-Usually docked, carried jauntily at an angle of about forty-five degrees.

Coat.-In the Russian, wiry, like horse-hair; in the French, like wool; in the corded, made up of long ring- 
lets; but in all it should be very thick, springy to the feel, and glossy.

Color.-Pure white or pure black, though a sort of liver-color seems to be coming into fashion.

\section{CLASS V.}

PASTORAL DOGS AND THOSE USED FOR DRAUGHT.

Sheep Dogs. - These include the rough collie, the smooth collie, and the bob-tailed sheep dog. All these breeds are remarkable for high general intelligence, no doubt largely due to long and close association with man and to selection of the best specimens for actual work, in which psychical qualities have been more considered than physical ones. However, it must be apparent that dogs physically adapted to the work would alone survive. Their chief use for a very long period has been as assistants to cattle-drovers, and especially shepherds. Such dogs must of necessity be capable of adapting to a bleak climate, such as prevails on the hills of Scotland, etc. ; hence a coat capable of resisting wet and cold is indispensable. These dogs must also be of a strong racing build, capable of easy and rapid movements. Docility of a high order and an intelligence specially developed for this one occupation of herding sheep and horned cattle are found in admirable combination.

The rough collie has become very popular of late as a show dog and companion, even as a house-dog.

The collie is of a somewhat jealous disposition, and does not welcome strangers, either human or canine, very cordially; and in a kennel with dogs of other breeds he may prove very troublesome.

There seems to be a tendency to pay undue attention 
to profusion of coat and high quality, especially in head, to the neglect of other qualities in the show dog. The standard allows for coat 20 per cent. of the total marks in the rough collie.

Rough Collie.-IIead.-Skull quite flat and rather broad, with fine tapering muzzle of fair length, the upper teeth projecting slightly beyond the lower; eyes wide apart, almond-shaped, and obliquely set; skin of head tightly drawn, no folds at corners of mouth; ears as small as possible, semi-erect when surprised or listening, at other times thrown back and buried in the "ruff" (p. 312).

The rest of the build corresponds to that combination of speed and strength so often referred to before. Neck rather long; loin also.

Tail (brush).-Long, "wi' upward swirl" at the end, and, except under excitement, carried low.

Coat.-Except on legs and head "as abundant as possible"; outer coat dense, straight, hard, and rather stiff; under coat furry and so dense that it would be difficult to find the skin. The "ruff" and "frill" very full; but little feather on fore-legs, and none below hocks on hind-legs.

Color.-Immaterial, but sable and white, black and white, and black and tan are popular.

Size.-Height of dogs, twenty-two to twenty-four inches; of bitches, twenty to twenty-two inches. Very small and very large and coarse specimens are to be avoided.

The Smooth Collie.-He bears a close resemblance, except in coat, to the rough dog, but his head is not so foxy in expression nor so wedge-shaped.

Coat.-Short, hard, and smooth. 
The Bob-tailed Sheep Dog.-This breed is, above all others, the drover's dog, and seems to take to his work almost as a duck to water. The best specimens are devoid of even the semblance of a tail, have very long, shaggy coats, both head and legs being abundantly covered. Though not handsome, he is very courageous, and useful in the highest degree (p. 320).

The Pomeranian, Spitz, or Loup-Loup.-Employed in his native land as a sheep dog, he has become in Britain and America a ladies' pet, of attractive appearance. In appearance and size he is between the collie and the fox, except in carriage of tail, which is peculiar. Head-parts are very foxy. Coat and color are important, counting thirty per cent. Very small specimens are now favored in Britain.

Coat.-More like coarse fur than hair; undercoat woolly; general distribution of long and short hair, feather, etc., as in the collie.

Color.-Black or white, quite pure.

Tail.-Carried curled over the back and usually on the left side; heavily feathered and rather short in dock.

The Newfoundland.-Employed for draught purposes on the island from which he derives his name, but elsewhere chiefly as a companion. Being an animal of wonderful sagacity and nobility of nature, he was long one of the greatest of canine favorites, but at present yields in popularity to the gigantic St. Bernard. His feats in lifesaving have done much to make the canine race popular and respected (p. 328).

The Newfoundland's general appearance is that of a dog of strength and general activity. He should move freely 
on his legs, with the body swung loosely between them, so that a slight roll in gait should not be objectionable; but at the same time a weak or hollow back, slackness of loins or cow-hocks, constitute grave faults.

Head.-Broad and massive; top of skull flat; occipital protuberance well developed, but, unlike the St. Bernard and mastiff, he has no decided stop; muzzle short, cleancut, and rather square in shape, covered with short, fine hair; eyes small, dark-brown, rather deeply set, without haw and somewhat wide apart; ears small, set well back, square, with the skull lying close to head, covered with short hair and without fringe.

Should be sound throughout. A sway-back, slack loin, cow-hocks, and splayed feet are very objectionable, as before stated, and they are not uncommon.

Tail.-Without flag but covered with long hair, usually carried low, and with slight curve; when the animal is excited or in motion, carried higher, but never curled over the back, and should never have a kink (turn to one side) in it.

Color.-Jet black.

Coat.-Flat, dense, coarse in texture, oily, elastic.

Height and Weight.-Average height, twenty-seven inches at shoulder for dogs and twenty-five inches for bitches; average weight, one hundred pounds and eightyfive pounds, respectively. Large size desirable if accompanied by other good points and general symmetry.

Other Varieties of Newfoundland. -The St. John's or Labrador dog is smaller and more retriever-like in form; in fact, it is probable that this breed has entered into the formation of the retriever. 
The Landseer Newfoundland should in all respects follow the black dog except in color, which may be any that disqualifies for the black class; but those most in favor are bronze or black and white, beauty in markings to count high.

The Esquimau Dog.-A moderately large dog of twenty-two to twenty-three inches in height, of wolf-like appearance, though the head is rather foxy, covered by long hair with woolly undercoat and a long, gently curved, almost bushy tail.

They are only half domesticated, though employed in large teams to draw sledges over the snow and ice of northern America, usually under the leadership of one of their number, that is acknowledged as master. They are left to shift very much for themselves, and getting but little of man's confidence or affection, give but little in return.

\section{CLASS VI.}

\section{WATCH-DOGS AND HOUSE-DOGS.}

The dogs of this class not being employed for securing game, are not required to have either the scenting powers or the conformation necessary for speed or for endurance in locomotion found in hunting-dogs; but, on the contrary, that adapted for attack on intruders in the case of the larger breeds, and in all the disposition and intelligence fitting them for guarding persons and property.

Most of them give warning by barking, and, in fact, in some of the smaller members of the class such is the more important part; to this, however, the bulldog is an exception, as he usually attacks without any warning by the voice. 


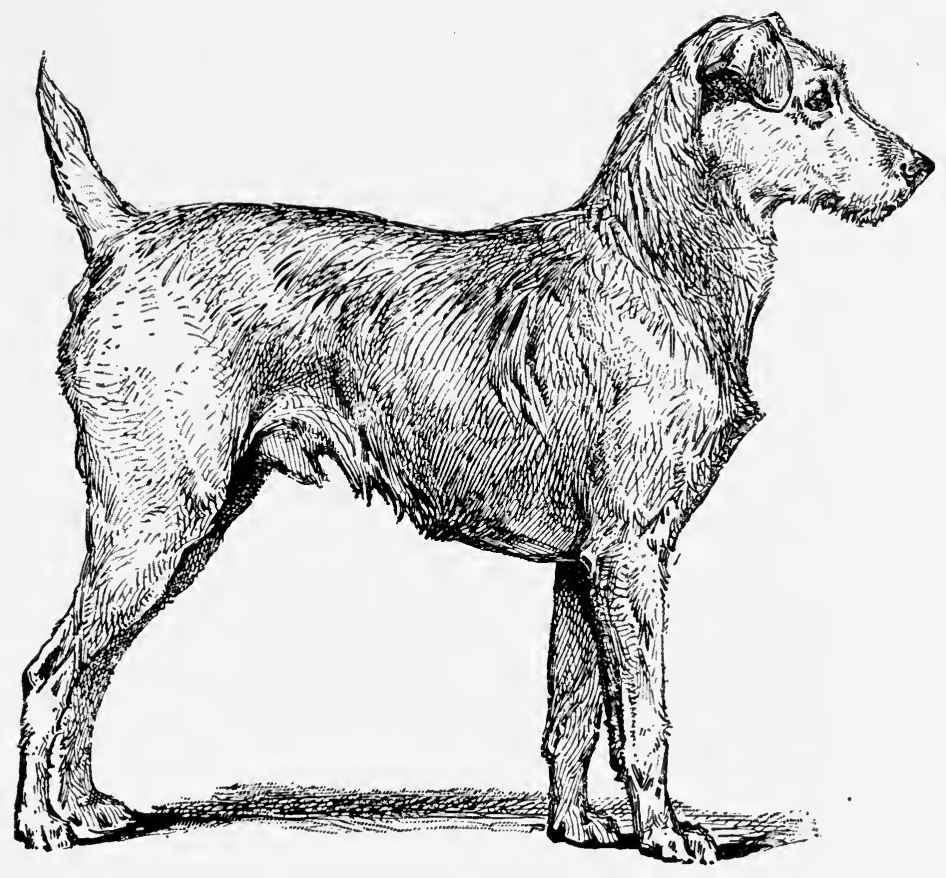

THE IRISH TERRIER PILGRIM.

(K. C. S. B., 28,110.)

For description, see page 49. 


\section{-}


The Bulldog.-It is quite impossible to understand this dog either physically or psychically apart from its history. In the days when our ancestors delighted in badger and bull baiting a dog was formed adapted in every way to seize and to pin down these animals; and a study of the bulldog will show that for this purpose he could scarcely be improved upon. He was taught to attack the bull (and other animals) at the head, and if he could not hold, either from lack of courage or lack of jaw power, etc., he would have little chance in the contest. It may be said that the whole dog exists for his jaws; hence that enormous head and front generally as compared with the parts behind the ribs; hence that indomitable courage, that tenacity, in fact, which knows no yielding, for, as Stonehenge well says, the bulldog is not only "the most courageous dog, but the most courageous animal in the world." This breed may be considered the very opposite in all particulars of the greyhound, and taking these as the extremes, we can learn the extent to which man's capacity to take advantage of the variations Nature produces has been carried. Viewed from another standpoint, these are the results of "artificial selection" in the most pronounced way (p. 344).

A breed like the bulldog should not be expected to possess high intelligence, great affection, or indeed any long list of noble qualities; nor to be amenable in a high degree to training. His skull is immense, but it is largely made up of bony processes for the attachment of muscles to work the enormous jaws, and is not capacious as a brain case; nor is the bulldog's brain larger than that of other dogs, as might at first be inferred from his enormous skull. 
However, it would be a mistake to assume that this breed is quarrelsome, ferocious, or utterly destitute of any attachment to his master. As in other breeds, much depends on his treatment.

General Appearance.-That of a smooth-coated, thickset dog, rather low in stature, but broad, powerful, and compact. Its head is strikingly massive, and large in proportion to the dog's size; its face is extremely short; its muzzle very broad, blunt, and inclined upward; its body short and well-knit; the limbs stout and muscular; its hind quarters very high and strong, but lightly made in comparison with its heavily made fore-parts. "The dog conveys an impression of determination, strength, and activity similar to that suggested by the appearance of a thick-set Ayrshire or Highland bull " (Standard).

The above seems to the anthor a very good description of the dog, except that the last comparison scarcely meets the case. We shall not go into further details except on a few points, leaving the reader to observe them in the cuts supplied.

Tail (stern).-Set on low, is round, smooth, thick at root, tapering, low carried. Is apt to be deformed (screwtail).

Size.-Most desirable size about fifty pounds.

The ear preferred is the "rose-ear," as opposed to the "button-ear." In the former the organ folds back so as to expose the inside.

The angles of the lips or flews are called the "chop"; and the back and loin, from rising into an arch, is termed " roach-back" or "wheel-back."

Coat.-Fine, close, short, smooth (not wiry). 
Colors. - Whole-colors and smuts (i. e., whole-color with black mask or muzzle). It is worthy of note that the bulldog is the only breed in which the undershot jaw is called for; this, in conjunction with the turned-up muzzle, permits of great holding power, and allows the animal to breathe at the same time that his jaws are buried in the flesh of the creature attacked. "Ugly" the bulldog may be in one sense, but he is, or was, an example of beautiful adaptation.

The Mastiff.-There have been other breeds named mastiffs, but the mastiff is essentially an English dog, dating back considerably more than half a century. Physically he is one of the largest and certainly the strongest and most muscular dog known, unless it be certain specimens of the great Dane (p. 352).

In the words of the standard of the Old English Mastiff Club: In general character he has a "large, massive, powerful, symmetrical, and well-knit frame. A combination of grandeur and good nature, courage and docility."

The mastiff is the watch-dog. In no other breed is watching his master's property a pure instinct to the same extent, and this is the highest test of the strength of any quality.

The mastiff at sight is not attractive in appearance to all. He is not the embodiment of grace and activity; but if ever there was a good reliable dog, honest through and through, that $\operatorname{dog}$ is the mastiff. He makes an admirable companion for all, is perfectly gentle, and may be trusted with women and children, to whom he will prove a faithful protector. Of course there are occasional exceptions, as with all breeds. As a watch-dog he has the great 
merit of arresting and retaining the intruder without, as a rule, seriously injuring him.

His voice is extremely low-pitched, and, though powerful, is not irritating.

General Appearance of Head.- "In general outline giving a square appearance when viewed from any point. Breadth greatly to be desired, and should be in ratio to length of the whole head and face as two to three."

General Description of Body.-Massive, broad, deep, long, powerfully built, or legs wide apart and squarely set. Muscles sharply defined. Size a great desideratum if combined with quality. Height and substance both important if combined in due proportion.

Since 40 per cent. of the total value is assigned to head, it may be well to describe it in detail.

Skull.-Broad between ears, forehead flat, wrinkled when attention excited, brows slightly raised, muscles of temples and cheeks (temporal and masseter) well developed. Arch across skull a rounded, flattened curve; a depression up center of forehead from median line between eyes to half way up sagittal suture.

Face or Muzzle.--Short, broad under eyes, and nearly parallel in width to end of nose, which is square-cut at end and of great depth; under-jaw broad to end; canine teeth powerful, sound, and wide apart; incisors level (if the lower jaw projects beyond the upper, teeth not visible when mouth closed).

Length of muzzle to whole head and face as one to three. Circumference of muzzle (measured midway between eyes and tip of nose) to that of head (measured bcfore ears) as three to five. 
The author believes it would greatly advance standardmaking if comparative measurements like the above were generally given. Exact knowledge dissipates many prejudices, and prevents misunderstandings.

Ears.-Small, thin, wide apart, set on at highest points of skull, lying flat and close to cheeks in repose.

Eyes.-Small, wide apart, divided by at least the space equal to two eyes; hazel-brown, the darker the better, and showing no haw.

Nose.-Broad, flat in profile, nostrils wide.

Lips.-Diverging at obtuse angles with septum, and slightly pendulous, so as to show a square profile.

Such a head is the very ideal of strength, massiveness, and grandeur, and any one who has felt the bump of a mastiff's head as he throws it about in play can understand how bull-like in force his attack must be as he springs against an intruder.

Such a head implies a neck and chest in proportion, while these again should be balanced with good hind parts, or an undesirable weakness will exist and be apparent to the eye. The shoulders, chest, etc., are not those of the hunting-dog, but of a wholly different type for obvious reasons.

The legs and feet should be of a size to suggest strength and due proportion.

Tail.-Set on high, reaching to hocks or a little lower, wide at root and tapering to end, hanging straight in repose, but forming a curve with end upward (but not over back) under excitement.

Coat.-Short and close-lying.

Color.-Apricot, or silver fawn, or dark fawn brindle. 
In any case, muzzle, ears, and nose black, with same color round orbits and extending up between them.

The st. Bernard.-Of a dignified, sweet, and noble expression of countenance, of majestic size, and beautiful coat, color, and markings, with unbounded good nature, courage, and sagacity, it is not surprising that this breed is by far the most favored of the large dogs of the day, though it is possible that some reaction may follow his present amazing popularity for reasons to be given later (p. 368).

Great importance is attached to size, to head, and to markings, even to the detriment of the general soundness of make-up of the breed, we fear; though, so far as expression and character go, it is well to lay great stress on them, for we must have the dog as well as the animal form, which is somewhat apt to be overlooked by those breeding show-dogs. Of what use is a mere mountain of flesh without true character-i.e., without the proper disposition and intelligence? These the judge can often only ascertain by the expression and bearing of the dog, and they should count high in the estimate of the animal as a whole.

Ilead.-Like the whole body, very powerful and imposing. The massive skull is wide, slightly arched, and sloping at the sides with a gentle curve into the very welldeveloped cheek bones. Occiput slightly developed; supra-orbital ridge (brows) strongly pronounced, forming nearly a right angle with the horizontal axis of the head. Between the two supra-orbital arches and starting at root of muzzle runs a furrow over whole skull, producing a decided stop, which extends upward, getting more and 
more shallow toward the base of occiput. Skin on forehead forms deep wrinkles, more or less distinct, and converging from top of brows toward furrow over forehead.

Slope from skull to muzzle sudden and rather steep.

Muzzle.-Short, not "snipy," and depth at root (stop) must be greater than length ; bridge of muzzle not arched, and over its surface runs a rather wide, well-marked, shallow furrow. Flews of the upper jaw strongly developed, not cut at right angles, but turning with a graceful curve into the lower edge, and are slightly overhanging. Flews of lower jaw not pendant. Teeth rather weak in proportion to size of head. Black roof to mouth desirable.

Nose.-Very broad.

Ears.-Of medium size, set on high, with well-developed "burr"; standing out slightly at base and dropping with a sharp bend to the side, lying closely to head without fold.

Eyes.-Placed more to front than to sides, of moderate size, brown or nut-brown, set moderately deep, with a sagacious and good-natured expression.

Shoulders.-Rather more sloping than in the mastiff.

Legs.-Massive.

Feet.-Broad; single or double dew-claws, set on low, so as to broaden foot and prevent breaking through snow.

Tail.-Starting broad and powerful directly from rump, is long, heavy, ending in a blunt tip; carried down in repose, but turning gently upward on the lower third; in action higher, but not over back or curled.

Coat.-Two breeds of St. Bernards are recognized, differing only in coat, althongh many specimens intermediate in this feature are to be found. 
In the smooth the coat is very dense, broken-haired (Stock-Haarig), flat, tough without feeling rough to the touch; thighs slightly bushy. Tail at root eovered with longer and denser lhair, gradually getting shorter toward tip. Tail appears bushy, though not provided with a "flag."

In the rough-coated dog the coat is long, flat, to slightly wavy; never to curl, be rolled, or shaggy.

Tail bushy; hair not to be parted or feathered. Face and ears covered with soft, short hair, long and silky; hair allowable at base of ears; fore-legs slightly feathered; thighs very bushy.

Color and Markings.-Orange and orange-tawny are now preferred, with white markings and dark shadings. Whole-eolored dogs are at a disadvantage. The following white markings are absolutely necessary: White chest, feet, tip of tail, muzzle (nose-band), and collar ; white spot on nape, and a blaze are very desirable.

Dark shadings on face and ears are much esteemed.

Since the markings have much to do with the general expression and eharacter of the $\operatorname{dog}$ as it appears to the eye, it is fitting that they should rank high; but it is manifestly easy to overestimate color in any dog kept for a useful purpose. In the ease of a toy dog the subject assumes a wholly different aspect.

All the large breeds of dogs are liable to similar defects-viz., disproportion of parts and weakness in back, and especially in parts behind the ribs. First-class legs and feet, back, loin, and quarters, with correct and easy movement, are rather the exception than the rule in the show St. Bernards of the day. Grand heads and great 


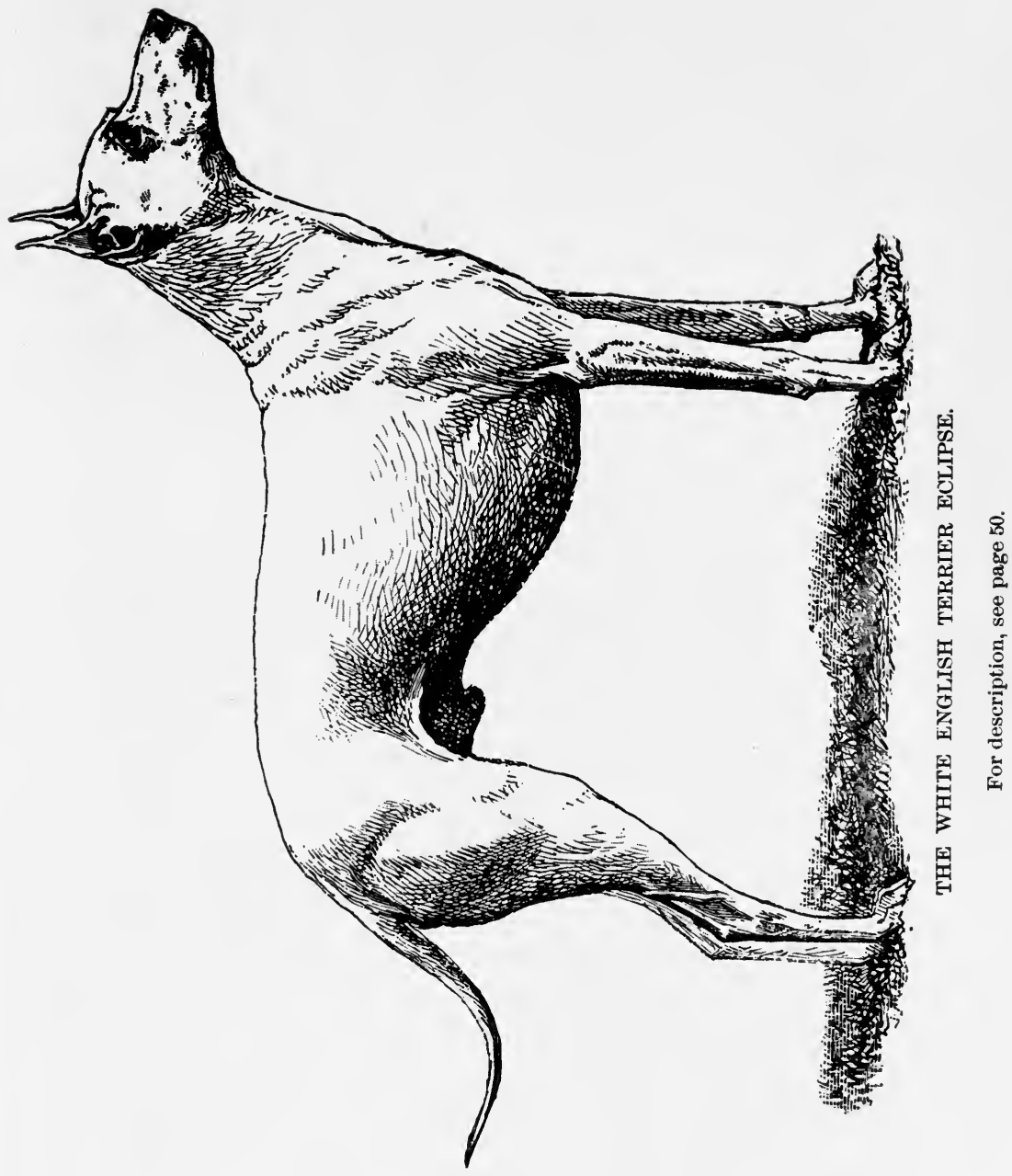



size and weight have been attained. The author attributes the defects, which seem to be more pronounced in St. Bernards now than in other breeds, to the following causes : Aiming to get vast size too speedily and by forcul feeding, causing a too rapid and consequently imperfect growth; the overuse of certain popular dogs in the stud, enfeebling their constitutions and, of necessity, that of their offspring; judges favoring dogs that are giants in size, though with the above defects, so that these dogs get a factitious value in the stud and propagate their defects; insufficient exercise to develop bone, muscle, and stamina; show-dogs carrying too little muscle and too much fat (lumber), which is greatly against health and high vitality; too much of the unnatural surroundings of show life; the inadequate feeding of many rapidly-growing puppies, causing rickets, etc.

In the interests of this noble breed these things should be pondered.

Toy Dogs. - Several causes tend to render toy dogs somewhat delicate. The small size demanded has led to a constant selection of smaller and smaller specimens, which, being naturally weaker and lacking in stamina, have rendered the whole class difficult to rear and keep in health. Being so much confined to the house, getting but little exercise, and tempted with all sorts of tidbits, indigestion and constipation, with the accompanying foul breath, follow. But, by judicious breeding from dogs small enough, yet healthy, and by due care in rearing, etc., these difficulties may be overcome.

Toy dogs are usually fairly intelligent, from their opportunities of mingling with mankind, but are apt, like 
spoiled children, to be somewhat wayward and trouble some, and so ready to bark on the entrance of strangers that they may be considered in some sense watch-dogs.

They are in most instances kept more, however, for their good looks than any other qualities they may possess; hence, in the standards of these breeds, more importance is attached to superficial characters than in the case of utility dogs.

The principal toy breeds of Britain and America are the pug, the toy spaniels, the Italian greyhound, toy terriers (already described), and the Mexican hairless dog, which is comparatively rare.

The Pug.-A dog of fair intelligence, moderately active, with a very independent and consequential bearing (p. 376).

In general form and appearance (tail excepted) very like a diminutive mastiff, but entirely opposite in bearing and disposition. He is essentially a squarely built, cobby dog. Considering that head parts count thirty-five per cent., and symmetry and general carriage fifteen per cent., or these together fifty per cent., we get a good idea of the way toy dogs are rated.

Head.-Skull large, massive, round, with large and deep wrinkles. Muzzle short, blunt, square, but not upturned as in the toy spaniel. Eyes very large, dark, bold, prominent, globular, bright, soft, and solicitous in expression. Ears thin, soft (velvety), small, either "rose" or "button," the latter preferred.

Body, legs, and feet suitable to a cobby, strongly made dog.

Tail curled as tightly as possible over the hip. The double curl is perfection. 
Coat fine, smooth, short, soft, glossy, neither hard nor woolly.

Color, silver or apricot fawn, very decided and pure.

Markings. - All to be clearly defined. Muzzle or mask, ears, moles on cheeks, thumb-mark or diamond on forehead, back-trace (dark line from occiput to tail) to be as black as possible, and especially the mask.

Size.-A very compact dog of thirteen to seventeen pounds. A leggy, lanky pug is not to be tolerated, as such an one is wholly false to the type.

Toy Spaniels. - These are cobby, long-haired, small pets, of an affectionate and docile disposition (p. 384).

Symmetry, condition, and size count twenty per cent. and head parts about fifty per cent. of the total.

The different varieties are founded on color distinctions.

Head.-Skull well domed, almost semi-globular, projecting over eyes; stop between eyes very deep; muzzle very short, with nose turned up between eyes; lower jaw wide between its rami or divisions, and fitted well to the upper, with lips concealing teeth; eyes wide apart, with eyelids square to line of face, large, lustrous, very dark, with pupils widely dilated; ears very long, measuring twenty to twenty-two inches from tip to tip, set low, heavily feathered. The ears are longer in the King Charles than in the Blenheim.

Tail.-Usually docked to length of three to four inches. Not to be carried above level of back.

Coat.-Long, silky, soft, wavy but not curly. In the Blenheim a profuse mane extends well down front of chest. Legs and feet well feathered, also tail, so that a "flag" of a square shape results. 
Color Varieties.-King Charles: Glossy black and deep $\tan -i$. e., with $\tan$ spots over eyes and on cheeks, legs, etc.

Blenheim: A ground of pearly white, with large patches of rich chestnut or ruby-red evenly distributed; ears and cheeks red, with a blaze of white extending from nose up to forehead and ending between the ears in a crescentic curve. In the center of this blaze there should be a clear "spot" of red of the size of a sixpence.

Tricolor or Charles I. spaniel : Like the last, but with black instead of red; ears and area beneath tail should be lined with tan. This breed has no "spot."

Ruby: A uniform red; nose black.

It is difficult to breed King Charles spaniels free from white.

Size.-Cobby little dogs of about ten pounds weight.

The Italian Greyhound.-An active, lithe, graceful little creature, rather delicate and very sensitive to cold (p. 388).

The more nearly he approaches the greyhound in shape the better; but he is not likely to have so good a head. The skull is apt to be relatively wider, the muzzle shorter, and the ears larger and not so well carried. The eyes are much larger and very soft in expression, but "weeping" is not tolerated as in the toy spaniel.

Coat is short, soft, and silky.

Color (value fifteen per cent.), fawns much preferred.

Symmetry (value fifteen per cent.) is naturally high in a toy.

Size (value fifteen per cent.), dogs not to exceed seven to seven and a half pounds, bitches five to six pounds.

The Schipperke.-Imported from the Continent of 
Europe, especially Belgium, this breed has lately come into some favor both in Britain and America. It is remarkable in being tailless. This dog is a very active, small, longhaired, black animal, suggesting the fox in head and general appearance, though much higher on the leg (p. 392).

The Whippet.-A small cross-bred dog of the greyhound type, much used in competitive racing over short courses, for the enjoyment of the onlookers.

The Mexican Hairless Dog. -This small breed is almost destitute of hair. The skin is somewhat copper-colored, spotted more or less with black.

In concluding this account of the breeds of dogs recognized in British and American shows, and almost the only ones known as companions to those speaking the English language, we remind the reader of the principles which we have already stated as underlying breeding and the formation of standards-viz., that the form and physical and psychical characters of each breed should correspond with a type or ideal founded on the purpose for which the breed is used or supposed to be used. Unless this is constantly kept in view there is no limit to which the vagaries of mankind or the caprices of fashion may cause a departure from Nature, and therefore from sound sense. A second principle is the one which we have not yet insisted upon, because less important and not so likely to be neglected, to the effect that every breed should be sufficiently distinct in type to merit an independent existence. Unless something is to be gained of downright worth, it is only a useless expenditure of energy, that might be employed in perfecting existing valuable breeds, to set about the formation of new ones. A merely popu- 
lar craze, which must be in the nature of the case fleeting, or pecuniary gain to a few, can not be sufficient warrant for disregarding, as this implies, the importance of the work of generations of breeders that have passed away by thus attempting to replace their well-earned results in the formation of noble breeds of dogs by new varieties without new merits.

\section{THE MANAGEMENT OF DOGS IN HEALTH.}

Our object should be to develop dogs to the utmost, both physically and psychically. Mongrel specimens are so much more easily kept in health that the directions given in this part of the work will be supposed to refer to the most highly-bred animals, unless otherwise stated.

Management resolves itself chiefly into housing, feeding, exercise, grooming, etc.; amusement, training, and occupation; also breeding in all its aspects.

On every one of these topics the most diverse-indeed, totally opposito-opinions have been expressed, which is probably to be explained by the limited experience of the writers and their inability to perceive that the application of principles must vary with circumstances.

So that every reader may be able to judge for himself, the writer proposes to lay stress on principles rather than their application, since only sound judgment will ever insure good practice, and the formation of that judgment, in so far as it can be formed by the perusal of any work, is best secured by clearly setting forth those fundamental principles of Nature which must underlie all applications. When these are distinctly grasped, "rule of thumb" will be impossible, and all experience will prove really useful, as it 
must tend to establish principles; and then they become like the compass in actual practice. The possession of a compass will not make a man a mariner or explorer. On the other hand, he can not become either in any worthy sense without it; so is it with underlying principles.

In the understanding of the dog no advice can be better than that of the old Greek, "Know thyself." Of all the lower animals none is so like man as the dog, unless perhaps the monkey; but of the latter this is true only in a certain sense. The monkey does not respond sympathetically to our moods and our environment like the dog.

This idea will be the key to this book throughout, and by making it so the author hopes to bring the whole subject within easier and more effective grasp of both the professional and non-professional reader.

If dogs were generally viewed as we do children of different ages, their whole nature and management would be better comprehended; at least such is the view to which the best study we have been able to give to animals generally, and the dog in particular, for a long period has led us.

In the entire management of the dog two things must ever be kept in mind-his origin from wild ancestors on the one hand, and on the other the great modification he has undergone during ages of association with man, in consequence of which he has been assimilated to mankind in numberless respects, both physically and otherwise.

The whole problem is greatly simplified if only one breed of dogs is kept, for so great are the differences in the breeds as to disposition and bodily habitudes that the treatment that is adapted to one does not suit another. 
The views of those who have kept only one breed must therefore often seem unsatisfactory to those who have always been associated with one of opposite tendencies. In the end, whatever the advantages of specialization, and they are very great, careful comparison and correlation can alone lead to deductions at once safe and broad.

The writer will endeavor, so far as possible, to avoid narrow views that apply to but a measurable extent, and while the limitations of space will prevent exhaustive discussion, the foundations for conclusions and practice will be laid as broad as possible.

The Housing of Dogs.-If even but one dog be kept, and he a house-dog, experience has taught that he will prove more satisfactory if there be some other place than the house to which he can retire for a time daily. The dog appreciates his privileges more and deports himself better. In the case of several dogs, it is needless to say that a special home or kennel is necessary.

The best conception of a kennel is that it is a canine home, and that all its arrangements must be shaped in harmony with this view. It should therefore be not only a comfortable and healthy, but a happy, attractive place.

The chief considerations for health are, as in a human habitation, light, ventilation, temperature, drainage, cleanliness, absence of dampness, etc. In the absence of any one of these, dogs can not be healthy any more than human beings; in fact, owing to their being usually less separated, there is the more need to attend to them; for it would be a mistake to assume that a pure-bred dog can be kept in the best condition under circumstances very much less favorable than those suited to a rugged man. 


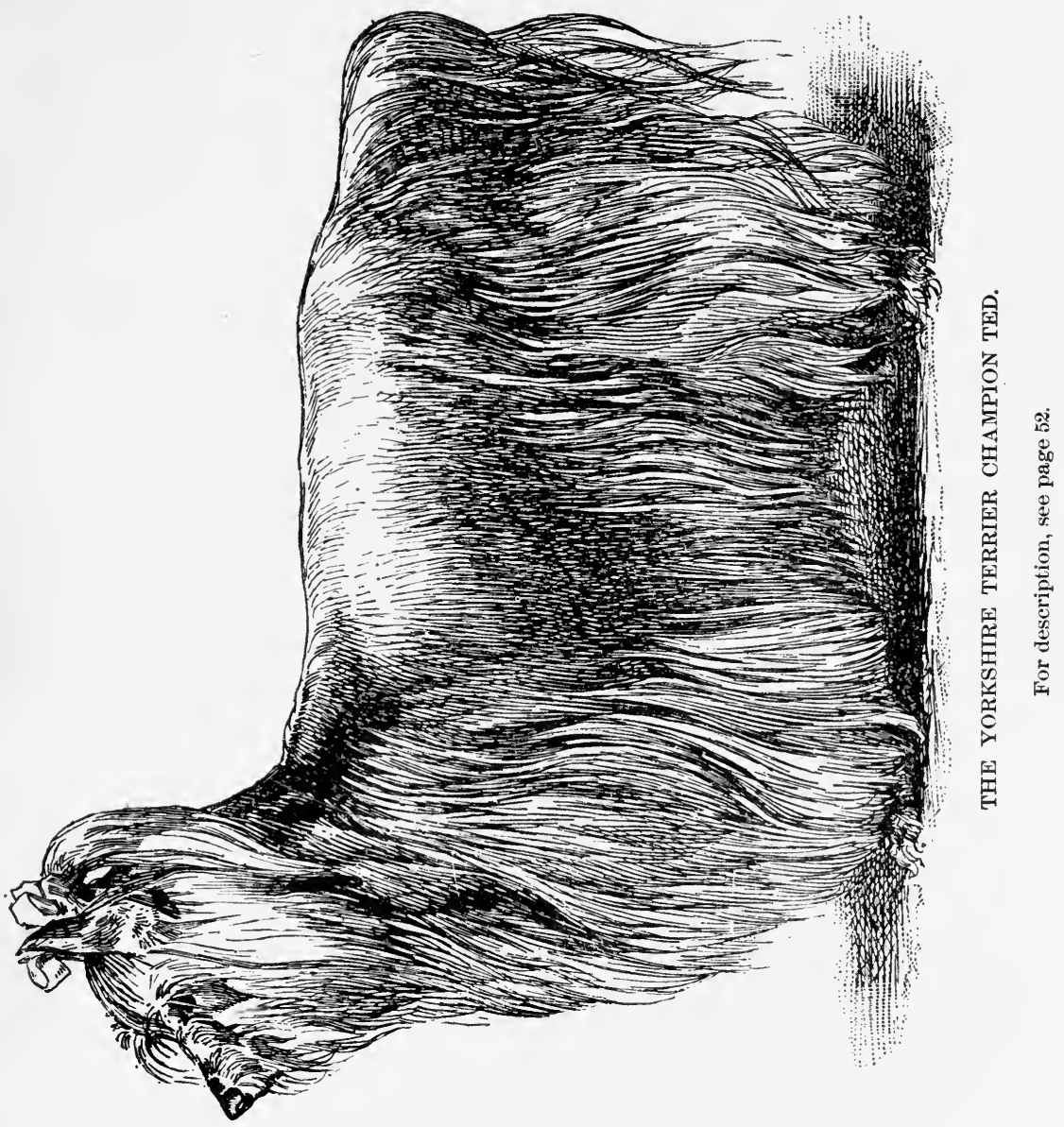


In addition to the above, if the arrangements of the kennel permit of some regard to the beautiful, it will not be withou's its effect on the inmates, though this is of course a subordinate matter; but of all creatures the dog is most influenced for good or ill by his surroundings.

Dampness is perhaps of all evils, after extreme crowding, the greatest in connection with a kennel. With a damp kennel it is impossible to keep dogs in health, and this condition will sooner or later ruin the best collection of dogs that can be got together, no matter what their stamina.

A good foundation, then, which will prevent the dampness of the soil from effecting the kennel, is desirable in any case, and absolutely essential if the soil is clayey or adapted in any way to retain moisture. If the soil is light, it will be well, if no foundation is used, to make a bottom of loam and ashes, the latter being in large proportion.

The slope of the ground is of some importance.

Dampness may arise from hoar-frost on the walls in very cold weather if no artificial heat be used; and though this is not so injurious as that which arises from a bad floor, it is nevertheless a serious objection, especially when the severity of the weather mitigates. Of course brick and stone walls are more liable to favor such dampness than wooden ones.

The outlook of every kennel should be toward the south, so that it shall at no season of the year be devoid of the heat and light of the sun, and if direct so much the better in the winter. Exaggerated stress can not be laid on the value of sunlight, and it is scarcely too much to say that animals can not be kept in health without it. 
A dark kennel is a wretched dog prison, unfavorable alike to health and canine happiness.

There are special reasons why kennels should be well ventilated. However cleanly dogs may be, and however well their tendencies to be so may be encouraged, it will happen that excretions will lie on the kennel floor at times. Apart from the vitiation of the atmosphere, there is that more fatal poisoning that arises through emanations from the lungs and skin of the animals. At the same time ventilation must be accomplished without draught, except in the hottest days of summer, when a slight breeze is as refreshing as to ourselves. But draughts, even in summer, at night, are a fruitful source of diarrhœas, other disturbances of digestion, etc. Ventilating-shafts through the roof, that can be closed to a greater or less extent as occasion demands, prove successful. In addition, the kennels may be well aired several times a day, when the animals are out, by the doors and windows.

If the space can be afforded, the plan that has worked so well in some educational institutions, and, as we happen to know, in some very large kennels, should be provided for, which is having certain rooms or compartments used only half the time-e. g., room A is used to-day as the habitation of the dogs while room $\mathrm{B}$ is being cleaned thoroughly and abundantly aired, while on the succeeding day room $B$ will be occupied. This is far in advance of all other methods when it can be adopted.

If the climate will permit, it is to our mind clear that hardier dogs will be reared if no artificial heat be used in the kennel. It is preferable even to blanket the dogs, though that is not as easily carried out as with horses; 
but with thick walls, filled between the boards with sawdust and covered with tar-paper within, with boxes large enough to hold two dogs in winter, and abundance of good straw, except in the coldest climates the kennel need not be heated.

The danger from artificial heat arises in the changes in the temperature likely to result, for such irregularities will utterly derange the health of the strongest dogs. If a constant temperature of about $55^{\circ}$ to $60^{\circ} \mathrm{Fahr}$. could be maintained in severe weather, hoar-frost would be kept from the walls and the animals would no doubt be more comfortable. The expense of the planking would probably be saved in food, as it is well known that all animals consume food in proportion to the temperature of the surrounding air.

But sudden changes-now a fire and again none-are utterly demoralizing.

After these vital considerations of light, heat, ventilation, dryness, etc., come many minor ones of great importance to the kennel manager, and of no less moment in the development of the dogs. We have stated our view that a kennel should be made a healthful, happy home, and not a mere lodging place. To insure this, as with a family of human beings, the individual dog or the individuality of the members must be considered as well as the community. Dogs of different breeds do not usually get on very well together, and dogs differ so in disposition, even when of the same breed, that the kennel arrangements must, to be successful, meet these facts.

Several smaller compartments are better than a few larger ones. Bitches and dogs must be kept apart absolute- 
ly at certain periods; old dogs and puppies rarely agree, while sometimes the very best mode of correction of misconduct in a dog, as in a child, is solitary confinement for a time. It is also often desirable to associate dogs of opposite temperament occasionally.

Every kennel should be so arranged as to permit of the free and full natural development of the individuality of each dog. To allow one dog to be bullied or cowed by another, not to say worried or perhaps killed, as not infrequently happens in some kennels, is culpable negligence and cruelty.

The more orderly, systematic, and complete the arrangements of any kennel, the better both for the kennel manager and the dogs. It will mean a saving of energy, the avoidance of anxiety and worry to him, and comfort, health, and happiness to the canine household.

There should be a place for everything and everything in its place, as in any well-ordered establishment.

As to the exact buildings and internal arrangements by which all this is to be carried out we have not the space to speak; and indeed these must necessarily vary with the number of dogs kept and the depth of the owner's purse to some extent; though a good kennel need not be an expensive one, nor the latter a good one.

Cleanliness is important both in reference to health and the character of the dog. Much can be done to render dogs cleanly in habits, but to prevent evil results arising from urine and fæces that will inevitably be deposited on the kennel floor, special precautions must be taken.

The most essential at the outset is a suitable floor; the very best is one of concrete, which, though expensive 
at first, is economical in the end. A wooden floor, being repeatedly wet with urine, soon gets saturated, foul, and rotten, favoring the breeding of fleas, etc.

Fresh pine sawdust, not too fine, spread on the floor to the depth of two inches, disinfects or deodorizes stools and catches much of the urine, thus saving the floor and obviating the evils that would otherwise arise. But this can be spread on a concrete floor also, and the latter can be frequently washed over and will dry much sooner than a wooden floor, especially if very warm water be used.

Some prefer benches or raised platforms for the dogs to lie on. For large dogs with long coats, that do not readily feel cold, they serve well enough; but in most instances a cheap packing box, never resting directly on the floor, open only in front to allow of ingress and egress, and well supplied with straw, answers a better purpose. They are warm, and allow the dog the independence and privacy of his own little room. If he wishes a partner, he can take one; if not, he can keep the intruder out, and in no case should one dog be allowed to drive another out of his bed. It does the character of both harm. Such movable boxes can be readily cleaned and disinfected, or when hopelessly infested with vermin, burned and replaced at slight expense. In summer, when it is excessively warm, the kennel inmates often prefer to lie on top of the boxes, or simply on the floor.

Feeding.-This subject, being of such vast importance and one in regard to which the greatest difference in theory and practice obtains among breeders, deserves more than passing notice, especially since errors in feeding are responsible for a large proportion of canine ills. 
So that the whole subject may be grasped in a rational manner, we remind the reader of certain well-established physiological principles.

All foodstuffs for animals are divisible into-

I. Organic.

1. Nitrogenous: (a) albumins; (b) albuminoids (as gelatin).

2. Non-nitrogenous: (a) carbohydrates (sugars, starches); (b) fats.

II. Inorganic.

1. Water.

2. Salts.

Every animal to remain in health must have all of the above in its diet, as has been abundantly proved by experiments-i. e., the food must be chemically adequate. But, in addition, food must be in such a form that the digestive juices can attack it-i. e., it must be physically suitable; and finally it must be suited to the peculiar organization of each animal, which Nature expresses by what we term liking-i. e., the food in question must be craved. If a diet fails in any of these respects it is not suitable. But however good any article of diet in itself, a change is absolutely essential from time to time.

We have no hesitation in saying that the whole art of feeding dogs or other animals consists in the judicious application of these few principles.

It is well known that nearly all animals, and certainly all dogs, will accept milk with avidity. Milk is a perfect food because it meets all the above requirements. It is what Nature has provided for all young mammals.

But observation shows that wild mammals do not all 
choose the same foodstuffs, though all their foods meet the above conditions; and according as they derive their supplies from the bodies of other animals, from the vegetable kingdom alone or from both, are they termed carnivora, herbivora, or omnivora.

It is found that while the digestive apparatus has a common resemblance in all, it varies in details of size, structure, etc.

In the carnivora the stomach is always simple and the intestine relatively short, especially the large gut; in the herbivora the stomach is always in part a reservoir for the storing of food as well as an organ for its digestion, and is often much divided into compartments, each with a different function, while the intestine, especially the large intestine, is voluminous. The digestive tract of the omnivora is somewhat intermediate, but approximates that of the carnivora rather than of the herbivora.

In type the dog is unquesionably carnivorous in both organization and tendencies, as is shown in a puppy's eagerness for a bone almost as soon as its eyes are open.

Nevertheless, it must not be forgotten that habit for ages has greatly modified this tendency, and with the dog's altered environment there must come changed feeding.

Experience proves exactly what we should expect from the dog's ancestral relationships, that the more he approaches in mode of life the carnivora, with their extremely active habits, the more completely may he be fed on flesh-in fact, must he be so fed if he is to prospere. g., dogs hunted hard daily may be fed better on a flesh diet than on any other, perhaps, in the large proportion 
of cases. On the other hand, to feed a house-dog on flesh entirely is simply to invite the onset of disease.

However, as we should suppose, no dietary for the dog can ever be considered complete from which meat or its equivalent is wholly excluded. Such practice ignores completely the origin of this animal. But between these two extremes lies that territory in which there is the greatest room for discretion-in fact, the closest observation and study, especially when several dogs of different breeds are kept together.

Even under identical circumstances all the dogs of a kennel must not be fed alike; and it is the failure to perceive these differences for breeds, and especially for individuals, that is the fertile source of so much wretchedness for dogs ; for certainly more than one half of all cases of skin disease, diarrhœa, etc., arise from dietetic errors.

We find breeders of experience advocating the most opposite kinds of feeding. One all meat, the other little or none; one abundance of milk, another condemning it as the source of disease; one plenty of vegetables, another opposing them as unnatural; one advocating corn-meal as cheap and wholesome, another declaring it unfit for the dog under any circumstances; one flesh in the raw state, another only when it is cooked, etc.

We think these divergent views can be reconciled. So long as any diet meets the conditions set forth above, it may vary in many respects and yet prove suitable under a different environment; in a word, it must ever be borne in mind that the food must vary with the environment.

Now, if we apply that principle on which we have 


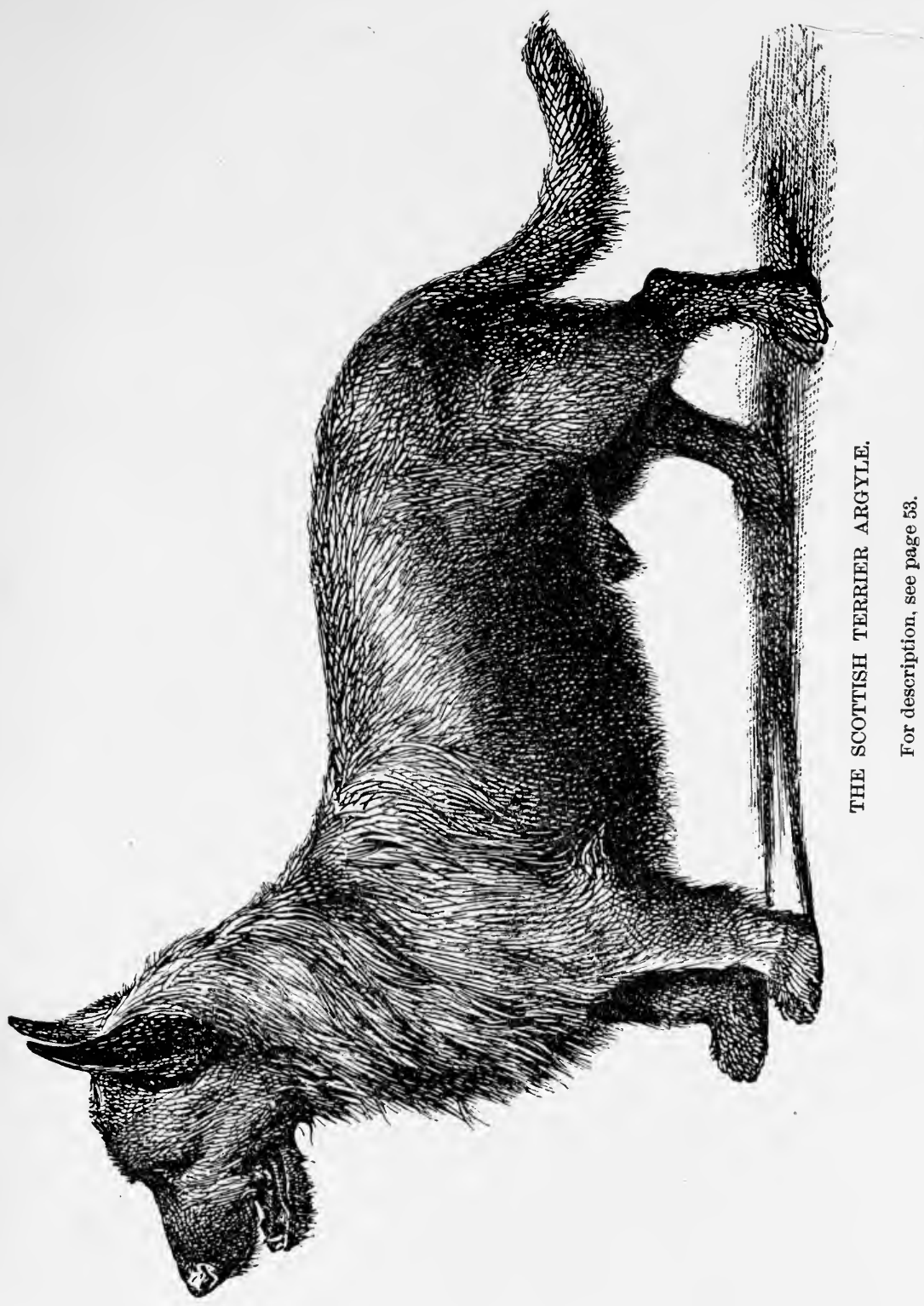


already laid such stress; the whole matter will become plainer to the most unscientific or inexperienced.

As are the ways of men so are the ways of dogs-in feeding as in other matters. Our own diet, when we follow our instincts freely, is made to vary with the seasor, the climate, mode of life, and a thousand other things we can not always define. Exactly so is it with dogs-altogether more so than with any other of our domestic animals.

The diet of the plowman or lumberman differs widely from that of the clerk or bookkeeper; and if the latter were to change his occupation, he would soon be under the necessity of altering his diet to a more nitrogenous one-i. e., one in which flesh, etc., was. more prominent; though we have in the Highlanders of Scotland a people that flourished on oatmeal and milk. But then milk and meat are similar in nutritive qualities if not in effect on the activities of the body.

Whole kennels of mastiffs have been kept largely on horseflesh. But these dogs roamed the country fields, had abundance of exercise, pure air, etc.

Certain vegetables when cooked-such as carrots, cabbage, etc.-furnish little nutriment for man or dog, but they do under certain circumstances serve to rectify the workings of the machinery of life. They are in a sense medicines or correctives rather than foods. Plainly they are not at all necessary under some circumstances, and may be positively injurious in some cases, as in dogs hunting day after day. But why does the dog nibble grass, etc., if green vegetables serve no purpose under any circumstances? 
Milk in large quantities continuously tends to dilate, render flaccid, and to weaken the digestive tract; yet, used with discretion, there can be no better food for man or dog than milk.

A diet of porridge and milk is a good diet, but not constantly and without change. We have in such a diet all that is involved in the principles we have set forth as established. It has the merit of being very easily digested; but in some conditions of the stomach, induced by certain modes of life, as we ourselves know, it is not relished or well-borne by men, nor, as observation also teaches us, by dogs.

The problem as to the amount and form of a meat diet often arises for practical solution.

As a rule, cooked meat is the best to be fed in large quantity. Raw meat, moreover, may contain parasites or their germs, hence it should be fed sparingly and be closely examined. Raw liver is on this account dangerous, though a little cooked liver acts nicely as a gentle aperient to the digestive tract. The habit of throwing sheep's-heads and ox heads to dogs is also open to the same objection (parasites). Beef and mutton are the best meats for dogs.

But it is difficult to conceive of a more suitable and agreeable meal for a dog than such as may be prepared by boiling sheep's-heads (or ox-heads) till the flesh falls off and the ligaments, etc., are reduced to a gelatin. A rich broth, which may be slightly flavored with salt, and a large part of the fat skimmed off (in most instances), results. After removal of the bones, the whole may be allowed to set, after some of the broth has been removed, perhaps, and the 
solids minced. This preparation may be mixed with porridge made of oatmeal, corn-meal, wheat-meal, etc., or stale bread, broken biscuits, or such like, which furnish the necessary proportion of starchy food. A small proportion of vegetables may be boiled with the above, to flavor, etc.

Certain it is that all meal preparations should be boiled till reduced to a jelly, for a dog's stomach is no more adapted to digest raw or half-cooked meals than a man's. It is probably this ill-prepared meal food, such as may do for fowls, that has been condemned by so many breeders, and rightly; but their disapproval is not wisely extended to good porridge. However for summer use especially, wheat-meal porridge serves a better purpose than either corn-meal or oatmeal. It is less apt to cause irritation of the digestive tract, and reflex effects which show themselves in irritation of the skin.

Very generally the question of economy is an important one. In Britain and on the Continent of Europe horseflesh is obtainable at a low price. In America not so easily, perhaps; but butchers' offal-such as heads of oxen and sheep, the "pluck" (heart, liver), etc.-may be secured cheaply, and makes excellent food in the hands of a discreet kennel manager; but in no case should such food be given raw.

Raw flesh in small quantity occasionally acts like a tonic to nearly all dogs, however kept.

What of patent foods, such as Spratts's? Very admirable preparations, most convenient, saving much trouble, but rather expensive, and not suitable for continuous use as the sole food any more than any uniform diet that can be devised. Change is at the foundation of life itself, and 
must be recognized by all who would understand the management of dogs.

Starchy foods if given in excess tend to digestive derangement (fermentation, etc.) and favor skin disease. Meal in excess is unduly exciting, and will also cause inflammation of the skin and other disturbances. Milk alone and uninterruptedly is too bulky, and enfeebles the digestive tract.

A mixed diet, in proper proportion and properly cooked, will suit most of the conditions under which the dog is kept better than any other. Cakes or biscuits made of the entire wheat, ground moderately fine, make good food, and may at times be fed dry to advantage.

The question of quantity is of very great importance. Experience shows that the tendency is usually to overfeed. The result is digestive troubles, an undue taxing of all those organs that get rid of the waste or poisons of the body, with numberless reflex disturbances which in the dog, for reasons to be explained later, generally express themselves on the skin.

But the quantity must vary not only with the breed and size of the dog, but, above all, with his surroundings and the amount of exercise he gets.

A dog that is worked to the fullest extent may probably nearly always be left to be his own judge as to when he has had enough of food. But under any other circumstances this would scarcely be a safe rule for all dogs. Some are gluttons, and would constantly be out of condition if fed as much as they would eat. But a pack of hounds hunting daily will scarcely eat too much-even the most ravenous dogs being able to use up, in the long-con- 
tinued and violent exercise they get, the material (source of energy) which they store up in their tissues.

Some dogs are such uncertain and capricious feeders that their care taxes to the utmost the skill of the most judicious. Such specimens are commonly defective in stamina, easily disordered, and unsuitable either as stud dogs or brood bitches, as their progeny are apt to inherit these undesirable qualities.

A word of warning may be in place regarding bones. While useful as indicated above, when very hard they wear down the teeth, and it is often a question whether they should be allowed to old dogs at all. They clean a dog's teeth, and if they can be secured of the right kind it is well not to withhold them entirely. But very hard bones, and those which when broken present sharp edges, as those of fowls and of game birds, are absolutely unsafe, as there can be no doubt that they have caused death by puncturing the digestive tract, especially the intestines.

A question much debated is the frequency of feeding. Should an adult dog be fed only once, twice, or oftener, during the day? To all such questions no categorical answer can be given. Circumstances must be taken into account. It has been said that the dog's stomach is large and his digestion slow; that the carnivora often subsist for days on a single meal, etc., and therefore the dog should be fed only once a day:

The dog's stomach is rather large as compared with man's; but the rapidity of his digestion depends greatly on a variety of circumstances. Digestion is less rapid when the stomach is distended, and in an animal in a gross con- 
dition, as compared with one not thus burdened with flesh.

The argument from the wild carnivora must not be pushed too far, since their mode of life is very different

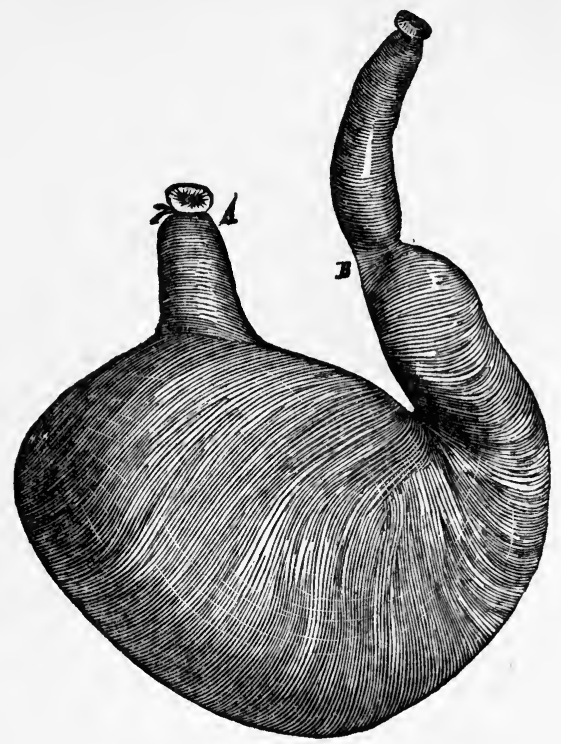

Fig. 3.-Stomach of the Dog.

$A$, Esophagus ; $B$, Pylorus.

In the Dog and Cat the ventriculus is but little curved, and is pear-shaped, the small extremity corresponding to the pylorus. The cardia is dilated like a funnel, and is nearer the left extremity of the organ than in other animals. The œesophageal mucous membrane is not continued beyond the margin of that orifice. The simple stomach of the carnivora forms only a single sac, whose internal mucous membrane presents, throughout its whole extent, the same organization as the membrane lining the right sac of solipeds. This membrane is remarkable for the regular and undulated folds it forms when the stomach is empty. Nothing is more variable than the capacity of the dog's stomach, because of the great differences in the size of this animal, according to breed. M. Colin has found the minimum to be $11 / 4$ pints, and the maximum to be $13 /$ gallons; he calculates the average to be about $2 \%$ quarts. In the cat, the average is from 2 to $2 \frac{1}{4}$ gills. (Cut and description from Chaveau.)

from that of the dog at the present time. More reliable instruction may be got from a study of ourselves. 
Some men eat four times a day, others three times, and some only once; and those who have varied their habits in this respect know that the result is often much the same whether the individual eats twice or three times daily.

The actual quantity of food taken is the principal thing. However, there are persons who, having tried different methods, find that the number of times food is taken greatly modifies their comfort and efficiency.

So far as the feeding of packs of hounds and large kennels is concerned, convenience, rather than any exact study of the question, has probably determined that the dogs shall be fed but once in twenty-four hours, and then allowed as much as they care to eat. The result is that the animals, being very hungry, gorge themselves to distention, and lie about in a very lazy manner for some time afterward, and in this they no doubt imitate their wild congeners.

But it seems more than doubtful whether this is the best way, regarded from the point of view of the dog's welfare rather than the keeper's convenience.

Dogs, like other animals, require more food and a larger proportion of fatty food in winter than in summer; and to feed a dog but once a day during the severe weather of winter seems little short of cruelty in the larger proportion of cases.

A light breakfast of, say, porridge and milk, or a few wheat-meal biscuits, with a good meal at night, will probably serve the best purpose. But to all rules there are exceptions, and some dogs will do much better if fed but once a day, even when getting a moderate amount of ex- 
ercise, which latter has been assumed throughout in the discussion of this subject.

Again, with very hard-worked hunting dogs a breakfast has only proved in some cases a source of indigestion and diarrhœa. But, in any case, dogs should never be hunted or violently exercised just after a meal. It has been proved that in such cases food may remain for hours undigested in the stomach, the animal's energies being used up, especially by the muscular system.

Dogs may be allowed such exercise as they will themselves take in play just after a meal, or very soon after, at all events.

The feeding of toy dogs, on account of their delicacy of constitution and unnatural mode of life, requires special care. Meat must be sparingly given, yet not absolutely withheld. Milk and its various preparations with eggs, may be well substituted, with stale bread, biscuits, etc. When only a single dog is kept, as is perhaps usually the case, table scraps make an excellent fare, given twice a day in moderation, but avoiding rich gravies and pastry except in small quantity. In the large majority of cases the family dog is fed too often and too much, and were it not that he is generally a hardy mongrel, the results would be more frequently manifest in skin disease and other troubles. Rice is an excellent staple, when well boiled, for toy dogs that are poor feeders.

When dogs are allowed many bones of a kind that can be masticated and swallowed, they are apt to become constipated, owing to the excess of lime, etc., forming insoluble soaps in the intestine.

Errors in feeding are responsible for more derange- 
ments of the dog than perhaps all other causes put together; hence we have dwelt on this subject.

The views set forth may be thus summarized: The diet should be a mixed one in which all the essential foodstuffs are duly represented. Meat may occasionally, under exceptional circumstances, be safely and wisely given as the exclusive diet; usually it can be allowed only in limited quantity, but in no case must it be permanently withheld. Vegetables are to be regarded as correctives rather than as foods. Of all the cereals, wheat, ground moderately fine and used to make bread, biscuits, and porridge, is the best. Oatmeal and corn-meal answer a good purpose, especially in winter. Milk is useful, but not in large quantities at a time, nor continuously. Bones under due precautions serve an excellent purpose. Patent foods are good, but not as a staple or for continuous use.

Whatever foods be employed, variety is of the utmost importance. The less exercise a dog gets, and the more unfavorable his surroundings, the greater the care necessary in regard to food in all except its nutritive qualities. With the hard-worked animal the latter is of the greatest moment.

The actual quantity consumed within a given period is of more consequence than the intervals at which food is given. As a rule, twice in twenty-four hours will be quite sufficient, with many exceptions in favor of one daily meal.

In all matters relating to feeding, the circumstances under which the animal lives, and its individual peculiarities, must be carefully considered. 


\section{EXERCISE AND OCCUPATION.}

The dog still retains, in most breeds, the activity that is characteristic of the group to which he belongs-the carnivora.

He no longer, it is true, seeks prey, but he naturally hunts some form of life by inherited tendency, and man avails himself of this to train the dog to various kinds of hunting, to watching, guarding, etc.

Exercise and occupation we couple together, because the former is best secured with the latter, since it naturally follows that the sort of development, both physical and psychical, which adapts him for the intended use must be best. Apart altogether from this, however, dogs, like other animals, indeed much more so than most others, require exercise to keep them in health. We can not disregard with impunity any animal's ancestral or inherited tendencies. To do so is to overlook the true nature of the animal. So that if a dog can not be taken to fields or woods, he should be given the opportunity somewhere not only to walk, but to romp freely. Exercise should be pleasant; the dog must have some opportunity to gratify his instinctive tendencies, or exercise will be so destitute of the element of occupation or interest that it will accomplish but a small part of its purpose. To lead a dog out by a chain is better than no exercise at all, but it is at best but a poor substitute. To keep any dog constantly chained is simply downright cruelty. The yard should always, when at all possible, allow of moderate exercise and freedom.

In only exceptional eases will a dog take too much exercise in a yard, however large. But, even with the 
freedom such circumstances permit, every dog should be introduced daily, weather permitting, to the larger outer world, for change, to develop his intelligence and to stimulate him to greater efforts and attainments.

We shall treat the whole management of puppies later, when their exercise, etc., will be specially considered.

It would puzzle the best physiologist to explain fully why exercise is so beneficial. It seems to be a part of the actual constitution of protoplasm, that foundation for all function, to be in constant though varying action. What we term rest is only diminished activity; and that principle of change to which attention has been called as regards diet is but a special application of that law of incessant change which seems to be essential in all life-processes. It is a change in the life of muscle to pass from "rest" or diminished activity to greater activity and back again. Hence rest and exercise can not be separated in a healthy existence. With continuous rest or continuous activity, failure of vital powers is inevitable. Under exercise the circulation is quickened with a corresponding increase in every function of the body. Dogs are very subject to constipation, yet observe how freely a dog will empty the bowels during a ramble in the fields. Exercise fills the lungs with fresh air; the dog beholds new sights, hears new sounds, sniffs fresh scents, and is stimulated in every fiber of his being.

But let exercise, good as it is in itself, be carried beyond a certain point, and the result is harm rather than good. An exhausted dog is not ready to digest foodgood evidence that his exercise has been an injury.

It is not usual to give dogs when brought in from ex- 
ercise as much care as horses; but there is the same necessity for it. The dog takes cold also, and if he does not show his derangement in the same way, it is not to be inferred that it is a matter of indifference whether he is allowed to throw himself down anywhere, or whether he is groomed as is the horse. It adds enormously to the value of exercise, and diminishes all its risks, to see that afterward the dog is rubbed dry if wet, and mud or dust removed-in a word, to make sure that his skin is reduced to a comfortable and healthy condition; and if to this the dog be shampooed or manipulated like an athlete in training, the results for good will be as satisfactory as they may be surprising to those who have not been accustomed to observe such things.

It is difficult to convince kennel men that these details are of great importance, but, in the light of physiology, they are not difficult to understand, as will presently be seen.

It will be much more satisfactory to accustom dogs to exercise before meals; in fact, exercise of a violent character after a large meal is directly contra-indicated. The dog's energy should then be directed to his digestive system, and not diverted to his muscles; and it must be borne in mind that about one quarter of all the blood in the body is distributed to the muscular system, with a corresponding diversion of nervous energy.

Occupation founded on natural instincts, which furnishes the best amusement for the dog, is too often neglected. It is essential for the best physical and psychical development. This, of course, varies with the breed; but a dog that is a mere loafer is not apt to be any more a de- 
sirable companion than the human being of like character. No dog is naturally such, and it is almost cruel to force such a life upon him.

The difficulties in large cities of meeting these requirements as to exercise and occupation are considerable, but the writer is of opinion that unless a dog can be kept without perverting his nature, he should not be kept at all; and in most circumstances a little thoughtful consideration will overcome the hindrances to natural development.

\section{THE CARE OF THE DOG'S SKIN.}

The skin in all animals serves three main purposes: (1) It is a means of communication with the outer world, or a collection of sense-organs which have to do with "feeling" in its widest acceptation. (2). It is an organ or collection of organs for getting rid of the waste of the body-an excretory apparatus. (3) It is protective in a mechanical way and against loss of heat.

In the dog the first and the third functions seem to be most developed. As to the first, little need be said now. The protective functions of the animal's skin reside chiefly in the hair, which is kept more or less oily, and thus shielded against wet, by the oil-secreting glands (sebaceous glands) connected with the individual hairs. Small muscles attached to the hair-follicles permit of the erection of the hair. Sudorific or sweat-glands are less abundant in the skin of the dog than in that of man or the horse.

We take the opportunity here of referring to the whole subject of excretion briefly, as it will not only render the understanding of the dog's skin the more clear, but throw light on other subjects to be considered hereafter. 
The whole body of an animal must be regarded as a sort of factory, in which numberless chemical processes

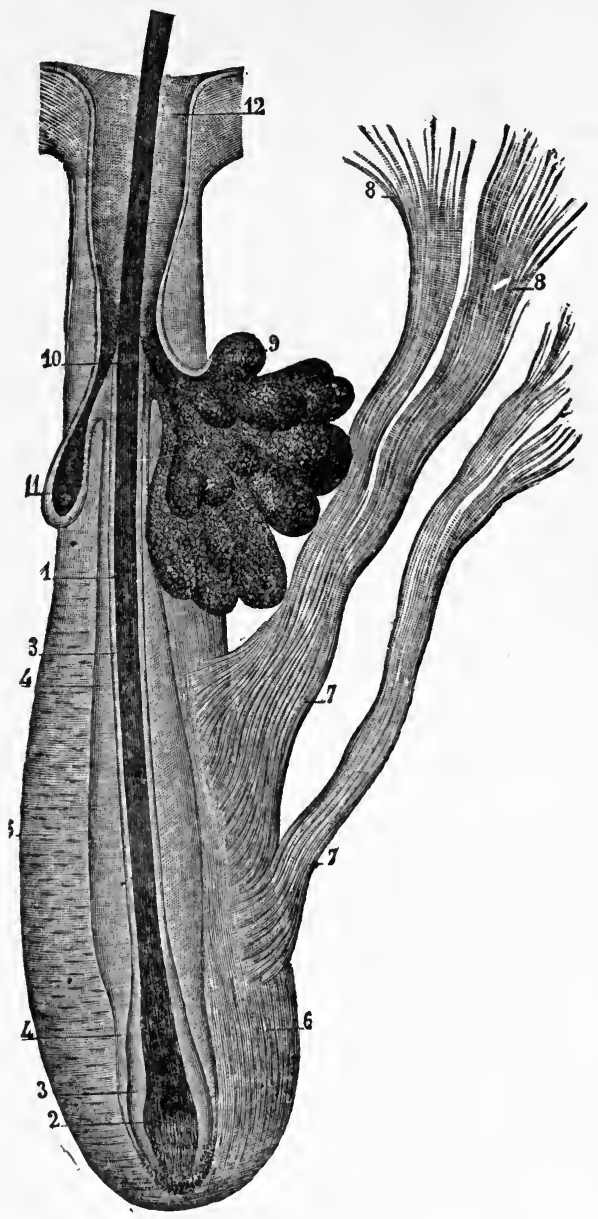

Fig. 4.-Hair and Hair-follicle (aFter Sappery).

1, root of hair ; 2 , bulb of hair ; 3 , internal root-sheath ; 4 , external root-sheath ; 5 , membrane of hair-follicle; 6 , external membrane of follicle; 7,7 , muscular bands attached to follicle; 8,8 , extremities of bands passing to skin ; 9 , compound sebaceous gland, with duct (10) opening into upper third of follicle; 11 , simple sebaceous gland; 12 , opening of hair-follicle. 
are constantly going on, with the result that useful and harmful products are being constructed. This, if not the essence of life, is inseparable from all vital processes. The animal in all its parts is built up from its food, but sooner or later the whole fabric is renewed completely; as a matter of fact, the building up and tearing down go hand in hand, and constitute what physiologists term the

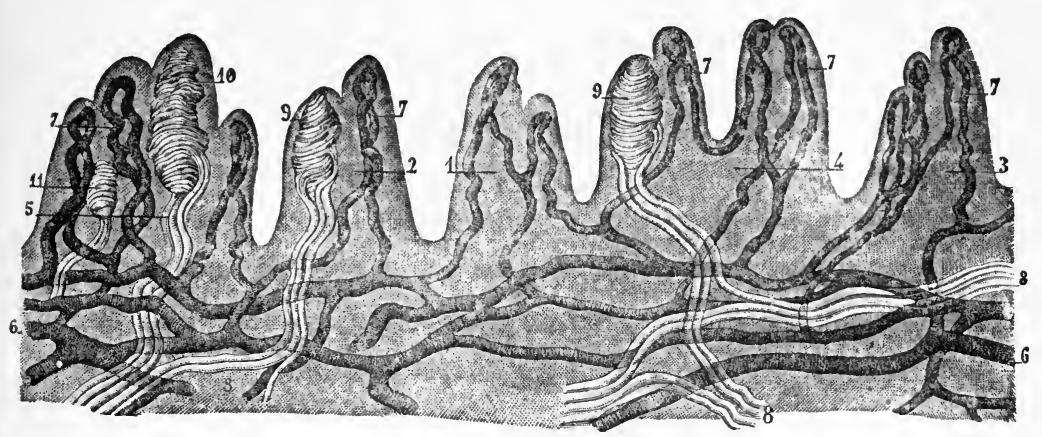

Fig. 5.-Papillie of Sinin of Palm of Hand (after Sappey).

A vascular network in all cases, and in some nerves and tactile corpuscles, enter the papillæ.

metabolism of the body. Science can not at present trace all the changes a piece of meat undergoes from the time it enters the body till it leaves it. There are no doubt very many intermediate bodies formed of which we are as yet ignorant. But we do know part of the story. The meat is digested or changed to blood albumin; this is assimilated or built up into the different parts of the body, and is finally broken down and expelled in forms of relative chemical simplicity.

Taking food as a whole, it may be considered as reappearing in the waste of the body (excretions) largely as water, carbon dioxide (nsually called carbonic-acid gas), 
salts, and certain nitrogenous compounds, of which the principal is urea. While these are the compounds best known, there can be little doubt that there are others expelled in small quantity, but which, when retained, soon poison and derange the whole mechanism of life-a statement which applies with more or less force to every body that enters into the excretions. The principal excretory or eliminative organs are the lungs, skin, kidneys, and bowels. Water and carbon dioxide pass off chiefly by the lungs; nitrogenous waste by the kidneys in the urine. Exactly what is expelled by the bowels beyond the undigested remains of food is not so well known. The skin gets rid of a good deal of water, some salts, a little nitrogenous waste (urea), and several acids-i. e., in those animals whose skins are very active, as is the case with man and the horse.

The dog gets rid of an excess of water by the respiratory tract and the mouth. He does not sweat largely. It would seem as though the kidneys, lungs, and mucous membrane of the mouth of the dog, perhaps also his salivary glands, did some of the work that in certain animals is accomplished by the skin.

The connection between the different excretory organs is important in all animals. Each is supplemental to the other; each can to a certain extent act for the other, but only for a limited period if the animal is not to suffer. What Nature seems to aim at is a balance of work with division of labor, each organ being a sort of specialist, but one that is not wholly out of touch with the others.

In all management of animals, in health and in disease, there is no more important truth to be kept in mind than 


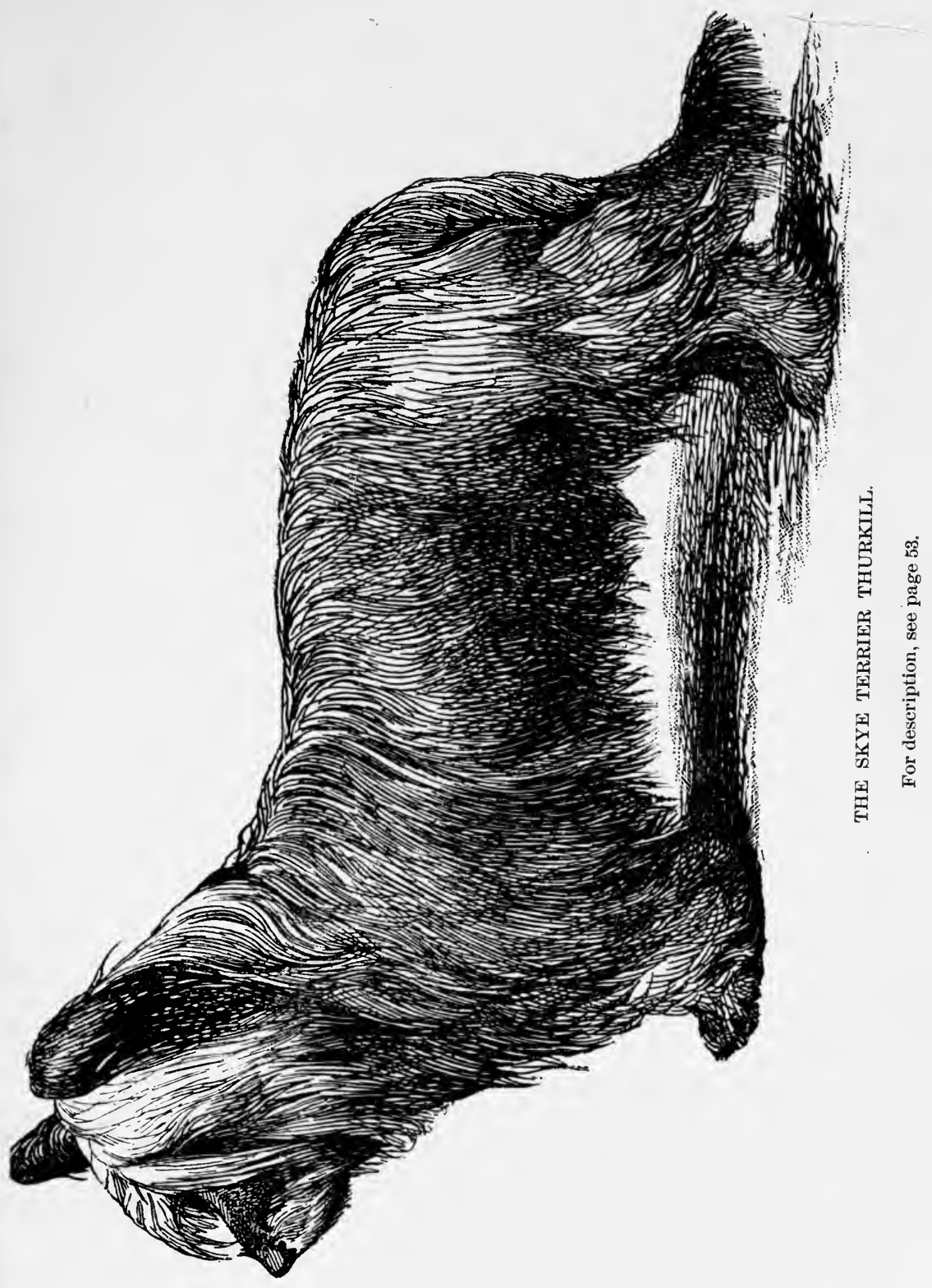



these relations of repair and waste, of assimilation and excretion, and of the mutual dependence of parts. They must be recognized by the breeder and the medical prac. titioner, though not necessarily in a conscious way. IIowever, a clear understanding is always an improvement on a merely practical adaptation. Good science with good practice is better than either alone. In a way, every stableman knows that grooming a horse is useful; hence the very term "groom"-one whose business it is to attend to the skin of the horse. But there can be no question that attention to the skin of the dog is of quite as much or more importance.

The skin of the dog in all pure-bred varieties is singularly liabie to reflect every ailment of the animal, possibly because of its limited ability to throw off poisonous matters. The skin of the carnivora has been specialized for protective rather than excretory functions, and when much of this work is imposed upon it by the partial failure of other organs, it seems to break down under the task. Derangements of the digestive tract are immediately expressed in the skin.

For many reasons, therefore, the care of the skin becomes of great practical importance, and in carrying this out we must not neglect any of its functions.

All agree that grooming-i. e., the brushing, etc.-of $\operatorname{dogs}$ is well enough, if not greatly impressed with its value; but on the subject of washing there is more difference of opinion. In the light of the facts we have just considered, it will not be difficult to outline the best methods of caring for the skin, and to give them a foundation that is both sensible and scientific. 
The wild carnivora, from contact with grass, forest brush, clean soil, etc., do not get fouled as dogs roaming a city or living in a kennel. The former have running streams and lakes to bathe in when so inclined. Their tongue is the only brush needed to supplement the natural rubbing and massage they get. We will do well to imitate Nature, and this implies cleansing the dog, when really befouled, by washing, but avoiding the necessity for this as much as possible; also daily grooming and massage.

Washing.-The only circumstance actually ealling for washing is the presence of real dirt on the dog's skin such as can not be removed by dry treatment, as grooming. The dangers and objections to washing are primarily the liability to disturbances of the circulation, shock to the nervous system, catching cold, and allied results, together with the removal of the protecting oil, etc.

These are to be obviated by care in the following: Wetting the dog's head with cold water before he is placed in the bath; keeping him free from draughts in a building at a temperature not lower than $60^{\circ}$ Fahr. during and especially after the cleansing; using water of a temperature related to the season of the year; rapid and nearly complete drying by cloths, followed by much friction, hand kneading, and rubbing; taking the animal at once, when fully dry, for a brisk run.

It is better not to wash just before or after a meal, as the shock, etc., disturbs digestion; a few mouthfuls of food with a drink of warm milk after the dog is done with the hand-rubbing is a good precaution.

After all these measures the dog must be kept free 
from draughts. If washing must be done in winter or for medical purposes, blanketing after, for a few hours at all events, may be necessary.

Washing generally requires the use of soap, and this especially removes the oil from the hair, so that the coat after a good wash is generally somewhat dry and harsh to the feel, while repeated washings render it coarse and otherwise unnatural.

The soap should be well rinsed out with soft water colder than that used for the general cleansing. This acts as a stimulant, and tends to prevent taking cold.

Our own experience teaches us that headache, nausea, etc., are much less likely to follow a bath if the head be wet first.

It is important to see that the ears are gently but well dried far within; otherwise eczema of the flap and possibly inflammation of the middle ear, may follow.

Grooming.-This implies friction to the skin with appropriate means, such as brushes, gloves, cloths, chamois leather, and especially the naked hand. Common sense dictates that this must vary with the breed, size, sort of coat the dog has, etc.

The idea is to remove dead epithelial scales (dandruff, scurf), foreign matter, as dust, to straighten hair and remove dead hair, quicken the functions of the sebaceous glands so that the hair will be oiled by a natural process, cause a distribution of blood and nervous energy to all parts of the skin, and so encourage all its functions. Of late, massage or kneading of the skin and deeper parts in a systematic way has come into use in human medical practice with the best results, though its value has long been 
known, if not well understood, to trainers of men and other animals for feats of speed, etc.

There can be no doubt that these influences, carried in to the nervous centers from the skin in grooming and

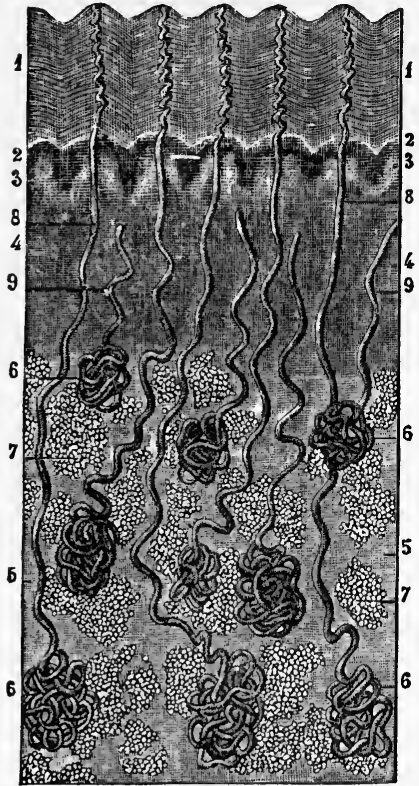

Fig. 6.-Sudoriparous Glands. $1 \times 20$ (AFTER SAPPEY).

1,1 , epidermis ; 2,2 , mucous layer $; 3,3$, papillæ ; 4, 4, derma ; 5, 5, subcutaneous areolar tissue; $6,6,6,6$, sudoriparous glands ; 7, 7, adipose vesicles; 8,8 , excretory ducts in derma ; 9, 9, excretory ducts divided. massage, are reflected to all the organs and tissues of the body, and serve as the very best sort of a regulator or natural tonic.

These means are especially valuable just after exercise, and on those days when the weather does not permit of the animals being taken into the fields or on the highways.

The larger breeds of dogs that carry a heavy coat are apt to suffer from the heat of summer. When these animals can not be taken to some natural body of water for a bath, it is a comfort to them to supply an artificial bath into which they can themselves go as they feel inclined. It requires a little study to manage this, and at the same time not allow the dogs to get into dirt afterward. A grass run is very valuable in such a case. The excess of oil in the coats of these breeds makes them resisting to water, and they are 
not spoiled, as in the case of other dogs, by frequent wettings.

Of course a dog can not be kept clean unless provided with proper surroundings. Every place where he is accustomed to lie should be ready for his reception. To his bed especial attention must be paid. For a large part of the year nothing equals good straw; it is both warm and clean. It should be changed before it gets very short and broken up, when it packs and irritates the dog in many ways, and before it becomes saturated with emanations from the animal's skin, when it is unhealthy and harbors vermin. Pine shavings make a good summer bed, but are apt to cling to the dog when he leaves his restingplace.

Some disinfectant beneath the bed tends to preserve it sweet and to keep away vermin.

\section{BREEDING.}

In the lowest animals there is no distinction of sexes, and reproduction of the species is maintained by division of existing forms, one becoming two or more separate individuals. Among the invertebrates the two sexes are in many groups united in one individual, a common example of which is the tape-worm. In all vertebrates the sexes are distinct, and copulation or its equivalent is the rule. Both male and female furnish their quota to the new being. To explain more fully, in the higher vertebrates-e. g., in the dog tribe-the female organs of generation at definite periods undergo changes consequent on a special accumulation of energy, resulting in the maturation in the ovary of eggs (ova), which are discharged into the 
oviducts (Fallopian tubes), where they become impregnated by the male cells (spermatozoa) when coitus takes place.

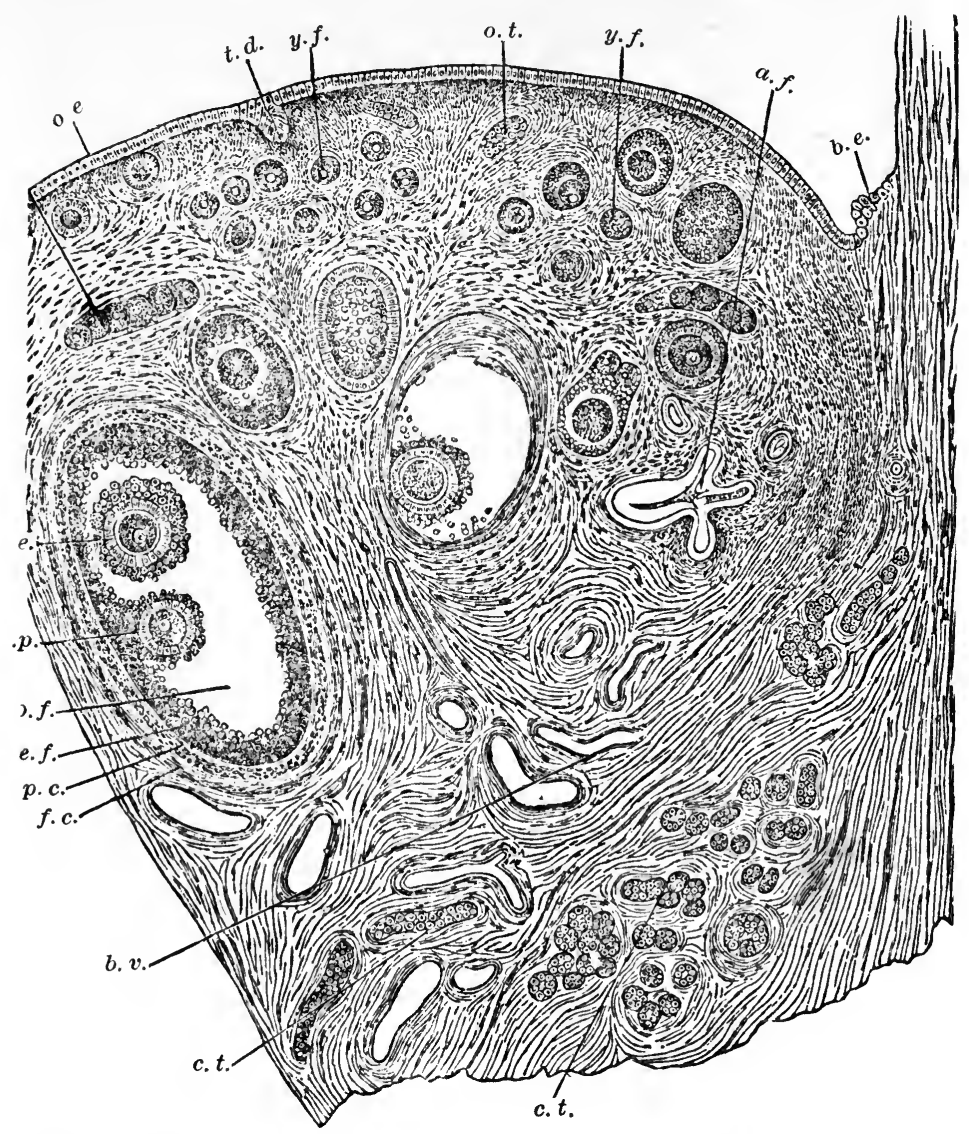

Fig. 7.-Sagittal Section of the Ovary of an Adult Bitch (after Waldeyer).

$o . e$, ovarian epithelium; o. $t$, ovarian tubes; $y$. $f$, younger follicles ; o. $f$, older follicle; $d . p$, discus proligerus, with the ovum ; $e$, epithelium of a second ovum in the same follicle; $f . c$, fibrous coat of the follicle; $p$. $c$, proper coat of the follicle; e. $f$, epithelium of the follicle (membrana granulosa); $a . f$, collapsed atrophied follicle $; b . v$, blood-vessels ; $c . t$, cell-tubes of the parovarium, divided longitudinally and transversely ; $t$. $d$, tubular depression of the ovarian epithelium, in the tissue of the ovary; $b . e$, beginning of the ovarian epithelium, close to the lower border of the ovary. 
In all that relates to the sexual functions in the female we have an illustration of the great law of periodicity of rhythm. A bitch experiences these recurrences of sexual activity at regular more or less fixed periods, usually twice a year, and, though these may be delayed or shortened, they are upon the whole very regular.

Naturally the entire nature of the animal participates in corresponding changes. Usually they are preceded by a short interval of excitement, indicating the approach of a more profound change. The mammary glands may slightly enlarge; the bitch, if young, may show rapid growth; some fall off in flesh; the disposition is modified; etc. The generative apparatus forming a connected whole, it is not strange that the activity of the essential organs (ovaries) is accompanied by a corresponding increase in vascularity or blood supply of other parts, so that the external genitals (vulva) enlarge. There is a visible flow of mucus, to be soon followed by blood.

As soon as the ova are mature the female will accept the male. This is not usually prior to the appearance of blood, but may be before it has disappeared or soon after, generally the latter.

As there is nothing to show clearly that the period of the coitus or service has anything to do with the sex of the offspring, the bitch may be allowed to choose her own time for congress with the male.

As it is not possible to be certain that all the ova mature at one time, it is not irrational to allow of a second service after an interval of one or two days, though it is likely that if the first was in every way a 
complete coitus and mutually desired, a second is superfluous; but of this one can never be sure.

The mode of coitus in the dog is characteristic, owing to the peculiar structure of the penis, the action of the female's vagina, etc.

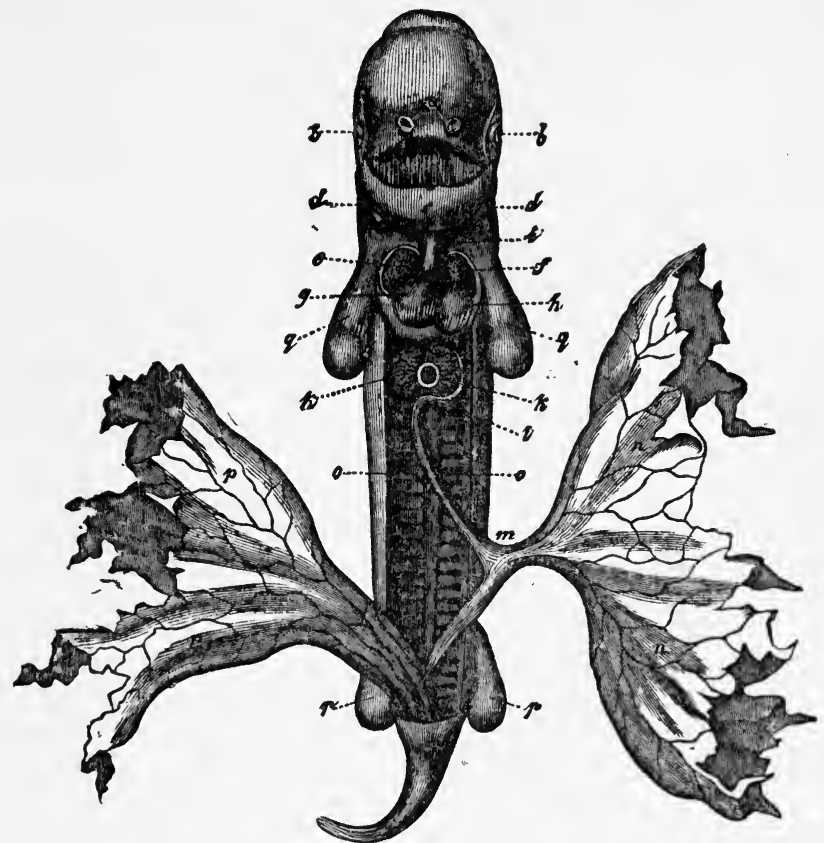

Fig. 8.-Embryo of Dog, Twenty-five Days Old, Opened on Ventral Side. Chest and Ventral Walls have been Removed.

$a$, nose-pits ; $b$, eyes ; $c$, under-jaw (first gill-arch); $d$, second gill-arch : $e, f, g, h$, heart ( $e$, right, $f$, left auricle ; $g$, right, $h$, left ventricle); $i$, aorta (origin of); $k k$, liver (in the middle between the two lobes is the cut yelk-vein); $l$, stomach; $m$, intestine ; $n$, yelk-sac : $o$, primitive kidneys ; $p$, allantois ; $q$, fore-limbs : $h$, hind-limbs. The crooked embryo has been stretched straight. (Haeckel, after Bischoff.)

The penis consists of two erectile portions. In the anterior part of the organ there is a bone. The posterior erectile region is the larger, and during copulation is spas- 
modically (reflexly) grasped by the muscles (sphincter cunni) of the vagina, so that the male organ can not be withdrawn until erection subsides. Since certain glands (Cowper's) that secrete diluting fluids are wanting in the $\mathrm{dog}$, as well as the reservoirs (seminal vesicles) in which in many animals semen is stored up, the importance of this arrangement enforcing prolonged copulation can be understood.

The forcible separation of dogs in coitu may lead to rupture of parts and dangerous bleeding.

The whole period of being in "heat," "in season," or "in use" extends over about three weeks, but often longer, and of course in a minority of cases less. During the whole of this period, as a rule, it is of the greatest importance to keep the bitch entirely separate from all dogs except the one selected. The sexual appetite of bitches is strong and persistent, and no risks should be taken.

The meeting of male and female cells usually results in impregnation or that commingling of their parts which results in the division (segmentation) of the female cell (egg, ovum) and its whole growth and development. Strictly speaking, however, we should say that the two are blended for growth, etc. If this were more carefully kept in mind the whole subject of breeding might be discussed in a more intelligent manner.

The two united cells making up the as yet undeveloped individual soon provide arrangements for receiving nourishment from the mother and getting rid of the waste of their own life-processes. This is accomplished by certain outgrowths which develop into the placenta, which may be finally said to consist of two parts-a maternal and 
a fotal-in each of which the structure is essentially similar, viz., blood-vessels covered with a layer of cells which elaborate the material from the mother's blood and fit it for the nourishment of the young animal, and which also excrete into the mother's blood the waste that has been thrown into the blood of the foetus by its own excretory organs.

It is highly important to understand clearly the nature of impregnation and the relation of the mother and fœtus in utero.

From these relations we think the following principles must of necessity follow:

1. The offspring must be in some degree a compound of the nature of both parents, but not equally in most cases. Some stud dogs are "prepotent," or have an unusual power in imparting their own nature to their offspring. The same applies to some bitches.

It is also evident that all in the same litter may not equally represent both parents. It would be strange if it were so, as the actual influence of the male cells may not be equal on each ovum or all male cells may not be equally potent. In fact, there is of necessity great room for all sorts of variations in such matters, so that all rigid dicta as to which parent exercises the most influence on the offspring are out of place.

2. The dam, from her long connection with the fœtus, must exercise an influence peculiarly her own. Since her health, her temper, her occupation, etc., all have an influence on her own nutrition and that of her offspring, it is of the highest importance that the brood bitch should be given the greatest care. 
Everything that tends to her welfare in any way must influence the offspring more or less, and the reverse.

3. From the close connection between mother and fœtus, it follows that the fœtus must also influence the mother, and more or less permanently; which explains why the members of subsequent litters may show an unmistakable resemblance to previous sires. The nature of the sire is of necessity impressed on the dam to some extent, but in most cases it is slight and not obvious; but it is difficult to see how, from the nature of the connection between mother and fœtus, the sire's influence can be wholly avoided.

"Reversion" or "atavism" is resemblance to a previous ancestor.

There is a wide-spread belief among breeders that the offspring resemble the sire in external form and the dam in the internal or hidden form, or that which determines disposition, stamina, etc.

But it is not to be forgotten that a sire is generally selected with more care than a brood bitch, and often because he has a striking and pleasing form and with but little regard to his constitution, which is but seldom a subject of special inquiry.

Mating.-All sound rules for mating must be based on such principles as we have endeavored to set forth.

Both parents must be equally considered.

In wild animals there is the freest choice and the greatest degree of intercrossing within the limits of the species, which result in bringing together in the male and female cells protoplasm of the most diverse experiences, which seems to result in the highest vitality; while the 
more inbreeding the less vigor at all events, as a rule, whatever else may be attained.

Pure-bred dogs must, in the nature of the case, be very much inbred as compared with mongrels, which in great part explains why they are less hardy and more liable to all sorts of derangements.

The problem with the breeder narrows itself down to this: How can the highest perfection of type in its most comprehensive sense, including physical and psychical qualities, be attained? The more he strives for form, the more liable is he, perhaps, to fail in some other direction; for, having got certain strains which meet his ideals pretty well, he fears to introduce outside blood lest he disturb, by the meeting of protoplasm more unlike than that of his own strains, the balance that exists, and thus get, perhaps, a series of "variations" or departures from the type he does not desire.

We think the solution lies in this principle: to keep within the lines that give the type as long as there is no sign of deterioration in any direction, notably in size, stamina, or intelligence, which are apt to suffer by inbreeding; but when an outcross is necessary, to introduce one as similar as possible; in other words, to make departures by gradual steps only.

Pedigree is indispensable in breeding; but in considering family lines the conditions under which the animals have lived are of no little moment. To breed a brother and sister brought up in the same kennel is quite a different natter from breeding the same relatives one of which was reared in England, say, and the other in America.

As a rule, the less closely animals are bred, provided 
type can be secured and maintained, the better, and the reasons must be clear on a little consideration.

But similarity is fatal to success if carried beyond a certain point. We, of course, refer to that deep, underlying similarity commonly expressed by the term "same blood," but which is better understood if we use the term protoplasm, or life-stuff of similar experiences. All the cells of the animal body are, of course, composed of protoplasm.

But in all cases the parents must be considered much more than the other ancestors. Why is this?

Because the parents are the outcome of the entire ancestry, and while they may have hidden or latent qualities, good or bad, dependent on the ancestry, we can not hope that those obvious qualities which they possess will not appear in the offspring. As a matter of fact, they do usually crop up; and when a mating is made, the problem is always a complex one, with many factors known only in a vague way by the pedigree, but others more clear and certain as actually existent in the parents.

Glaring faults are almost sure to be reproduced, no matter how good the mating in other respects, so that an animal of very pronounced defects in physical or psychical qualities should be rejected as a breeder; all the more so if these were known to exist in the more remote ancestors.

Disposition and stamina are of the utmost importance, in the brood bitch especially, as they are very likely to be reproduced in the offspring. But inasmuch as two dogs ideal in all respects can not generally be found for the mating, we inquire, What is the best to be done?

Assuming that in the bitch there is good intelligence, disposition, and stamina, if she have no defects of form, 
etc., beyond mediocrity, good results in a fair proportion of the litter may be looked for if she be mated with a dog not only free from these faults, but possessing the opposite qualities even slightly in excess. But from two extremes or from two decided opposites good results need not be expected from a single mating. Faults when pronounced can only be corrected by degrees.

It will be found that bitches with poor digestion, and defective in stamina generally, and those that in addition are liable to any form of disease, rarely make good breeders or nurses. If they are not able to cope with the environment under ordinary circumstances, how can they be expected to do so when they are handicapped in providing for half a dozen other creatures from their own resources?

Dogs lacking in health, vigor, and resisting power should not be used in the public stud, especially where, if they happen to be famous winners, they may be much in demand, and so have their vitality diminished still more. It is difficult enough to raise pure-bred puppies when the parents are both all that can be desired in these respects.

It will very often be found, for the reasons stated, that a show bitch is a poor breeder, while a more homely but strongly-made and vigorous creature, judiciously mated, provided she come of good stock, will produce offspring much superior to herself in form and other qualities.

\section{THE CARE OF THE STUD DOG.}

There is plenty of evidence to show that the condition of the dog chosen to mate with a bitch is not a matter of indifference, but may have a marked effect on the constitution of the progeny. He should be in such con- 
dition as fits him for doing the work for which the breed is intended, and should in no case be overburdened with flesh, soft in muscle, or suffer from any derangement of health.

When a dog is placed in the public stud the drain on his vital powers may be so great that unless unusual pre. cautions are taken the dog may be broken down in health, or, at all events, become prematurely old, not to speak of the natural result of impaired vitality, etc., in the offspring. Of such dogs the greatest care must be taken even to the minutest details. They may require at times very concentrated and nutritious food-as eggs, strong broths, and even such special helps as cod-liver oil, phosphates (containing iron), etc. It is to be remembered, however, that such frequent use of a stud dog as to require such adjuvants, especially if he be in his prime, clearly proves that he is being overtaxed.

The extent to which a dog, with a bitch in season near, will lose flesh in a few days indicates that the stud dog should be kept so far away from bitches in this condition that he will not be aware of their presence, and thus have no superfluous source of drain on his vital powers.

Every stud dog should have periods of sexual rest to allow of natural recuperation-somewhat analogous to turning a horse out to pasture.

\section{THE CARE OF THE BROOD BITCH.}

The bitch, still more than the dog, if possible, should be at her best in every way before being mated. She should be fully matured. In the author's opinion, a bitch should never be bred in her first season, no matter 
of what breed or how fully grown she may seem to be. Her constitution can not be matured, and to put on her the severest strain possible is unwise, if not cruel, as regards the offspring, and still more the bitch herself. This is especially true of the larger breeds.

It is well known that a fleshy bitch is apt to miss conception, and as at some period of gestation the usual exercise a dog should get must in her case be cut down more or less, if she is even a little thin but extra hard in muscle it will be well.

Many bitches that have failed to conceive will do so when reduced to a very thin condition. It is also recommended to give such a brisk run just before and just after copulation, especially the former.

Barrenness exists to some extent among all animals. Before a bitch in her prime is given up as hopelessly barren, she should be reduced to a low condition of flesh and tried at successive seasons with different young and vigorous dogs. Even purgation and bleeding, to reduce the animal still lower, have been tried, it is said, with success.

While in "season" the bitch must often, to avoid accidents, be less exercised than usual, in which case her food must be cut down in quantity and be less stimulating -i. e., contain less meat, and consist more of milk, porridge, bread, etc.

It is a wise precaution to give exercise on chain, considering the eagerness of bitches to meet the opposite sex regardless of pedigree, the methods they will employ to escape, and in how brief a moment the best-laid plans may be shattered.

It occasionally happens that a dog will not mate with a 


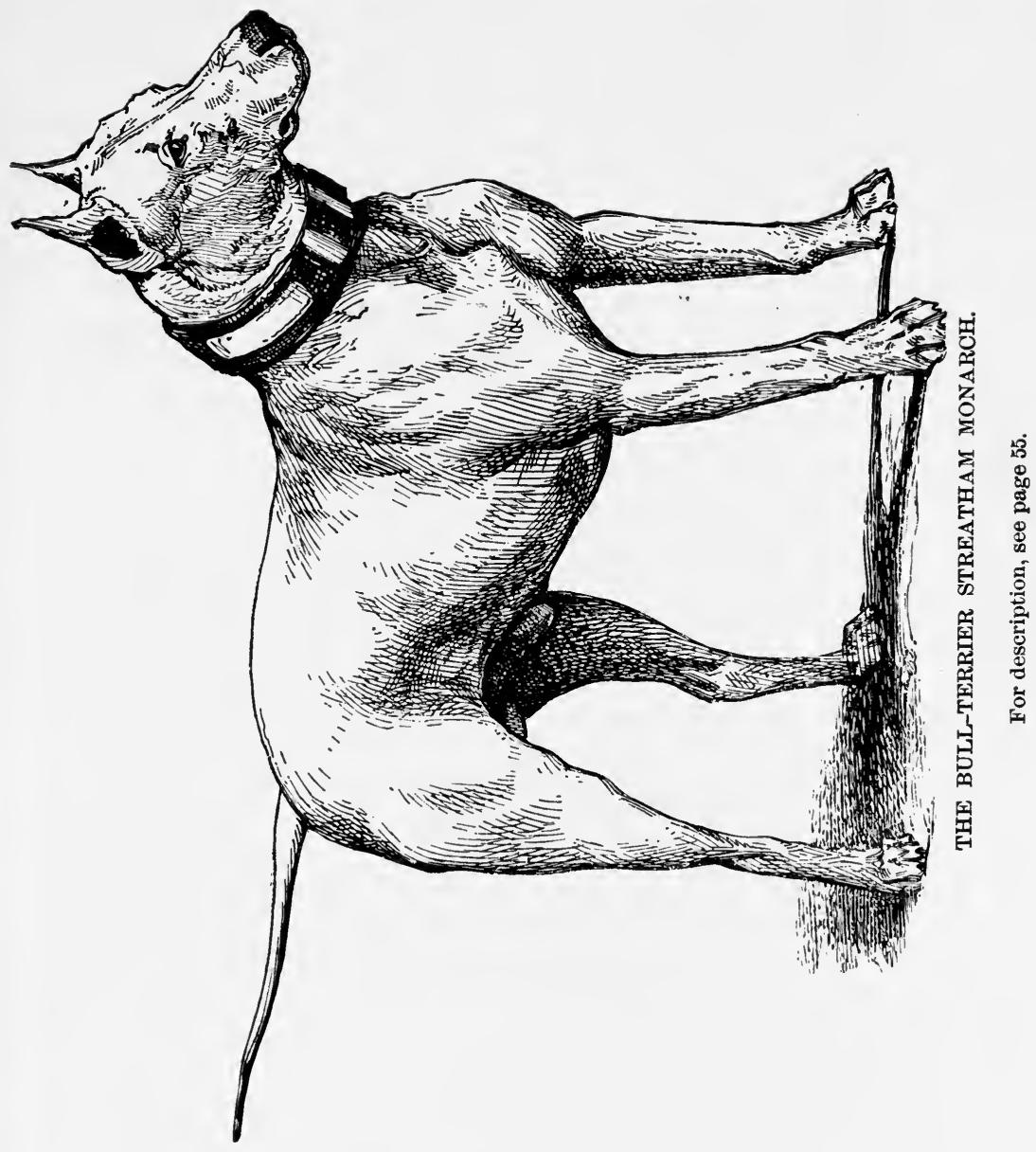


certain bitch, or that a dog seems to be unable to effectually copulate even if inclined, as they now and then are not. It is impossible to lay down any definite rule to meet such cases. A consultation with some experienced breeder, or practitioner of canine medicine, will be best for the novice. It means, of course, that there is something wrong either in the health or the formation of the genitals of the dog or bitch, most likely the former. Such cases are rare, and often a little common sense solves the problem. An unwilling or forced service on the part of the bitch may not prove unfruitful, especially if the first one. The treatment of the bitch after conception is of much importance.

It must constantly be borne in mind that several young are being developed entirely at the expense of one organism, that of the dam. In wild animals their natural conditions and their unerring instincts suffice. But when man takes matters into his own hands, as with our domestic animals, all this is changed in large measure.

In most bitches some little alteration in demeanor may be detected by the experienced eye which suggests that the mating has been successful.

It is seldom that change in size, shape, or weight is appreciable before the fourth or fifth week of gestation. Sometimes at this period there is only the slightest modification in shape. But often when the bitch is laid on her side or back the young may be felt through the walls of the abdomen in the horns of the uterus. If the bitch is not somewhat enlarged at the sixth week, the case is not hopeful, though not hopeless.

The whole period of gestation extends over nine 
weeks, or from fifty-eight to sixty-five days. Puppies are not likely to be born alive before the fiftieth day, though they may be delayed several days without any apparent detriment in many cases. The average period of gestation is about sixty-three days.

There is room for the greatest discretion in the management of the brood bitch, and common sense with a few guiding scientific principles are worth volumes of rules without reasons, for no two cases precisely resemble each other.

For the first month there is so little change in the bitch, the fotuses being very small, that there seems to be no special reason for departing from the usual practices in the management. At the same time there may be periods when the close observer will see that the animal is disinclined to exercise, needs not only abundance of food, but some special change, etc. It is during the first six weeks that plenty of exercise can be given, including galloping, provided the bitch is not given to abort. If so, she must be exercised gently.

Her appetite may or may not be increased.

There can be little doubt that if a bitch is engaged in her proper occupation-e. g., a hunting-dog in huntingit will be better, or shall we say may be better, for the psychical development of the offspring. This the author believes is borne out by both theory and practice. And, at all events, every animal enjoys its life most and thrives best when following its natural instincts-i. e., when it has some occupation congenial to it.

The last three weeks are the most important in themselves, and for this period the bitch should have been pre- 
pared in the preceding weeks. Exercise must usually be gradually diminished. Toward the end of the period some animals are very much disinclined to exercise, and lose flesh in spite of good feeding and the best of care in other respects. In such cases it would be unwise to exhaust the energies by their undue diversion to the muscles by vigorous exercise. Common sense must dictate.

The appetite may greatly increase, and the animal's food should be abundant and very nutritious. If she shows any falling off, she must be given cod-liver oil or chemically pure lime phosphate or Parrish's food, especially if the bitch be herself light in bone. The digestion must be carefully watched. If the bowels are not regular in their action, if the eyes run, if the tongue be whitish, a change of diet, or possibly a little less for twenty-four hours, will prove helpful. Medicine is to be avoided if possible, and violent purgation is never called for-in fact, may cause abortion.

Ventilation is of importance, as the bitch must provide for the aerration and purification of the blood of the young within her as well as her own. The more she can live out of doors the better.

A bitch may often with advantage be fed three times a day instead of twice. She may then not become so dis. tended and uncomfortable, since she requires to take less at each meal.

About the sixth week she should be treated for worms. This is always a matter of safe routine, unless the bitch is unusually delicate, has aborted previously, or for some other special reason. Later, such treatment is not so free from danger; but if there be clear symptoms of 
worms, especially tape-worms, treatment is justifiable. The pumpkin-seed treatment (see page 355) is comparatively safe even during the last week. It is also well to treat the bitch for worms just as she is coming into season, or a little before, when the dosing should be thorough.

The brood bitch should not be fat at any period of gestation, but above all at its close. Such nearly always implies lack of vigor and inability to meet the strain of whelping. It moreover presents a mechanical impediment, as with external fat there is generally internal fat, and at this time all the room possible is wanted within.

When a bitch with a ravenous appetite tends to get fat, it is well to give more meat and less starchy food. The excess of fat must be removed, not by starving, which is dangerous for the young, but by modification of the diet, and especially by more exercise.

Preparation for whelping should in every case be made. All forms of dirt and every kind of vermin on the dam are a source of danger for the puppies.

A bitch may be safely washed a few days before whelping-time, and in nearly every case will be benefited by it if done with proper care. Of course there is more risk in winter; but, except in rare cases, breeding should be regulated to have the puppies whelped in spring or summer. The former is the better period, as distemper is often rampant in the fall, and the older the puppies, if attacked by this malady, the greater are their chances of survival. Naturally, the months from April to November are those permitting of that outdoor life essential to the development of puppies. 


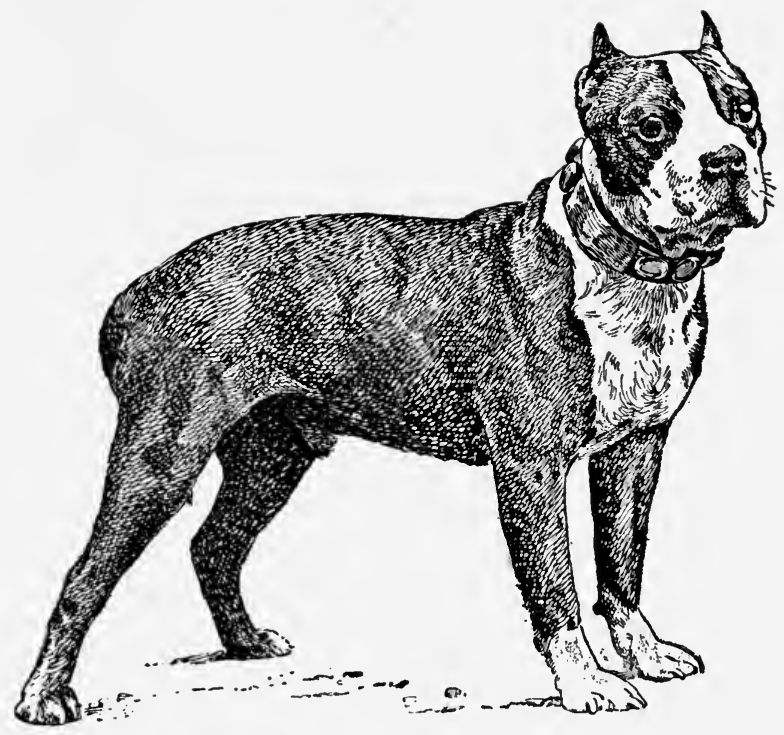

THE BOSTON TERRIER PRINCE WALNUT, WINNER OF TWO PRIZES.

By comparing the illustration of the bulldog and the bull-terrier, it will be seen that the Boston terrier is intermediate in form. 



\section{WHELPING.}

Natural instinct generally shows itself in the bitch, leading her to seek retirement, to keep more quiet, to eat less, etc.

When the brood bitch is one of a kennel, her instincts should be assisted. She should be allowed an entirely separate abode, out of sight of all other dogs, and given lighter food, especially if her appetite is capricious. A meal of porridge and milk tends to open the bowels; but if they are confined, a dose of castor oil is demanded, or an injection of warm soap-suds with castor oil.

The latter is preferable if the bitch's stomach is not in first-rate condition. Medicine is to be avoided if possible, as there is no sense in prematurely disturbing a nature that must soon be put to a great strain. Actual constipation should not be allowed in the brood bitch at any time, above all toward the close, since a full bowel must prove a great mechanical hindrance to the passage outward of the young, not to speak of the general disturbance to health.

Some bitches become very nervous, almost maniacal, just before whelping. Soothing, quiet, even darkness, help such; but if these do not suffice, a dose of twenty grains of bromide of potassium may be given with safety. However, medical treatment will be considered in another part of this work.

While a bitch should be allowed considerable freedom in the choice of her whelping-place, there is a limit to this. If the animal be left in a fair-sized apartment, such as a "stall" or "loose box" in a stable, out of sight and out of hearing, if possible, of other dogs, given some straw in 
one corner, she will in general take to it and whelp quietly and well. But a few additional precautions are not superfluous. Beneath the straw a piece of old but clean carpet may be tacked to the floor, on which latter a little of some disinfectant has been placed, and over this the straw. The idea is that the claws of the puppies shall, by catching in it, enable them the better to suck the dam, as the straw beneath them is generally clawed back. The carpet must be soon removed, however, or it will become a source of disease. The writer does not consider it essential.

A shallow board guard placed around one corner will keep in the straw, and give the bitch the feeling of comfort arising from having a little spot all to herself.

Some recommend a ledging, about four inches wide and a little way from the floor, to be provided so that the bitch may not crush the puppies against the wall, etc. It may prove useful in some cases, but in others will not be necessary, and may prove a source of inconvenience to the mother.

Only those whom the bitch knows and likes should approach her when whelping; better if only one, and he as seldom as possible. Still, some little oversight is necessary withal, and in many more than a little. It can be managed so as not to disturb the bitch, but to assure her. She will soon perceive its object. Gentle caressing, a little milk-gruel, or merely cold water, if offered in the right spirit, will be appreciated even if not taken; but fidgetiness will do only harm. That very coarse and lowly organized sort of human nature to which animals are sometimes intrusted is never more out of place than about the pure-bred bitch during parturition. 
The temperature of the whelping department should be such that the delicate, newly born puppies may not be chilled if they get separated from their mother. It should not be lower than about $68^{\circ} \mathrm{F}$, and may even be higher.

Cleanliness in the whelping nest is looked after by the dam herself for a considerable period. She usually, as soon as a puppy is born, gnaws the navel string (umbilical cord) across, thus disconnecting mother and offspring in a safe and ready way.

She also disposes of the after-birth (placenta) by eating it eagerly; and it would seem that, owing possibly to the discharges (meconium) it contains, this acts as a natural laxative for the bitch.

The escape of the waters (liquor amnii), etc., leaves the bitch herself and the bedding in a very unsuitable condition, though the mother licks the puppies themselves into perfect cleanliness.

As soon as the puppies have been all, or most of them, born, it is well to renew the bedding carefully, using a little of some disinfectant, as "Sanitas sawdust," and to sponge off the bitch where she most needs it with warm water, to which a few drops of carbolic acid, etc., may be added, drying well with cloths.

Toward the end of the first week, if all goes well, she may be carefully washed all over in lukewarm water, finally rinsing with cooler water, drying quickly, and using much hand-rubbing, to prevent unfavorable effects (see p. 122).

The strain of whelping and the attempt on the part of the organism to adjust to the new conditions, including the activity of a large amount of gland tissue in the secretion of milk, may not be so perfect that there will be no 
febrile reaction. Consider how great is the adaptation that must be made, and that this is sometimes affected without the rise of a single degree in the temperature, and we have an illustration of how marvelous is Nature's power to modify to such a greatly changed state of things. As to this, much will depend on the previous management of the brood bitch, as well as on her natural organization.

Very generally the secretion of milk is gradually prepared for by an enlargement of the mammary glands prior to whelping-often weeks in advance; but in this matter there is the greatest individual variation. Some bitches have plenty of milk days before parturition begins; others have but little for from twenty-four to forty-eight hours afterward-all within the limits of health and safety.

As a rule, the indication is to allow the puppies, as soon as they can suck the dam, which they will generally attempt, to do so, unless for some special reason. This is to be encourged, as it seems to have a beneficial effect on the bitch's nature in every way.

Occasionally, however, the trials and sufferings of the mother during labor or afterward justify the temporary removal of the whelps, when they must be kept warm and carefully coddled.

From the first every facility should be offered for the free and natural action of the mother. She should be given to understand that she is not a prisoner, but should be encouraged to leave the nursery to attend to nature's calls, get a little fresh air, stretch herself, etc. But nothing must be strained or forced, otherwise the effect on her nervous system is likely to be felt in either the quantity or quality of the milk, her digestive powers, etc. 


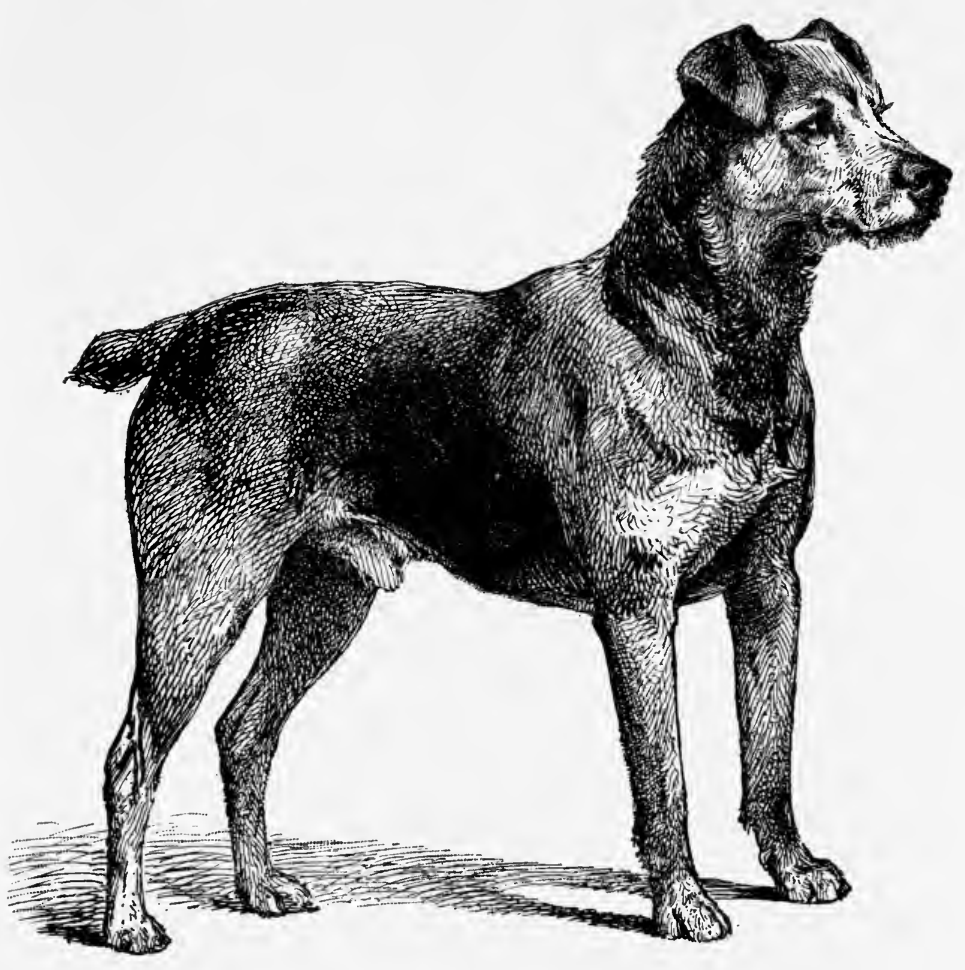

THE WELSH TERRIER BRYNHIR PARDON.

(K. C. S. B., 28,29\%.)

For description, see page 56 . 

In the case of the brood bitch, as in all else that concerns the dog, we must act as if a human being were concerned, and a similar regard for the animal's feelings should be shown as in the case of a member of the human family; in fact, in the case of some dogs more, the submissive, dependent, gentle, and approval-loving traits of the dog being among its most pronounced attributes. No one can better manage a brood bitch than a lady of refinement, who has had some experience with the canine race and is gifted with discretion and a practical turn of mind. Men, in dealing with dogs in whelping, must try and feel as women, and to do this is worth more than any amount of specific directions, especially if there be an intelligent comprehension of the nature of the physiological processes involved.

\section{CHOICE OF PUPPIES.}

It very generally happens that more puppies are born than the dam can rear successfully or without great injury to herself.

In most litters the puppies are not all equally beautiful or equally vigorous; and if the purpose is to breed to the best advantage rather than to supply the market, it will be wise to follow Nature and send the weakest to the wall, or imitate " natural selection," for, without doubt, the weakest do generally perish in the litters of wild animals.

When some are very obviously both weak and small, these are plainly to be selected for drowning, and he who can not drown should not breed. "The survival of the fittest" is Nature's law, and it must be followed 
out when the fittest or the unfittest can be selected with certainty.

But how, in many cases, to choose the best is no easy matter even to the most experienced. One is greatly aided often by past experience of puppies raised by the same bitch, such and such like puppies having grown up with such and such merits and defects.

It sometimes happens that the smallest at birth may become the largest, and a coarse-looking puppy may show, when developed, both vigor and quality.

It is not possible to lay down rules that will apply alike to all breeds, but it is certainly always very risky to retain the smallest and weakest puppy. Delicate animals greatly increase the breeder's worries, no matter what their beauty. Often the young seem so much alike in form, etc., that one may as well choose for color and markings. The advice of an experienced breeder is often of the utmost value to the novice in the choice of puppies. In general, a bitch can not raise well, in justice to herself, more than four to six puppies. To leave to a dam of any breed from eight to twelve puppies is sometimes downright cruelty and generally very poor policy, unless the welfare and future of the puppies, and especially of the bitch, are to be wholly ignored. An animal has only so much vital energy, and if this be exhausted in rearing one litter, the bitch must of necessity be made prematurely old.

Often, however, the puppies are so valuable, from their breeding (pedigree), that the owner can not afford to sacrifice any of them.

In other cases the mother is, from varions reasons, unable to suckle any of the litter. She may be very much 
exhausted, may be dangerously sick from blood-poisoning, inflammation of the womb, etc.; she may lack milk, or it may act as a sort of poison. In all such cases, if the litter is to be saved, a foster-mother is to be secured.

\section{THE FOSTER-MOTHER.}

The essential qualification is the ability to take the actual dam's place as completely as possible. The bitch must be not only vigorous, free from skin disease, etc., but, in addition, good-tempered, and able to supply at once, and to continue to do so, an abundance of milk of good quality. If a past history, showing that the requirements have been met by the particular animal in question, can be obtained, so much the better. As a rule, a bitch with a good appetite and digestion bears the strain of supplying half a dozen hungry, growing young puppies with their entire nourishment for four weeks, and with a good part of it longer, and so makes the best foster-mother. A dainty feeder may be at once rejected.

If the animal be of the same or closely allied breed, so much the better. Even a cat may serve for small puppies.

If the foster-mother has just whelped, or is about to whelp at once, the case is most favorable to the ready adoption of the stranger offspring. Before introducing them they may be allowed to lie awhile with her own progeny in her absence, to get the scent from them, then have their heads, etc., smeared with some of the foster-mother's milk, and be introduced cautiously at night. However, much must be left to the discretion of whoever undertakes this delicate and sometimes impossible task.

The mother herself should be removed so far away 
that she shall not know what has become of her offspring. It is important that the milk glands of the mother be relieved from distention in those cases where it is found desirable to remove puppies while the bitch is in full milk. One at least had better be left. If not, the secretion of milk should be limited by giving laxatives, dry food, etc. At first, after the birth of puppies, there may be an abun. dant and rapid secretion, and if this be not removed by the nursing of a puppy, with or without aid by the hand, febrile reaction may be severe, or even caking or inflammation of the mammary glands may occur.

The method of drying up the milk, which is really preventing its secretion, will be considered shortly.

\section{THE CARE OF THE BROOD BITCH AFTER WHELPING.}

In anticipation of febrile reaction or milk fever, it is well to feed lightly, both as to quantity and quality, for the first twenty-four hours or longer, unless the bitch shows great exhaustion, when easily digested but concentrated nourishment is demanded; so that gruel, milk, eggs beaten up with milk, stale bread and milk, etc., are ordinarily indicated. But some bitches dislike such food even when prepared in the nicest way, and, as a rule, unless there is positive fever or other contra-indication, their tastes may be consulted with little risk-at all events, in moderation.

The stools should be especially looked to, as they are an index to the state of the digestion. Constipation is serious, and diarrhœa must be checked, or the strength of the bitch wili suffer and her milk possibly fail. However, a relaxed condition for one or two days is rather to be 
favored, as tending to prevent fever and get rid of tissue waste, ete.

Constipation may best be relieved by a rectal injection. The less medicine the brood bitch is given the better, consistent with actual safety, as it not only modifies her own vital processes, but, through the milk, that of the puppies.

After the first week the bitch should be given exercise regularly, at first only walking her, then gradually introducing more and more of that form of exercise which by breed, previous habits, etc., is best adapted to her. It will be more pleasant in many eases to her to accompany the other dogs of the kennel, when she will thrive all the better in that case.

The feeding of the nursing bitch ean scarcely be overdone, if her appetite be taken as a guide and she does not gain in flesh. After three weeks she is apt to show a falling off, and it may be necessary to add to the food those helps to nutrition referred to previously.

A nursing bitch should almost from the first be fed three times a day. The demands on her are very great, and if not met by food, the supplies will be drawn from her other tissues, to her detriment-i. e., the milk glands will rob the other tissues of the body.

At the best she will suffer temporarily after the nursing period is over, if not before then. A biteh always loses her coat after whelping, usually grows thinner, the skin becomes irritable, and eczema is liable to follow. If neglected in the matter of food, she may be ruined; her constitution may be hopelessly undermined. However, the digestive powers must be carefully watched, for they are not always equal to the needs of the tissues. 
It is needless to remark that every means employed to keep dogs in health should be specially used in the case of an animal so taxed as the brood bitch. As a matter of fact, however, such practices as grooming, washing, even exercise, are too often neglected, so that the unfortunate creature often enough pays heavily for the pleasures of maternity.

We are now in a better position to answer the important query: How often should a bitch be bred?

Considering how much is involved in the four months of maternal life of a bitch, it is not surprising that experience has shown that to breed a bitch as often as she comes in season is one of the surest ways to render her prematurely old. Once a year at most is often enough to breed any bitch, and too often for many. As a rule, the higher the show quality of the animal, the more important is it to spare her. Surely this matter should be looked at from a humanitarian point of view!

\section{THE REARING OF PUPPIES.}

A large proportion of the worries and discouragements, as well as the pleasures and successes, of the breeder of dogs have their source in puppies.

Until a young $\operatorname{dog}$ is matured, especially till he is one year old, he must be a source of more or less anxiety to one who really knows the risks. During this age of growth and development there are, however, times of greater danger, or eritical periods. These are when being weaned, when getting the permanent teeth, and between these two periods chiefly, or, to put it otherwise, till the puppy is eight or nine months old. 
"To be forewarned is to be half armed," applies in a very high degree in regard to these youthful troubles. Prevention is better than cure always, but especially so in this case; for such is the delicate nature of all young, pure-bred dogs, as compared with the curs that run the streets, that it is very often a grave question whether medicine, which may help in the troubles of older dogs, will not do more harm than good with puppies. Certainly all the arrangements should be made with a full realization of possible dangers and their prevention, rather than of dosing with medicines. The breeder who does not act on this principle will not be a success; and the practitioner of canine medicine, like his colleague in human medicine, is discharging his highest functions when he advises so as to prevent evils which, in a good proportion of cases, he can but imperfectly remedy.

But in this as in every other case, if we would proceed on a sound basis, we must grasp those few underlying principles on which all the details hinge.

Let us consider that we have to do with a rapidly growing being that must adapt its own altering constitution to a changing environment. There is a double instability. The constitution of the creature alters constantly and rapidly, and this alone is no small factor ; and the changing animal must be adapted to all vieissitudes of climate and to everything that enters into the environment, so that the practical problem with the breeder is this: To adapt the environment, as far as possible, to changes that are inevitable in the organization of the puppy; and in doing this two extremes are to be avoided - constant coddling and neglect. 
For its development the young animal requires abundant and suitable food, pure fresh air, exercise, amusement, occupation, and training, with protection against the inclemencies of the weather, against filth, and all else that hinders development and tends to favor actual disease.

Now, manifestly here again we must not lay down iron rules. Every one must, in a large degree, be his own judge as to how best to attain these ends, for not only are all puppies not alike, but environments must of necessity differ very widely. It will be our purpose to indicate the fundamental principles which should guide, not to supply rules for combinations of circumstances that are never twice alike. It must not be forgotten, either, that perhaps the most important factor of all in the environment is the individual who undertakes the work of rearing puppies. If he lack intelligence and a sympathetic feeling with dogs, by which alone they can be comprehended, it is idle to hope that any directions will be of avail. A litter that with the same general management will grow up to the highest perfection they are capable of under one man, will be miserable culls under another who may think he is following the same course, but who neglects details of adaptation which all the books in the world could not furnish.

\section{WEANING PUPPIES.}

So long as the puppies and the dam are perfectly well they should not be separated. It but rarely happens, however, that a pure-bred bitch can suckle puppies longer than four to five weeks without immediate or future detriment to herself especially, and not seldom must the dam 


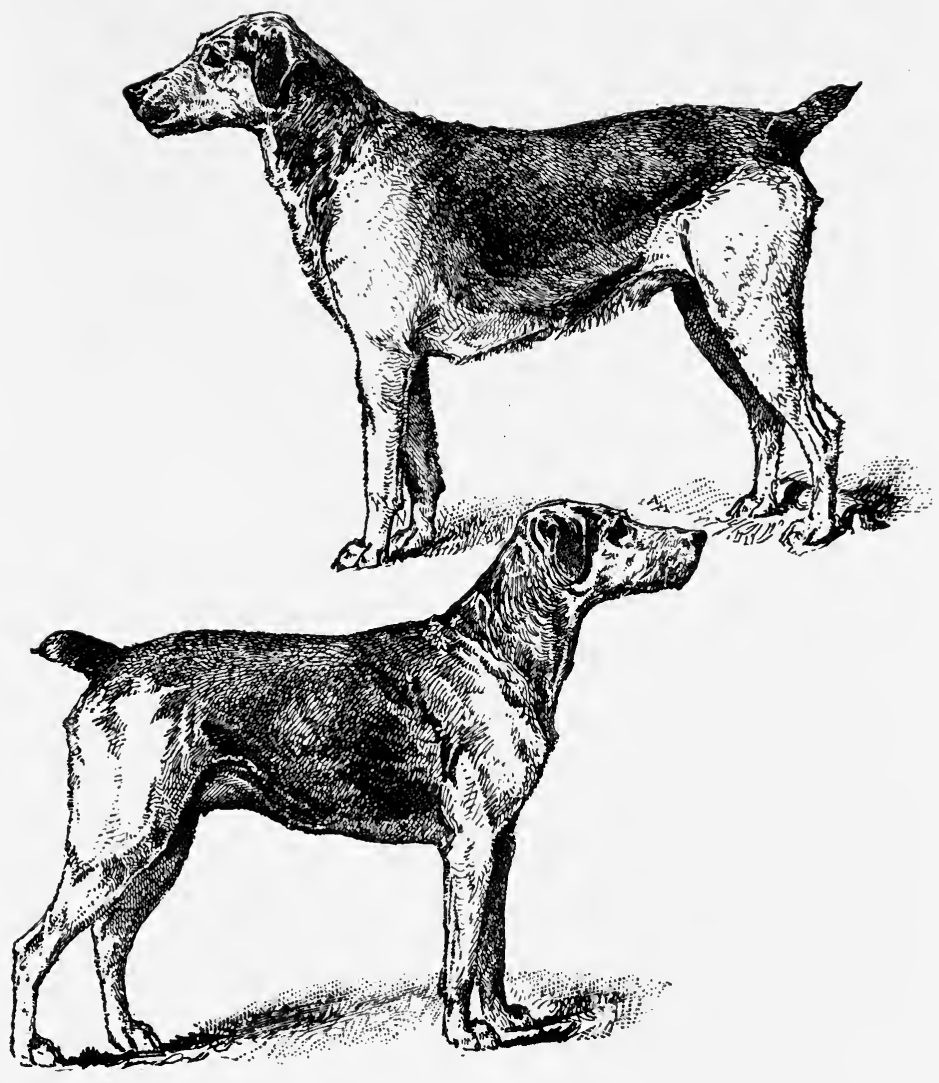

THE AIREDALE TERRIERS

CHAMPION NEWBOLD TEST AND CHAMPION VIXEN III.

For description, see page 56 . 


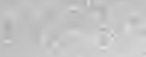

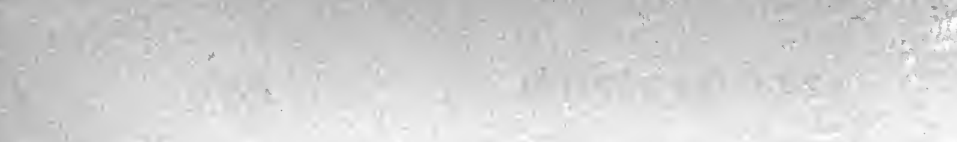

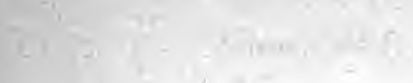

$\rightarrow$ 
be helped in her duties after the third week. This should be done very gradually, for the change from mother's milk to any other food implies a grave strain on these delicate stomachs.

It now and then happens that an attempt must be made to hand-feed puppies from the first, when a fostermother can not be secured. With one this may be managed, just as an infant is fed from a bottle, but at best it is of doubtful success, and with a whole litter it requires a patience almost beyond human nature.

The only suitable first food of the puppy is, of course, that most like what he has had-viz., milk-and practically this must be cow's milk. Experience shows that this can not at first be given undiluted, not because it is richer than bitch's milk-for the following table shows that the latter far exceeds most other kinds of milk in nutritive qualities-but because the stomach, etc., can not at once adapt itself to the new food.

Percentage Composition of Milk.

\begin{tabular}{|c|c|c|c|c|}
\hline Constituents. & Woman. & Cow. & Mare. & Bitch. \\
\hline 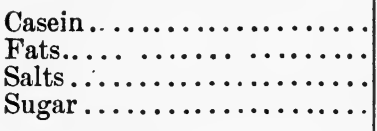 & $\begin{array}{l}2 \cdot 00 \\
2 \cdot 75 \\
0 \cdot 25 \\
5 \cdot 00\end{array}$ & $\begin{array}{l}4 \cdot 00 \\
4 \cdot 00 \\
0 \cdot 60 \\
4 \cdot 40\end{array}$ & $\begin{array}{l}2 \cdot 50 \\
2 \cdot 00 \\
0 \cdot 50 \\
5 \cdot 00\end{array}$ & $\begin{array}{r}10 \cdot 00 \\
10 \cdot 00 \\
0 \cdot 50 \\
3 \cdot 50\end{array}$ \\
\hline 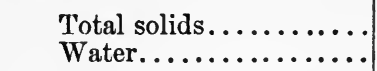 & $\begin{array}{l}10 \cdot 00 \\
90 \cdot 00\end{array}$ & $\begin{array}{l}13 \cdot 00 \\
87 \cdot 00\end{array}$ & $\begin{array}{l}10 \cdot 00 \\
90 \cdot 00\end{array}$ & $\begin{array}{l}24 \cdot 00 \\
76 \cdot 00\end{array}$ \\
\hline
\end{tabular}

About one half water for a couple of days, gradually strengthened to full quality, will suit best. Puppies soon learn to lap milk, which should, of course, be made all the more like that of the mother by being warmed, and a little sugar added for a few days. 
Very soon easily digested solid food, as boiled rice, well-cooked oatmeal porridge, and stale bread, may be added to the milk; and in a few days more a little broth, rather weak and free from fat, may replace part of the milk, etc.

But if the puppies bloat under any food, either they have worms or the food is not agreeing with them in quality or quantity. Gradual adaptation, with simplicity yet some variety, is the key to successful puppy feeding at this period.

The weaning usually may be accomplished in about ten days, and it is a critical period, during which many puppies are lost. If the whelps do not seem to thrive as they ought, the addition of a few drops of cod-liver oil for each may prove very helpful.

The difficulties of this and the period of the succeeding weeks arise in part from the fact that the mother, that up to this time has been a most faithful groom and scavenger, begins to weary of this no longer very pleasant work. The canine infants evacuate the bladder and bowels frequently, hence their nest is soon badly fouled, they themselves get dirty, the air is poisoned, and a whole chain of evils sets in, the end of which is not infrequently death, though the average observer may not always see the connection.

One source of mischief, and among the greatest, has received surprisingly little attention in writings on the management of the dog; but in the author's opinion it is one of the gravest of all.

All puppies, as soon as they begin to feed, and especially after they have left the dam entirely, get smeared about the head parts with the food used. True, they will 
attempt to lick each other clean; but, in the case of longeared dogs especially, these, if not kept carefully cleansed, by hanging into the food, become the source of much mischief. The food dries on the puppies' hair, irritates the skin, and will of itself cause eczema, both external and internal (canker); and worse still, perhaps, such neglect is almost certain to be followed by lice, which soon become a plague, that from the constant irritation utterly derange the health of the animal, cause universal skin disease to add to its misery, and have sent many a fine puppy to an untimely grave. Their treatment we will consider in the medical part of this work, along with that of other parasites; but prevention is now our theme.

My own plan is the following: Immediately after eating, each puppy is cleansed with a sponge dipped in lukewarm water and rubbed dry with a clean cloth. If the ears are long, they are pinned back by the hair behind the neck with spring clothes-pegs. If the bed be clean, and the other precautions to be suggested later be observed, no lice need be feared. However, the inexperienced are warned to look for these creatures carefully, especially about the outer ears, as they are not easy to detect if few, clinging as whitish specks close to the actual skin. They are best seen when the skin is wet.

At the time of weaning the dam must not be forgotten. Her milk must be gradually dried up-i. e., its secretion lessened, and finally wholly arrested. Usually this is facilitated by a little simple treatment, though in occasional cases the matter takes care of itself. The application of camphorated oil, fluid extract of belladonna (poisonous, and must not be licked off, which the bella- 
donna liniment is less likely to be), strong vinegar, etc., tends to arrest the secretion of milk. But perhaps a strong solution of camphor in alcohol is, upon the whole, the best, and is perfectly safe for external application several times a day. In obstinate cases a drop of the fluid extract of belladonna may be given twice a day.

Then, great care must be taken to get the bitch back to her former vigor as soon as possible. The skin is very liable to suffer, and requires careful watching-in fact, as is usual with dogs, it is a remarkably good index of the general health of the animal. The neglect of brood bitches that have faithfully done their duty, as too often witnessed, must grieve any right-minded man sorely.

Not seldom must the bitch have tonic treatment, as cod-liver oil, iron, phosphates, quinine, etc.

\section{FEEDING PUPPIES.}

The principles underlying the feeding of dogs having been already pretty fully discussed, it will only be necessary to point out certain precautions to be taken in the case of puppies. It must always be borne in mind that puppies are in need of food to construct new and rapidly growing tissues, as well as to maintain ordinary wear and tear, like adult animals; hence their food must be abundant, nutritious, complete-i. e., contain all necessary constituents. But it must, in addition, be suited to the changing needs of the animal and the condition of the digestive tract, which, of course, vary from week to week.

It must not contain too much liquid or be sloppy, else the digestive system is relaxed and enfeebled. An all- 
milk diet is not suitable, nor one wholly of broth. While it is not true that milk directly causes worms, through conveying their germs, there is nevertheless some foundation for this prejudice, inasmuch as it does when largely and continuously used by weakening the digestive organs, favoring excess of mucus, etc., tend to produce an environment suitable for the development of parasites.

When bread and milk, broth and bread, and such like foods are used, the dry material should be allowed to soak up the liquid, so that the whole will be moist but not surrounded by liquid. Dry bread-crusts and biscuits are useful, and tend mechanically to remove excess of mucus, the worms themselves and their germs. Powdered charcoal is sometimes administered with the same end in view, as well as to prevent that flatulency and distention not uncommon in puppies.

Sour milk or buttermilk given now and then acts as a tonic, especially in hot weather, if not used in too large quantity at once; and the acid it contains is no doubt unfavorable to worms.

But since buttermilk lacks the fat (and some of the casein) of entire milk, it is not a suitable food for dogs in quantity or continuously. Dogs "at walk" in the country often get too much of it for their best development, it is feared.

Puppies, as soon as they cut their teeth, should be allowed bones that are suitable-i. e., large ones-that they can gnaw and suck but not break, and not hard enough to wear down or fracture the teeth. They strengthen the teeth, jaws, etc., as well as amuse.

All puppies after eight weeks require a little meat, the 
quantity varying with the breed, conditions of life, the in. dividual, etc. A diet of meat alone is too stimulating for a puppy of any age, while one destitute of it will never develop a dog of the highest quality. A little raw meat, cut very fine, has a tonic effect on the digestive system; but, as a rule, the greater part of the meat given dogs should be cooked, for reasons previously given (parasites).

The older the puppy, the stronger its food should be in nitrogenous or albuminous material-the more meat. But puppies of the larger breeds usually require more meat from the first.

After six or eight months, or when the puppy has got its second teeth, it may be fed, like older dogs, on table scraps ; in fact, after this period the feeding may be much as in mature dogs.

How often should a puppy be fed? Since its needs are so great and digestion feeble, a young puppy must get its meals often. It is surely better to give food more frequently, than to feed so seldom that the puppy must eat to distention to satisfy his appetite.

For puppies under three months, five or six times a day is not too often, the last meal being given late at night and the first early in the morning.

For those from three to six months, four times daily may suffice, and from six to eight months three times; after that two good meals will answer. It is best to feed each puppy separately.

\section{OTHER MANAGEMENT OF PUPPIES.}

If we could only imitate Nature's ways, we should be eminently successful. We find that the carnivora, the dog 
tribe included, bring forth their young in secluded places, as caves, holes in the earth, burrows, etc.

As soon as the whelps are old enough to move about, their surroundings are favorable for cleanliness and exercise, while they can readily resort to their natural shelter in case of storms or other stress of circumstances, and for undisturbed repose.

What better grooming for the skin than that furnished by fresh earth, grass, forest brush, dry leaves, etc. ? Earth is a perfect deodorizer, if not an actual disinfectant; it furnishes a means of removing dirt and vermin; and tends to produce those ingoing nervous influences which have, as already pointed out, such a salutary influence.

Now, if we but imitate these conditions, our puppies will be fairly healthy, notwithstanding that in breeding and in many features of the environment we must depart from Nature in keeping pure-bred dogs around human habitations.

Puppies, when well, always play much-the best exercise they can get. What is wanted, then, is a shelter to which they can resort for quiet and shade during the day; a kennel free from draughts or other source of danger at night, with free ventilation and cleanliness.

Puppies can not develop sound bodies, especially good legs and feet, without liberty to run; hence they should have a yard, if not a field; they must be free to scrape up and burrow in earth, and this should be encouraged; their stools must be constantly removed; and they should have access to good, cool water. A grass run is very desirable, but not as the sole resort, for it is very difficult to keep it 
clear of excrement. A heap of coal ashes, in the absence of opportunity to burrow in earth, is useful.

When four or five months old the puppies may be taken out together for a little scamper. This they will greatly enjoy, and the change will do them good. They should not at this period accompany older dogs, nor be allowed to meet many strange dogs, lest they catch distemper.

Washing puppies is to be avoided, if possible, till they are six months old, and then as seldom as may be. Young puppies feel the shock, and are apt to catch cold, suffer in their digestion, etc. Nevertheless, washing is preferable to that filthiness which favors all sorts of parasites and renders the creature's life a burden. With the precautions we have indicated as to cleansing after feeding, and with freedom and encouragement to burrow, washing will seldom be required. But if it must be undertaken, let it be done quickly and well.

The amount and kind of grooming young puppies will need must vary very much with the surroundings; after six months they will require more attention in this respect.

When a puppy is kept in a small yard special attention must be paid to his dejections. A box of earth, ashes, or saw-dust, from which a little material may be taken to cover the offensive matter at once, will be indispensable, even if it is removed as soon as it should be.

Any arrangements which do not permit-in fact, do not favor-the puppies retiring to where they can get undisturbed sleep after eating or when tired with play are very defective. Rest is as absolutely demanded as exercise.

Young dogs of different breeds, from their dissimilar 


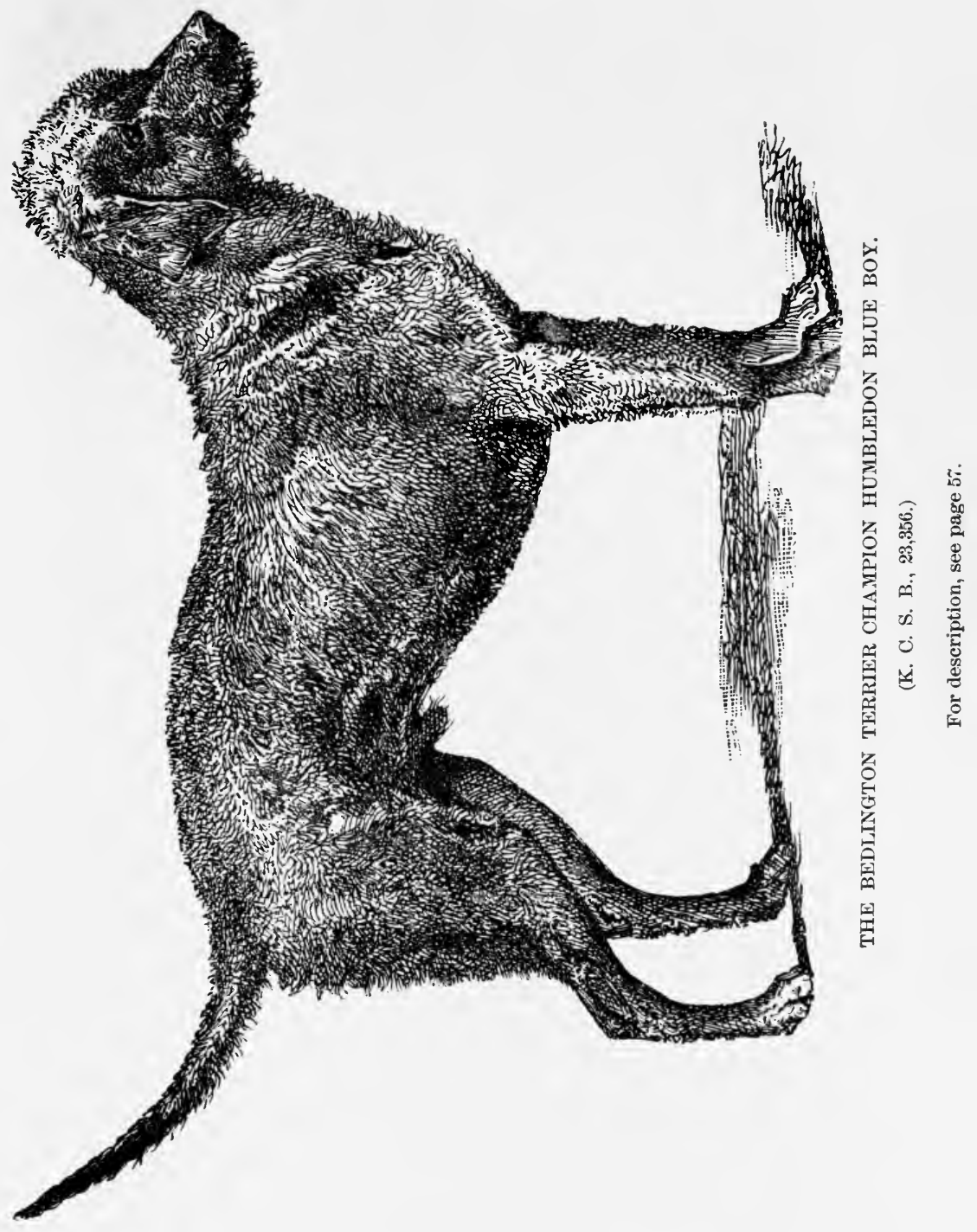



habits and tendencies, do not usually do well together, one being generally a source of annoyance or worry to the other, sometimes of positive danger from fighting. All problems are greatly complicated when several breeds are kept in the one kennel, even if separated. But if study is the main object, there is more to learn for him who has the eye to see.

\section{EXERCISE AND TRAINING OF PUPPIES.}

These subjects are so closely associated in practice that they may be treated together to some extent. We have already tried to show that the best exercise for a dog is that which fits him for his work, and that in the very nature of the case this must be taken in connection with that work. Such is Nature's method. The young carnivora soon take part in catching, etc., the maimed animals the parents bring home.

An analysis of our own psychic life, complex as much of it is, compared with that of the dog, shows that a great part of our mental processes are not concerned with abstractions and generalizations of a very high order, but with actual concrete perceptions and conceptions; that we think in pictures rather than words; that our thoughts are the result of past associations; that the machinery of the mind or brain is so connected that when one part is moved, so to speak, a whole series of connections are established. Hence the psychic life of every creature must be related essentially to its past experiences.

If this be true-and it can not be doubted-we think, then, the puppy's intelligence, like our own, begins to develop, and continues to do so exactly in relation to its 
environment. We can make that environment pretty much what we will; and with the dog, his master from the first, and always, is the principal factor.

Two extreme views have for a long period been entertained in regard to the training of the $\mathrm{dog}$ : the one that he is a wild, wayward creature to be "broken," the other that he needs no special correction if properly taught from the first. Neither is quite correct.

A puppy full of life tends to do exactly as his impulses urge him, till the highest motive power, a desire to please his master, is substituted. It follows that a puppy can not be too soon led to understand that he has a master-kind, honest, intelligent, and firm. He must be consistent with his puppy. All caprice is fatal; it utterly confuses and demoralizes the dog.

Remembering, as we indicated long ago, that the dog is very like ourselves, we can suggest a few principles for training that we think will meet the test of experience. The puppy at one period is like a young infant, later like a two-year-old child, and at the best most dogs never get beyond the intelligence of a young child in most respects, though in some qualities the wisest man is far behind the dog.

For practical purposes the puppy may be treated as an infant, but as a rapidly developing one. He gets his information through his senses, and his training must be related to this, and to the fact that he is a creature with strong impulses but of little self-control.

It is a well-established law of the nervous system, that what has happened once is likely to occur again under the same circumstances; hence in the training of 
puppies first experiences are of much importance, and all the arrangements of the kennel, and in fact the whole environment, should be shaped in relation to this principle.

The puppy should not be allowed to get into habits which will later need correction. Let him from the first be encouraged in cleanliness, self-respect, love of esteem, respect for the rights of other puppies his fellows, etc.

Very early begin to instill into him lessons of restraint, bat only for the briefest periods, for the creature is as yet weak in brain and will power, though strong in instincts and impulses.

The master or trainer must not be associated in his mind with unpleasantness, but with the reverse. Do not, therefore, punish him, but let him learn almost unconsciously that certain actions and certain pleasures are connected.

He should soon be taught his name, should always come when called, but not be summoned too often, especially if playing. It is well to carry a bit of biscuit, cheese, etc., to reward him for coming at first. Later a pat of approbation will suffice.

The trainer should never undertake what he is not reasonably sure of accomplishing; and the first aim should always be to secure the dog's attention and interest and to make the accomplishment pleasant. But he must know what is wanted, and if he can not comprehend this, the lesson is unsuitable at this period. He must, however, obey if he understands; gentle compulsion, when once the purpose is understood, may be exercised-e. g., if he will not come when he is called, he must not be whipped, as that will make the whole set of associations unpleasant, 
but he must be gently dragged by the back of the neck or bodily carried to where the trainer stood when the command was given; he should be very gently reprimanded, then forgiven and made to feel that he is forgiven, and the lesson repeated, always rewarding obedience in some way.

Obedience to what is right pleasant, disobedience unpleasant, is the rule for us all, dogs and men. On these principles yard and house training is simple with well-bred dogs. They mean to please if they can. Make obedience and right-doing understood, possible, and pleasing, and it will be preferred, especially if the wrong-doing is followed by the reverse experiences.

Dogs are naturally cleanly, and will not foul their kennels if they can betake themselves to a more suitable place; but this latter must sometimes be pointed out to puppies. An animal confined must of necessity evacuate his bladder and bowels, but a dog that has from his puppyhood had a chance to be cleanly will often suffer much before fouling his dwelling-place. The author has known a puppy at the point of death drag himself from his sleeping-box to evacuate his bowels.

Dogs are not filthy in their habits, but some people who keep them are, and others do not understand what is required to enable a dog to follow his instincts of cleanliness. Where a dog has once been to respond to Nature's call, he tends to visit again, and this is a guide to enable us to avail ourselves of natural instinct to maintain cleanly surroundings. The same general principles apply when dogs are taken afield to be worked on some sort of game. At first the puppy may run toward almost every form of life he sees. This is natural, and he would not be worth 
keeping if he did not show some such tendency to investigate the world about him.

But he must be restrained gradually. He must associate certain acts with the approval and others with the disapproval of him he respects, loves, and would delight to please if he only knew how.

But such is the strength of the impulses of some puppies-now, we will suppose, six or eight months old-that they find it very difficult to restrain themselves. In such case we must lessen the stimulus or source of excitement rather than resort at once to the application of the principle of making the act unpleasant, as by the use of a spiked collar or check-line.

These may later be useful in a modified form, but not at first; indeed, such methods are usually quite unnecessary if a proper course be pursued. To illustrate: Suppose that a brace of setter puppies eight months old be taken to some wood where there is but little game. If they tend to run wild without any reference to the whereabouts of the trainer, and disregard his calls or his whistle, it surely would not be wise to whip those puppies soundly at once, or attach a spiked collar or a check-line. To do so would probably confuse them, humiliate them, and retard their development in every way. Now, if the trainer secrete himself for a little while, the puppies will probably get frightened a little, feeling that they are lost, and will after this be more cautious how widely they range. When they do come in they may be scolded, but not whipped at this stage.

All dogs should be taught to come in to whistle and to "down charge," or to drop at some word of command or 
at the upraising of the hand. This applies to all breeds, though more especially to dogs used in shooting. A dog in the field should also be guided by the motions of his trainer's hand. In learning this, the voice, the whistle, and often a long cord will be useful.

But the author wishes to avoid giving the impression that there is only one way of accomplishing these things, as many previous writers seem to have thought, with the result that many who have attempted to follow their rigid rules have disgusted themselves and spoiled their dogs.

It is to be remembered that all lessons require frequent repetition. "Little and often" applies to training as a cardinal principle.

No one should undertake the training of a dog to work on game who is not possessed of patience and good temper. Lacking these, the puppy is apt to cause the trainer great worry and to get little good from him, if he be not actually spoiled. It is, in fact, better to go afield expecting that the puppy will do nothing as desired at first; then one is prepared for the worst, and may soon lay his plans to accomplish what he aims at, which must always be done in relation both to the dog and the circumstances.

But with dogs example is strong for good or evil. A steady, old, trained dog is invaluable, while a disobedient, headstrong one will most assuredly ruin the puppy. But it is clearly foolish to expect a puppy under a certain age to work on game with an older dog-indeed, to work on game at all-though ranging, obeying the whistle, dropping, etc., should all be tanght before the puppy is introduced to game. He must learn restraint and obedience, though it must be confessed that a day's work on actual game 
often quite transforms some puppies. But, as a rule, ten or twelve months will be quite soon enough to introduce a puppy to actual work.

Retrieving may be taught at home, using a soft ball of yarn, etc.; and if the puppy is inclined to bite hard on this, a few wires may be pushed through it. He must always at first be rewarded, when he brings the ball when thrown, with a little meat, cheese, etc. The words "fetch," "seek," etc., may be employed. Soon he will understand, and seek when no ball is thrown. To get him to "seek dead," some article may be hidden, and at first some meat, etc., must be employed, and the dog assisted to find it. Later a real bird may be used, or a wing. The same word of command should always be used. If the puppy will not bring the article-will not retrieve-take him to the spot and place it in his mouth, holding it there and obliging him to carry it and finally deliver it at command; reward him, and then try him again.

Some dogs take to retrieving naturally, requiring no training, while it is almost impossible to get others, often of high intelligence, to learn this at all.

Most puppies need a good deal of attention before they are perfectly steady on point, and to wing and shot, as their natural tendency is to secure the game when they have found it. How best to overcome this it is not always easy to decide. The dog must be encouraged to remain steady while his trainer moves up. Often the assistance of a second person to flush the bird will be desirable, while the dog is approached and encouraged but not allowed to rush on. In this case a check-cord may be useful-to be employed as little as possible. The example of a reliable 
old dog is invaluable. Some form of check that will make the dog defeat or punish himself is preferable to direct administration of punishment by the trainer.

Gun-shyness is but an exaggerated form of fear of unusual noises, and must be treated accordingly. Let the dog be gradually introduced to louder and louder noises, never being allowed to escape, but made to see that no harm is meant him or can happen to him. As to whether it is worth while to attempt to cure the worst cases will depend much on other circumstances, such as the dog's breeding, general intelligence, "nose," etc. It may or may not be inherited.

The author, in conversation with a very successful trainer of horses, once asked: "Can you teach any horse these things?" "I can do so, but it would not in many cases be worth while," was the reply. The same may be said of dogs: some of them are not adapted for certain kinds of work and acquirements to a sufficient degree, to make it worth while to persevere in teaching them; just as some boys would never become expert enough at certain vocations to warrant their pursuit. But before abandoning a well-bred specimen that seems to possess courage, "go," and fair general intelligence, it might be well to get the advice of some second person of much experience. Many dogs, unpromising at first, have become a great success afterward. The ability to read dogs very thoroughly is given to but few men, and these, provided they have patience, good temper, and perseverance, must of course make the best trainers.

Though we have spoken chiefly of the training of hunting dogs, it is simply because that is usually more 
elaborate. All training is based on essentially the same principles, for the mind of the trainer and that of the dog are relative constants, while the circumstances are the variables.

In every instance the dog, from the earliest period, must know the trainer as his master, as one who knows his own mind and is always to be obeyed. But, in order to insure this, the principles we have already endeavored to enforce must be faithfully and intelligently applied; and it is very important, we repeat, that nothing be undertaken that can not be performed, and every advance in instruction approached by slight gradation and frequent repetition. All sound training must constantly keep in mind the individuality of the animal. The assumption that all dogs should be treated just alike, is as erroneous as that all stomachs may have the same diet.

A dog kept constantly in a kennel can never attain his highest psychical development ; and it is the author's experience that it does every dog good to bring him into the house occasionally for short periods and allow him to mingle with the family. It raises the animal in his own estimation, and attaches him to his master, for whom he will have increased respect.

The exercise of puppies is, of course, of more importance than that of grown dogs, as not only their health but their development is to be considered. Bearing in mind their eagerness, their inexperience, the ease with which they are exhausted, the immature character of their tissues, and their general instability of nature, certain precautions are very necessary.

It has been already pointed out that the object of exer- 
cise is the best development of the dog, physical and psychical; that it should be in great part in reference to the work-in fact, in connection, if possible, with the work-the animal is intended to perform.

This is not always possible. A setter puppy can not always be taken to the woods, etc. In such case, the nearest approach to the ideal must be striven after. He can be taken to fields, along country roads, etc. It is desirable that all dogs be taught to lead on chain without straining or worry, and to walk "at heel." To accomplish this latter a stick with a spring snap attached to one end, that can be put through a ring in the collar, will serve to hold the dog in the desired position, always accompanying the action with the word "heel," so that soon this apparatus may be dispensed with.

This should not be undertaken too soon with puppies, or their natural spirit will be too much curbed. It is more than desirable to keep very young puppies out of temptation to run wild, where they can do mischief, while giving exercise.

It is far more important in a puppy than in a grown dog to avoid exhaustion; nor should the young dog be allowed to race at the top of his speed till he is tired and then drop and continue to lie on the cool earth, for he may get one of those chills so favorable to the onset of distemper, pneumonia, or some less serious form of disturbance.

Racing over hilly and rough country without previous preparation, especially if long continued, is very apt to strain the muscles and ligaments, and is no doubt responsible for many of the imperfections of the legs and feet that we see in hunting-dogs. Especially is this likely to follow 
if the dog is not well groomed and rubbed after coming in, the legs included.

Big dogs, such as St. Bernards, mastiffs, etc., are not adapted to the same sort of exercise as setters, terriers, and smaller dogs; but it is astonishing how active and fast such dogs become when judiciously exercised, and now and then, in a field not too large, allowed to romp with dogs of some more active breed for a short time and after preliminary training.

We have already said that no dog should be kept constantly on chain. The tugging at a chain will not improve the form of any dog, and will most certainly deform a puppy ; in fact, to keep a dog on chain is to subject him to entirely wrong conditions, all his natural instincts being checked and his nature perverted.

Many accidents also are liable to happen, such as hanging, etc. In nearly every instance chaining up could easily be avoided.

\section{THE DEVELOPMENT OF THE DOG; DETERMINATION OF AGE.}

All mammals are born in a more or less undeveloped condition, and to this the dog is no exception. The newly born puppy is capable of but little locomotion; and though it can both taste and smell, the eyes and ears are not yet complete in development, the external ears being closed and the eyelids not yet separated, so that the creature is both deaf and blind. In ten or twelve days these organs are functional, and from that time the puppy's advance is rapid. He soon gets control of his muscles, and uses his senses and locomotive powers to investigate the world 
about him and prepare for an independent existence. Every organ of the body becomes by degrees more active, and puppy coat, carriage, form, etc., are gradually exchanged for those characteristic of the adult of the breed to which he belongs.

Those familiar with a breed by raising puppies can, with considerable accuracy, estimate the age of a puppy by its general appearance and demeanor, as they can also of an "old dog," though in the latter case with much less certainty.

It is easier to decide the age of a very young puppy than of a dog of any other age, while it is not possible to determine with any degree of certainty the age of a wellreared dog between his first and his fourth or fifth year. The same reliance can not be placed on the teeth as in the case of the herbivora, especially the horse, in which their rate of wear is fairly constant and their appearance for each year of life up to old age characteristic. The fact is, the dog scarcely uses his teeth to masticate food at all, unless it be in gnawing bones. But considerable dependence may be placed on the teeth to indicate age within the first year of the dog's life.

It will be borne in mind that a tooth consists of a part imbedded in the gum and jaw, the root or fang, and of an exposed portion, or crown. The latter is capped by an extremely hard substance-enamel-beneath which is the "ivory" or dentine, made up of fine tubules into which the substance of the pulp extends. The tooth is supplied with blood-vessels and nerves through the pulp, which fills the hollow interior of its root or roots, and corresponds to the marrow of bones in some degree. (Fig. 9.) 
The teeth of the dog, as in other carnivora, are adapted for seizing, holding, tearing, and cutting, rather than grinding.

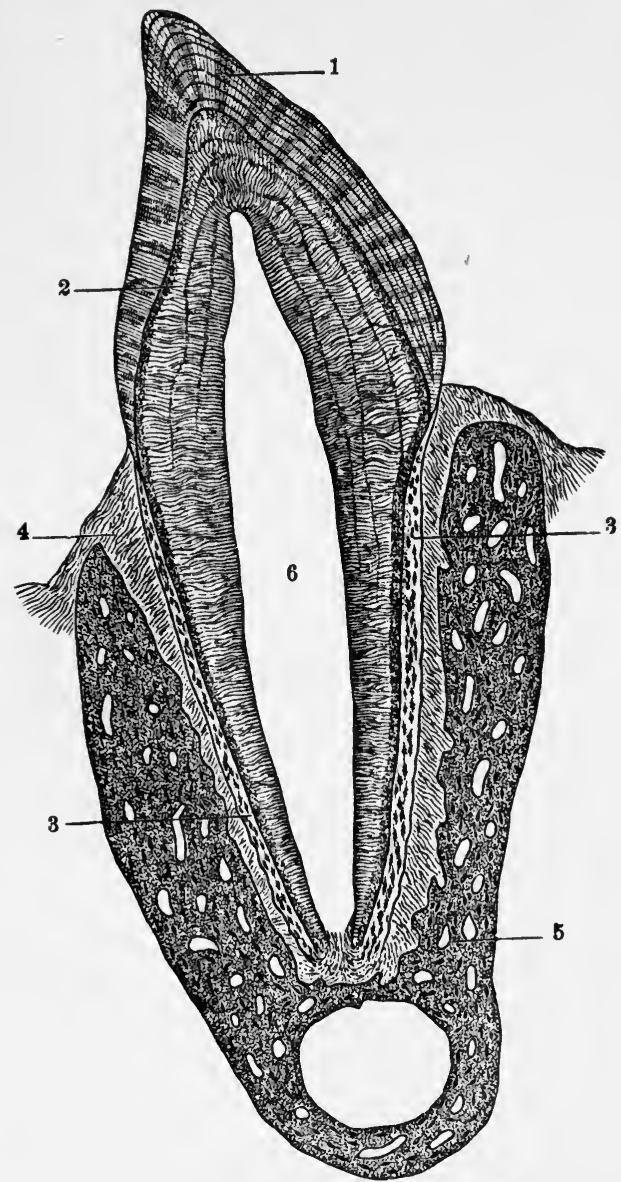

Fig. 9.-Tooth of Cat in Stru (Waldeyer).

i, enamel ; 2 , dentine ; 3 , cement ; 4 , periosteum of alveolar cavity ; 5 , bone of jaw ; 6 , pulp cavity.

The first or milk-teeth may soon after birth be felt within the gums of the puppy, and the period of their 
eruption is fairly constant. The larger breeds and bitches get teeth earlier by a little than smaller breeds and dogs. It may be said that, in general, the front teeth or incisors appear before the back teeth or molars, though the tooth actually erupted first is usually the lower middle molar, and at about the eighteenth to the twenty-second day. Then follow, after one to two days' interval, the incisors -i. e., "nippers," "intermediates," and "corner teeth" -

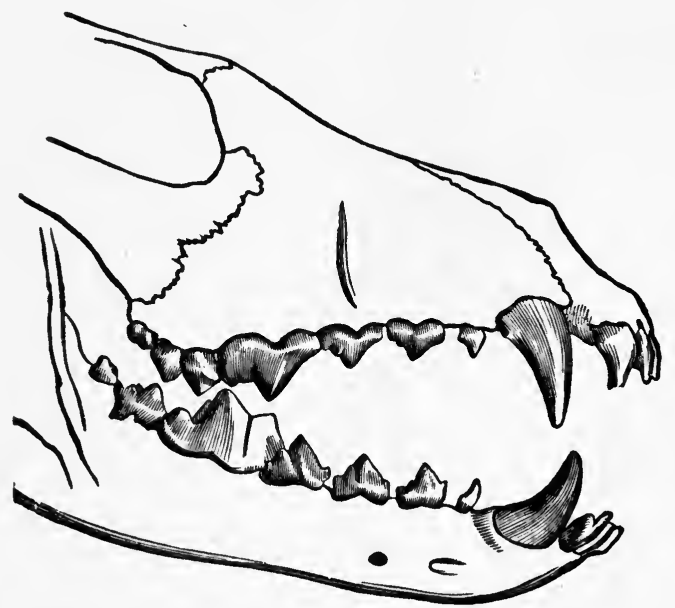

Fig. 10.-General and lateral View of the Dog's Teeth (Chauveau).

in the order indicated, though this is not constant; and the interval between their appearance may be inappreciable, so that they often seem to erupt at once. At about the same time the canines (tusks) appear. The first and third molars are cut about the fourth week, and in a couple of days later the middle upper molar pushes its way through; next comes the last upper molar, and then the first upper molar, so that by the fifth week the whole of the milk-teeth may be through the gums. 
The temporary teeth are twenty-eight in number-six incisors, two canines, and six molars in each jaw.

They are softer, wider apart and get more so with the growth of the jaw, smaller and more pointed, than those that will succeed them. The incisors of the dog are very characteristic, owing to their cusps or points, usually three in number.

The shedding of the teeth begins at about the fourteenth to the sixteenth week; but in this case the central incisors are the first to be renewed, and the upper molars

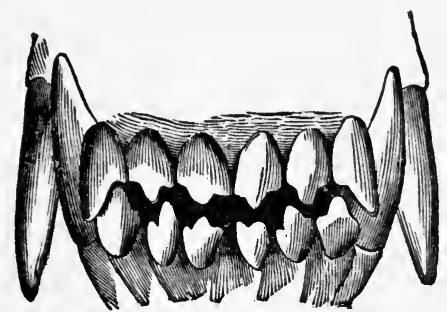

Fig. 11.-Anterior View of the Incisors and Canine Teeth in a Year-old Dog (Chauveau).

are cut before the lower. Usually the canines appear soon after, but they are more frequently delayed than the other teeth. However, there is a good deal of difference, often in even the same litter, as to the exact age at which the renewal begins, the teeth are all shed, and the permanent set is completed. Usually the dentition is complete before the fifth month, but in the smaller breeds the completion of the process may be delayed till the sixth or eighth month.

There is no increase in the number of incisors or canines, but the molars in the second set are twelve in the upper jaw (occasionally fourteen) and fourteen in the lower, making the total number of teeth forty-two, as in- 
dicated in the following tabular comparison with the dentition of man:

\begin{tabular}{|c|c|c|c|c|}
\hline Dog & $\begin{array}{l}\text { Incisors. } \\
\cdot \frac{3-3}{3-3}\end{array}$ & $\begin{array}{l}\text { Canines. } \\
\frac{1-1}{1-1}\end{array}$ & $\begin{array}{l}\text { Premolars. } \\
\qquad \frac{4-4}{4-4}\end{array}$ & $\begin{array}{l}\text { Molars. } \\
\frac{2-2}{3-3}=42 \text {. }\end{array}$ \\
\hline & $\frac{2-2}{2-2}$ & $\frac{1-1}{1-1}$ & $\frac{2-2}{2-2}$ & $\frac{3-3}{3-3}=32$. \\
\hline
\end{tabular}

The usual order of eruption is: Fourth, above ; fifth, above; fifth, below, soon followed by the sixth and seventh; three anterior above; about a week later the three anterior are replaced below. The four first molars on each side are often termed premolars.

From the nature of the case, it is impossible to determine the age of a dog by his teeth after the permanent set is complete, as their condition varies greatly with the sort of wear to which they are subjected, this depending on the food, etc.

In a perfectly healthy dog the teeth remain white for several years ; but if there be abnormalities of the digestive juices, the teeth are apt to become discolored by tartar, an accumulation of lime-salts, entangling foreign matters.

It is well to give a dog, therefore, suitable bones, hard biscuits, crusts of bread, etc., to clean the teeth.

Dogs of most breeds are at their best physically in their third year, though some individuals of these, and many in the larger varieties, continue to improve up to the fourth year.

After the sixth year a dog usually shows signs of failure; after the eighth he is old, and after the tenth year he is, as a rule, unfit to propagate his kind or engage in those 


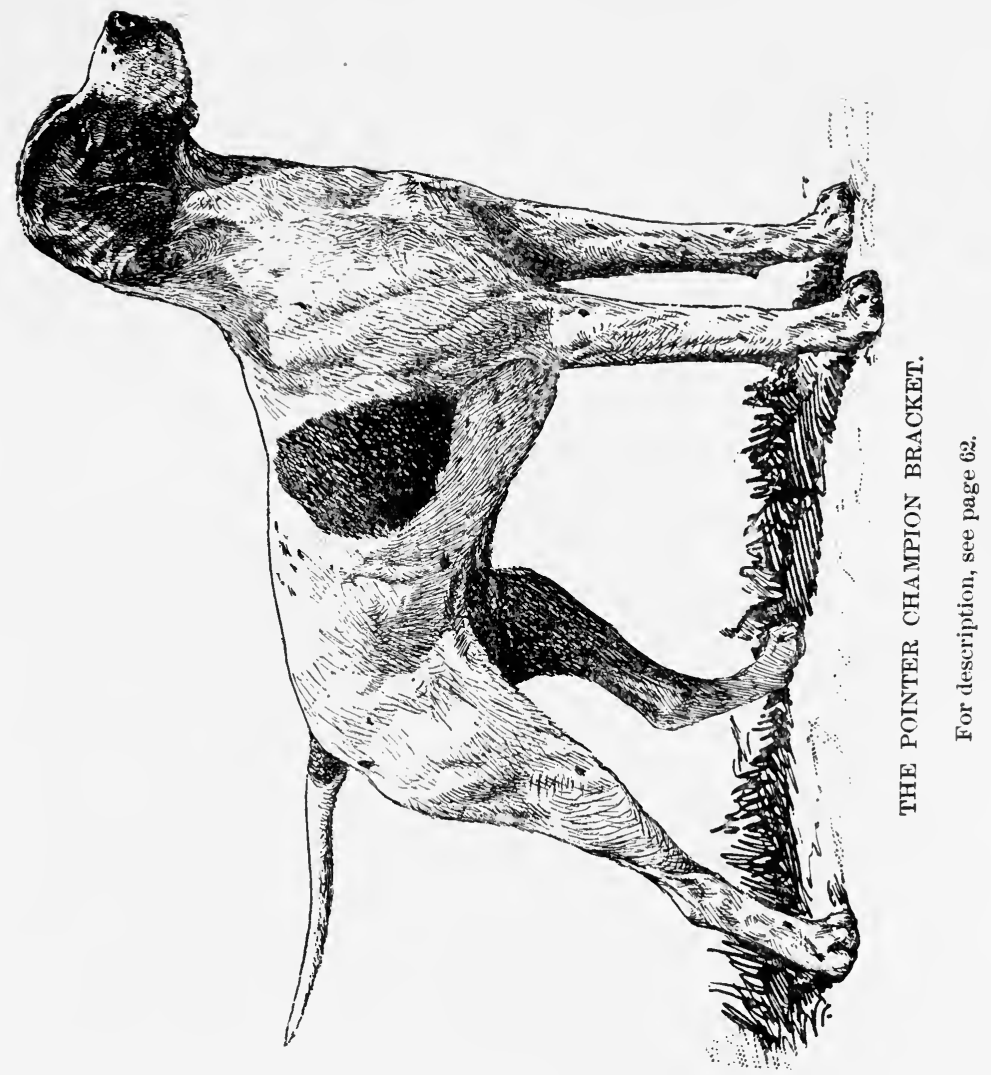




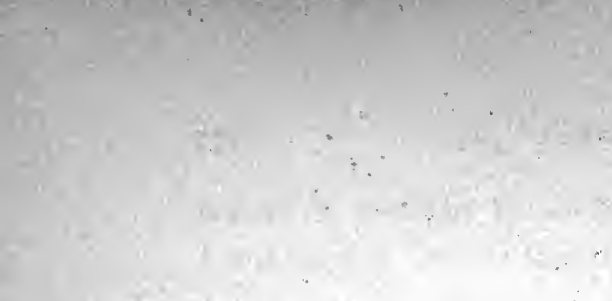

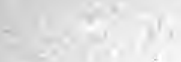

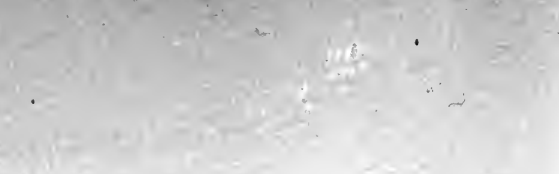

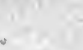
$+2+\frac{1}{2}+$ 1- ne 
pursuits which afforded him so much pleasure in earlier years. As a rule, the smaller breeds are the longest-lived.

Dogs, like human beings, improve in judgment with advancing years, become more staid, and prefer quiet observation to activity. Like men, too, they show grayness about the head and face, though, as in the human subject, this sometimes appears early and as an hereditary trait.

The age at which a dog ceases to be useful or to enjoy life will depend largely on inherited stamina, and especially the care he has been given. The dog is an animal in which maturity, both physical and psychical, is speedily attained, decline rapid, and life short. His is a brief, intense career. He lives much though not long; the tide of his life is rapid and full, but evanescent. 


\section{GLOSSARY.}

THE author has thought it well to gather together in a list those terms in common use among dog-fanciers, with the meaning attached to them, though a large proportion of them have been already explained in the text as they occurred. Such terms are often used in the reports of dog shows published in papers devoted to kennel interests.

Apple-headed. Roundness instead of flatness of skull; a common fault in the toy black-and-tan terrier, etc.

Babbler. A dog that gives tongue in hunting when he should be mute.

Back. For illustration of the terms applied to different parts of the dog, see the cut, p. 29.

Belton. Applied to an English setter with small, evenly distributed flecks of some other color on a white ground-e. g., black (blue Belton), lemon (lemon Belton), etc.

Blaze. White extending up the center of the skull, as in a St. Bernard.

Brisket. The lower and forward part of the chest.

Brush. The tail in some breeds with long hair on this part, as in the collie.

Butterfly-nose. The end of the nose not of a uniform color, as black, flecked with white-always a fault.

Button-ear. The lappet of the ear hanging down so as to cover the entrance to the auditory canal.

Cat-foot. The foot short and round, as in the cat. Desired now in most breeds.

Chaps. The lips, especially the back parts.

Character. See p. 26.

Checky. Unduly prominent on each side of the skull; a grave fault in a terrier.

Clean. Free from loose skin, etc.; an important point in the neck of most breeds of dogs-e. g., the pointer, great Dane, the terriers, etc. 
Cobby. Of compact form, as in a cob-horse; an important point in most breeds of spaniels.

Condition (good). That physical and psychic state, arising from the health and vigor of the animal as a whole and of every part, and reflected in the eye, coat, movement, etc.

Couplings. Certain joints. A dog is long-coupled when he is too long between the shoulder and the hip-joint; or he is too long between the couplings, so spoiling due proportion.

Cow-hocked. The hock-joints turning in toward each other, instead of pointing straight back, and generally too close together; most apt to occur in large breeds; a grave fault.

Crest. The upper ridge of the neck.

Cropped. Ears not natural, but designedly cut.

Dew-claws. Partially developed toes or claws, generally most pronounced on the hind leg.

Dewlap. The loose skin on throat and neck; undesirable in most breeds, but called for in the bloodhound.

Dish-faced. The opposite of Roman-nosed-i. e., with muzzle higher toward the end than elsewhere. The upper plane of the nose should be level.

Docked. The tail shortened by cutting, etc.

Drop-ear. The lappet falling to the side of the face; the opposite of prick-ear.

Dudley-nose. Flesh-colored.

Elbow. "Out at elbow"-i. e., with the elbow inclining to the outer side, and not pointing straight back, as it should.

Faking. Attempting to improve the animal by illegitimate means, as dyeing, clipping, singeing, etc.

Feather. The long hair on the back of the legs, on the tail, etc., as in setters.

Fiddle-headed. Long and wolfish, rather than massive; a fatal defect in such a dog as the mastiff.

Flag. The tail, especially in setters.

Flat-footed. The opposite of well knuckled up.

Flews. The hanging lips; should be abundant in the bloodhound.

Frill. The abundant long hair on the under side of the neck and chest, as in collies. 
Hare-foot. Elongated, as in the hare, and opposed to cat-foot (see illustration of the Russian wolfhound, p. 32).

Haw. The red "third eyelid" seen at the inner angle of the eyelid in the bloodhound.

Heat. In season, in use; the period of sexual excitement in the bitch. Huckle-bones. Tops of the hip-joints.

Knuckled. Toes are well knuckled up when they are bent up so that the foot looks thick through, as seen in the illustration of the greyhound, p. 10.

Leather. The lappet of the ear.

Leggy. Too long in the leg.

Level. Teeth level-i. e., the teeth of both jaws meeting evenly in front.

Lippy. Lips too free when they should be tight-lipped-e. g., in the bull-terrier, black-and-tan terrier, etc.

Lumber. Useless tissue; material that is a hindrance to a dog in his work; a serious defect in a hunting-dog.

Mane. The long hair on the neck and shoulders of a collie.

Orershot. The upper incisors projecting arpreciably beyond the lower.

Pigeon-toed. The toes turning in when walking.

Pig-jawed. Overshot; the upper jaw longer than the lower, so that the upper incisor teeth project beyond the lower appreciably.

Piley. Applied to the coat of some dogs, as that of the Dandie Dinmont; a mixture of hard and soft hair.

Prick-ear. The ear standing erect, as in the Pomeranian, etc., but a serious defect in most breeds.

Quality. See p. 26.

Roach-back. The back or loin arching considerably, as in the bulldog; much the same as "wheel-back."

Rose-ear. The lappet so turning back that the inner part is exposed to view; preferred in the bulldog (see p. 344).

Ruff. The long hair back of the head in the collie.

Snipey. Muzzle not square at the end, but narrowing gradually.

Splay-footed. Same as flat-footed.

Standard. Written description of a breed by which it is supposed to be judged. 
Stern. The tail; used of the pointer, etc.

Stop. The indentation between the eyes at the root of the muzzle.

Throatiness. Excess of loose skin on the throat and neck.

Tucked-up. A "nipping" or gathered-up appearance at the flank. Called for in some varieties, but a defect in dogs of a breed that should be cobby.

Tulip-ear. Half-pricked ear.

Turn-up (and lay back). Applied to the turning up and back of the muzzle of the bulldog and toy spaniel.

Type, typical. See p. 26.

Undershot. The lower incisors or front teeth projecting beyond the upper ones.

Vermin (Varmint) Dog. One used to hunt vermin or creatures that annoy mankind, as rats, etc., and so applicable especially to terriers.

Well-turned Hock. 'The joint strong, and the bones at a good angle at this (ankle) joint. The hocks in a dog intended for great speed for short distances, as the greyhound, should be placed low or relatively near the ground. 


\section{PAR T II. \\ THE DOG IN DISEASE.}

\section{GENERAL PRINCIPLES.}

The processes or functions of the animal body in a natural condition, or in health, have been considered in one brief chapter (page 10), which it might, at this stage, be worth the reader's while to review.

We have now to consider those deviations from the normal which constitute what is termed "disease," and, before undertaking the discussion of specific forms of disease, it may be well to consider some of the main principles which underlie the subject.

Causation.-The environment may be regarded as the entire collection of conditions under which an animal lives, life being the resultant of the action of the environment on the organism. If this be unfavorable, disease results, and the unfavorable factor is termed the cause of the disturbance. Causes are divided into predisposing and exciting. Thus, everything that tends to lower the vitality of the animal is a predisposing cause of distemper in the $\mathrm{dog}$, while a specific germ is the probable exciting cause of the disease. 
Medical practitioners (and we always use that term for those that practice on the lower animals as well as on man) use the terms "diagnosis," "prognosis," "prophylaxis," "treatment," etc., as applicable to every disease. Diagnosis is the recognition of a certain group of disturbances or symptoms as characteristic; prognosis is simply another term for the outlook, the probable issue; prophylaxis is the technical expression for means of prevention; while treatment implies all that is to be done to help the patient.

It can not be too well remembered that disease is not an entity, something that can exist apart from an animal. Disease is nothing more than altered function, a more or less serious departure from the natural condition; hence to know what is the natural condition of an animal is the first requisite for the understanding of disease. We must always have a standard of comparison. Scientific medicine is impossible without scientific pathology or knowledge of altered function, and this again is dependent on a sound physiology or knowledge of the normal behavior of the body. Treatment is based on both, as well as a knowledge of causation, for the first principle of treatment is always to remove, if possible, the cause, and, if that is not to be done, to neutralize it as far as we can.

Disease always implies altered nutrition, or, to use a more modern and expressive term, metabolism, or series of essential changes that make up the life-work of a cell, organ, or entire organism.

It is both convenient and necessary, in considering disease, to bear in mind the alterations that take place in each of the great systems of the body, as well as the general expression or result of this; moreover, nearly every dis- 
ease attacks, or, as we should more correctly say, results in a greater alteration of one system or set of functions than of others; e. g., there are diseases peculiar to the digestive system. However, an equally important truth is to be recognized, viz., that no system can suffer alone; the body is a whole.

It has been customary to assign a very prominent place to the changes in the blood-vascular (circulatory) system both in health and disease; but it must be remembered that changes in the blood-vessels are dependent in most cases directly on changes in the nervous system. In all diseases, as well as in health, the nervous system is the head and director of the processes of the body. This truth has for some years been rather ignored, but is again being recognized. There are certain central cells in the brain and spinal cord that preside over all other cells either by direct government or influence or indirectly, and their action depends on the influences or stimuli that reach them through the afferent or sensory nerves, while their commands or governing influence are conveyed by the efferent or outgoing nerves, the whole constituting a sort of circuit which we may compare, after a fashion, to the circuit of a battery. Influences of some kind, good or bad (irritation), are always passing to and from the central cells, and any doctrines of pathology or therapeutics (treatment) that overlook this are radically defective.

The preceding part of this book has dealt with dogs as they are at the present day, and has explained how they are to be managed to produce their best development and to avoid disease. But do our best, we can not always so perfectly adapt the environment to the animal that serious 
disturbances may not arise; hence the necessity for chapters on disease, which disease as a matter of fact exists and carries off many of the finest specimens of the canine race.

In a large proportion of disturbances inflammation and altered conditions play a very prominent part, and to these, in the briefest way, attention is now invited.

An organ may contain an excess of arterial blood, owing mostly to enlargement of its arterioles, and is then said to be hypercemic; if the organ contain an excess of venous blood, from the latter not being removed as rapidly as usual, the part is possibly congested, or there is stasis, though the latter term is applied mostly to slowed current in the smallest vessels or capillaries.

When the vascular (circulatory) and associated disturbances constitute inflammation, we have dilatation of bloodvessels, afflux of blood, slowing of the blood-current, changes in the walls of the vessels, in the blood within them, and in the tissues around them.

The small blood-vessels dilate, the colorless corpuscles become more actively amœboid, the vessel-walls are changed, and, in consequence of the relations between the blood, the vessels, and the tissues being altered, the corpuscles pass through to a greater or less extent, especially the colorless ones (leucocytes), and also a fluid derived from the liquor sanguinis, or plasma.

The tissues around the vessels may enter on a more active condition and produce immature cells.

These changes are accompanied by heat, pain, redness, and swelling in most instances, and may give rise to constitutional disturbance of varying degrees of severity, 
indicated nearly always by more or less elevation of tem. perature, as well as other changes.

Locally the exudation from the vessels, the cells that pass from them, and those that are produced in the neighboring tissues, may collect to form an abscess.

An inflammation may end in resolution or return to the normal without formation of abscess, etc., or result in abscess, gangrene, or death of parts when very severe, softening and disintegration, and various forms of degeneration; or poisonous products may be formed, taken into the general circulation, and cause the most serious disturbance, or even death.

Hypercemia may lead to increased growth, or may go on to inflammation or return to the normal.

Venous congestion is very apt to issue in some form of "exudation"-i. e., a fluid derived from the plasma of the blood, allied to it in general composition, but to be regarded as "foreign" in a considerable degree. By pressure and otherwise it may do much harm.

The Causes of Disease-Any sudden and great alteration in the environment is apt to be followed by such inability on the part of the organism to adapt itself to it that what we term disease arises. Prominent among these are extremes of temperature, too little and too much food, over-exertion, etc. Such are to be classed among predisposing causes in most instances.

Of late our knowledge of disease has been greatly extended by the study of a world of extremely minute vegetable organisms by means of powerful lenses, artificial cultures, and other kinds of experiments.

It has been shown that animal life may be preyed upon 
by such organisms, distinct in form and equally distinct in functions, each variety of which produces a train of symptoms peculiar to itself. Some of these are powerless to affect certain species of animals or individuals. It is now definitely known that the greatest scourges that afflict man and his dumb companions are attributable to these or to similar lowly-organized animal forms.

And it might be well to point out that most of the recent advances in human medicine, especially in that most important department of preventive medicine, have been owing to experiments on the domestic animals, or on animals living about human habitations.

These minute organisms, by feeding on the fluids and tissues of the animal, cause-as they are present in vast numbers, mechanically, and more especially by direct irritation, and by the poisons they produce-an effect on the entire organism that may be best termed poisoning; and, of course, the greater the vigor of the animal, the better prepared it is to withstand such influences and to eliminate both the micro-organisms themselves and their poisons. As yet our knowledge of combating these enemies is confined to preventive inoculation in the case of a few diseases-all that can be desired, perhaps, if it were established for all microbic maladies and to preventing infection in some degree. But direct destruction of the germs when once within the body remains as one of the triumphs to be attained. Nevertheless, it can not be denied that the progress of medicine within the past decade has never before been in the slightest degree approached. 


\section{NORMAL TEMPERATURE OF THE DOG.}

The bodily temperature of any animal is the result of that series of chemical processes inseparably associated with life. The fact that the temperature remains, under the most varying circumstances, constant within narrow limits, is one of the most wonderful examples of adaptation of complex vital mechanism to environment conceivable.

Physiologists now universally recognize two factors in this equilibrium-heat production and heat dissipation or loss, which in health balance each other. Heat production, as well as heat regulation, is controlled by the nervous system. Heat is lost chiefly by the skin and lungs, though in a slight degree by the passage of urine and fæces.

The amount of heat produced in any tissue or organ is dependent on its activity. The muscles are the greatest source of heat, and among glands the liver. The blood is constantly being cooled at the surface of the body and in the lungs, and as constantly being warmed in the deeper muscles and the internal organs. With exercise there is increased metabolism, augmented chemical activity, more heat produced, and the necessity for greater dissipation of heat if the balance is to be maintained; hence the $\mathrm{dog}$ loses heat by his skin and by his lungs to a greater extent, breathing faster and with open mouth. Some animals lose a great amount of heat by sweating; the dog not so much in this way.

It is plain that whatever will throw these two processes out of balance will give rise to a departure from the normal temperature, either in the direction of 


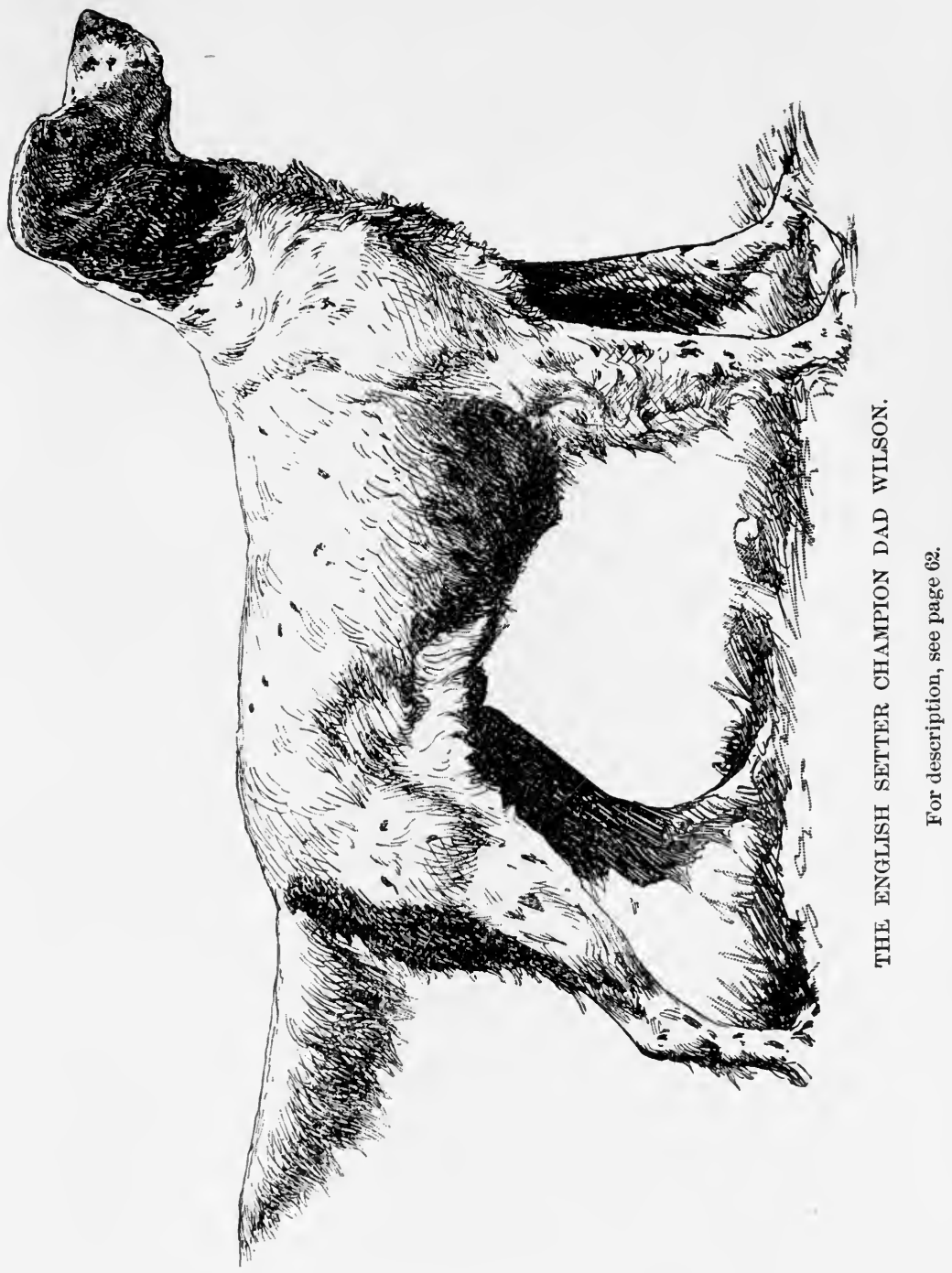



lowering or elevation of the temperature. The latter is the more common, and is termed fever. Since fever implies elevation above a normal, we shall now discuss the natural temperature of the $\mathrm{dog}$; and, finding that this had received but little attention, the author has investigated the subject recently with the assistance of some of his students, and will give a few of the results.

It is known that in man and other animals the tem. perature varies within limits in the twenty-four hours. The tabular statement on the next page will illustrate this, and indicate what is the dog's exact temperature.

It will be noticed that these temperatures do not quite correspond; and investigation has proved that we must recognize differences not only for breed, age, sex, etc., but also for each individual. It is true these are slight, but they must be taken into account in drawing conclusions for both the healthy and the diseased. The rectal (or vaginal) temperature is the most reliable; that in the groin under favorable circumstances is usually about one degree less than in the rectum, but it can not be relied on.

The $\operatorname{dogs}$ on which the observations were made belong to the author's own kennel, and were disturbed as little as possible during the act of taking the temperature. The animals were a pedigreed greyhound $\operatorname{dog}$ and pedigreed Gordon setter bitch, of almost the same age-about two and a half years.

The following is extracted from the author's recordbook: Animals fed at 8.30 A. M. and 5 P. M. Dogs removed from the kennel while taking the day temperatures to a room in the house, and kept there during the night of observation, January 3 and 4, 1891. The thermometer 
used in the rectum was a corrected, certified Hick's instru. ment. Time occupied in each observation ten minutes :

\begin{tabular}{|c|c|c|}
\hline 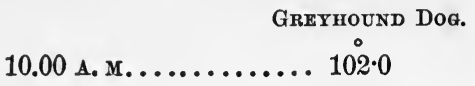 & $\begin{array}{c}\text { Gordon SETTER } \\
101^{\circ} \cdot 4\end{array}$ & BITCH. \\
\hline 12.00 noon. . . . . . . . 102.2 & $102 \cdot 2$ & \\
\hline 2.00 р. м. .......... 102.4 & $101 \cdot 7$ & \\
\hline 5.30 Р. м.......... 101·7 & $101 \cdot 9$ & \\
\hline 8.15 Р. м.......... 101.5 & $101 \cdot 6$ & \\
\hline 10.30 р. м. . . . . . . . 101.5 & $101 \cdot 6$ & \\
\hline 12.00 р. м............ 101·4 & $101 \cdot 2$ & \\
\hline $2.00 \mathrm{~A} .1 . \ldots \ldots \ldots \ldots . . \ldots 100.4$ & $101 \cdot 8$ & \\
\hline 4.00 А. м........... $100 \cdot 4$ & $100 \cdot 7$ & \\
\hline 6.00 А. м........... 100.4 & $100 \cdot 8$ & \\
\hline 7.40 А. м.......... $100 \cdot 6$ & $100 \cdot 5$ & \\
\hline
\end{tabular}

The following appears from the above : That there is a curve of temperature; that the maximum differs from the minimum (in this case $102.4^{\circ}, 100.4^{\circ}, 102 \cdot 2^{\circ}, 100.5^{\circ}$ ) to the extent of about $2^{\circ}$-quite an important matter in determining the temperature range in fever.

While there is a maximum in every case examined, it has been found that the hour has not agreed in any of the dogs examined, though kept under the same conditions. The individual differences in temperature, like the individuality of animals generally, have been somewhat ignored by writers on science and medicine.

The rectal temperature very rarely falls below $100^{\circ}$, and it is important to note that it may rise, as the author has many observations to show, above $102^{\circ}$ considerably; so that a conclusion that fever exists can not be made on a reading of even $102.8^{\circ}$, especially in a puppy in which the temperature may naturally be higher than in an adult $\mathrm{dog}$, and is liable, as in human infants, to oscillate very rapidly. 
But temperatures under $99^{\circ}$ or over $103^{\circ}$ should arouse suspicion of disease, and even a temperature of $102.6^{\circ}$, if constant, can not be normal.

\section{FEVER.}

An elevated temperature is an indication of that disturbance of the bodily processes known as fever, which is usually accompanied by an increase of heat production and a decrease in heat dissipation. That there is increased chemical activity is shown by the augmented output of urea, carbonic dioxide $\left(\mathrm{CO}_{2}\right)$, and still more by the excess in consumption of oxygen. More fuel and more smoke generally mean more heat, and so it is with the body.

It would seem that fever may be caused by poisons produced within the body, or by any agency that will derange the nerve-centers or certain parts of them.

Usually there is excess of solids in the excretions with diminution of fluids.

Many diseases are marked by febrile symptoms-i. e., elevated temperature, rapid pulse and respiration, with diminished excretions, etc. Most, if not all, germ diseases are characterized by febrile symptoms.

\section{THE PULSE.}

As indicating the rapidity and character of the heartbeat, and the condition of the arteries, the pulse conveys to the experienced a world of information. It may be conveniently taken in the groin of the $\mathrm{dog}$; but often it will be necessary, especially in the case of small dogs, to attempt to get at the state of the heart directly, which can be readily done in the dog by feeling the organ through 
the chest-wall. As the dog is an excitable animal, he must be quieted and soothed a little when the pulse is being taken or the heart examined, especially by a stranger. In all cases it must be ascertained that the pulse is not merely transiently affected as the result of temporary excitement from the very process of examination or otherwise.

The variations natural to the different positions of the body are not to be forgotten.

The pulse at birth is very rapid, 130 to 160 ; for the first three months, 120 to 140 ; at from the sixth to the ninth month, 90 to 110 ; after one year, 70 to 90 . It will be understood that these are only rough estimates, so wide are the variations with age, sex, breed, position, temperament, etc.

A merely rapid pulse, with no elevation of temperature or other unfavorable symptoms, is not of great significance usually. It is to be borne in mind, too, that when an adult $\operatorname{dog}$ is quietly sleeping the pulse may be very slow-indeed, 40 to 50 .

The author desires to draw special attention to a feature of the pulse of the dog to which reference is seldom made. After puppyhood the pulse is subject to a sort of normal irregularity-i. e., with each expiration the pulse is slower and stronger, and the beats uneven-a condition of things, in fact, which in man or any other animal would be a certain sign of disease in the large proportion of cases. The phenomenon in question is never shown decidedly in a young puppy, and it is never absent in a matured $\mathrm{dog}$, so that it constitutes in some measure an indication of age. By the inexperienced these peculiarities might 
readily be mistaken for abnormalities of the heart. The ratio of the respiration and pulse in the $\operatorname{dog}$ is about the same as in man-i. e., about one to four.

\section{THE METHODS OF STUDYING THE DOG IN DISEASE.}

He who is most familiar with the appearance and deportment of the dog in health at the various periods of his existence will most readily appreciate all departures from the normal. It follows that the student of canine medicine should associate as much as possible with the dog to acquire the desired familiarity. The idea that a student of medicine can get all the knowledge of dogs that is required from seeing sick animals as they may be brought to an infirmary, though widespread, has not proved correct, and perhaps explains in no small degree that lack of confidence in veterinary surgeons, as regards the dog, which is certainly prevalent if not well founded.

The careful study of even a single puppy throughout its whole period of growth and development by one of good powers of observation and a reflective habit of mind is one of the best possible preparations for the study of canine medicine, and the more of this that an be done the better. Departures from the normal can only be adequately appreciated by him who knows the normal (healthy) dog.

If the veterinarian were known to be a man who understood well the various breeds of dogs in health, and was in sympathy with dogs as dogs, there can be little doubt that he would be more frequently consulted, especially by breeders; and we see no reason why he should not, like the "family physcian," be periodically called in 
to advise so as to prevent disease-a subject on which modern medicine has made great advances.

To the really intelligent practitioner there is little satisfaction in pouring medicine into a dog whose case is plainly hopeless, but which might have been saved, possibly, if an early consultation had been sought. It is for owners and practitioners to so understand each other that advice will be valued and asked early. A certain proportion of breeders, etc., are men of enough intelligence to appreciate medical discussions-at all events, sufficiently to know when to attempt treatment themselves and when to call in experts in medicine; accordingly, the author will endeavor to keep this part of the work free from needless technicalities, while it is made scientific, his object being to make the book as widely useful as possible.

Diagnosis.-Different persons arrive at a diagnosis or determination of the nature of the ailment by different methods. The safest, in fact the only absolutely safe way, is by the process of exclusion-i. e., considering all possible or probable diseases, and finally narrowing down to one by determining that the malady can not be any of the others; apparently a tedious method, but in reality with practice pretty rapid.

Every help must be secured, so that the dog's attitude, expression, carriage, etc., are to be considered before he is taken in hand for a careful examination of each system of the organs of the body. The latter implies what is termed physical signs, as ascertained by palpation, or feeling different parts; auscultation, or listening to various sounds derived from the chest-wall usually; percussion, or tapping with the fingers or instruments over different regions 
with a view of learning whether they are more or less resonant than normal, etc. But it will be perceived that all this can have but little meaning to him who does not understand the normal; hence every sort of examination should be practiced on healthy dogs of various breeds and sizes. The physical examination of the dog is easy in itself, but may be troublesome if the animal is restive or fractious.

This leads us to consider the manner of dealing with dogs during examination. Some recommend that the dog be taken out of the sight of his master, quickly thrown down, and so handled that he will be taken by surprise and offer no resistance. But in all dealings with dogs it can not be too well remembered that they are very sensitive creatures, of strong likes and dislikes, and good memories. A dog may be so treated that it will be almost impossible for the same person ever to succeed a second time in examining him. Moreover, if a dog resists it is not possible to form correct judgments always, as his functions are disturbed thereby.

If the dog is treated so that he shall see that no harm is meant him, he will usually quietly submit according to his natural amiability. A little rubbing of the head, a few soothing words, a gradual approach toward the real object, may occupy a few minutes at first, but save infinitely in the end. Now and then there are exceptions, but, in our experience, they are of the rarest.

Before making any examination, the history of the case should be obtained. To the experienced especially it means a great deal, and upon it alone a fairly safe diagnosis may often be made. While the history is being re- 
lated the dog may be observed, and an acquaintance that shall win his confidence established. If there are no febrile symptoms, a large class of maladies may be excluded. But it is especially necessary to point out that the cool, moist nose may be very deceptive. A dog with a high fever and dangerously sick may have a cool nose; nor is the pulse of the sick dog always accelerated. The only safe rule is to use the thermometer.

In making a diagnosis the greatest importance is to be placed on the symptoms, physical signs, and history of the case, as they make up a whole; and any one who neglects to consider them all together is sure to make mistakes.

In making an examination of the dog it is most important to do it in such a way as will render it easier of accomplishment on the next occasion; and unless this be carried out so that it is at least not disagreeable to the animal, or as little so as possible, the trouble will increase on each repetition.

\section{REMEDIES AND THEIR MODE OF USE.}

The closest investigation the author has been able to give the dog has convinced him that this animal is more like man in his physical constitution than any other animal, as is proved in part by the character of his diseases and the way in which medicines and other remedies react on him. It is quite impossible to treat the $\operatorname{dog}$ on the same principles as the horse, ox, etc., while with comparatively few reservations human medicine is directly applicable to the dog. This is fortunate, for our knowledge of none of the domestic animals at all approaches in exactness and thoroughness the condition to which ages of 


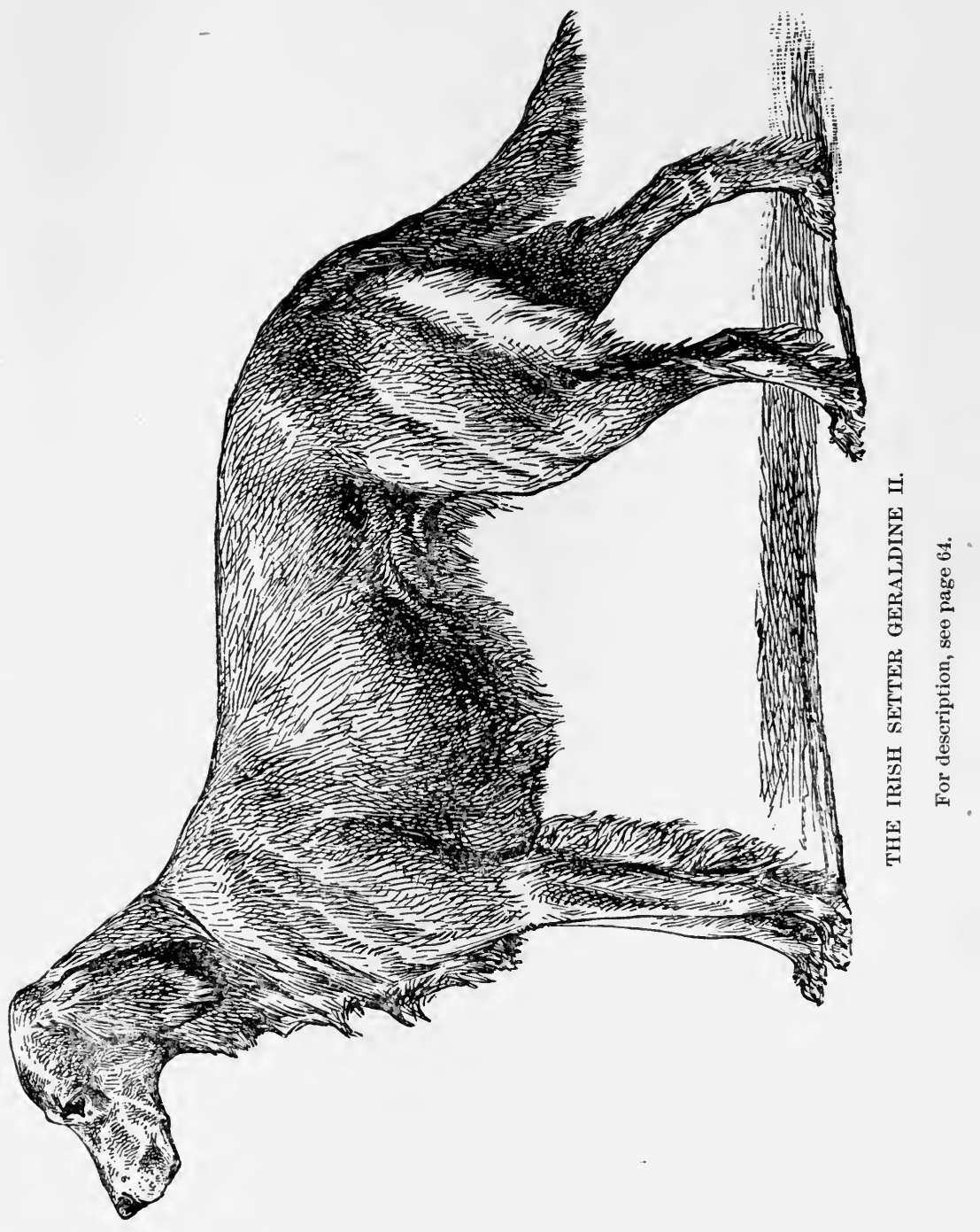



study under more favorable conditions has brought human medicine.

As the treatment of the dog falls not to the practitioner of human medicine, but to the veterinarian or practitioner of comparative medicine, it is all the more necessary that a special study should be made of the dog, taking human rather than equine medicine as the standard of comparison.

More and more must canine medicine become a specialty; and in time it will no doubt develop its own peculiar doctrines, treatment, etc. In the mean time, the closer human practice is imitated the better will it be for the dog, always observing those exceptions that experience shows must be made. Hence in treating the dog we have to use similar food stuffs for the sick, similar medicines in like doses, and the same external and internal treatment generally as with man.

\section{DRUGS AND THEIR ADMINISTRATION.}

A very few drugs are known to be required in larger doses for the dog than for man-e. g., aloes; but this medicine alone is not a good remedy for either dogs or human beings. Dogs are peculiarly liable to be salivated, or even fatally poisoned, by a comparatively small dose of calomel, or mercury in other form, so that great care must be taken to see that it is administered in very small doses (one fourth of a grain to three grains), and speedily removed from the system by a saline or other aperient; nor is it safe to use, in most cases, mercurial ointments. Turpentine has been instanced as another drug dangerous for the dog; but the same applies to man, except it be used in very 
small doses and shielded by mucilage, milk, etc. It is very important to note that opium and its derivatives-as morphia - can be tolerated to an almost unlimited extent by dogs, so that it can be in rare and urgent cases added to ointments which may be licked off without serious harm. A large dose of opium nauseates a dog profoundly, but is not at all likely to poison him.

A rule for the dose of any medicine suitable for the dog, based on the quantities given to horses and other domestic animals, is extremely difficult to lay down; in fact, any attempt to do so is apt to mislead the inexperienced very seriously. In general, it may be said that for the largest dogs-as full-grown St. Bernards-the dose may be exactly as for an adult human being; but for other dogs, of say forty pounds, the dose is about that suitable for a child of twelve to fourteen years, or about two thirds that for an adult man; in the case of small, matured dogs-as terriers, toy spaniels, etc.-from one third to one half the latter will be near the mark.

In the case of puppies under two months of age the less medicine given the better ; but if it must be administered, the doses should be very small and tentative. In fact, for a young dog the first dose especially should always be smaller than is usually safe, with a view to any possible idiosyncrasy, and to allow the stomach and constitution generally to adapt themselves somewhat to the foreign substance, for such it is.*

Sucking puppies may be treated, as for constipation, through the mother, since drugs are in many cases ex-

* A tabular statement of the principal drugs recommended in this volume and their doses will be found at the end. 
creted into the milk. As a rule, very young nursing puppies can not be safely drugged directly.

The method of administration of medicine is of similar importance to the method or manner of him who undertakes the examination of dogs, because of the difficulties that arise if the animal becomes unmanageable or objects seriously to the treatment. Harshness with dogs is so radically opposed to their nature that it in every way defeats the end in view. (See Fig. 39, page 389.)

The following methods have been recommended: 1 . To back the animal into a corner, press the lips against the teeth, and, when the mouth is opened, pass the medicine far back, rapidly close the mouth, and wait for the dog to swallow, covering the nostrils, if necessary, to compel him to do so. 2. Inserting the neck of a small bottle containing the medicine in the pouch between the angle of the lips and gradually pouring the liquid back. 3. Pouring the medicine down, if liquid, from a spoon. 4. Giving pills in pieces of meat. 5. Attaching a cloth to the upper and lower jaws to hold them open in the case of dogs large and hard to manage. 6. To keep the head up by a fastening after the administration, to prevent vomiting.

As a matter of fact, while each of these methods may be useful as guides, and successful or necessary in some cases, the nature of the dog and the amount of experience one has must greatly determine the method. If possible, it is well that a dog should not know that he is getting medicine at all, so that if the latter can be given as small pills in meat it is most desirable. Modern pharmacy has provided a large number of preparations, etc., for the practitioner of human medicine. In some respects these 
are far more necessary for him whose duty it is to minister to sick dogs. They can not understand the object of what must seem to them ill usage; they are keen to feel any affront, as this liberty by a stranger often must appear ; their stomachs tolerate nauseous draughts and boluses very badly; and altogether there is every reason why dogs should get their medicine in the way that will cause least disturbance of their feelings, which, as we have before pointed out and as we know by ourselves, has much to do with the bodily condition; and without that exhaustion which may follow a struggle to give medicine.

It pays, in every sense of the word, to use means to prevent dogs tasting the medicines they must take. Hence, to have pills either gelatin-coated or sugar-coated, or to use gelatin capsules, will be most important. So many drugs are now put up in useful combinations for man's use that the canine practitioner can avail himself of a large field for selection. Gelatin capsules No. 0 and No. 00 serve every purpose for dogs. Occasionally liquids must be given.

Spoons of various sizes, strong, with blunt edges, and capable of containing more than the dose intended, will be useful. For obstinate cases, the medicine spoon as used in human practice will be a useful addition.

It is often necessary to give castor oil to dogs. This can be done with greater satisfaction if it be somewhat warmed (the spoon also) and floated in a little milk, when it will run off the spoon and down the dog's throat easier.

Quickness in the administration of medicines is of the greatest importance.

The author's own practice in giving medicine is as fol- 
lows: Never to use fluids that must be poured down, if possible to avoid it; to get the dog against a wall, a corner preferred, between the knees, press on the lips just enough to cause the mouth to open, then insert the gelatin capsule, moistened with saliva, far back on the tongue, and, giving it a gentle but rapid push down with the fingers, suddenly close the dog's mouth, when he usually swallows, almost unaware of what has happened. Then a pat on the head and an encouraging word, and he thinks no worse of his physician than before, especially if he gets a taste of meat or a sup of milk just after. Even in giving pills we now often prefer to put them in a small gelatin capsule, so that the dog actually tastes nothing at all. However, the above method is varied a great deal.

Following this method, the author can administer, without trouble to himself or offense to the dogs, a dose of medicine repeatedly to any of the more than twenty inmates of his kennel at the present time. But in the case of some very sensitive dogs-e. g., Irish setters-it may be well for the master or trainer to get some one else to give medicine, so that he may not be associated with any unpleasantness in the mind of the puppy. Sometimes a syringe may prove very useful in giving medicine. It should be of hard rubber, or, if of glass, well guarded with metal. Large balls or boluses are unsuitable for dogs. It is better to make them into smaller masses (pills), which can be given several together. However, gelatin capsules are so cheap and convenient that there can be no reason for neglecting their use.

Dogs may be given injections by the rectum or vagina without trouble. They object to hypodermic injections, 
which should only be used in extreme cases demanding a very rapid action, as in collapse, internal hæmorrhage, poisoning, etc. When the stomach will not tolerate medicine, it may be given hypodermically or by the rectum. But, in all dealings with dogs, decision, rapid action, gentleness, etc., can not be too much insisted on.

As a rule, to which there are some exceptions, medicines had better be given after food, in which case they do not so readily act on any one part of the stomach and are more gradually taken into the blood. This rule applies to all preparations of iron and arsenic. Aperients should be given on an empty stomach.

\section{DIET AND CARE OF THE SICK.}

In some of the gravest troubles to which the dog is subject, food and the surroundings of the patient are of infinitely more importance than medicine, while in many minor ones attention to these alone is required. Perhaps the best advice that can be given either the breeder or the student of medicine is to make himself familiar with the actual preparation of those various articles of diet that have in recent times proved invaluable in the hands of the enlightened human practitioner and trained nurse. "Know thyself" applies here again in full force.

Dogs have sensitive stomachs, and may altogether refuse to eat. Often this is Nature's method of restoring a disordered digestion or assimilation; but during the progress of febrile diseases the animal must either be tempted with palatable food and coaxed to eat, or forced, if his life is to be saved. Food that is light 
and easily digested, or food that is readily digestible and also highly nutritious, is indicated.

Broths, milk, eggs, rice prepared in various forms with the greatest skill, may be taken when all else is rejected. Often the dog will accept a little given to him from the hand, and will so improve in the interval that at the next feeding period he will eat spontaneously.

When a dog is rapidly losing flesh and strength, if he will not eat he should have small quantities of suitable food forced down his throat every hour or two. If the stomach is very irritable, small pieces of ice, or a very little spirits with broth, fluid beef, eggnog, etc., may be useful. In fact, the addition of a little wine, brandy, or whisky to liquid food in prostrating diseases may mark the turning point in the case. An excellent combination is broth and boiled rice, the latter being so easily digested. But if a sick dog will take nothing else, he may relish raw meat. The best beef or mutton, grated or minced, sometimes acts like a charm, and need rarely be denied.

The opinion of one who knows the individual dog well, provided he is one of those keen and sympathetic observers, should be given the greatest weight, even by the most accomplished practitioner. We must beware of giving liquid food too long, lest the stomach rebel against it. The aim is to furnish food for a wasting, disordered organism in a form that can be used, and often the instincts of the animal, if duly consulted, will be the best guide.

As a sick dog is in every way at a disadvantage, the more care must be observed as to all matters of ventilation, cleanliness, a suitable temperature, quiet, and comfort generally, including a ministering to his self-esteem 
and love of approbation. Who has not been touched by the friendly wag of the dog's tail when not far from the end of all things to him? Who has not seen the effort to eat, simply to please the one whose slightest wish it has been the very highest delight of his life to meet?

\section{DISINFECTION.}

Disinfection as a preventive of disease must play a great part in the medicine of the present and the future. Since it is now known that very many of the most fatal diseases are of microbic (parasitic) origin, and that these germs can, in many cases, live outside of the body, and so perpetuate disease in animals exposed to them, their destruction by suitable agents is plainly indicated. Such destruction of the germs themselves and the poisonous products they create is disinfection.

A disinfectant may or may not be a deodorizer, and in practice it is very important that a strong smell of carbolic acid, chlorinated lime, etc., shall not of itself satisfy the mind.

Disinfection of kennels, whether there has been contagious disease or not, at regular periods, is a precaution the proprietor will never regret.

It is to be remembered that the germs of disease are usually propagated by spores, or microscopic vegetable cells, which have great vitality-i. e., can resist conditions fatal to most forms of life about us. Thus they bear, many of them, prolonged drying, great extremes of temperature, etc. Such facts probably explain the amazing tenacity that such a disease as distemper has in maintaining itself in a kennel in which it has once broken out. 
Disinfectants have been divided into two classes-those capable of destroying spores, including fire, steam under pressure (twenty-five pounds), boiling water, solution of chloride of lime, liquor sodæ chlorinatæ (Labarraque's solution), and mercuric chloride in solution (corrosive sublimate). The second group is effective only in the absence of spores, and includes dry heat $\left(230^{\circ} \mathrm{Fahr}\right.$. for two hours), sulphur dioxide, carbolic acid, solution of copper sulphate, and solution of chloride of zinc.

The strength of the above solutions should be considerable and their application thorough. It will be seen that the agents of the first group must be the most reliable, and should be resorted to in all doubtful cases.

In the absence of disease, and merely to keep a kennel sweet and free from vermin, some of the various preparations on the market serve a good purpose, such as Jeyes' fluid, "creosin," "sanitas sawdust," etc. "Sanitas sawdust" is one of those easily handled preparations that are most useful for kennels and dog-shows. But none of these should be relied on after distemper.

In actual practice it will be the safest to use several methods of disinfection. The subject is so important that it will receive attention again in connection with the disease distemper.

\section{AUTOPSIES AND MOKBID ANATOMY.}

Disease or alteration of the natural functions to an extent detrimental to the animal's welfare does not usually exist long without changes of either a gross or microscopic character; and as experience has shown that certain sets of symptoms are generally associated with definite altera- 
tions in the size, color, consistence, vascularity, etc., of organs, for the purpose of being sure as to the actual disease a post-mortem examination must be made; and while one familiar with the normal appearances in a dead animal may know that such and such departures exist in any given case, yet their exact interpretation is especially the duty of the expert.

It is plain that the sooner after death the autopsy is made, especially in very warm or very cold weather, the better the chance of learning the conditions as they existed during life, which is what is aimed at but not so easily attained. The position of the animal at death and since should be noted, as this will explain gravitation of blood and other fluids, the neglect of which has led to very erroneous conclusions. Naturally the veins contain most of the blood after death, so that if the small arteries or capillaries are full, inflammation, etc., is to be suspected. The condition of the heart is very instructive. If full of blood and distended, death must have taken place during the relaxed phase (diastole) of the organ, and this is always so in cases of strangulation from any cause.

When the heart is smaller, contracted, relatively pale, death must have taken place during contraction (systole) of the organ. Generally with the full heart the lungs are engorged with blood also, and in fact the appearance of every organ may be modified by the condition of the heart as affecting its blood-supply at the moment of death.

Bearing this in mind, all other departures from the normal can only be estimated by experience in examining the dog or some other animal (the more closely allied to it the better) that has died from bleeding in the one case and 
from suffocation in the other. The student is recommended to investigate this subject on young puppies that must be killed soon after birth-worthless curs, kittens, rats, ete. Having learned what is normal, then a knowledge of the deviations produced by disease can be gradually gained by autopsies on animals, the history and the symptoms being well known, for without these any one may be puzzled, and to the beginner they are absolutely indispensable.

Of course, post-mortem blood-staining is to be distinguished from inflammatory redness, bile-staining from eseape of bile, etc.

The object of the present section is not, however, to furnish a systematic treatise on morbid anatomy, but to point out the great importance of studying the appearances of organs after death in both the healthy and diseased.

A very few brief directions in making autopsies on the dog may not be out of place. It must always be remembered that the organs must be studied in relation to each other, and, before any one of them is removed or cut into, its own appearance and that of related parts well observed. If the examination be systematically conducted, the cause of death can usually be assigned.

The general appearance and condition of the animal, its position, etc., is to be noted.

Observations are to be recorded in writing, it being always stated how long after death the examination was made.

The chest is to be opened by removal of the sternum by cutting through the rib cartilages on each side after 
the skin has been dissected back from the middle line. Ręmoval of hair by scissors will often be advisable.

The circulatory and respiratory systems are so closely related that heart, lungs, etc., should be examined early. If any fluid is present in the chest it should be described, removed, measured, etc. The statement of the position of organs if abnormal is very important.

If the abdomen is opened before the heart or circulatory system in any part is disturbed, some valuable observations may be made throwing light on the question of congestion, inflammation, etc.

After noting the position, appearance, etc., of the heart, great vessels, lungs, and other contents of the thorax, the heart may be incised in position, the presence of clots observed, the amount of blood in a fluid state, etc., all cuts being made so as not to injure the valves.

Then the organ may be removed, cutting away as much of the great vessels with the heart as possible, when all parts may be opened up fully for more complete observation.

The lungs should be removed with the trachea and larynx, so that all may be carefully examined. It should always be stated, in case of suspected disease, whether sections of the lungs will float or not. The character of secretions in the bronchial tubes is to be stated, and, in case of sudden death, foreign bodies looked for in the larynx, bronchial tubes, etc.

The same care should be taken before removal to note the position of organs in the abdominal and pelvic cavities as in the thorax. 
Intussusception, or one part of the intestire pushed within another, is not very uncommon in the $\mathrm{dog}$, and at this stage it should be looked for-also perforations; in fact, let everything possible be done to detect lesions before the removal of organs. The stomach should be included between double ligatures at both extremities, and then cut free. After the removal of the intestines both may be examined on a suitable table or board, on which they may be spread out, slit open, and, after inspection of the contents, washed by running a stream of water over them from a small kettle; the position, numbers, and kinds of parasites, ulcers, adhesions, etc., noted, and so with all other organs.

It sometimes becomes necessary to examine the nervous centers, the brain, and spinal cord, more frequently the former. This task is more difficult from the very perfection of their bony protective cases. Small saws and bone-forceps of different kinds are required. The cuts, after removal of the skin of the head, may be made just above the base-on a line with the root of the ear in a good many cases. The saw should not penetrate soft parts within the skull, or lacerations will result that may prevent any safe conclusions being drawn. The degree of distention of the blood-vessels of the coverings of the brain, any unnatural adhesions, tumors, clots, etc., should be noted before the brain is lifted from its case for systematic slicing.

A blunt chisel-like instrument is of great service, after the saw-cuts are made, in prying off the brain case. The removal of the spinal cord is difficult, and, fortunately, not so often required. The vertebral arches must be 
opened from the back either with bone-forceps or by these together with a saw.

The cause of death is always finally by the heart and lungs, so that the problem resolves itself into what has caused the arrest of their functions; and while in some instances, as in the case of violent hæmorrhages, this may be easy enough, in others the chain of events is long and complicated, and some of the links almost impossible to find.

Every practitioner of medicine should aim at being an expert in making and interpreting autopsies; while every breeder who will secure the assistance of the expert may get much useful help in avoiding future calamities, and aid in the most effectual way in the advancement of medicine.

\section{DESCRIPTIONS OF DISEASE, RELATIVE PREVALENCE, ETC.}

Reference has already been made to the term "type," or "typical," as applied to breeds of dogs. The same may be used for the characteristics of disease. In studying any disease it is found that the combinations of symptoms are rarely, perhaps never, quite the same in any two animals-a statement which also applies to their intensity, order of appearance, etc., though the latter is often fairly constant. These variations, as we have already tried to make clear, are due to the inborn and acquired differences in the constitutions of animals of the same species, which are inseparable from and constitute individuality. As there are so many breeds of dogs, these principles apply forcibly. But in reading most works on medicine which 
are professedly systematic treatises, one meets with such a long array of maladies, such a host of symptoms, and such a variety of "complications," that he is at first surprised, when an actnal case of the disease presents itself, that not a quarter, perhaps, of the symptoms enumerated are really present, while the complications are likely enough wholly absent.

Further, with increasing experience, it is found that in ordinary practice, either as a breeder or practitioner of canine medicine, not a few of the diseases so fully described are scarcely met at all. While it is desirable that the expert shall know all the possibilities, it is only just to the learner, whoever he may be, to point out that some of the departures from health described in books are merely pathological curiosities. And it is especially necessary to warn the beginner not to expect to find all the symptoms that may be enumerated actually present in any one case, or in any score of cases. But it is most important that the reader grasp the general character, the type, the facies of the disease under consideration-that combination of phenomena, whatever we term it, which will enable him to understand in a general way what is going on within the body of the animal whenerer such a disturbance exists as is denominated the disease in question. After that each case must be studied on its merits. It will be clear that there is always room for the exercise of the greatest judgment in diagnosis, prognosis, and treatment.

The weakness of patent remedies in the light of such considerations must be plain. There can, in the very nature of the case, be, as a rule, no panaceas, no remedies 
of universal application. But what is possible is a mastery of the principles of physiology, pathology, and therapeutics; an acquaintance with symptoms as they group themselves in disordered animals; a knowledge of gross and microscopic lesions, etc.

It will be the aim of the remaining portions of this book to be a guide to the accomplishment of this in so far as space permits, though, of course, it will be quite impossible to teach, $a b$ initio, such sciences as physiology, pathology, and therapeutics, while we ever gladly point to them as the only true lights in scientific medicine, canine or other.

Relative Prevalence of Disease.-As a matter of fact, the greater number of dogs die within the first year of life, or, as in the human subject, during the period of very early youth, infancy, or puppyhood, as we term it, respectively; and for this high mortality parasites, mostly internal, and distemper are chiefly responsible, always including all possible complications and consequences (sequelae); to these must be added disturbances of the digestive tract and skin disease, as frequent though not commonly fatal maladies. A considerable proportion of puppies die of inflammations of the respiratory organs.

But if any large breeder of dogs were to look over his mortality records for a long series of years, he would, we venture to state, be able to place fully three quarters of all fatalities under debility, parasites, and distemper.

The first is scarcely a disease; it is rather lack of vitality, usually traceable to injudicious mating or inadequate care of the brood bitch. 


$$
1
$$



So that, to meet the needs of actual practice, whether as it falls to the breeder or the veterinarian, we shall discuss fully those conditions which are found in fact to be the cause of three quarters of all canine misfortunes, and only briefly, if at all, diseases of the rarest occurrence, and others requiring but common sense, general medical knowledge, and a knowledge of canine nature generally, to enable any one to cope with the conditions.

However, as it is more scientific and, in the end, better in practice, we shall consider the derangements of each main system of the body; though the reader is again reminded that all the systems are inseparably connected, and that every one is in sympathy with the other-a result to be explained chiefly through the nervous system, the blood, and the lymph which is derived from the blood and is the real food of the tissues.

In cities the veterinarian is very frequently consulted in regard to toy dogs-pampered pets-whose physical nature rebels against what their perverted instincts tolerate. Most of their ailments are traceable to the alimentary tract; and dieting, or positive abstinence from food for a time, proves most serviceable for them.

As before indicated, it will be assumed that we are dealing with pure-bred dogs, for any treatment that will be efficacious with them is still more likely to succeed with mongrels, that are both less liable to disease and more readily restored to health.

\section{DISEASES OF THE RESPIRATORY ORGANS.}

Anatomical and Physiological.-The respiratory tract is the area over which the gases that are concerned in the 
ventilation of the blood pass, and extends from the nostrils to the air-cells.

Briefly, the tract consists of a mucous membrane covered with epithelial cells, abounding in blood-vessels and lin-

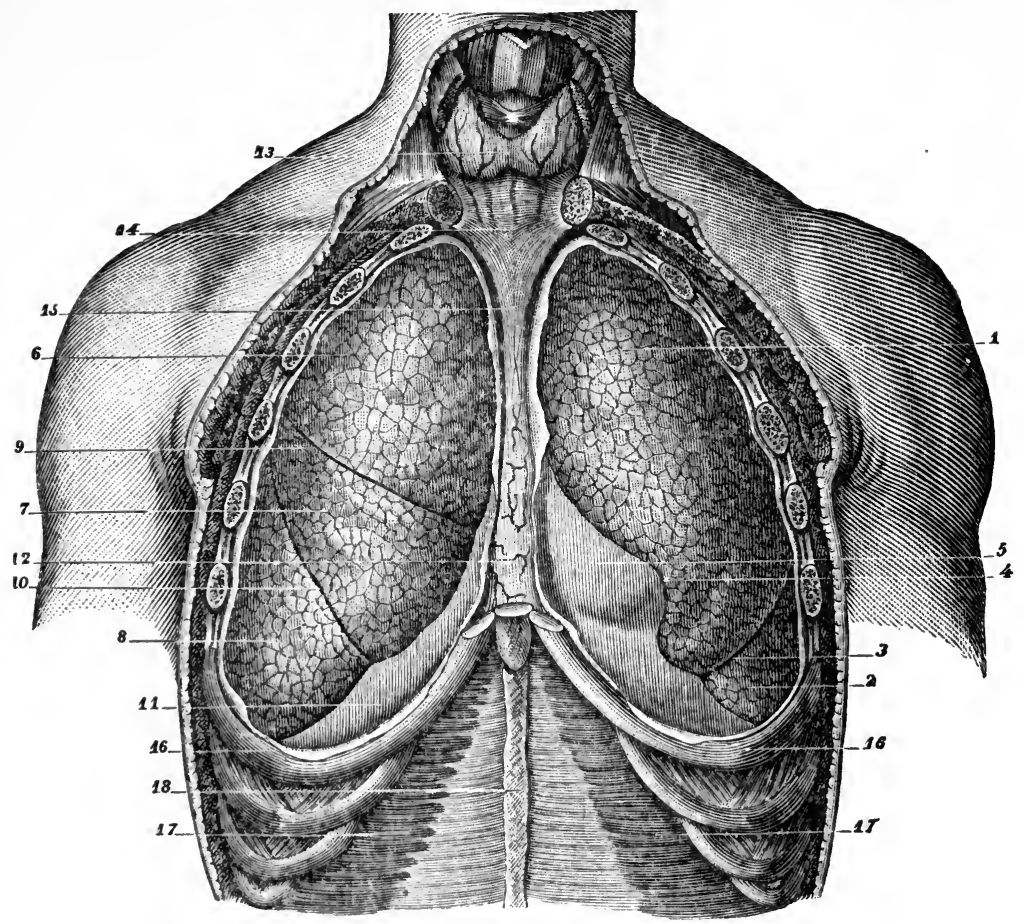

Fig. 12.-Lungs, Anterior View (Sappey).

1, upper lobe of left lung; 2 , lower lobe ; 3 , fissure; 4 , notch corresponding to apex of heart: 5 , pericardium ; 6 , upper lobe of right lung; $\tau$, middle lobe ; 8 , lower lobe; 9 . fissure; 10 , fissure; 1 . diaphragm ; 12 , anterior mediastinum ; 13 . thyroid gland; 14 , midille cervical aponeurosis; 15 , process of attachment of mediastinum to pericardium; 16,16 , seventh ribs; $1 \%, 1 \%$, transversales muscles; 18 , linea alba. Though this cut refers to the human subject, the relations of parts are substantially the same in the dog.

ing the nose, back of the throat, the roice box (larynx), the wind-pipe (trachea), its subdivisions (bronchi), and blend- 
ing with the essential lung membrane (air-cells, alveoli). The tubes constitute a tree-like framework, upon which the lung tissue proper is supported. The mass of this is elastic tissue. The atmospheric air rushes into the respiratory tract when the chest is enlarged by the muscles attached to

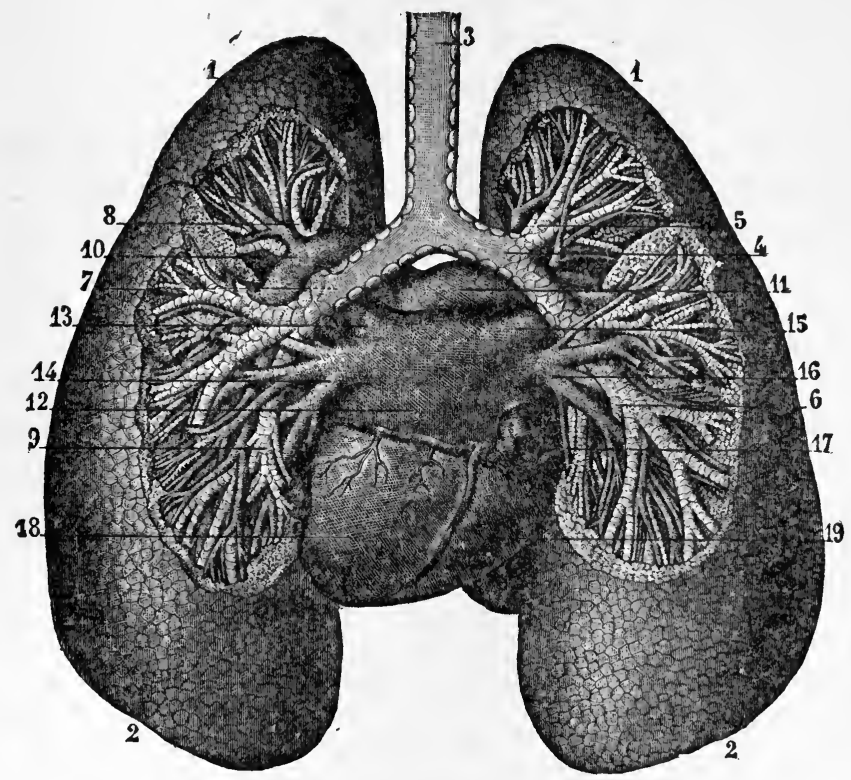

Fig. 13.-Bronchial Tubes and Lungs, Posterior View (Sappey).

1,1 , summit of luugs ; 2,2 , base of lungs ; 3 , trachea ; 4 , right bronchus ; 5 , division to upper lobe of lung ; 6 , division to lower lobe : 7 , left bronchus ; 8 , division to upper lobe ; 9 , division to lower lobe ; 10, left branch of pulmonary artery ; 11, right branch ; 12 , left auricle of heart ; 13 , left superior pulmonary vein ; 14, left inferior pulmonary vein ; 15 , right superior pulmonary vein ; 16 right inferior pulmonary vein; 17 , inferior vena cava; 18 , left ventricle of heart; 19 , right ventricle.

it, because the lungs everywhere fit its walls closely; and air is expelled when the muscles are relaxed, the whole to be explained on physical principles; but the action of the muscles is due to commands or nervous impulses originated 
in a collection of nerve-cells or center in that portion of the brain (medulla oblongata) just anterior to the spinal cord. This center is accessible to the blood, and may be influenced by nervous connections of the most extensive kind, so that the breathing reflects the changes that are taking place elsewhere in the body.

The essence of respiration is the interchange of the oxygen of the air and the carbon dioxide $\left(\mathrm{CO}_{2}\right)$ of the blood; but beyond that there can be no doubt that many poisonous substances are eliminated from the blood by the lungs.

The blood is exposed in the lungs in extremely minute blood-vessels (capillaries), which are everywhere distributed over the air-cells, so that the whole process may be said to be resolved into the exposure of blood to the air by the intervention of the cells that compose the capillary blood-vessels, the basement membrane of the lungs and the cells covering it-all of which are of the very thinnest.

The retention of the carbon dioxide and the poisonous excreta referred to stupefies and poisons the animal, while the withholding of oxygen from the blood starves the tissues, all of which constantly require it for their very existence, and gives rise to a feeling of distress which we can ourselves artificially produce by holding the breath. The oxygen is carried to all parts by the coloring matter of the red blood-corpuscles, which is lighter or darker according to the amount of oxygen it retains. Such facts enable us to understand many of the phenomena of inflammation and other affections of the respiratory tract.

The principal inflammatory diseases of the tract are laryngitis, bronchitis, influenza, pneumonia, and pleurisy. 
All diseases of the respiratory tract, notably all acute inflammations, have much in common. In all, from diminution of the breathing capacity or the aerating functions, the e is more or less disturbance in respiration, with a corresponding alteration in the circulatory system. In addition, as in all inflammations, there are febrile symptoms, while the whole system is affected by the retained poisonous products, lack of oxygen, etc.

The onset of all is favored, if not actually caused, by exposure to great and sudden changes of temperature, especially after exercise, or when sleeping in cold and draughty kennels.

Prophylaxis.-Good feeding, regular and sufficient exercise, comfortable and well-aired kennels. Wet, with cold, and, above all, draughts, are especially to be avoided.

Common Pathology.-This depends on the fact that there is in all these diseases an inflammation, so that there is more or less sudden arrest of secretion, with swelling of the mucous membrane, followed by excess of and altered secretion, and modified function generally.

Common Symptoms.-Rapid breathing and pulse, tendency to nausea at the outset, a chill, febrile symptoms, anorexia (loss of appetite), more or less distress or actual pain, altered physical thoracic signs, changed secretions, etc.

Prognosis.-Good, if not arising as complications of other diseases, and if the animal is not debilitated and the treatment be judicious, especially the hygienic surroundings and the feeding.

Treatment.-(For doses of medicines, see table at end of the book, and for formulæ, pages 235 and 236.) The indication in all is at the outset, and only in the stage of 
hyperæmia or congestion to attempt to abort the mischief. This is rarely successful, as the case is not usually observed early enough. But at the moment of chill, a laxative, a good dose of quinine with bromide of potassium, the application of the chest-jacket, to be presently described, and perhaps a little whisky, to be followed in an hour by Dover's powder, may cut short a threatened attack. This will not usually be successful, and the aim must be to favor the aeration and purification of the blood by the closest attention to the atmosphere surrounding the patient, which should be kept pure by frequent interchange of air. The temperature must be even, not less than $60^{\circ}$ to $65^{\circ}$ Fahr., and the air rather moist.

Draughts are fatal. To relieve pain, quiet the heart's action if rapid and strong, or support it if weak. Keep the temperature within bounds; administer a suitable diet, light usually at first, later very nutritious, but easily digested.

In this class of maladies the danger is from poisoning of the system by retained products, both natural, which are not eliminated as usual, and altered secretions; the heart is overworked, and death often occurs, sometimes suddenly, from cardiac failure, so that the pulse must be carefully watched. The rate of the heart's action is not of so much importance usually as its character.

When the heart is weak, tonics, and especially digitalis, with alcoholic stimulants, administered in small doses but often, are called for. The animal's strength must be maintained at all costs. If it will not take food, the latter, in the form of concentrated extracts or of the nature of fluid beef, must be given; also eggnog, etc. 
On stimulants, hygiene, and feeding must the reliance be placed in extreme cases. Drugs are of subordinate value.

Convaléscence is assisted by gentle exercise, sunshine, massage, amusement, tonics, cod-liver oil, etc.

It is well to keep records of the respirations and pulserate, as any very markedly disturbed ratio should arrest attention, and is by no means a good sign.

Some additional remarks on each disease, to enable the reader to grasp the salient features, will now be better appreciated.

Influenza.-This disease, long known among men and horses as an epizoötic, is rarer among dogs, and is of very varying degrees of severity. There is an inflammation of the mucous membrane of the respiratory tract, beginning usually in the nose and extending downward, sometimes, especially in the debilitated and old, ending in pneumonia.

The symptoms are altered breathing, frequent sneezing, dryness, and burning sensation (if we may judge by man's experience), with high temperature and great prostration.

Diagnosis.-The eyes soon become affected. The watery secretion from the nose and eyes, and the sneezing, with the fact that the disease generally goes through an entire kennel, will render the diagnosis easy.

Prognosis.-Favorable, if pneumonia does not intervene, at least in vigorous animals.

Treatment.-Quinine, phenacetin, etc., with bromide of potassium at the outset; attention to temperature of the dog's apartment and other hygienic conditions, to food, etc.

If much depression, stimulants. Convalescence must 
be carefully watched, tonics, especially nux vomica and strychnine and cod-liver oil, which latter may be considered as a food as well as tonic, being very useful.

Acute Laryngitis is not so common by itself in the dog as in the horse and in man, unless that very mild form associated with a common cold; but it may result from cold, from chemical or mechanical injury, as from tugging at a chain, etc. Inflammations of other parts often extend to the larynx.

Diagnosis.-There may be difficulty in swallowing, but usually an alteration in the voice of the dog, with more or less husky cough, tenderness on pressure, etc., establish the diagnosis.

Prognosis.-Favorable if œdema (thickening of tissues by effusion of liquid into them from the blood-vessels) does not set in.

Treatment.-Good hygienic conditions, as indicated above. Simple cases require nothing more.

The bowels to be kept freely open. Counter-irritation by means of turpentine, coal oil, stimulating liniments, or St. George's paint, over the upper trachea and the larynx, will tend to relieve and prevent the inflammation spreading to the parts below.

Inhalation of medicated vapors, though most useful, is not easily carried out with the dog; but he can be much helped by having his food given in small quantities in liquid and semi-liquid form, very hot; and the air may also be kept moist and warm with steam. Any attempts to apply hot fomentations to the dog are apt to be frustrated, but in an extreme case they should be tried.

As there is usually some pain and cough, sedatives may 


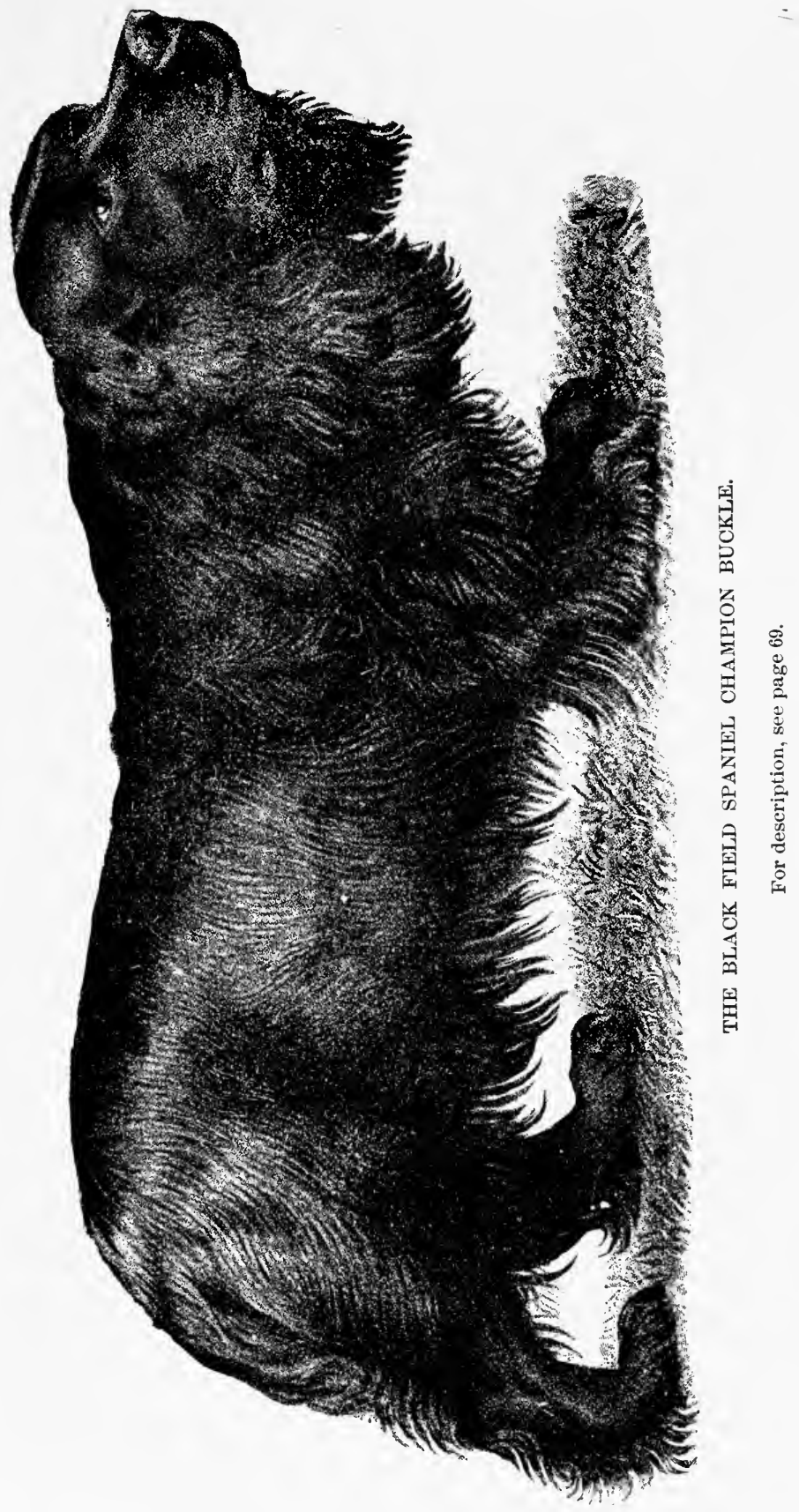




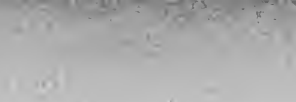


be given in the form of conium, hyoscyamus, belladonna, and especially Dover's powder.

Certain oils and balsams, as copaiba, balsam of Tolu, etc., seem to exercise a beneficial effect.

If suffocation threaten from swelling, tracheotomy should be performed-an operation to be avoided, if possible, on account of all wounds about the neck of the dog tending to bleed excessively.

Should the disease become chronic, various applications found useful in human practice may be tried with the dog, though to place a solution with any degree of certainty in the larynx itself is not always possible. A brush with handle bent at a right angle will be most serviceable. A solution of chloride of zine in water to the extent of ten to forty grains to the ounce, and then diluted one half with glycerin, is excellent; but at first great care must be exercised lest glottic spasm be produced.

Pleurisy.-The inner surface of the thoracic walls, the upper aspect of the diaphragm, and the lungs themselves, are covered with an elastic smooth membrane, lubricated in health with a small quantity of fluid secreted by its own investing cells.

In pleurisy or inflammation of this covering it becomes dry, the friction of the opposed surfaces gives rise to pain, and sometimes to a rough grating or crackling sound-" friction sound"-which is diagnostic.

Causes.-Similar to those producing other inflammations of the respiratory tract, but, in addition, various conditions of the system, as rheumatism, kidney disease, blood poisoning (septiccemia), etc. It is a frequent complication or accompaniment of other diseases of the lungs when it is 
not easily detected. Various injuries, as fracture of the ribs, also induce it.

Pathology.-Dryness of the membrane, followed by increased secretion of an altered material, either permanently fluid or with a tendency to coagulate-"plastic lymph." The fluid may or may not be absorbed, and the semi-solid matter disappear or become organized and cause adhesions, limiting the action of the lungs, which is one of the gravest results ; or the fluid produced may be purulent-also a very serious state of things.

Prognosis.-As a simple disease and not a complication, with but little effusion, and in the absence of pus, the prognosis is good; otherwise uncertain.

Diagnosis. - The differential diagnosis is between bronchitis and pneumonia, chiefly the latter.

The pain, the shallow, quick, catchy breathing, the anxious expression, possibly tenderness on percussion, and especially the "friction sound" heard on auscultation, with absence of dullness at the same time, make the diagnosis pretty certain.

The temperature is not usually as high as in pneumonia.

Of course, in the latter disease we get at the outset more or less dullness and altered respiratory sounds, which, as the disease progresses, become more pronounced, till there is positive "wooden dullness" on percussion, with the total absence of respiratory sounds over that region, and intensified sounds with "blowing" or "bronchial" breathing elsewhere on the affected side.

The difficulty in diagnosis is only in the earliest stage, before the physical signs of pneumonia are well estab- 
lished. Later, if there be dullness in pleurisy, owing to fluid, it is shifting in extent, and varies with the position of the animal.

In bronchitis we usually soon hear sounds (râles) of some sort on auscultation, which may be present in pneumonia, though not without the signs of solidification.

Percussion and Auscultation.-Percussion should precede auscultation. We believe that the best results will follow the practice of very light percussion without the help of instruments, placing two or three fingers of one hand flat on the chest wall and striking quickly and lightly with one or two fingers of the other, so that the blows fall evenly and but once on a single spot, the hand working only, and not the arm. Rapid comparison can thus be made and slight differences noted. It is a good plan to percuss corresponding areas on both sides, for each animal must be a standard for itself (its own norm.).

It is well to learn to listen with the ear applied to the chest, interposing only a thin piece of cotton, as well as with a stethoscope. It is often a great advantage to use the modern flexible binaural stethoscope. Apart from hearing more distinctly, in the case of dirty dogs infested with vermin the advantage is obvious. Shy animals are also less disturbed, not to mention the absence of the necessity for stooping, etc.

One who has learned the normal percussion and auscultation sounds by examination of healthy dogs of different breeds and sizes, will not find much difficulty in soon becoming familiar with the main departures in disease, while mere verbal descriptions alone are of little real service. 
Treatment.-Much as in other diseases of the chest as to diet, hygienic surroundings, etc.

Pain must be relieved at once with an opiate, say fifteen grains of Dover's powder for a dog of fair size.

Counter-irritation is decidedly useful-e. g., an application of turpentine, followed by the chest-jacket (see p. 226); a mild aperient, and aconite to quiet the circulation, may all prove useful in this stage of the disease.

Pleurisy with effusion is dangerous in proportion as the lung space is replaced by fluid and the vital organs displaced. Absorption should be facilitated by counterirritation, and every measure that will improve the general health.

Some like to administer small doses of calomel, others iodide of potassium and digitalis, to stimulate the kidneys to do extra work, carry off more fluid from the blood, etc.

But if within a reasonable period the fluid does not disappear, and especially if it tends to increase, or if it becomes purulent, constituting empyema, it must be drawn off either with a small trocar and canula ("tapping") or an aspirating needle; but in no case very suddenly or all at once, for fear of heart-failure. The puncture should be made low and far back, and with the position of vital organs in mind.

Convalescence may be encouraged by the best of food, tonics, etc.

Chronic pleurisy, either as a localized subacute inflammation or with effusion, which is most common and most serious, is not of very frequent occurrence in dogs of a good constitution.

The symptoms are much as in the acute form of the 
DISEASES OF THE RESPIRATORY ORGANS. 221

disease, except that the fever, pain, etc., are not so marked.

Treatment is to be directed especially to the removal of the effused fluid, either by natural absorption or "tapping," and the greatest attention to the general health of the animal.

Bronchitis.-This disease is an inflammation of the mucous membrane of the bronchial tubes.

When the smallest tubes are involved the affection is termed capillary bronchitis, most common in very young, very old, and debilitated subjects, and so is by far the most dangerous form.

Pathology.-There are swelling and dryness of the lining membrane of the tubes, followed by a mucous discharge in excess, which is apt to become to a greater or less extent purulent.

The cells lining the membrane die, are thrown off and expectorated in the case of man. As dogs do not properly expectorate or cough to much purpose, they are at a great disadvantage. However, they frequently vomit when coughing, which tends to expel the excessive and altered discharge, and furnishes a hint for treatment.

Prognosis.-Favorable if not associated with gangrene or death of lung tissue, abscess, dilatation of the tubes, and if the strength of the animal be good.

Symptoms.-More or less cough, moist sounds on auscultation, with sympathetic congestion and catarrh of the eyes and nose.

Treatment.-At the outset an emetic of twenty grains of sulphate of zinc, which, if not effective, in a few minutes may be followed by two to four drachms of wine of 
ipecacuanha, a laxative, attention to general comfort, and to the ventilation especially.

When the cough is dry a choice of some of the following in combination may be made, viz.: Ipecac, squills, ammonia, spirits of chloroform, hydrochlorate of apomorphia, paregoric, morphia, potassium cyanide, etc. Later, ammonium carbonate, syrup of Tolu, or senega may. replace some of the preceding. Possibly remedies of this character may be required; but the sooner drugs can be dispensed with the better, for they all tend to disorder the digestive tract. Quinine, iron, nux vomica, and other vegetable bitters may be useful after the acute stage has passed.

In chronic bronchitis, tonic treatment, including codliver oil, is of great importance.

A moderate allowance of alcoholic stimulants, as wine, whisky, or brandy, is often called for when bronchitis threatens to exhaust the animal, or when it overtakes a dog already enfeebled by disease. Supporting treatment, with an emetic at the outset, will be best in the capillary form of bronchitis.

In all forms of the disease counter-irritation and the chest-jacket are very beneficial.

Verminous bronchitis, owing to the presence of parasites in the bronchial tubes, is a rare and unmanageable disease, generally leading on to a fatal result. An attempt should be made to dislodge the worms by emetics, inhalations of the fumes of burning tar, etc.

Pneumonia is an inflammation of the substance of the lungs, and may be confined to a portion of one lobe or may include the greater part of both lungs. Such exten- 
sive inflammation is not common, and is almost of necessity fatal. Pneumonia is divided into lobar (croupous, diffuse) and lobular (patchy, catarrhal). In the latter, only limited and usually scattered portions of the lung tissue are involved. This form is most common as a complication of bronchitis, and especially when it arises in the course of other diseases.

Causation.-The onset is favored by wet, cold, anything inducing a chill, etc. Some cases are almost certainly due to a microbe, and the disease then seems to be infectious. It will be safe in treatment to regard all cases as infective.

Pathology.-In lobar pneumonia we have a typical inflammation with hyperæmia, soon followed by escape of red and white corpuscles from the blood-vessels, and effusion of a coagulable fluid with increase (proliferation) of the lining and other cells of the tissue of the lung. The portion of lung involved gets red and solid, when removed after death, sinks in water, cuts firm, and looks not unlike liver. This is the stage of red hepatization, and is succeeded, when the course of events is typical, by a fatty degeneration of the morbid products, a stage known as gray hepatization. Resolution is the return to the normal by the absorption or removal of this foreign material, a natural state of the blood-vessels, etc. Untoward results may occur, abscess or purulent infiltration-i. e., breaking down of the lung tissue-and gangrene or local death, usually followed by breaking down of a portion of the lung. Both the latter conditions frequently prove fatal. With pneumonia there is usually more or less bronchitis, and often pleurisy. 
Prognosis.-As a matter of fact, pneumonia is a disease that carries off a considerable proportion of the canine race, both as a primary affection and as a complication and sequel of other affections, which is probably owing to its attacking weakly animals when a primary disease, to neglect at the outset, and to indiscreet treatment; while during the course of and subsequent to other diseases the constitution is naturally often unable to bear the additional strain.

Much in the prognosis will depend on the amount of lung tissue involved, the condition of the heart, and the patient's vitality and resisting power.

Symptoms.-Usually pronounced. Dyspnœa (distressing breathing), characteristic anxious facies or expression, injected (red) eyes, dry and hot (not always) nose, and most characteristic attitude. The animal sits on his haunches, with his head extended and mouth open, evidently suffering from lack of oxygen. If the dog attempts to lie down, he keeps the head supported high on some object. In extreme cases he may be unable to lie down at all. Percussion reveals a more or less dull sound over the affected area; auscultation, fine crackling sounds. However, neither of these may be very distinct.

If pleurisy be present, a friction sound is to be heard (crepitant râles), and this friction of dry surfaces explains the pain in great part, if such exist.

The attack is usually ushered in by a chill-a symptom which should always be inquired for and to which the greatest importance should be attached, as invariably indicating that something serious is at hand in any animal the subject of it. 


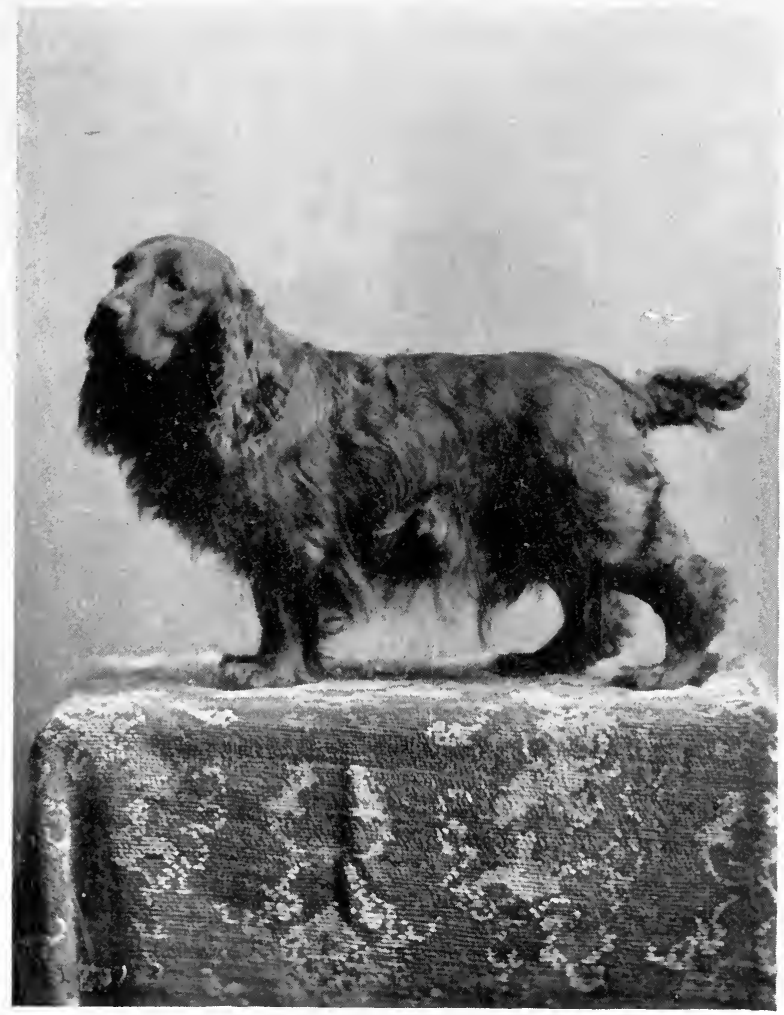

THE BLACK COCKER SPANIEL CHAMPION BLACK DUKE.

For description, see page 69. 

The pulse is usually rapid, and disturbance of the pulse-respiration ratio is apt to occur. Instead of the normal four to one, it may be two to one, or less.

The temperature may reach $104^{\circ}$ to $106^{\circ} \mathrm{Fahr}$., with other indications of fever.

In pneumonia too much reliance must not be placed on physical signs, as there may be very grave disease without the former being at all well pronounced.

But prostration, a weak, irregular, very slow or very rapid cardiac action, or greatly disturbed pulse-respiration ratio, are indications calling for a cautious prognosis and the most watchful treatment, especially if with these there be much dyspnœa or cyanosis (blueness of mucous membranes, etc.), indicating that the blood is being very poorly ventilated.

Less frequently than in man does the dog cough up the characteristic rusty sputum-i. e., mucus, etc.-with blood enough to color it. When this is seen, the diagnosis of pneumonia is clear.

Diagnosis.-The altered respiration, the position of the animal, the dullness on percussion, etc., usually suffice to establish the diagnosis in lobar pneumonia, by far the commonest form as a primary disease.

The patchy or lobular form is more difficult to make out; but if there be limited areas of dullness, or more diffuse but ill-defined dullness on percussion appearing during an attack of bronchitis or other disease, this form of pneumonia is to be suspected.

Treatment.-The greatest difference of opinion prevails on this subject both as regards human and veterinary practice, some even maintaining that when no treatment 
whatever beyond careful nursing is adopted the results are just as favorable.

While there may be some truth in this so far as typical cases are concerned, it is not a safe doctrine to teach to the young practitioner, nor a position with which medicine should be content even if the assertion be true, which we very much doubt. Directly opposite has been the practice in regard to local applications, some recommending them warm and some cold.

But as a matter of experience, it is found that it is unwise to apply either kind to dogs under ordinary circumstances. Heavy poultices are apt to shift, the dog is restless, and in changing any sort of moist applications the animal is apt to get chilled, so that this mode of treatment may be considered quite unsuitable for dogs. The same may be said of cold applications.

The chest-jacket, before referred to, we have found invaluable in all chest diseases. The object is to have a close-fitting coat or jacket, which shall absorb the moisture from the animal's skin and protect it from variations in the external temperature. The exact construction is of minor importance provided that it is of even thickness, fits closely, and can be kept in place. Dogs do not usually attempt to remove such a comfortable body bandage.

In winter it may be made of two layers of flannel or horse blanket, with or without padding of cotton-wool quilted in; and it becomes still more effective if it fit neatly and be sewed on the dog in such a way as to lie close and feel comfortable, the object being to prevent access of cold air. For summer use the whole may be 
less warm, but, as a matter of fact, pneumonia is much less common at this season.

Openings may be made for the fore-legs, or the whole may be attached by strips of cotton in front and firmly stitched over the back. It is well that it extend far back over the loin. Closeness of fitting without being so tight as to embarrass the breathing is important, both to preserve it in position and to prevent the access of cool air. Often the dog will breathe easier at once when this dressing is applied.

When there is pleurisy especially, it will be advisable to use some form of counter-irritation first. Turpentine answers very well, and leaves no stain, as does iodine.

Blistering is never called for. It is the writer's opinion that under no circumstances whatever in any acute disease (if ever) is blistering of the dog justifiable. The amount of pain and irritation is out of all proportion to any possible good in an animal with so responsive a nervous system as the dog's. Counter-irritation is often useful ; blistering never.

The hygienic surroundings should be of the best, the air being frequently changed, the temperature even and not above $60^{\circ} \mathrm{Fahr}$.

The food must be light at first, unless there be marked prostration, and largely fluid or sloppy while the fever is high.

If the pulse is very rapid and full, tincture of aconite in frequently repeated small doses may be useful, watching the pulse carefully, especially if Fleming's tincture be used. Some practitioners are opposed to this treatment.

If there is evidence of pain, or if cough is troublesome, 
a little paregoric, or, better, Dover's powder, on account of its favoring the action of the skin and kidneys, may be given. Bleeding has been recommended in very sthenic cases.

Chlorate of potassium has a good reputation in diseases of the respiratory tract, and is favorable, it is thought, to the oxidation of the blood: As it is somewhat depressant to the heart, its action should be carefully watched.

In the early stage the author likes to give, in a gelatin capsule, powdered bromide, acetate, and chlorate of potassium with tincture of aconite. After this is swallowed, the dog may be given water to drink to dissolve and dilute the dose. Being thirsty, he is only too glad to get the liquid. He may relish buttermilk or sour milk, and it will be useful at this period. At night fifteen grains of Dover's powder, with a like quantity of bromide of potassium, in capsules, will be useful in securing rest.

It is important not to give aconite if the heart be weak, even if rapid, and it should be stopped if it does not within a moderate period quiet the circulation, as a depressant action may set in later and prove dangerous.

Death in pneumonia is nearly always by heart-failure, and this organ must therefore be most carefully observed throughout.

Assuming that resolution has begun, the general strength is to be maintained. If the appetite is not good and the temperature is not high, vegetable bitters-as nux vomica, cinchona, gentian, etc.-will be useful; also quinine, citrate of iron and quinine, etc.

During convalescence the treatment already recom. mended for other diseases of the respiratory system is suitable. If the temperature runs very high, quinine in 
large doses, antipyrin, or phenacetin, will meet the views of some. One large dose of ten to fifteen grains of quinine, with twenty grains of bromide of potassium at the outset, may be worth a trial; but repeated doses of the above remedies are of very doubtful efficacy.

If the disease is of a low type from the first, with evidences of weakness or positive prostration, the chief reliance must be on good feeding and alcohol, with such stimulants as ammonia, strychnine, strong coffee, caffein, etc.

Whisky or brandy, given in doses of a teaspoonful or less with fluid beef or eggnog if the dog refuses nourishment, or diluted with water, given simply as medicine, often produces the happiest effects. In fact, in some cases at the outset a small dose of whisky has seemed to mitigate the symptoms at once. Of course, with the bounding pulse and a generally sthenic type of the disease this is plainly not indicated.

Certainly if the dog will not take nourishment it must be forced on him, with as little exhaustion of his strength as possible.

If the heart becomes very weak or irregular, resort must be had to digitalis, say five drops of the tincture every two hours for an adult dog of medium size, watching its effects carefully. It is a most valuable remedy in skillful hands. It may be combined with carbonate of ammonia and some vegetable bitter, and, if quinine has not already been given freely, small tonic doses (one to two grains) may be given three times daily. Quinine is a well-tested remedy for dogs and men; but, in the case of dogs especially, it must not be given without duly guarding against a depressant action. 
As in the case of man, unpleasant head symptoms may be obviated by giving with this drug ten to twenty grains of bromide of potassium, according to the dose of quinine, the age, etc., of the dog; but it is somewhat depressant.

Asthma.-Spasmodic asthma, so common in man, is of rather rare occurrence in the dog. This form of the disease is the result of more or less local constriction of the bronchial tubes, owing to spasm of the unstriped muscular fibers found in their walls.

The causes inducing it are various, as certain atmospheric conditions, certain mechanical and chemical irritants in the form of dust, gases, etc. It may also be excited by parasites in the intestinal tract, and more frequently by their presence in the bronchial tubes themselves. It is sometimes traceable to dietetic errors.

The other form of asthma, sometimes spoken of as "congestive," is due to a thickening of the mucous membrane of the air-tubes from congestion, as in heart-disease, from bronchitis, etc., and to the lessening of the caliber of the tubes by the pressure of tumors, etc., when the symptoms may be described as asthmatic rather than as arising from asthma as a disease.

Asthma is not common in young dogs; but more or less dyspnoa of an asthmatic character is not at all infrequent in old, fat, lazy dogs permitted to lie about the house and feed to excess.

Prognosis.-As to complete cure, unfavorable; generally relief can be given. The disease of itself is rarely if ever fatal.

Symptoms.-Loud, wheezy respiration, labored breathing, characterized by prolonged expiratory efforts, dilated 


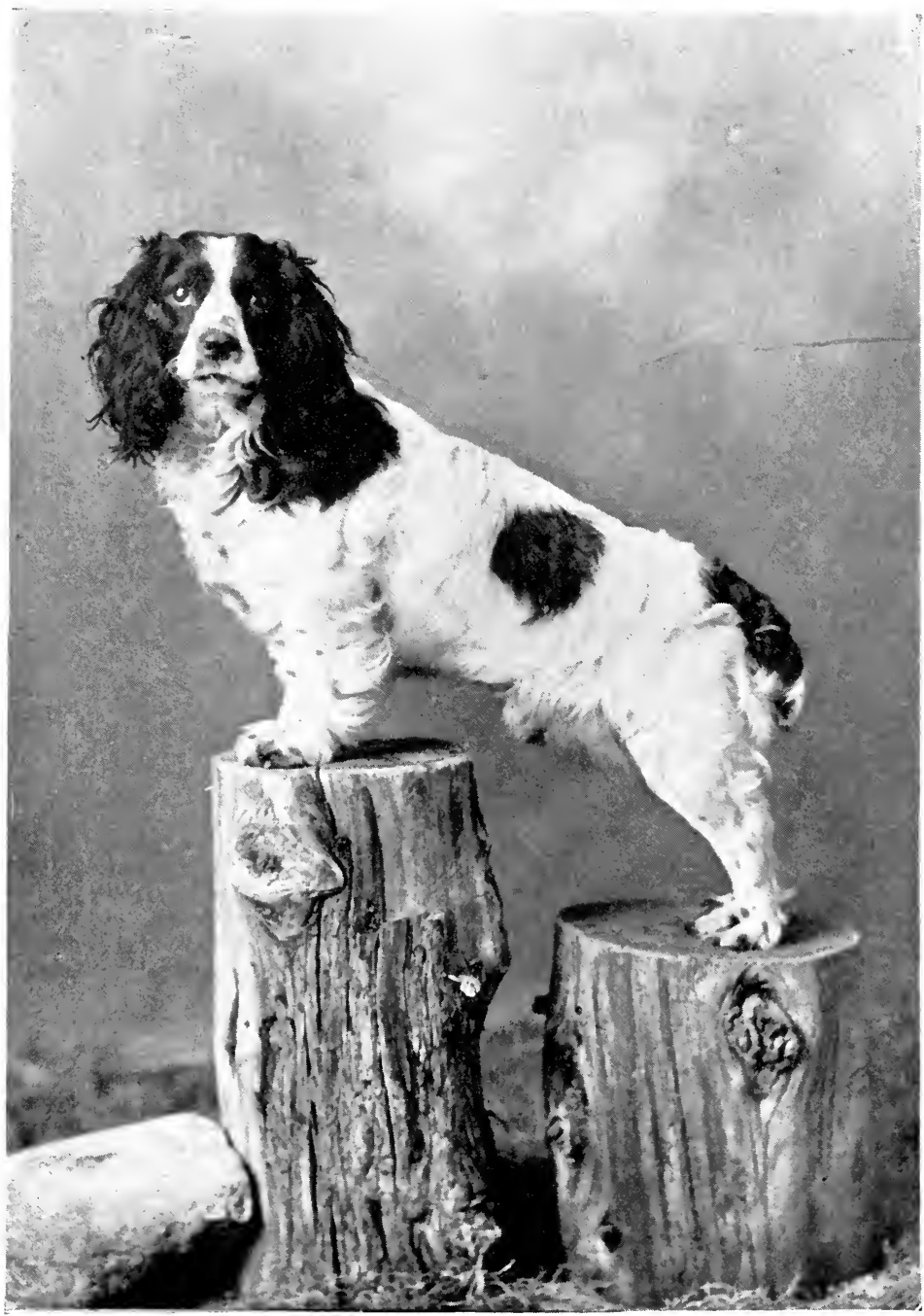

THE COCKER SPANIEL OTHELLO.

For description, see page 69 . 
nostrils, perhaps open mouth, with numerous evidences of imperfectly aerated blood.

Diagnosis.-Is very easy, but the cause is not so readily made out in all cases.

Treatment.-In the spasmodic form the dog should be removed to a small chamber, in which tar or kindred substances may be burned, especially if the symptoms arise in connection with bronchitis.

Paper dipped in a solution of saltpeter and tincture of stramonium and then dried may be burned with relief to the patient sometimes.

If the $\mathrm{dog}$ be gross and overfed, his diet must be cut down and simplified. This is a clear case for feeding only once a day.

The liver and digestive organs generally may be benefited by the timely administration of a compound cathartic pill at night, followed by Epsom salts in the morning, while the compound rhubarb pill may be given daily for a time.

When associated with bronchitis, the indications are to treat that disease, of which it is but a sort of superadded symptom. In the case of tumors, removal, if possible, is indicated. If this can not be done, attention to the general health and condition of the dog may alleviate the distress.

Iodide of potassium in small doses, gradually increased and kept up for a considerable time with intermissions, may effect a complete or partial cure. The dose may be from one to five grains, though some dogs do not tolerate this remedy any better than some people.

Tuberculosis.-This, in pulmonary or other form, is very rare in the dog, though it may be induced. When it 
occurs it is to be recognized by wasting, altered respiration, cough, etc.-in fact, the same symptoms as in other animals, while the treatment must be on similar lines also. For dogs to swallow the sputa of consumptives is dangerous.

\section{LOCAL AFFECTIONS OF THE NASAL PASSAGES.}

Nasal Catarrh.-Sometimes, though rarely, as the result of a "cold," more frequently of a succession of "colds," in dogs badly kenneled, an excessive discharge of mucopurulent matter from the nose results, and is an indication of a relaxed and weakened if not a low inflammatory condition of the membrane lining the nose. It is apt to follow distemper, and to improve or get worse as the dog's general health varies.

Very often the mucous membrane covering the front of the eyeball and the inner surfaces of the lids (conjunctiva) partakes sympathetically (reflexly), or as a result of the original inflammation of distemper, etc., in the catarrhal condition.

If unchecked, the nasal catarrh may lead to ulceration of the soft parts of the nose or to inflammation of the bones of the organ, with resulting death of part of the bone (necrosis, caries); or the secretion may become altered, or be retained and give rise to a most offensive smell. From such inflammation, eatarrh, etc., nasal polypi or growths of a highly vascular character occasionally arise, and may so obstruct respiration, or cause such disturbance generally, as to demand treatment.

Acute catarrh when not associated with distemper does not usually require local treatment in the $\operatorname{dog}$, as it is transient. 
When a catarrh does not yield to treatment in a moderate period, the dog should be anæsthetized and a care ${ }_{7}$ ful examination of the nasal passages and mouth made by the help of bright sunlight or a reflecting mirror and a speculum.

If growths are found, they should be at once treated either by burning off with a strong wire at a bright-red heat, or torn out, if larger, with a wire snare, and the bone cauterized with the hot wire as before, which usually also arrests all hæmorrhage.

These chronic eatarrhs tend to undermine the health of the animal and to become less amenable to treatment the longer neglected.

The nose must be washed out with a syringe and warm water, to which a little carbolic acid (about five grains to the pint) has been added; or, better still, if the dog can be kept quiet, a spraying apparatus may be used, though, considering the length of the dog's muzzle, this is somewhat difficult to manage.

For a spray such a formula as the following will prove very useful :

B Sodæ biborat............... $3 \mathrm{j}$;

Sodæ $\operatorname{carb...................~} 3 j$;

Acid. carbolic................ gr. v;

Glycerinæ................. $\xi \mathrm{j}$;

Aquæ.................. ad $\xi$ viij.

\section{Inject.}

Often the cleansing in this manner, faithfully carried out, will effect a cure. If not weak, astringent solutions may be sprayed up the nostrils or carefully injected by a syringe; but strong applications do only harm. 
Sulphate of zinc, about two to six grains to the ounce, half water and half glycerin, is one of the best.

When there is much foulness, a little boracic acid or iodoform may be blown up to advantage.

The external parts must be protected from the irritating discharge or a form of eczema will result. For this purpose the oxide-of-zinc ointment, or one containing a little iodoform, etc., will be useful.

Attention to the general health is very important, tonics-as quinine, iron, phosphates, cod-liver oil, etc.being demanded, and proper evacuations of the bowels, etc., indispensable.

A dog long affected with catarrh is apt to get into a dejected condition, and his psychic treatment is not the least important.

Ozæna is the term applied to a form of catarrh with a fetid, more or less bloody and purulent discharge, which tends to irritate all parts with which it comes in contact.

If it does not yield to the treatment for chronic catarrh, a careful examination of the nasal passages is called for to ascertain whether there is not disease of the bones, etc. The external openings of the nose should be protected with some antiseptic, as iodoform ointment or vaseline. This is also a good application internally, or iodoform powder, etc., may be blown up the nostrils.

Catarrh may also be due to parasites.

IIints as to Formula and Administration of Medicines in the Treatment of the Before-mentioned Diseases. - To economize space, we shall employ now and later the following commonly used abbreviations : $\mathrm{B}$ for prescription, recipe; gr. for grain; 3 for drachm; 3 for ounce; 
ft., make ; mist., mixture; pil., pills ; gtt., drops ; ungt., ointment; sig., directions; aquæ, of water; dr., drachm; oz., ounce.

It will be assumed that an adult dog of say forty to fifty pounds is to be treated.

To relieve pain, Dover's powder, in ten-to-fifteen-grain doses, morphia sulph. in pills of one eighth to one half grain, paregoric in doses of one half to two drachms. Laudanum is effective, but more apt to nauseate. All preparations of opium, except perhaps Dover's powder, tend to check secretion-a very grave objection in most diseases of the chest.

To moderate the heart's action and mitigate other symptoms in pneumonia, etc. :

B Tinct. aconit. $\operatorname{rad} . \ldots \ldots \ldots \ldots \ldots, 3$ ijss. ;

Pot. bromid............... $\xi_{\text {ss. }}$;

Pot. chlorat................ $\xi$ ss.;

Pot. acetat................ $\xi$ ss.;

Syrup. aurant................ $\xi \mathrm{ij}$

Aquæ................. ad $\xi$ viij.

Ft. mist.

Sig. : A dessertspoonful every two hours.

As before stated, it is easier to give most remedies not in solution, as assumed above, but as powders in gelatin capsules, with the tinctures, etc., dropped on the other ingredients, offering the dog water to drink just afterward, or, if he will not take this, a little milk.

N. B.-If Fleming's tincture of aconite is used, the dose must not exceed one drop and the effect be carefully watched. In the later stage of pneumonia, ammon. chlorid. may be substituted for pot. bromid. in the above formula. 
In troublesome cough, potassium cyanide in very minute doses (gr. $\frac{1}{16}$ ), hydrochlorate of apomorphia, or spirits of chloroform, may be used when opiates are contra-indicated, as well as tinct. hyoscyami or conii.

Useful in acute bronchitis :

B Spt. chloroformi............. ₹ ss.;

Vini ipecac............... $3 \mathrm{iij}$

Tinct. scillæ.............. $3 \mathrm{v}$;

Syrup. aurantii.............. $\xi \mathrm{ij}$

Aquæ................. ad $\xi$ iv.

Ft. mist.

Sig.: Teaspoonful in a little water every two to four hours.

Of use in the later stages of acute bronchitis and in chronic bronchitis :

B. Spt. ammon. aromat........... $\xi \mathrm{ij}$;

Tinct. senegæ.............. $\xi$ ss.;

Spt. eth. nit................ $z^{i j}$

Spt. chloroformi............. z $\mathrm{j}$;

Syrup. aurant................ $\xi \mathrm{ij}$

Aquæ................ ad $\xi$ viij.

Ft. mist.

Sig. : Dessertspoonful every two to four hours.

In chronic laryngitis, balsam of copaiba may be given in doses of ten to fifteen drops in mucilage, olive oil, raw white of eggs, or placed in capsules.

When iodide of potassium is to be administered it is well to combine it with a vegetable bitter, as tinct. gent. co.

In asthma, such a prescription as that recommended for chronic bronchitis may prove useful.

Tonic Treatment.-We again remind the reader that 
tonics had better be given some time after food-i. e., not on an empty stomach. Pill form answers admirably. Dogs often lick up cod-liver oil and phosphates (e. g., Parrish's syrup) very well when stirred up in a little milk.

\section{DISEASES OF THE BLOOD AND THE CIRCULATORY SYSTEM.}

The blood consists of an albuminous fluid in which colored and colorless cells abound, the latter in relatively scanty numbers. This fluid, owing to the arrangements of the circulatory system, is conveyed to every part of the body, but never during health actually escapes from the containing vessels

The principal function of the red cells is the conveyance of oxygen. The blood as a whole is at once the source of supply for all tissues and the medium of removal of all waste-i. e., all waste, gaseous and other, sooner or later gets into the blood and is carried to those various organs that serve to eliminate the different harmful constituents.

Nature, then, it would seem, is constantly striving to maintain the equilibrium of the blood. When much is taken from it the nervous system becomes conscious of it, so to speak, and hunger for food or oxygen is the result; an attempt is made to furnish food and thus renew the blood from the digestive supplies, while the lungs do the work to furnish oxygen. It thus appears that there is a very close relationship between the respiratory, circular latory, and digestive systems. (Fig. 14.)

But in reality the tissues are not nourished directly by blood, but by lymph, which may be regarded as an albu. 
minous fluid analogous to the fluid part (plasma) of blood secreted by the capillaries, according to the needs of the tissues in any particular region. This fluid $($ lymph), when

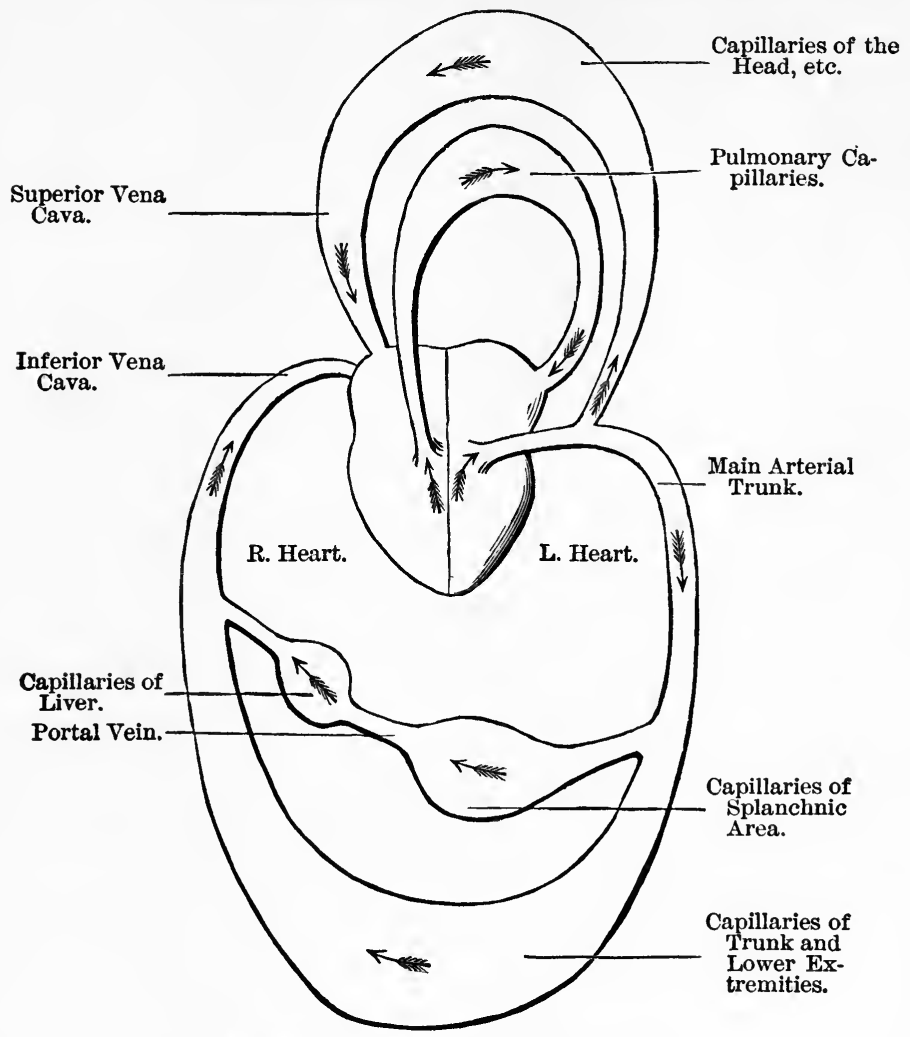

Fig. 14.-Diagram of the Circulation.

The arrows indicate the course of the blood. Though the pulmonary, the lower and the upper parts of the systemic circulation are represented so as to show the distinctness of each, it will be also apparent that they are not independent. Relative size of different parts of the system is only very generally indicated.

it has served its purpose, is in great part removed by another set of vessels, very like blood-vessels, known as lymphatics. It is also likely that not a little is taken up 
by the capillaries themselves, though of this we have not very much positive evidenee.

It is worth while to bear in mind, too, that the blood and the blood-vascular system are developed in the fœtus together as parts of one whole. A knowledge of these cardinal physiological truths makes mueh in the eausation, pathology, and treatment of disease less obseure.

\section{BLOOD DISEASES.}

It is likely that the white eorpuseles become relatively too numerous in eertain conditions in the dog as in man; but little, however, is positively known on this subject, and there is ample room for investigation of the blood of this animal in disease.

Anæmia-which implies an imporerishment of the blood, especially as regards the quantity or quality of the coloring matter (homoglobin) of the blood as eontained in the red cells-oecurs in dogs as in other animals.

It results under unfavorable surroundings, as a badlylighted, damp kennel, in ill-fed animals, in those whose nutriment is abstraeted by parasites, in bitches bred too frequently and exhausted by suckling, ete.

Pallor of mueous membranes, as well seen in the mouth, makes the diagnosis certain.

Treatment.-Remove the cause and substitute the best eonditions possible; feeding on the most nutritious food, including raw flesh, and the administration of eertain tonics and alteratives. As the eoloring matter of the blood eontains a eertain proportion of iron, on which its vital properties largely depend, this mineral, in the form best suited to the animal, is indieated. 
The muriated tincture, reduced iron, the saccharated carbonate, phosphates containing iron, as well as cod-liver oil, and, if the appetite is poor, the citrate of iron and quinine-all may serve a good purpose.

In some cases minute doses of arsenic or corrosive sublimate will help the action of iron or do what this drug alone can not. However, the importance of gentle exercise, of sunlight, and of grooming and massage, is very great. Parasites, if present, must of course be expelled.

Plethora is the opposite condition to that just described, and is most likely to occur in vigorous young dogs that are insufficiently exercised and overfed.

The remedies are plain: low diet for a time, given but once a day, plenty of exercise gradually increased, an occasional laxative, etc.

\section{HEART-DISEASE.}

Until the physical examination of dogs is practiced more systematically, and post-mortem examinations much more frequently made, we shall continue to be a good deal in the dark on this subject.

All violent exercise, if long continued, tends, both in man and the lower animals, to induce disease of the heart and blood-vessels.

The dog has a large and powerful heart, and the elasticity of the arteries of the dog and other of the domestic animals is not so often impaired by disease as in the case of man; nevertheless, dogs violently exercised-such as coursing greyhounds and field-dogs that engage in frequent competitions-do occasionally die suddenly from heartdisease; and dogs, probably oftener than we are aware, 


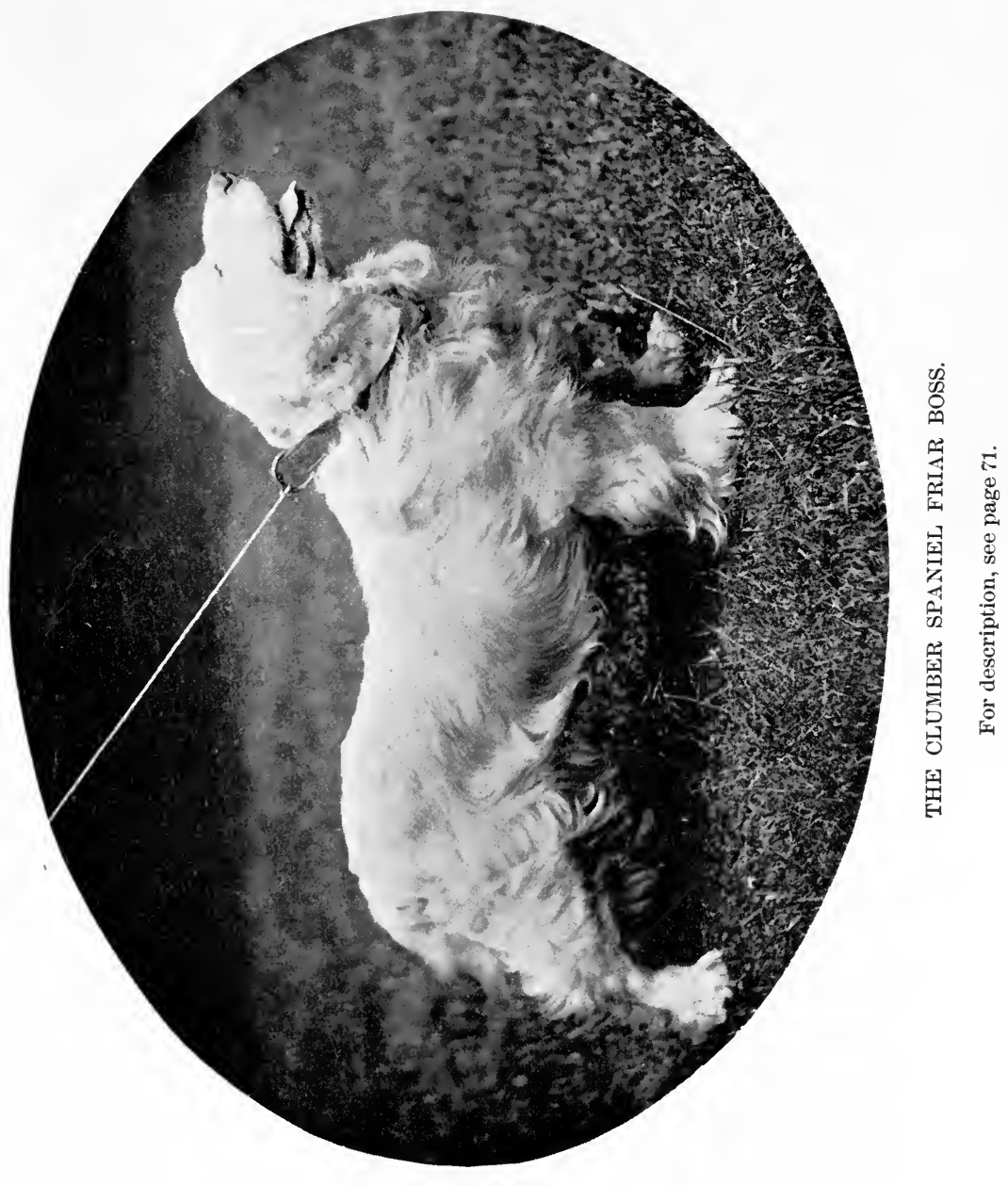


suffer from enlargement, dilatation, or valvular disease of the heart. The latter may result from rheumatism, etc. It is true that the physical investigation of the heart of the dog can not be carried out as easily as in man; nevertheless, any marked alteration in size, and especially any change in the heart-sounds, is readily made out in the one case by percussion and palpation, in the other by auscultation.

Hypertrophy, or increase in the thickness of the muscular walls of the heart, is not of itself of such serious import as dilatation, for this results in imperfect closure (incompetency) of the valves, regurgitation of blood, damming back of blood in the venous system of the body, engorgement of the lungs, and that long list of evils arising therefrom, such as œdema or dropsy of the tissues, dropsy of the various cavities of the body, indigestion, hæmorrhage from the stomach, disturbed sleep, etc.

Prognosis.-With care in the case of hypertrophy the prospects are good; of dilatation, in old dogs especially, not hopeful.

Treatment.-Cure, or a return to the normal can scarcely be expected. Palliation is all that may be hoped for in most cases.

The dog must never be allowed to compete with fast and vigorous animals. If not excitable, he may accompany his master quietly alone or with some easy-going companion. If spirited, exercise on chain may alone be allowed.

Special attention must be paid to the condition of the bowels and digestion, especially in dilatation.

At the same time, to forbid exercise altogether would be a capital mistake, both as regards the heart itself and 
the dog's general health. Drugs should be used only when urgently needed. In dilatation, digitalis is the most useful single drug as regards the heart itself.

However, every case must be treated on its merits with the utmost discretion, and professional advice will be valuable accordingly.

\section{DISEASES OF THE BLOOD-VESSELS.}

Aneurism is a local dilatation of an artery. It is said to have been the cause of the death of the noted coursing greyhound Master McGrath. Such a tumor is generally preceded by a local weakening of the walls of the vessel, owing to disease of one or more of the coats, and, in such cases as that mentioned above, is caused by straining of the vascular system. The prognosis is bad.

Diagnosis.-Dullness over the area on percussion, abnormal respiration, pulse, heart's action, pain, etc., are the most reliable signs.

Treatment.-Absolute quiet, a diet as free from liquid as possible, and iodide of potassium in gradually increasing doses, have been most useful in human practice, and might be imitated in the case of the dog.

\section{DISEASES OF VEINS.}

In old dogs dilatation of veins in the extremities is not uncommon.

Inflammation of veins (phlebitis), except in bitches after whelping or following on blood-poisoning, is not eommon.

Diagnosis.-An alteration in the circulation, tenderness on pressure, with full veins in the neighborhood, 
swelling of the limb, etc., are very suggestive, especially if accompanied by febrile symptoms.

Treatment.-Quiet, relief of pain, hot fomentations to the part if possible, these to be medicated with opiates, bland diet, etc., during the acute stage; tonics, good food, and massage to the part during convalescence after ail tenderness has disappeared-are the indications.

Dilatation of veins in the extremities and elsewhere may be counteracted to some extent by bandaging and cold sponging, followed by suitable gentle massage.

\section{DISEASES OF LYMPHATICS AND OF CERTAIN GLANDS.}

Inflammation of the lymphatics (lymphangitis), except from injury of a mechanical or kindred nature, is rare in the dog, and it scarcely ever arises, as in the horse, from overfeeding and want of exercise.

The treatment is about the same as for inflammation of veins.

Of course the lymphatic glands are usually involved as well as the vessels.

Scrofulous enlargement of these organs, so common in man and some of the domestic animals, is very rare in the dog.

Glands in the neighborhood of the mammoe, especially in old dogs, become chronically enlarged. Painting with tincture of iodine, the application of the officinal com. pound iodine ointment, or removal, are the indications, though they are rarely dangerous.

Bronchocele, goitre, or enlargement of the thyroid gland, is frequent in the dog; the cause is not well known. 
It is recognizable as an enlargement of the neck without the redness, heat, and other signs of inflammation that would precede the formation of an abscess, although this is a possible result, especially if the part has been injured. It is most frequent in young dogs, and is apt to give rise to trouble by interference with swallowing or respiration.

Treatment.-Surgical procedure is to be avoided unless an abscess forms, when it should be opened. Attention should be paid to the general health, and syrup of the iodide of iron or iodide of potassium and a vegetable bitter may be tried, as well as tonics, etc.

However, many cases will yield to counter-irritation, painting with tincture of iodine having special claims to success. Whenever this remedy is to be used on the dog it is better to snip the hair away as completely as possible over the affected region.

\section{DISEASES OF THE ALIMENTARY TRACT.}

General.-The disorders of this, like other regions of the body, become the clearer when the natural structure and functions are borne in mind.

Though certain organs, as the liver and pancreas, seem to be separate from the "digestive tract," as that term is commonly understood, the history of the embryological development of this region of the body shows that they are outgrowths from a main tube which is at one period a straight gut and which becomes differentiated as development proceeds. Such a fact explains in some measure that sympathetic connection which is very conspicuous in all ailments of these parts.

In general it may be said that the digestive tract con- 
sists of a long muscular tube of unequal caliber at different parts, covered with an elastic serous membrane externally, which tends to prevent distention, and internally with a mucous membrane well supplied with blood (raccular) and abounding in glands which secrete the various digestive juices. The muscular tissue is necessary for the movements essential to push on the food from place to place throughout the tract. Nervous structures are found in abundance, which explains how pain is caused in disease, and how the nervous centers affect and are affected by the condition of the tract. (Fig. 15.)

The solid organs, as the pancreas and liver, are really parts of the digestive tract, as already explained, and are connected with the main tube by outlets (ducts) for their secretions, which are, of course, emptied into the intestine.

From this brief description alone it must be apparent that a disease affecting, say, the last part of the whole tract, while localized to a certain extent, must also be expressed elsewhere, even at the very commencement; and, as a matter of fact, the appearance of the tongue is a pretty fair index to the condition of the stomach, intestines, etc.

While the causes of the disturbances of the digestive organs must be sought in anything that will seriously disorder any part of the body, it is more especially to that which the animal eats and its quantity, or to those conditions that affect the general health-as cold, wet, bad ventilation, etc.- that we must look for an explanation. Of acute forms of inflammation due to irritant poisons, nothing will be said till later, when treating the subject of poisoning. 


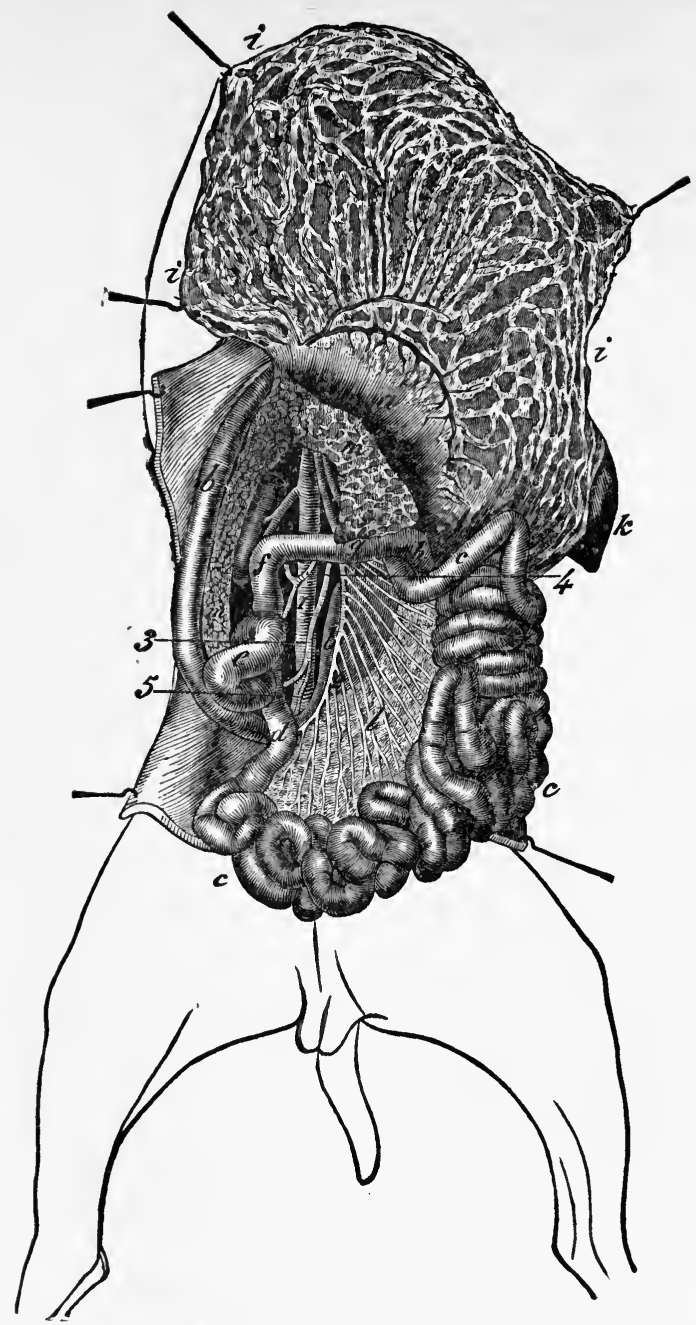

Fig. 15.-Intestines of the Dog (Chauveav).

$a$, stomach ; $b$, duodenum ; $c$, jejunum ; $d$, ileum ; $e$, cæcum ; $f$, ascending colon ; $g$, transverse colon; $h$, origin of descending colon; $i$, great omentum ; $k$, spleen $; l$, mesentery ; $m$, pancreas ; 1 , aorta $; 2$, great mesenteric artery $; 3$, artery of the duodenum $\cdot 4$, artery of the large intestine; 5 , small mesenteric artery. 
Indeed, nearly all the disorders of the digestive organs are traceable to bad management, which is one of the reasons why we have devoted so much attention to the care of dogs. The disorders of this region and their consequences in loss of "condition," and especially as regards the skin, are among the most frequent and trying of the minor ailments of dogs. These are evils with which all kennels have to contend, while many diseases that must be described in books are comparatively rare.

The treatment of such troubles when they do arise is so much a matter of careful dieting, that the principles of feeding should be well understood.

The general expression, especially of the eyes of dogs suffering from any digestive disturbance, is very suggestive to the experienced. Any redness, any catarrh of the eyes when not directly traceable to cold, etc., may usually be set down to digestive disorders.

The character of the evacuations of the bowels is always of the utmost moment as an index to both causation and condition; sometimes quite diagnostic.

All concentrated food tends to constipate, and, as a rule, coarse food, as porridge, to relax, as does also a vegetable diet.

But with abundant exercise the bowels rarely become constipated on any diet.

\section{AFFECTIONS OF THE MOUTH.}

We shall consider the salivary and mucous glandsthe tongue, the teeth, the gums, the pharynx, etc.

Warts may be so numerous over any part of the mouth as to require treatment. Cutting may be followed by too 
much bleeding, and caustics, except when very carefully applied, are apt to be too destructive. The solid nitrate of silver is one of the safest and best. Strong acetic acid is useful, especially when these epithelial growths are very numerous. It is to be swabbed or brushed on daily.

But perhaps the quickest and most effective method is the application of the red-hot iron of neat form. The dog should be narcotized first, of course, when the operation is to be at all extensive, though the actual pain, if the iron be at a bright-red heat, is slight. A single wart, or a few, may be cut off and the base cauterized.

Salivary Glands.-Salivation in greater or less degree is a frequent accompaniment of disordered digestion, especially of the stomach. Salivation to a dangerous extent, or as evidence of poisoning by mercury, is difficult to control. The breath is more or less fetid, and the gums and other parts usually suffer. When the secretion of the mucous glands or of the salivary glands is abnormal, tartar-i. e., a collection of lime salts entangling foreign matter-collects on the teeth. A dog of a thoroughly healthy digestion rarely suffers thus. It is important, as sooner or later the gums, and the teeth themselves, are corroded, resulting in ulceration of the gums (cancrum oris). The latter requires both local and constitutional treatment.

If due to digestive disorders, attention to the diet, regulation of the bowels by exercise and dieting, and, in more urgent cases, by medicine, usually suffice.

Mercurial salivation requires more attention. Locally, strong washes of chlorate of potassium and tincture of myrrh alternately will be useful. Iodide of potassium, combined with a vegetable tonic, should be given inter- 
nally thrice daily in doses of one to four grains, following any special indications as to the rest.

The Teeth.-If tartar tends to collect, alter the food, and, if necessary, the general management. It may be judicious to feed less, or to feed at more frequent intervals and in small quantities. Sometimes a good fast will be beneficial. Each case must be studied and treated according to its indications. Hard biscuits, crusts, and bones tend to clean the teeth. After removal of the greater part of the tartar with appropriate instruments, a brush and powdered charcoal should be used daily. In some cases this alone will suffice to restore the teeth.

If neglected, the gums are softened, abscesses may form, ulcers appear, the roots of the teeth be absorbed, the periosteal lining of the bone get inflamed, etc.

When matters get to such a pass, one or more teeth may require removal, or the gums to be lanced. Ulcers will need to be washed, as above indicated, for salivation, or perhaps a little boracic acid or iodoform dusted on.

Teeth may break off, leaving stumps that decay and give rise to evils that threaten both the gums and bone. Such roots should be extracted with suitable instruments, the dog usually requiring to be anæsthetized.

Coarse instruments and unpracticed hands are out of place about the mouth of the dog. The veterinary surgeon will get some hints as to what he needs by an inspection of the tools used by our modern dentists with their matchless outfit. In puppies the first teeth sometimes do not drop out in time, but are in the way and turn the permanent ones aside. They should be removed. 
Inflammation of the Tongue.-This is rare, but occasionally dangerous, from threatened suffocation arising from swelling. When moderate, it is marked by some swelling, redness, tenderness, painful deglutition, etc.

The bowels should be opened freely, the animal fed on light diet at first, and later on concentrated food if the strength fails. If he can not swallow, rectal injections of strong broth or eggnog are called for. Locally, washes of chlorate of potassium and alum, with incision of the tongue, or tracheotomy in threatened suffocation. Tonics are likely to be called for after the inflammation subsides.

Blain.-This term is applied to a vesicular eruption on the tongue, etc., which, bursting, is very apt to be followed by ulcers.

This is usually a disease arising from neglect, through which the animal gets into a debilitated condition.

Treatment by local washes similar to those already in dicated, and tonics internally, with good feeding, are the indications.

In all cases of disease when ulcers occur, the judicious use of the solid nitrate of silver as a caustic is followed by favorable results.

For internal use the following is recommended:

B Pot. chlorat ................ 3 iij;

Tinct. ferri mur.............. $\xi$ ss.;

Glycerinæ.................. $\xi \mathrm{ij}$

Aquæ.................. ad $\xi$ viij.

Ft. mist.

Sig. : Dessertspoonful after food three times a day.

It is better to give this as indicated, and not in capsules, so as to get its local effect. 
Pharyngitis is occasionally present in mild form, as the result of a cold. It often arises as a complication of other diseases. Except the irritation of foreign bodies, as corrosive poisons, and when due to bones of a sharp nature being caught in this region back of the tongue, it is seldom serious. When a dog can not swallow perfectly well, a careful examination should always be made.

Treatment is best carried out by attention to the general health, especially to the bowels, by administering warm liquid food and by careful nursing. The hot food acts in a soothing way. A little at a time and often, as in laryngitis, is best.

If there is not much fever, the prescription recommended for blain will prove helpful. But if the stomach is disordered, this remedy is contra-indicated.

\section{FUNCTIONAL DISORDERS OF THE DIGESTIVE ORGANS.}

The term indigestion is very vague, implying imperfect discharge of the functions of the digestive tract, and is also often associated with certain positive ailments. Many of the same symptoms that manifest themselves in consequence of actual structural or organic disease mark derangements that are purely functional-i. e., not associated with any changes of structure visible to the naked eye or by the aid of a microscope. In the dog these are very frequent.

Salivation as one of these has been noticed already.

Vomiting is one of the easiest acts for the dog, fortunately, and saves him many ills that we ourselves, and especially the horse and ruminants, must suffer from. 
It always indicates, when purely functional, that the food is unsuitable either in quantity or quality, or that the stomach is unfit to receive it, and so is better without it. The dog frequently, in warm weather, eats grass and causes vomiting, and thus in a way regulates his own digestive tract.

As a rule, when a dog is seen to vomit he should either be left without food for a time or have his diet wholly altered-perhaps both. It is very rarely that medicine is demanded. Vomiting may be due to worms, when the indication is clearly to give a vermifuge. When vomiting is frequently repeated, a careful investigation should be made, and poison, among other things, suspected.

A Capricious Appetite should always receive attention. It may be due simply to lack of stamina, or to debility owing to bad hygienic surroundings. It may be a sign of organic disease, of worms, etc. The bowels will generally be found at fault. If due to mere debility or atony of the digestive organs, vegetable bitters-as gentian, quassia, cinchona, etc.-are useful, especially in the form of the compound tinctures. Nux vomica, carefully watched, is excellent. A change in the feeding to raw meat only for a time may be wise. A trial may be made of a mixture of bicarbonate of soda, powdered rhubarb, and gentian, or the compound tincture of cinchona. If dependent on a sluggish condition of the liver, about which one can form some opinion by watching the stools, this must be treated. The color and consistence of the stools of the dog vary with the food. Meat causes them to be dark; a mixed diet some shade of yellow. They may be very hard and 
light-colored when the dog chews up bones, owing to the presence of lime salts derived from them. The fæces should never be so stiff as to cause the dog to strain to pass them, nor so fluid as to run from him in a stream. When of a pasty consistence and a dirty-whitish color, an absence of bile pigment may be inferrred, and that the liver is at fault. Of course, the appetite soon tells a tale when any part of the tract is disordered. In a dog well managed, however, purely functional gastric dyspepsia is rare.

Irregularities of the Bowels-as diarrhoea and constipation-are also, as may be inferred from what has already been said, usually evidence of injudicious management, mostly from too much or too little exercise, bad feeding, etc.

Diarrhœa arises from an excessive peristaltic action of the bowels, causing frequent evacuations, which must of necessity be of improper consistence. Generally this is due to the presence of unsuitable food or food in excess, giving rise to fermentation and its irritating products; sometimes to contact with the damp, cold earth, to draughts, etc. It is an effort on the part of Nature to get rid of offending material, and should not be arrested at once; in fact, only when there is danger of harm-as inflammation, weakness, etc. A diarrhœea may be caused by excessive discharge of bile, which is a more serious matter.

If diarrhœa is not checked by quiet and rest or by dieting, other measures may be necessary, especially if blood appears or much mucus. Easily digested food is, of course, indicated. Opiates and astringents should only be tried 
after a good dose of castor oil, to free the bowel from offending matter, if such there be. This is a safe procedure, even if the diarrhœa has lasted for days. If there is evidence of pain, ten to fifteen drops of laudanum may be given with the oil. Sometimes one dose of tincture of rhubarb in peppermint-water answers well, as there is a subsequent astringent action. If the relaxation still continues, the officinal lead-and-opium pill, or such astringents as kino or rhatany, will be in place.

Obstruction.-Obstruction may be due to prolonged constipation, and is serious, as it may end in inflammation of the intestine (enteritis). It is better to begin by enemas of warm soap-suds and castor oil or olive oil. Occasionally it may be necessary to scoop out the obstructing mass by mechanical means. Castor oil or syrup of buckthorn may be given by the mouth. Kneading the abdomen may be of service. "Reference will be made to this subject again, under "Peritonitis."

Constipation.-Except in old dogs, this is mostly due to errors in management, especially in feeding and from irregular or insufficient exercise. Dogs kept in small yards and on chain frequently suffer. It is a fruitful source of evil, including disorders of the skin. It may be necessary to feed vegetables, as a sort of medicine; though porridge tends to relax. Liver, which should be boiled, is also useful. Food that is very concentrated, and sometimes the opposite kind, tends to constipate. Exercise and a suitable diet remedy the irregularity in most dogs. In old animals the muscular coat of the intestine loses tone, and then medicine and massage of the abdomen is demanded. A pill made as follows will possibly do good: 
B Ext. belladon................. gr. ij;

Ext nuc. vom .............. gr. $v$;

Ext. Barb. aloes............ 3 ss.

M. Ft. pil. no. xxiv.

Sig. : One pill at night.

Constipation may arise from a sluggish liver, in which case "gray powder" (mercury and chalk), small doses of calomel at night, followed by Epsom salts in the morning and carefully watched, extract of dandelion, etc., are worthy of trial.

The author suggests as valuable remedies, in suitable form, for use in many disorders of the digestive tract, the officinal compound rhubarb pill and the compound cathartic pill. The first consists of aloes and rhubarb chiefly ; the latter, of colocynth, jalap, gamboge, and calomel. The first may be given as a digestive pill; the second is excellent when the portal system is overloaded-i.e., when the digestive organs are congested-when their circulation is not free, as often happens in overfed, underexercised dogs

These pills can be obtained coated with sugar or gelatin. One, except for the largest dogs, will suffice, given at night on a very light supper, and followed by a good dose of some saline in the morning. For habitual constipation the fluid extract of cascara sagrada has found favor. It may be given with or without castor oil. It should be given in capsules, as the taste is very unpleasant. However, persistent medication is bad, and enemata of soap-suds or the injection of a small quantity (teaspoonful) of glycerin, with a little cold water added, by a small syringe, is not much trouble. By all means accomplish the result by 
exercise and dieting if possible. It must not be forgotten that bones, when small and capable of being chewed up, are very constipating. While fine flour bread tends to costiveness, this article, made from unbolted wheat or Graham flour, is not, and constitutes a most suitable food for dogs. Spratts' foods rarely constipate, but at first may relax too much. As a rule, they soon agree well, and as patent foods leave nothing to be desired.

Colic.-When the contractions of the intestine are long continued at one spot, pain of a very depressing though more or less spasmodic character results. It is not in itself an inflammatory affection, though colicky pains (tormina) precede or accompany several intestinal diseases.

Causation and Symptoms.-Colic may be caused by unsuitable food, damp and wet, worms, lead when introduced to a poisonous degree into the body, the passage of gall-stones, renal (kidney) calculi, etc. Uneasiness, moaning, or sharp cries, arched back, difficulty in walking at times, as if paralyzed, a piteous expression, tense abdomen, etc.

Treatment.-Give at once a good dose of castor oil with twenty drops of laudanum, and apply to the abdomen a turpentine stupe for twenty minutes; this may then be removed and replaced by a modification of the chestjacket. If the bowels do not soon move, give an enema containing an opiate, and, if the pain still persists, twenty drops of chlorodyne or a drachm of spirits of chloroform, with a like quantity of aromatic spirits of ammonia, properly diluted with water, will likely afford relief.

Of itself, colic is not a fatal disease; and those maladies which are really inflammatory-as enteritis, though often 


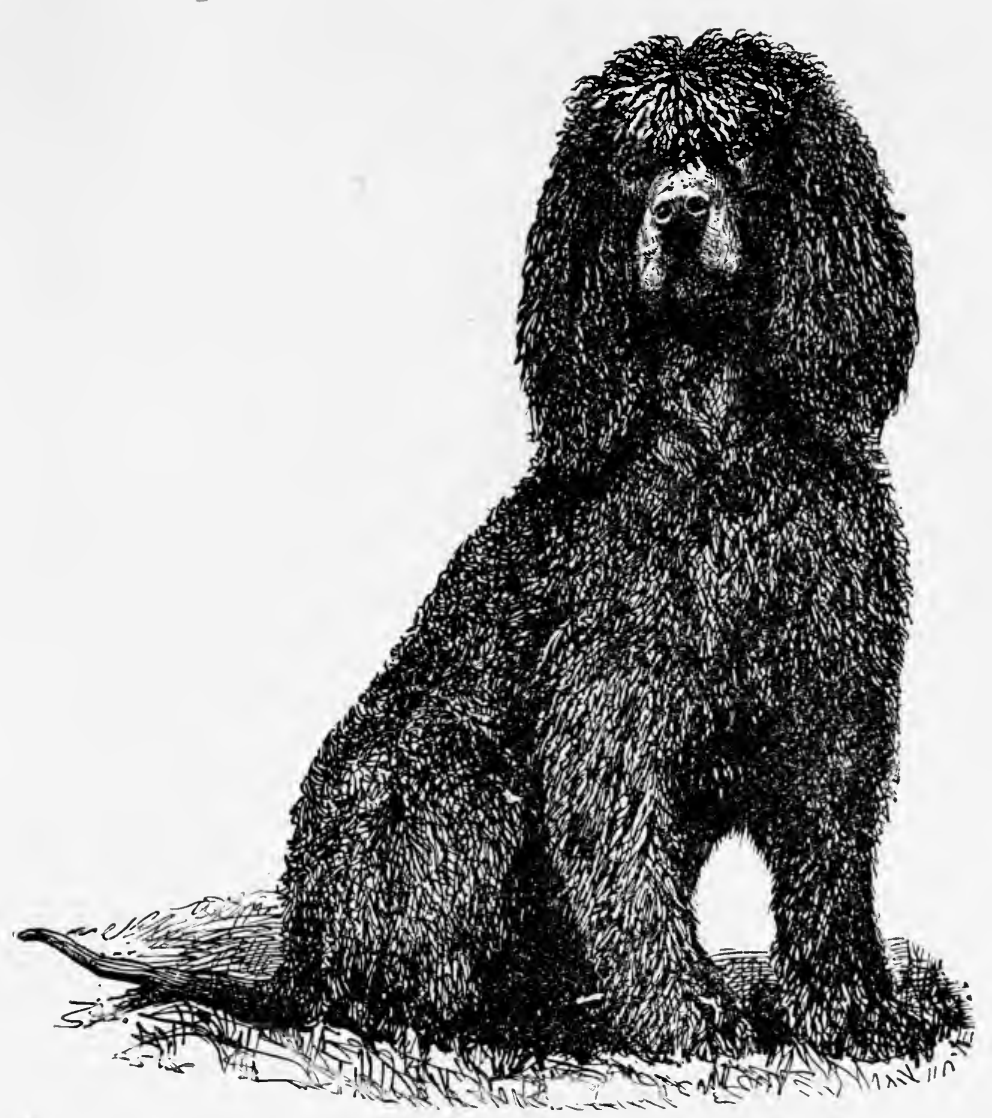

THE IRISH WATER SPANIEL CHAMPION SHAUN.

(K. C. S. B., 26,925.)

For description, see page 7. 

associated with colicky pains-should not be termed " colic."

\section{INFLAMMATORY AFFECTIONS OF THE DIGESTIVE ORGANS.}

In all these diseases the symptoms bear some resemblance, which also applies to causation, pathology, and treatment.

This is owing to similarity in structure of the intestine, stomach, etc., and to the fact that the different parts of one long tract are anatomically and functionally so related that one can not be seriously affected without the other sympathetically (reflexly) feeling the effects. To illustrate this again, if the stomach is inflamed, nervous influences proceeding from the disordered region inward to the centers by the nerves supplying the region in question so affect these centers (brain and spinal cord) that influences radiate from the latter along the nerves to the part affected, and to other regions often widely removed, and act through the blood-vessels and otherwise. (Fig. 16.) This explains how it is that the heart, the appetite, the intestines, etc., may be affected in an inflammation of the peritoneum, for example.

The most important discases of the alimentary tract are gastritis, or inflammation of the stomach; enteritis, or inflammation of the small intestines; dysentery, or inflammation of the larger intestine; and peritonitis, or inflammation of the serous covering of the walls of the abdomen, etc.

Common Pathology.-Increased secretion, etc. (catarrh), following a dry state of the mucous membrane, 
with redness, tumefaction, exudation, etc., owing to the usual changes in vessels and tissues at the seat of inflammation, as before described. Of course, the effects of

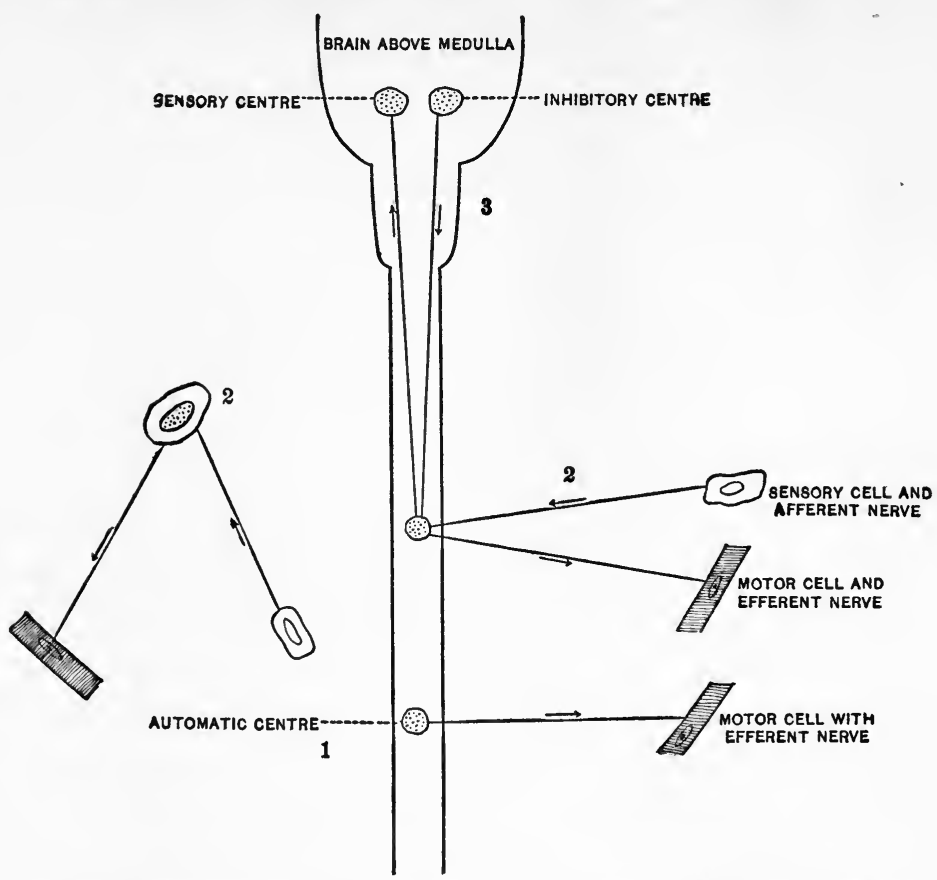

Fra. 16.-Diagram intended to illustrate nervous mechanism of-1, automatism ; 2 , reflex action; and 3, how nervous impulses in the latter case may pass into the higher parts of brain and affect consciousness, or be wholly inhibited. A reflex or automatic center may, for the sake of simplicity, be reduced to a single cell, as above on the left. The arrows indicate the course of the nervous impulses.

irritating products formed at the site of the disease, and absorbed or acting locally, must not be forgotten.

Common Causation.-Apart from poisons and such like irritants, unhygienic surroundings, especially damp with cold; unsuitable food, either too coarse and bulky or too exciting, too hot, too cold, or putrescent; blows, nervous shock, as from harsh treatment, etc. 
Common Symptoms.-Altered expression and attitude, modified appetite, thirst, vomiting, changed action of the bowels, either diarrhœa or constipation; pain or tenderness, alteration in the muscular tension of the abdominal walls, febrile symptoms, as elevated temperature, quickened and otherwise modified pulse and respiration; certain brain symptoms, as dullness, or, in bad cases, delirium or stupor (coma).

The common dangers are extension of the inflammation, gangrene or death of parts of the organ from the severity of the inflammation, exhaustion from pain, diarrhœa, vomiting, etc., or sudden collapse from hæmorrhage or nervous shock, heart failure, etc.

Common Treatment.-To look to all circumstances that tend to favor a return of the organs to health, which implies avoiding all sources of irritation, whether by what enters the digestive tract or by external conditions-supporting the strength, and attacking any symptoms that threaten to lead to any of the dangers above mentioned. In other words, we must pay special attention to feeding, absolute rest, comfort of body and mind, to allaying pain, checking vomiting or diarrhœa if excessive, and keeping up the strength, when failing, by suitable feeding, drugs, and stimulants.

Prognosis.-So long as pain can be controlled, the heart's action is not very rapid or feeble, and nourishment well taken, the prognosis is usually good.

Peritonitis, enteritis, and dysentery, a rather common disease, are often fatal.

All these diseases exist in a subacute and chronic as well as in the acute form. 
Instead of giving a systematic account of each disease, we propose to now add some remarks especially as to how to discriminate between them as they actually meet the practitioner of medicine, and in reference to treatment. We advise all owners and breeders of dogs, when their animals have prolonged diarrhœa or slimy and bloody stools, or give evidence of pain, to consult some medical expert, as delay is dangerous, and sound treatment not always possible except by one of special education and experience; though in all that relates to hygiene, feeding, etc., the intelligent reader, who has had some experience with dogs, should be fairly well prepared.

Differential Diagnosis between Colic, Gastritis, Enteritis, Dysentery, and Peritonitis.-In typical cases the diagnosis is not specially difficult, but such cases are comparatively rare.

Colic, pure and simple, should be easily excluded, as there are no febrile symptoms, the pulse is not quickened appreciably, vomiting is rare, and the pain is relieved on pressure, while in all the others the reverse is the case.

The symptoms of gastritis, very pronounced in the acute form, are thirst, vomiting, pain, tenderness, etc. The position of the animal is often characteristic, inasmuch as it lies stretched out on its belly-there is not the same tendency to arch the back as in colic; but in all these diseases the abdominal walls are tense and shrunken unless there be much flatulence, when distention with tension must result.

Enteritis may exist with less marked symptoms, and this should direct attention to the intestines. The tenderness will be more extensive and reach farther back if pres- 
ent, but it is not always well marked. It may be associated with colicky pains (tormina).

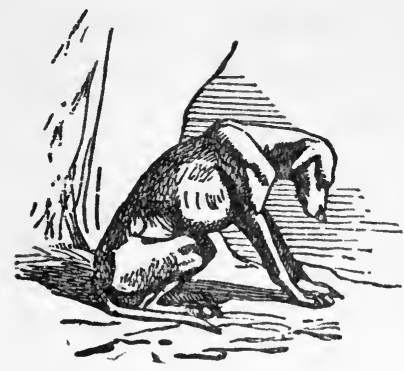

Inflammation of Lungs.

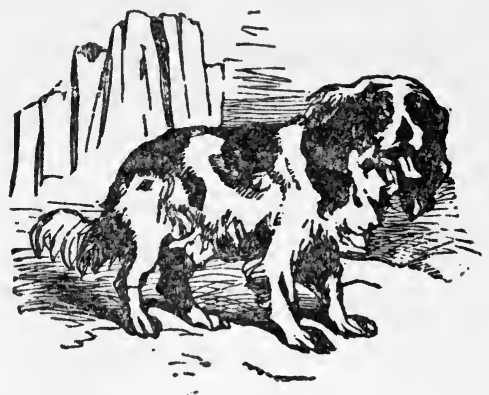

Asthma.

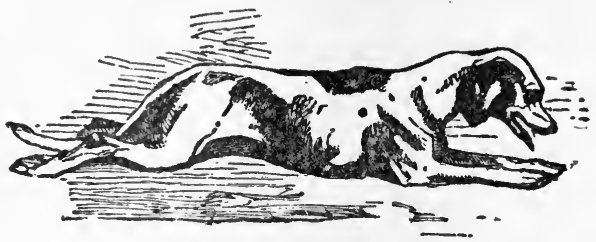

Gastritis.

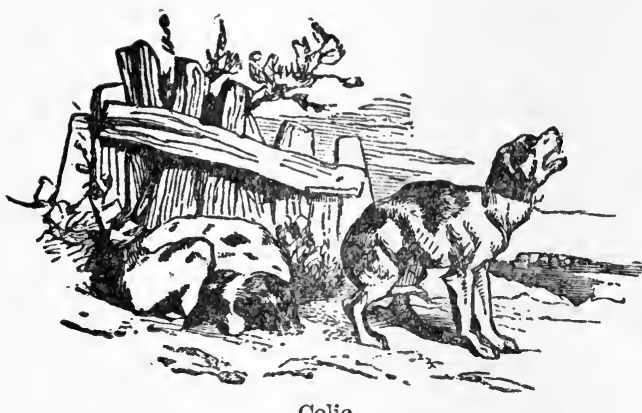

Colic.

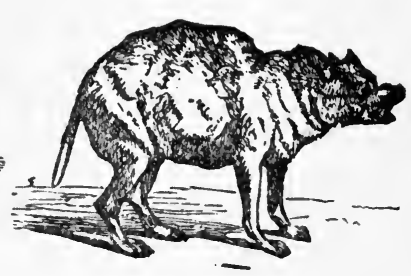

Rheumatism.

Fig. 17.-(Maynew.)

In dysentery, tenderness, if present, will not be so diffuse, and the stools are characteristic, at all events after the first, which may resemble those of a simple diarrhœa. Later they are soft, may contain little balls of fecal mat 
ter, but especially are they jelly-like from mucus, and stained with blood. Vomiting is not common, and there is far more straining, with or without expulsion of the morbid secretions, than in any other of the diseases in question. The febrile symptoms are not so marked as in gastritis, enteritis, and especially peritonitis.

Peritonitis is characterized by constipation, with much pain and tenderness. Thirst and vomiting may not be so marked as in gastritis, but flatulent distention, constipation, and a rapid, wiry pulse are highly diagnostic.

In the subacute and chronic forms all symptoms are less defined, and the general disturbance not nearly so marked.

As in inflammation of the serous membrane of the chest, there may be copious exudation of fluid or "plastic lymph," which may lead to adhesions that are sometimes the cause of future fatal obstruction of the bowels, and other evils.

When all acute symptoms have subsided, the same remedies may be used to facilitate absorption as in pleurisy, with the additional use of judicious massage, practiced daily at least.

Treatment should be both internal and external.

It is assumed that the patient is well housed, with entire separation from other dogs, and provided with a comfortable bed.

His food should be given in all cases in small quantities and often: bland and liquid or semi-liquid at first, gradually adding more solid food as he can bear it.

In all cases a turpentine stupe may be applied with advantage, to be followed by a well-padded but not heavy 
modification of the chest-jacket-i. e., a dressing to cover the parts affected and those immediately adjacent.

The stupe may also be applied somewhat beyond the region beneath which the affected organ lies, as the effect on sound parts seems to be beneficial to those actually diseased.

Counter-irritation in some form, especially at the outset, is certainly indicated.

Vomiting, when persistent, must be combated by internal remedies also.

Drink must not be allowed the dog except in small quantities at a time; his food must be liquid, and but little given at once. In some cases it may be worth while to add pepsin to the food, or give it immediately after, to assist digestion. Lime-water is an excellent addition to milk. If food is vomited in spite of all precautions, it is useless to further force it on the animal; but if there be urgent need of nourishment, it may be given by the rectum (injection or enema).

To arrest vomiting, trial may be made of small quantities of ice-water, small bits of ice, the dilute officinal prussic acid, very small doses of carbolic acid (one half to one grain) in a little ice-water, oxalate of cerium, the latter with small doses of sulphate of morphia (gr. $\frac{1}{8}$ ), subnitrate of bismuth alone or with cerium or morphia; hypodermic injection of morphia over the stomach. Warm and stimulating applications, as turpentine, will be worth a trial in all cases. •

The diarrhcea of enteritis, or dysentery, apart from the external treatment, may require special remedies, such as have been already indicated under "Diarrhœa" (page 
$253)$; but in dysentery great benefit is often derived from injections of boiled starch, with twenty to forty drops of laudanum, and a dessert-spoonful of listerine, the whole to be retained within the bowel by holding the hand, invested in a soft eloth, against the anus for ten minutes at least.

As already indicated, we think it wise, in both diarrhœa and dysentery, to make sure that the bowels are free from offending matter, and would commence the treatment with eastor oil or syrup of buckthorn and enough laudanum to relieve pain.

When dysentery tends to become ehronic, small doses of ipecacuanha, one to three grains of the powder, or three to eight drops of the wine every one to two hours, may be tried. It is frequently a most obstinate disease, . and much depends on judicious nursing and feeding.

In all these inflammatory affections pain may be severe and lasting, and may kill the animal by disordering the nervous centers, in consequence of which the nutrition (metabolism) is perverted and the main eenters of life, the heart eenter especially, worn out, so that the indication above all others is to relieve pain. This can be done by warm applications, counter-irritation, and opiates. Some recommend leeches and blood-letting. We doubt if either is practicable or judicious with the dog, but have no very positive opinion based on experienee.

Constipation may coexist with either gastritis or enteritis. It is not to be too soon relieved with drugs; better far to use enemas, at least while the aeute symptoms last.

In peritonitis, opium in some form is still the sheetanchor. Constipation is commonly present, and may be 


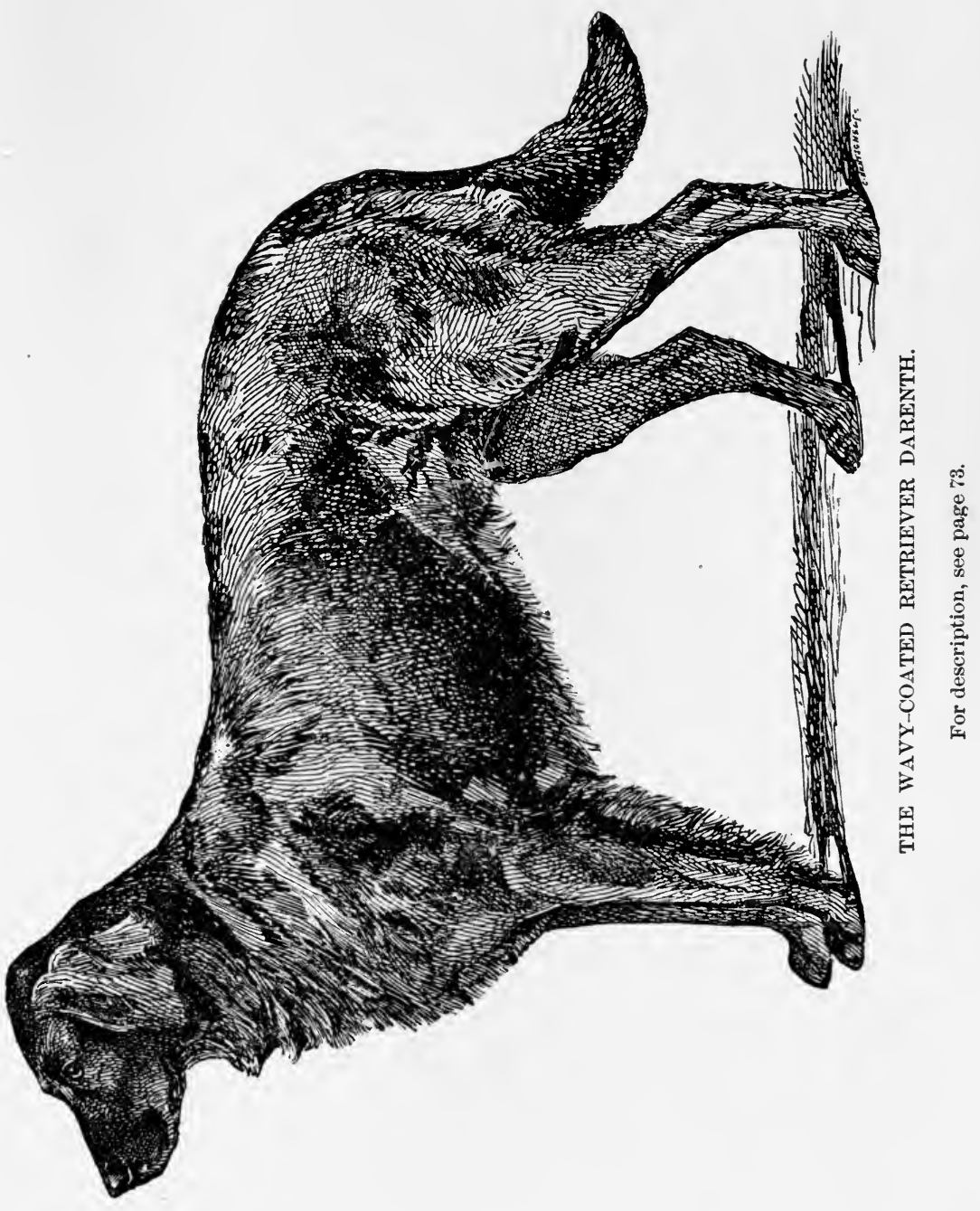



relieved after one to two days with an enema, but not with a purgative.

Hot applications are of great value; some believe in the administration of turpentine internally; better, we think, by the rectum in soap-suds and olive oil, when, in small quantities, it may relieve constipation and flatulent distention. Some also recommend ice-cold applications. The great indication is quiet, external and internal, and the relief of pain by opiates. The heart must be carefully watched, and, if it threatens to fail, stimulants-by the stomach, if possible-if not, by the bowel-must be given. Milk, eggs, and brandy make an excellent combination.

When it is remembered how great in extent is the surface of the peritoneum, covering as it does not only the walls of the abdomen, the under surface of the diaphragm, but also nearly all the organs of the abdominal cavity, the gravity of an inflanmation of a large portion of it is very evident.

During convalescence special attention must be paid to supplying a nutritious diet and to the use of tonics.

It is important that the dog be fed for a while about three times a day, and in moderate quantities only at each meal, to avoid distention of the stomach or intestines, which may, if it occurs, be a cause of lasting trouble. The dog must, in fact, be for some time carefully guarded as to exercise, housing, and all that relates to his well-being, including the maintenance of a good deal of self-esteem and cheerfulness, for the effect of the psychic nature over the body in well-bred dogs is very great; indeed, a fact that must ever be kept in mind in treating them in health and in disease. 
In all cases when the strength begins to fail, the most nutritious and easily-digested food should be given, and alcoholic stimulants, either alone in water or mixed with the food, especially if the latter must be forced on the animal, or in injections by the rectum of broths, eggnog, etc.

In threatened collapse, stimulants are plainly indicated.

\section{FUNCTIONAL DISEASE OF THE LIVER.}

Jaundice, the retention or reabsorption of the constituents of bile, results from failure of the liver to do its work, whether this arises from organic disease or merely from functional disturbance or obstruction to the outflow of bile. To the latter we now more especially refer.

Causation.-Chills, caused by bad management; injudicious feeding; obstruction to the discharge of bile from the liver cells; the poison of certain diseases, as distemper; exhaustion from violent exercise, especially if left without grooming afterward, etc.

Symptoms.-Usually the mucous membranes show, by their staining with bile pigment present in the blood, the true nature of the trouble. The animal is dull, appetite falls off or becomes capricious, urine high-colored and contains bile pigment. The stools are characteristic, being lacking in color, of a gray, dirty appearance, and usually tough, pasty consistence; often fetid. There may be diarrhœa, but usually constipation.

Treatment.-The dog is to be made very comfortable, and protected from draughts; gentle but regular exercise is to be given; food to be supplied in small quantity and of a very bland character, as rice and milk, stale bread and milk, biscuits, etc. Fatty food is to be avoided strict- 
ly. Buttermilk is useful. Massage over the abdomen may prove valuable after the first few days.

Gray powder or calomel in small doses (half a grain of calomel) three to five times a day; the compound rhubarb pill, after a previous dose of one compound cathartic pill, followed by a saline the next morning; powders of rhubarb and the bicarbonate of soda, or the following:

B Tinct. rhei. co ............. z jss. ;

Sod. bicarb................ $z_{j}$;

Tinct. gent. co............. $\xi$ jss.;

Syrup. aurantii............... $z \mathrm{ij}$

Aquæ..................... $\xi$ viij.

Ft. mist.

Sig. : Dessertspoonful a short time before food three times a day.

Taraxacum may also be tried; it often does good. If there be pain from the obstruction of the ducts by gall-stones or other cause, morphia or Dover's powder is indicated. It is also advisable in all such cases to apply simple hot fomentations, turpentine stupes, or the former sprinkled with laudanum.

\section{ORGANIC AFFECTIONS OF THE LIVER.}

Hepatitis (inflammation of the liver) of an acute form is rare, except in tropical countries-at all events, when not due to blows, etc. The causes are obscure, and the diagnosis not always easy. Tenderness over the liver on pressure, more or less pain, digestive disturbances, foul breath, altered respiration, lying on the chest and belly, probably jaundice, with characteristic stools, and febrile symptoms. If enlargement of the liver can be made out 
by physical examination, with such a train of symptoms, the diagnosis between this disease and gastritis or enteritis is pretty clear.

Treatment.-Much the same as for jaundice induced functionally, though no line of treatment by drugs has given much satisfaction. Attention must be paid especially to the diet and surroundings.

The termination of the disease in abscess of the liver is not uncommon, and usually proves fatal. When pus forms, attention must be paid to maintenance of the strength with the most concentrated foods, quinine, and, if the stomach will bear it, cod-liver oil, while alcoholic stimulants, that are strongly contra-indicated in the early stages, may now prove essential.

Chronic Hepatitis usually gives rise to dropsy, and a whole host of evils which commonly end in death. The symptoms must be combated as they arise, as it is impossible to do much with drugs by direct action on the affected organ. Occasional minute doses of calomel or corrosive sublimate (one thirtieth of a grain) or iodide of potassium (one to two grains) may be tried, given two or three times daily.

When disease of the liver is due to parasites, the only course is to treat the case according to the symptoms presenting, in the hope that the cause of the disease may be thrown off, which rarely happens.

\section{DEGENERATION OF THE LIVER.}

The form most common in the dog is fatty degenera. tion, which may be found in animals no longer young that have been overfed and little exercised. A cure is rare, 
but something may be done to mitigate the symptoms. Dieting, with special reference to both quantity and quality of food, is of the greatest importance. No fatty or starchy foods should be given for a time, and as little as possible later. The animal should be fed on a limited quantity of meat, on sweet milk and on buttermilk.

If the liver is greatly deranged, its glycogenic function may be altered - i. e., its manufacture of animal starch, and the distribution of this to the body as sugar by the medium of the blood. When this function is disordered, dieting is the chief reliance, and all saccharine and starchy food must, as far as possible, be withheld. Skim-milk is useful.

\section{CANCER OF ABDOMINAL ORGANS.}

In dogs past their prime, and especially in old animals, cancer is not so very rare. It does not commonly attack the liver primarily, but more frequently the stomach or upper part of the small intestine (duodenum), though it is rarely confined to these regions unless death speedily ensues.

The symptoms indicate serious disturbance of the digestive processes and great irritability of the digestive organs; hence vomiting, tenderness on pressure, loss of appetite, capricious appetite, and, as properly elaborated material is not supplied by the digestive tract to the blood, there is wasting and loss of strength, which the misery augments.

Cancer is generally, but not always, a painful disease. It is, perhaps, invariably fatal, and the only thing the practitioner can do is to make the patient as comfortable as 
possible, relieve pain, vomiting, etc. The diet must, of course, be specially studied.

It is important for purposes of diagnosis to get the animal to submit quietly to a careful palpation of the abdomen, as very often an enlargement of some organ, or possibly adhesions, etc., may be detected, and when the diagnosis is certain, the case is so hopeless that, if there is much wretchedness or rapid wasting, it may be kindness to chloroform the animal to death.

\section{INTESTINAL OBSTRUCTION.}

This serious and generally fatal condition may be due to foreign bodies, fæcal masses, the passage of one portion of the gut within another (intussusception), twisting of the gut, or constriction, the result of peritonitis or some other form of inflammation, and kindred causes.

Symptoms.-Usually constipation, which may be preceded by diarrhœa, increasing pain of a colicky character, general disturbance, flatulent distention, haggard expression, vomiting, which may increase in severity till bile, and later fæcal matter, is regurgitated, prostration, etc.

Diagnosis.-At first obscure. The abdomen should always be carefully palpated, with the view of detecting tumors within. When there is vomiting of fæcal matters, or prolonged vomiting in the absence of the other symptoms of gastritis, obstruction should be suspected.

Prognosis.-Very bad; the disease generally proves fatal. Occasionally the affected part sloughs away (drops off), and natural union of the adjacent parts follows.

Treatment should be directed to allaying irritation by emptying the bowel beyond the obstruction by copious 
enemas; but in no case should purgatives be given, as in the nature of the case they must aggravate the symptoms and endanger the patient. Pain must be allayed by fomentations and opiates, rest enforced, and vomiting quieted if possible.

If a positive diagnosis can be made moderately early, surgical procedure is indicated. The dog bears opening the abdominal cavity well. But this should be undertaken only by skillful hands, under strict antiseptic precautions, and after the operation the dog should be constantly watched, in a suitable compartment, by a discreet person, for at least twenty-four hours.

In some cases opening into the abdomen will be justifiable as a diagnostic measure. Very often a portion of intestine will require excision and the cut ends brought together by careful suturing. It is most important that ex treme cleanliness be observed, lest inflammation of fearful violence may be lighted up, or blood poisoning intervene.

\section{DISEASED CONDITIONS AROUND THE ANUS.}

Prolapse of the rectum-i. e., extrusion of a part of the gut-owing to a variety of relaxing and debilitating causes, as constipation, piles, etc., occasionally occurs. The indication is to reduce or put back the gut as soon as possible, before swelling, inflammation, or death and sloughing of the part takes place.

The gut should be washed clean from dirt with an antiseptic solution of weak carbolic acid or corrosive sublimate $(1$ in 2,000), the former preferred on account of its sedative action. There is no objection to adding a little laudanum or morphia, to still more allay irritation. The 
gut should be gently pressed back, the hind part of the animal's body elevated, then some cold water, or a solution made slightly astringent with tannic acid, injected gently and retained for a short time. The patient should have twenty grains of Dover's powder or a hypodermic injection of a quarter of a grain of morphia, to induce quiet and relieve pain.

If the intestine still tends to protrude, a special dressing or extemporized truss must be applied. No exercise should be allowed for some days, and then only gently. The bowels should be confined, and the diet nutritious and concentrated, but not abundant.

Piles are not uncommon in old dogs, especially if neglected. The circulation is weak, and if the strength fails becomes still weaker, so that injudicious management -as lack of exercise or a diet favoring constipation-leads to that portal (venous) congestion which tends to induce all sorts of digestive disorders. Any pressure, as from fæces, on the large gut tends to keep the veins over full, leads to loss of elasticity of their walls, slowing of the blood-current, coagulation within them, inflammation, ulceration, etc. Especially is this the case if the piles protrude from the anus. Blood in the stools, straining, licking the anus, dragging the hind parts, should lead one to suspect piles. So long as the piles are internal there is more hope of relieving the condition by medical treatment; when external, surgical measures will generally be required.

Treatment.-The indication is to remove the cause and allay irritation. Such food should be given as will of itself relax the bowel-as oatmeal or wheat-meal porridge with milk, boiled liver, or vegetables. A cure is hastened 
by the administration of laxatives, one of the best of which is sulphur, which dogs will generally take, when real hungry, in porridge, with milk or broth, or even in the ordinary food; but if not, it may be given mixed up in molasses, either with or without cream of tartar.

External piles may be treated with astringent and sedative washes, as a combination of tannic acid, glycerin, laudanum, and water; or with ointments of a similar character, as the officinal compound tannic-acid ointment, or one composed of oxide of zine with extract of belladonna or stramonium, ete.

It may be necessary to muzzle the dog to prevent his licking these off. The following will indicate the nature of such combinations :

B Unguent. zinci ox............ $z i j$;

Ext. belladon................ $3 \mathrm{ij}$.

M. Sig. : Apply three times daily.

B Acidi tannici.............. ₹ ss. ;

Morph. sulph............... gr. vj;

Glycerin................ 3 jss. ;

Aquæ................ ad $\xi$ iv.

Sig. : Apply this lotion several times a day.

When there is a tendency to inflammation without actual ulceration, the officinal compound lead ointment is very soothing.

Surgical measures are called for when such as the preceding fail.

Ligature and excision, or preferably the use of the thermo-cautery or the electro-cautery, the little tumors being grasped by a suitable clamp, have given good 
results. The dangers to be feared after operation are blood-poisoning, inflammation-as peritonitis, etc.-and hæmorrhage.

After operation, ice in cloths, held to the anus for some time, has proved useful in warding off these evils. The patient must be kept quiet and free from pain and the bowels confined.

Growths around the anus are mostly epithelial in character, as warts or polypi. When small, their treatment may be similar to that adopted when found in the mouth or other parts (see page 247); but when large, more care must be taken, as hæmorrhage may be difficult to control.

Excision, with the use of the thermo-cautery just afterward, may be demanded.

The differential diagnosis between such growths and cancer should not be difficult when the history and age of the animal are known. Cancerous growths, except during degeneration, are usually very firm. Cancer rarely attacks animals in their prime.

Perineal Abscess and Fistula in ano are closely related. Pus collected in the region of the perineum and constituting abscess is very liable, if not freely evacuated early, to affect the bowel and ultimately lead to an opening into it, constituting fistula, which is said to be blind when there is no external opening through the perinæum. The indication is to open the abscess and evacuate the pus by a free incision.

Fistula is rarely cured except by opening up the bowel and perineum, which can be done well by passing a grooved director through the external opening and then through the internal, turning the inner end out through 
the anus by the finger and incising all the parts that lie between the director and the exterior. A poultice or fomentation may be necessary for a short time afterward, and a little iodoform dusted on will tend to keep the parts sweet and facilitate healing. The diet should be simple and the bowels confined for a few days.

\section{DISEASES OF THE URINARY SYSTEM.}

We direct attention to certain anatomical and physiological facts important to bear in mind. Urine is secreted by the kidneys, a pair of organs situated in the loin (lumbar region), which are composed of a great variety of tubes of different shape and size, provided with numerous kinds of lining cells which secrete the constituents of urine, the whole of each organ being abundantly supplied with blood-vessels, lymphatics, and nerves. Urine is secreted constantly, and carried off to the bladder by a main duct (ureter) leading from each kidney.

The bladder is the receptacle for urine-a muscular organ situated in the pelvis, and lined with a mucous membrane. It communicates with the exterior by a tube or duct (urethra) of small dimensions, which passes in the male through the penis, but in the female it is short and opens into the ragina.

The urine of the dog is decidedly acid, of high specific gravity (1030 to 1050), clear and yellow, so that any dark color, turbidity, any stickiness from mucus, etc., should attract attention as probable evidence of disease of some part of the urinary tract.

Other symptoms which should lead to a suspicion of disturbance of this part of the dog's system are frequent 
or painful urination (micturition), dribbling or retention of urine, an awkward or straddling gait, tenderness over any portion of the urinary tract, nausea, febrile symptoms, etc.

None of these troubles are common in the dog; happily so, as treatment in bad cases is difficult to carry out.

Retention of Urine may arise from reflex spasm of the neck of the bladder or urethra, from swelling of the mucous membrane of the urethra, enlargement of the prostate gland, pressure on the urethra or swelling of this part from sexual excitement, traumatism (injury), the abuse of certain drugs, as cantharides, etc. Occasionally an excitable young dog after a long journey with confinement in a crate, or from the excitement of new surroundings, as in a bench-show, will be unable to empty the bladder. Generally he will do so if he be removed to an extremely quiet place, given perfect freedom, and has his mind diverted from what has been engrossing his attention and is soothed by words and caresses. However, if these fail, and the bladder is much distended, a warm bath should be given. The dog should be caused to sit on his haunches in a tub with enough water, as hot as can be borne, to reach above his loins, for twenty to thirty minutes. He should then be rubbed dry, and kept warm as a precaution against catching cold. If he still suffers, he may be given fifteen grains of Dover's powder and twenty grains of bromide of potassium. If the case grows urgent, an attempt to pass a catheter should be made. In the female this is not difficult, and the ordinary metal instrument used in human practice will serve the purpose, or a gum-elastic catheter suitable to the size of the bitch. 
In the male $\operatorname{dog}$ reaching the bladder in this way is not easy; a small gum-elastic catheter will be required. The dog should be laid on his side, the instrument warmed in hot water and well oiled, gently passed in till its point car be felt with one finger in the rectum, when it may be guided onward into the bladder.

This operation is to be avoided if possible, as it is neither easy to the manipulator nor agreeable to the dog; and if there be much struggling, harm may follow the attempt.

In extreme cases ether may be given, and, if the catheter can not be passed, an opening made into the bladder to save life ; otherwise rupture of the bladder and inflammation following this, if not sudden death, or uræmic poisoning result from retention of the material in the blood which the kidneys should remove; but it is seldom indeed that the treatment with opiates or the hot bath will not suffice.

Suppositories in the above and other painful affections of this region will be of great service if they can be retained in the rectum.

As an example of a suitable combination we offer the following:

B Pulv. opii................ gr. vj;

Ext. belladon ............... gr. iij;

Ol. theobrom.............. $3 \mathrm{ij}$.

M. Ft. suppos. no. vi. Use one every two to six hours, as needed to relieve pain.

Hot injections by the rectum of warm water medicated with laudanum or belladonna often prove very useful.

The dog may suffer from inflammation of the kidney 
itself (nephritis), of the bladder (cystitis), or from renal or cystic calculi.

As these are not very common affections, a general account, so as to enable a differential diagnosis to be made, will suffice.

The history of the case is important, and in all instances a careful physical examination should be made, to establish local tenderness if present, bladder distention, etc.

Tenderness over the loins when rheumatism can be excluded points to the kidney; tenderness above the pubes (between the thighs) to the bladder.

Ordinarily, percussion does not discover the dullness of the bladder, but on distention it should, while at the same time the hand may be able to make out a somewhat globular tumor.

Differential Diagnosis.-In acute nephritis the kidneys are swollen, and there may be escape of an albuminous fluid from the vessels, and of red blood-cells as well as leucocytes; hence albuminous urine, bloody urine, tenderness over the loins, with febrile symptoms, suggest acute nephritis.

Blood makes the urine "smoky" or brown in appearance. Blood may be positively diagnosticated by the microscope, or, better, with the spectroscope.

In Acute Cystitis, tenderness over the loins is not so likely to exist, though pain may radiate in various directions, and tenderness over the bladder is nearly always present. The urine is not so likely to contain blood, but the urine may be turbid, alkaline, or contain excess of mucus, which is not to be mistaken for albumin, which 
never constitutes a sediment, but is detected by boiling the urine and adding enough nitric acid to make it decidedly acid in reaction. If albumin be present, there will be coagulation.

In Chronic Cystitis the urine is often decomposed and alkaline when passed.

In Nephritis there may be frequent micturition from extension of the irritation from the kidney to the bladder, the alteration in the urine, etc.; but in cystitis there is always more or less trouble in this way. If there be abscess of the kidney, pus will appear in abundance in the urine.

Renal Calculus is often difficult to diagnose; but irregularity in the symptoms, with at times great pain and general tenderness over the kidney, are highly suggestive.

Cystic Calculus, or stone in the bladder, is also marked by aggravation of the symptoms at times, possibly blood in the urine, occasional retention of urine it may be, pain, etc. Small calculi may block the urethra and necessitate urethrotomy, or cutting into the urethra. While acute nephritis may be set up by cold, drugs like turpentine and cantharides, which should be used in the case of the dog with extreme caution, the forms of chronic nephritis so common in man are of extreme rarity in the dog.

Treatment.-In all these diseases warm and in every way comfortable quarters are essential. Food must be always easily digestible and unstimulating, but in the later stages of acute affections (convalescence), and in chronic affections, highly nourishing. In acute disease demulcent drinks, and in cystitis milk and lime-water, are especially indicated. In all, it is important to relieve pain with 
Dover's powder, suppositories, medicated injections, fomentations, hot baths, etc.

With care and ordinary good medical treatment, acute nephritis and cystitis tend to get well.

The chronic form of cystitis, and all affections dependent on calculi (stones, concretions), are very troublesome.

If stone in the bladder can be positively diagnosticated, an operation may prove successful; but there are great risks.

Washing out the bladder of the female dog with antiseptic and soothing warm solutions-as warm water containing boric (boracic) acid or carbolic acid, with a little morphia-is practicable, but not in the male, it is feared. Attention must be directed to maintaining the strength with tonics, good food, etc.

If from any cause uræmic poisoning is threatened, the bowels must be moved very freely. For this purpose jalap, in doses of fifteen to twenty-five grains, answers; but calomel must on no account be used, as it is especially liable to salivate. The purpose is to divert blood from the head and eliminate the poison. Warm baths should also be tried, keeping the head cool.

\section{DISEASES OF THE GENTTAL ORGANS.}

These are mostly of the nature of inflammations and their consequences, and morbid growths.

Inflammation of the passage from the bladder for the discharge of urine (urethra), termed urethritis, occasionally occurs in the dog as a result of irritation from some cause, including coitus with bitches similarly affected, or from unhealthy discharges of some part of the genital 


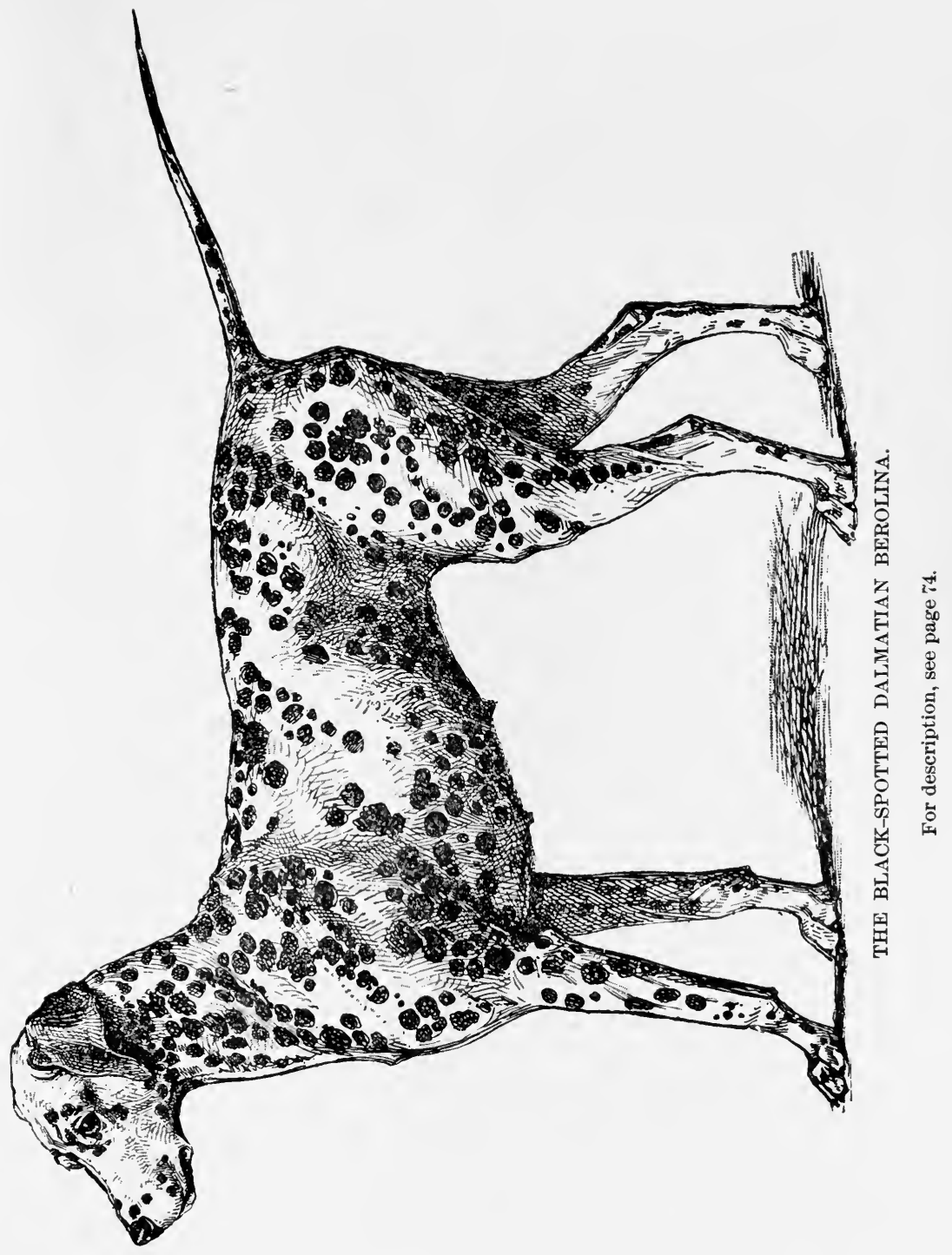




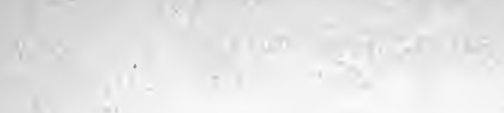


tract, from retained secretions in inflammations of the sheath, etc.

Some writers claim that the dog may have, like human beings, the specific inflammation known as gonorrhœa from sexual intercourse, and even syphilis. The subject is worthy of further investigation.

The symptoms of urethritis are uneasiness, possibly painful micturition, licking the penis, and especially a muco-purulent whitish or yellowish discharge, which can be traced within the penis-i. e., to the urethra.

Balanitis is an inflammation of the sheath (prepuce) covering the penis. The symptoms are as in the preceding, except that the urethral discharge is not a part of this disease, though the two may be associated, as they not infrequently are.

The sheath is swollen, tender, and soon gives rise to a muco-purulent discharge. The dog is disgustingly attentive to his genitals when they are affected.

If not relieved, the prepuce may become swollen to such a degree as to prevent the extrusion of the penis, (phimosis) and may even in some degree interfere with the passage of urine.

Occasionally, from long-continued sexual excitement, etc., the prepuce prevents the return of the penis within the sheath (paraphimosis), and the former becomes greatly swollen, and, in its exposed condition, liable to abrasions and ulcerations. The latter are apt to occur from pent-up discharges, as in balanitis, so that the whole may become very offensive to the associates of the dog, and a source of worry and humiliation to himself. The animal always licks the parts, his own method of cleansing and relieving 
pain and irritation. Inflammation may extend to the covering of the testicles (scrotum); or this may arise independently in old dogs, and requires attention lest the parts become the seat of malignant disease, as cancer or sarcoma. Balanitis in chronic form is common.

Treatment.-The indication in all these cases is to relieve irritation, both from the actual inflammation and from the discharges. The sheath should be kept clean by frequent washing with warm water or injecting up into it from a syringe the same, and, if this does not answer of itself, astringent and soothing solutions, such as tannic acid, sulphate of zinc, acetate of lead, etc., which are all the more effective if some glycerin be added.

A very good plan is to insert a little surgeon's lint or some cotton-wool dipped in the astringent solution within the sheath for twenty minutes. The addition of laudanum or morphia to the cleansing water or to the astringent lotion will be helpful.

In the case of urethritis, it will be necessary to inject one of these solutions after the use of very warm water into the urethra.

Such combinations as the following will illustrate how useful lotions may be made :

B Tinct. opii............... 3iv;

Acid. acet. dil............. $3 \mathrm{j}$;

Iiq. plumbi subacetat.......... $\xi \mathrm{j}$;

Aquæ................ ad $\xi$ viij.

Ft. mist.

Sig.: Apply or inject from two to four teaspoonfuls three to six times a day. 
B. Acid. tannic.............. 3j;

Acid. carbolic............. gr. xxx;

Morph. sulph............. gr. iv;

Glycerin................ $\xi$ jss. ;

Aquæ............... ad $\xi \mathrm{rj}$.

Ft. mist.

Sig. : Apply as the preceding.

Instead of the tannic acid, thirty grains of sulphate of zinc may be substituted in the above.

It is to be remembered that it is often desirable to change a lotion good in itself after it has been used a certain time, as it loses effect.

When there is much pain, Dover's powder, with bromide of potassium, may be given, or the soothing enemeta or suppositories referred to previously (see page $27 \tau$ ) employed.

The bowels should not be confined, but rather relaxed by suitable diet, or, if necessary, laxatives. Sometimes tonics and a complete change in the surroundings will do the dog much good. But little exercise should be given.

When phimosis or paraphimosis does not yield to such treatment, a warm fomentation sprinkled with laudanum or belladonna should be applied over the parts.

As a last resort and when death of the parts (penis, etc.) is threatened, all attempts at replacing the organ having failed, the sheath must be slit up with a very sharp knife or scissors sufficiently to allow the return of the penis. Circumcision may in some cases be necessary.

It is ever to be remembered, however, that a good surgeon never cuts or removes parts when other means suffice. It is easy to mutilate, but better to restore. 
When ulceration occurs, the healing process may be hastened by a touch with a crystal of sulphate of copper or nitrate of silver. Iodoform also has much to commend it. It may be necessary to muzzle the $\mathrm{dog}$, to prevent his licking off the applications and injuring himself thereby; but muzzling is always to be avoided if possible, as many animals worry under it to a degree that retards restoration to health. As the scrotum is so exposed, it will often be necessary when it is affected to cover up the applications by a dressing that may be kept on as long as desired.

Vulvitis, or inflammation of the external genitals, corresponds in the female with balanitis in the male, but is more readily managed. The parts are to be kept clean, and treated as in balanitis.

Vaginitis, or inflammation of the ragina or passage leading to the womb, when taken early, yields to astringent lotions, ete.

If chronic, attention must be paid to building up the health of the patient with tonics and the best of food, housing, etc.

Morbid Growths_as warts, polypi, etc. - must be treated as in other parts, always bearing in mind that the genitals, especially the mucous membranes, are very abundantly supplied with blood (vascular), and in all operations about them hæmorrhage is to be guarded against.

Ligation of growths, excision, and eauterization are the methods usually employed.

Prolapse of the Vagina, or eversion of the uterus, is rare except after parturition or in very debilitated bitches. The treatment is much as in prolapse of the rectum (see page 271). 
The indications are a speedy replacement of the part after perfect cleansing and disinfection, retention in position, and prevention of recurrence of the accident. Very often there is considerable pain, much straining, etc. If the stomach is not irritable, a dose of morphia or a hypodermic injection may be given at once. A soothing enema or suppository will generally be useful.

The parts should, before returning them, be thoroughly cleansed with a warm solution of corrosive sublimate ( 1 to 2,000 ) or weak carbolic lotion, to which a sedative-as laudanum, belladonna, conium, etc. - has been added. The hands of the manipulator should also be well washed and disinfected with the same solution. The replacement should be effected as gently and speedily as possible, and the hand, suitably covered, should, if necessary, guard the vulva to prevent extrusion afresh. The bowels should be opened by an enema, as any straining will almost surely lead to another prolapse.

The injection of cold water or astringent solutions (as above) will tend to prevent a recurrence of this evil.

Tonics should be given-as the pill of iron, quinine, and nux vomica-unless the bitch be febrile, when quinine alone will be better for the present. However, the general indications must be followed. Rigid rules are only misleading.

Metritis, or inflammation of the womb (uterus), is very rare except after parturition, when it becomes a most serious disease, causing the death of many valuable bitches annually. It is liable to follow on any sort of injury, external or internal, including the use of instruments, forcible removal of the after-birth (placenta), especially 
if the bitch has been much exhausted by the labor, or if any source of infection has existed.

The symptoms are pain, tenderness, possibly a purulent or more or less bloody or foul discharge, often irritating, nausea, fever, etc.

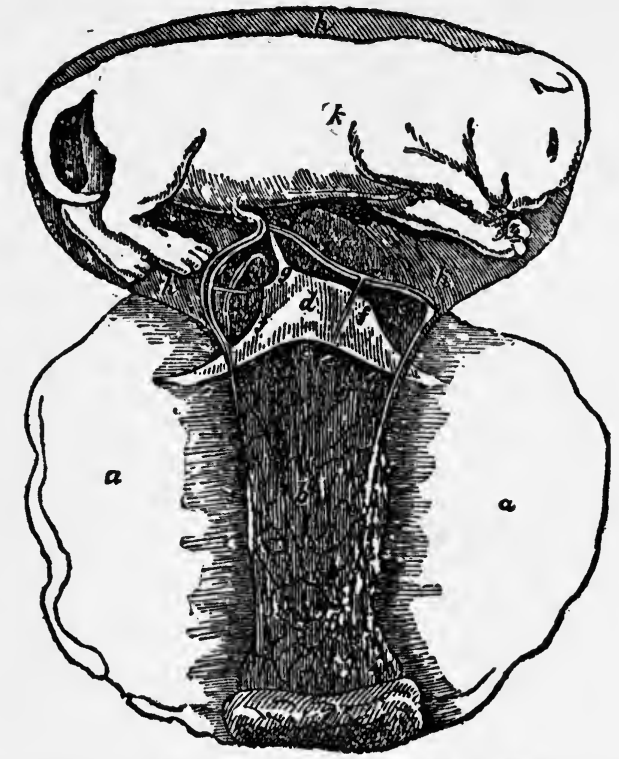

Fig. 18.-Fatus and its Membrane (Fleming).

$a$, chorion ; $b$, zonary placenta ; $d$, umbilical vesicle ; $g$, umbilical cord ; $h$, amnion ; $k$, fœtal puppy.

Diagnosis. - When the finger is introduced within the vagina toward the womb, indications of tenderness, swelling, etc., will suffice to point to the seat of the trouble, and to enable a diagnosis to be made between metritis, cystitis, peritonitis, etc.

This affection is very apt to be complicated with inflammation of neighboring parts, especially of the peritoneum, when the case becomes doubly dangerous. 
Prognosis.-This is bad when it follows parturition, and when there is a tendency to blood-poisoning, suppression of milk, etc.

Pathology.-The lining mucous membrane is first affected, and there is a tendency to a condition not unlike that often seen in the large bowel in the worst cases of dysentery. Parts of the membrane are apt to die. It may be that a portion of attached placenta is putrefying, and poisoning the whole system, or a sort of diphtheritic condition may arise which is often fatal.

Treatment.-The indications are to remove the cause, if attached placenta, blood-clots, etc. It may be possible to insert the hand and remove these, though not likely, when reliance must be placed on antiseptic injections, relieving pain, controlling fever, supplying concentrated nourishment, tonics, and often stimulants.

In a bad case of metritis, if there be nursing puppies they should be removed from within sight and hearing of the dam. If ever the gentlest and most soothing treatment is called for it is in such a case.

Unfortunately only too often, the stomach quite gives out, when food must be injected by the rectum.

The uterus may be washed out frequently with such antiseptic injections as are recommended in vaginal prolapse. These may have sedatives added if there be indications of pain.

Fomentations, very hot, frequently changed and medicated with opiates, etc., applied over the uterus as directly as possible, are of great service.

Quinine, in doses of four to six grains three to four times a day, is often called for, and, when blood-poisoning 
is threatened or actually occurs, is perhaps the most reliable medicine known. It might be worth while to combine chlorate of potassium, and, if much nervousness, bromide of potassium, with it. When the stomach is very irritable, the strength failing, fever high, or if there be delirium, etc., alcoholic stimulants are urgently demanded, and, if they can not be retained by the mouth, should be given in nutrient enemas.

But these cases are not hopeful, and every effort should be made to prevent their occurrence. Death usually results by blood-poisoning or exhaustion.

\section{COMPLICATIONS INCIDENT TO PARTURITION.}

These usually intervene in bitches improperly managed during gestation, as house pets unduly pampered, or specimens that have been overfed and little exercised. Occasionally labor is severe from the sire having been too large for the dam, the young to some extent resembling him in size.

In the entire management of the bitch during whelping the greatest attention should be paid to preserving her in a trustful, undisturbed state. (See "General Management of the Brood-Bitch and Whelping," pages 135, 141.),

Routine examinations of the parturient bitch by in. sertion of the finger in the vagina is uncalled for, and, as a rule, it may be said that the fewer examinations the better, on the principle that these are sources of irritation and possible infection.

If an examination must be made, as in a case of delayed labor, etc., the hands should be well washed, disinfected, and the examining finger anointed with carbolized 
oil (one to twenty) or simply with vaseline, the bitch kept perfectly quiet, and no force used.

Naturally, a bitch whelping for the first time is liable to be longer in giving birth to the first puppy. So long as there is no great constitutional disturbance, nothing to

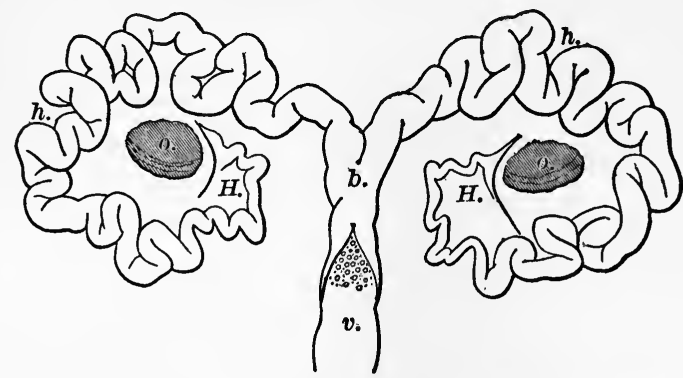

Fig. 19.-Uterus aNd OVaries of the Sow, semi-diagrammatic (AFTER DaLtoN).

$o$, ovary; $H$, Fallopian tube; $h$, horn of the uterus; $b$, body of the uterus; $v$, vagina.

indicate lack of muscular power in the uterus, no weakness or exhaustion, no foul smell, discharge, or other indication of a dead puppy, etc., patience is all that is required.

Occasionally false pains occur in the bitch near or just before the date of whelping. An opiate by the mouth, or an injection into the rectum of soap-suds medicated with laudanum (twenty to thirty drops), will relieve these. But in this and all cases it must be ascertained that constipation does not exist, for which an enema is the best remedy in such a case. When very severe, true labor pains may be mitigated by a dose of Dover's powder or of Battley's sedative solution of opium.

Malpresentations are very rare in the bitch, and puppies are so flexible that Nature often rights this matter. 
However, if a bitch has long been straining and to no purpose, the puppy being down within reach and pressing on the perineum, a little timely assistance during the pains only will facilitate progress. The hand alone should be employed in such cases. It may be that the puppy is presenting high in the vagina or in the uterus, and the natural efforts of the bitch do not suffice to move it. In that case the belly may be pressed upon during the pains and some part of the whelp brought within reach of the finger.

If a puppy is ascertained to be dead, from its being cold, etc., the sooner it can be removed the better.

The use of instruments is an important question. Considering the smallness of the passages in all but the largest specimens, the thinness of the vaginal and uterine walls, the readiness with which they are torn, bruised, or at least abraded, and the great danger of serious and infective inflammations, the subject becomes of grave import.

Except for the largest bitches, forceps, however small and well made, must be used with the greatest care, if at all.

We should be inclined to restrict instrumental interference to the worst cases only, with a view of saving the life of the bitch chiefly, and to such simple appliances as a very blunt hook or erotchet and a sort of snare, such as is used to remove polypi, etc., or some simple device extemporized for the occasion. All traction, whether with the hand or aided by instruments, should be steady, and only during the pains, unless these have quite ceased.

When there is a dead puppy in utero, and it seems to be hopeless to expect that the uterine contractions will expel it unaided, when the bitch shows signs of exhaustion 
and incipient blood-poisoning, as indicated by a dry, brown tongue, rapid, feeble pulse, great prostration, much nausea, etc.-prompt action is demanded, and unless she is soon relieved death will ensue.

All other means failing, opening the abdomen under antiseptic precautions is justifiable, and in skillful hands may prove successful After such an operation some thoroughly competent person should watch the bitch and keep her quiet, feed her, and in all respects meet her needs for the first twenty-four hours at least.

When should ergot of rye be given? Manifestly, as its action is to increase the uterine contractions, not when there is any obstruction from imperfect dilatation of the mouth of the womb, or any other impediment; but if the passages are dilated and covered with lubricating mucus, and the uterus at fault from inactivity, ergot may be given, always bearing in mind its danger to the young if they are not speedily expelled.

Very often a little whisky (one to two teaspoonfuls) given in a small quantity of beef tea, fluid beef, or milk and egg, or, if the stomach is not in a condition to bear these, simply in a small quantity of water, will result in calling forth efforts to a successful issue. Cold cloths applied over the lower abdomen are often effective in rousing the uterus to more vigorous efforts.

Post-partum Fever.-It is well, after the labor is over, to renew the bedding of the bitch, cleanse her behind with a weak solution of carbolic acid (one to eighty), dry well, and place the puppies at the breast.

Some, but not all, bitches show an elevation of temperature of one degree to two degrees within the first day and 
night. There may be a very sudden and abundant secretion of milk, and this increase in the heat of the body is the outcome of Nature's efforts to adapt to a new condition of things.

The food should be bland, largely liquid, and the nursing careful. No medicine is required. If the bowels do not move, an enema may be given, or a dose of castor oil, though it is to be remembered that all laxatives tend to diminish the secretion of milk.

But fever may arise from other causes. The secretion of milk may be arrested, there may be constipation, and if a chill and vomiting, there is ground for misgivings, especially if the discharge from the uterus is foul or totally arrested, and the mental equilibrium much disturbed.

Inflammation of the peritoneum or uterus is to be feared, and, if the labor has been severe or instruments used, septic parturient fever-i. e., fever owing to bloodpoisoning, which, unfortunately, only too often proves fatal.

The prompt measures recommended under "metritis" (page 287) must be taken and the puppies removed, as the milk is injurious, and the young only worry the dam. Fomentations, sedatives, judicious feeding, quinine, and stimulants, with all means possible used to keep the genitals free from the foul discharges are indicated. A turpentine stupe may prove useful applied over the uterus.

The mammary glands are liable to certain complications. One or more may be swollen, "caked," and ready to inflame. These must be milked out and softened with warm oil, gently and long rubbed in. If this does not suf- 
fice, and the redness, heat, etc., continue, fomenting with hot vinegar and water, to which a little laudanum has been added, may be useful.

Should an abscess form, it must be freely opened with the knife, or blood-poisoning may follow. The strength must be maintained, the bowels kept free, and pain relieved.

Fissure of the nipple is the presence of a small crack, which becomes extremely painful when the puppies suck.

I

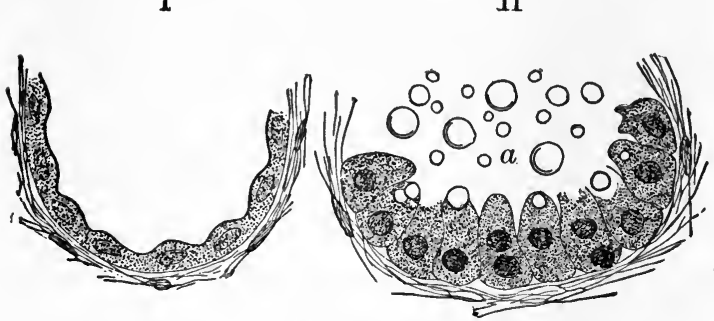

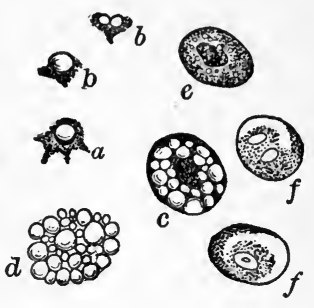

Fra. 20.-I. Portion of mamma of a bitch when inactive (after Heidenhain). II. During secretion of milk. $a, b$, milk-globules ; $c, d, e$, colostrum-corpuscles ; $f$, pale cells.

To harden the nipples, they may be washed a couple of days before the whelping with alcohol-only the nipples, not the glands themselves-and should be carefully examined for such fissures, or any signs of tenderness.

Occasionally a bitch from this cause will refuse to nurse puppies altogether.

Such a fissure had better be touched gently with nitrate of silver, or somewhat diluted carbolic acid, on a camel'shair brush, and then washed with the tannic-acid lotion recommended on page 283 .

If the nipple can be kept from the puppies altogether for a week, the prospects of cure are much better. In any 
case, the nipple should be washed with cold water after the lotion has been used, before the puppies suck.

Discharges from the genitals may indicate a condition of affairs within requiring treatment. The natural "involu. tion" of the uterus, etc., is attended by a breaking down of old structures, giving rise to a discharge for a few days.

Should this get foul, be attended by blood to any appreciable extent, become muco-purulent or thin and irritating, a condition of metritis or vaginitis, most likely of a subacute or chronic character, may be suspected in the absence of marked constitutional symptoms.

In these cases, injections of such lotions as before recommended, after previous cleansing, will generally lead to a cure; but unless these indications are met, the bitch is very likely to suffer considerably in health

Howorrhage of a serious kind rarely occurs during labor. Now and then, however, when the contractions are very severe, the whelp may be expelled with such force as to break the umbilical cord or tear away a part of the after-birth (placenta), when, unless the uterus contracts on the rest and expels it at once, bleeding will follow.

To stimulate contraction of the uterus and favor the arrest of bleeding from any cause, cold, applied in the form of external applications to the lower abdomen, a little piece of ice dropped within the vagina, or an injection of a small quantity of cold water, will usually meet the case.

Ergot of rye, when the uterus fails to contract after all the puppies are expelled, is indicated, other means failing. 
When prolapse of the vagina or eversion of the uterus is threatened, the perineum may be supported during the pains by the hand. Should these complications occur, the treatment is as previously directed (pages 271,283 ).

\section{DISEASES OF THE EAR.}

The ear is usually divided into external ear, middle ear (tympanum), and internal ear. The latter is the essential part of hearing, as it contains the auditory cells and the terminations of the auditory nerve. It is the most complicated sensory structure in the body, and is inclosed in a bony case.

The external ear may be regarded as protective to other parts of the organ, and serves to collect the atmospheric undulations that move the apparatus of the middle ear, which is made up of a membrane or drum-head attached to several small bones, the whole conveying the aërial undulations to the fluid within the inner ear, which fluid, when thus moved, stimulates the nerve-endings and gives rise in the nerve of hearing to those molecular movements which, being conveyed to the cells of that part of the brain concerned with hearing, give rise to that special consciousness and those judgments which we call "hearing." Vibrations from the atmosphere or from solids usually act throngh the drum-head, but the auditory nerve may be affected through the bones of the head directly.

The middle ear is protected not only by the outer ear (flap of the ear), itself covered with hair, but by the hairs within, and especially by ear-wax-a secretion from glands that are modifications of the sebaceous glands (ceruminous glands) - and which must be disagreeable to insects, 
as we know it is bitter and sticky, and is admirably adapted to resist wet, etc.

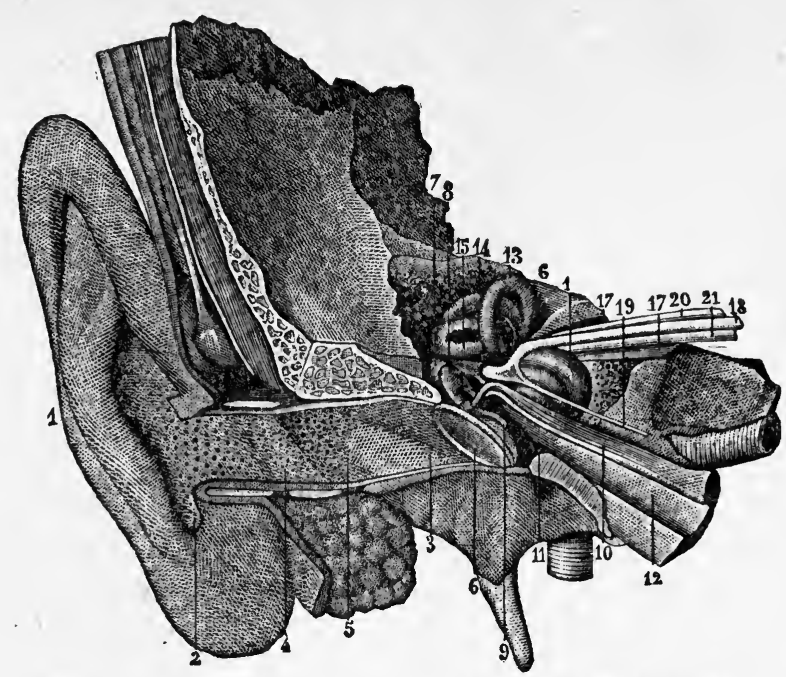

Fra. 21.-Section through Auditory Organ (AFTer SAPpey).

1 , pinna ; $2,4,5$, cavity of concha, external and auditory meatus with opening of ceruminous glands ; 6 , membrana tympani ; 7 , anterior part of incus ; 8 , malleus; 9, long handle of malleus, attached to internal surface of tympanic membrane-it is here represented as strongly indrawn ; 10 , tensor tympani muscle; 11, tympanic cavity ; 12, Eustachian tube ; 13, superior semicircular canal ; 14, posterior semicircular canal ; 15, external semicircular canal ; 16, cochlea ; 17, internal auditory meatus ; 18 , facial nerve ; 19 , large petrosal nerve ; 20 , vestibular branch of auditory nerve; 21 , cochlear branch of same. Though this cut refers especially to man, the relations of parts are essentially the same in the dog.

Canker, or disease of the external ear, is very common in the dog-more so than in any of our domestic animals. The exterior of the ear-flap may be the seat of various forms of disease independently of other parts, such as eczema, or it may become affected by extension of disease from within. The treatment in such case is little different from that of any other portion of the body when similarly disordered. Canker is an inflammation of the inner part of 
the external ear, but, if not checked, may extend both externally and internally. It begins with redness, swelling, etc., but is rarely seen in this stage except by those who are accustomed to make daily careful examination of all parts of the body of their dogs-a most excellent thing, which does not take much time, and often saves a great deal of worry to the owner and misery to the dog.

The dog even at this stage, feeling uncomfortable, may shake the head, scratch the ear, etc. Soon the usual inflammation with exudation, which dries and forms scabs, or actual pus may appear, run inward, become foul, irritate the drum-head, and give rise to inflammation of the middle ear. It greatly worries most dogs, and unless soon relieved they lose condition. The disease is most frequently attributable to wet and cold, combined with injudicious

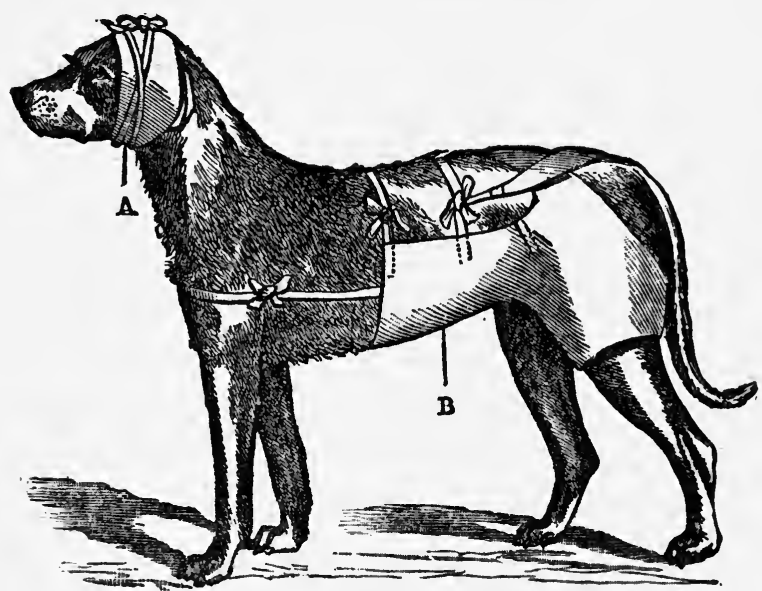

Fig. 22.-Vhrious kiNDS of BANDAGES (AFTER STEEL).

feeding, giving rise to general irritation of the whole skin, etc. The food may either be too stimulating or wanting in nutriment. 
It sometimes follows the dog's going into water, or a washing when the ears have not been carefully dried. There is a form of canker due to small parasites that irritate the surface. Often these vermin may be seen as whitish points. This form of the disease is contagious.

Treatment.-This should be prompt, to prevent extension of the disease. When the dog shakes his head much, it is desirable to control the flapping of the ears by some special form of covering, as a "canker cap." Some dogs, however, worry so much under any such device that the remedy is a failure. It may be more practicable in some cases to cover the hind-foot of the same side, so that the nails are ineffective.

The first great object in all kinds of ear disease is to remove all sources of irritation by cleanliness.

In the stage of redness, bathing with warm water and laudanum will do good. The oxide-of-zinc ointment is very useful in this disease in all stages on account of its soothing, drying properties; and it can be rendered still more useful, when the ear is red and painful, by the addition of a little morphia or opium.

It will generally be necessary, when the disease has got well inward, to use a good syringe and clean out the ear with warm water.

No unguarded probes or pointed instruments, and no cold liquids of any kind, must ever be used for the ear.

The liquid used should be as warm as can be borne against the human cheek. Often cleansing alone will effect a speedy cure. In all cases, however, when only water is used the ear should be carefully dried out with cotton-wool on the end of a blunt stick, etc. 
When the disease is chronic, astringent lotions, allied to those already advised for various forms of inflammation, are applicable. Tannic acid, borax, boric acid, zinc sulphate, etc., are all of value, and if some glycerin be used in their solution with water, they are more effectual, as they do not evaporate so soon.

The following may serve as an example:

B Acid carbolic............... 3 ss.;

Zinci sulph............... $3 \mathrm{j}$;

Sod. biborat................ $3 j$;

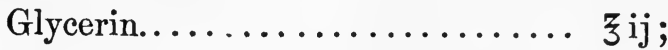

Aquæ................. ad $\xi \mathrm{vj}$.

Ft. mist.

Sig.: Pour in or inject a teaspoonful, warm, two to three times a day after cleansing with warm water.

The lotion recommended for ophthalmia, etc. (p. 309), is also valuable. In chronic cases tincture of iodine may do good. When there is much smell, iodoform blown in is invaluable. Medicated oils serve a good purpose.

If the discharge is profuse and the affection of long standing, astringent powders blown in will be more effective sometimes than liquid applications. Some of the best of these have been mentioned for lotions, and to the list may be added dry oxide of zinc and alum, or these mixed with subnitrate of bismuth to render them less powerful. For the parasitic form of the disease mercurial ointments are the most efficient. The yellow oxide of mercury, one grain to one drachm of vaseline, applied daily, often cures.

In nearly all cases the general health of the dog will require attention. The bowels should be relaxed, though purging is not called for. The alimentary canal is often 
at fault. It may be that alteratives, as arsenic, will be indicated.

When ear disease is chronic and the digestion is good, tonics-as iron, quinine, cod-liver oil, etc.-will hasten a cure.

Good feeding is as valuable as any part of the treatment. It should be very bland when the disease is acute, but nutritious. when chronic and discharges are profuse.

Otitis Media, or inflammation of the middle ear, as a primary affection is rare. It may arise from extension of canker, from blows or other injuries, etc., but sometimes it will not be possible to assign a cause.

At the outset the pain is often very severe; the dog may whine, cry out, or rub his head on the ground. In all such instances, if there are no external signs of disease, this affection may be suspected, especially if the cause can not be found in the mouth, as a decayed tooth, etc. After a few days pus is likely to issue from the ear, and then the disease simulates canker.

The danger to be most apprehended is extension to the brain, causing meningitis, or abscess of the brain itself, which may end fatally by pressure or blood-poisoning.

The prognosis should always be guarded.

Treatment.-The most urgent indication is the relief of pain by opiates, combined with bromide of potassium, warm medicated (belladonna, etc.) injections into the ear, and counter-irritation to the back of the head and neck. Warm syringing gives great relief, and should be frequent; but immediately after, the ear should be filled with cotton-wool dipped in a sedative solution and covered up well. Turpentine painted on moderately two or three 


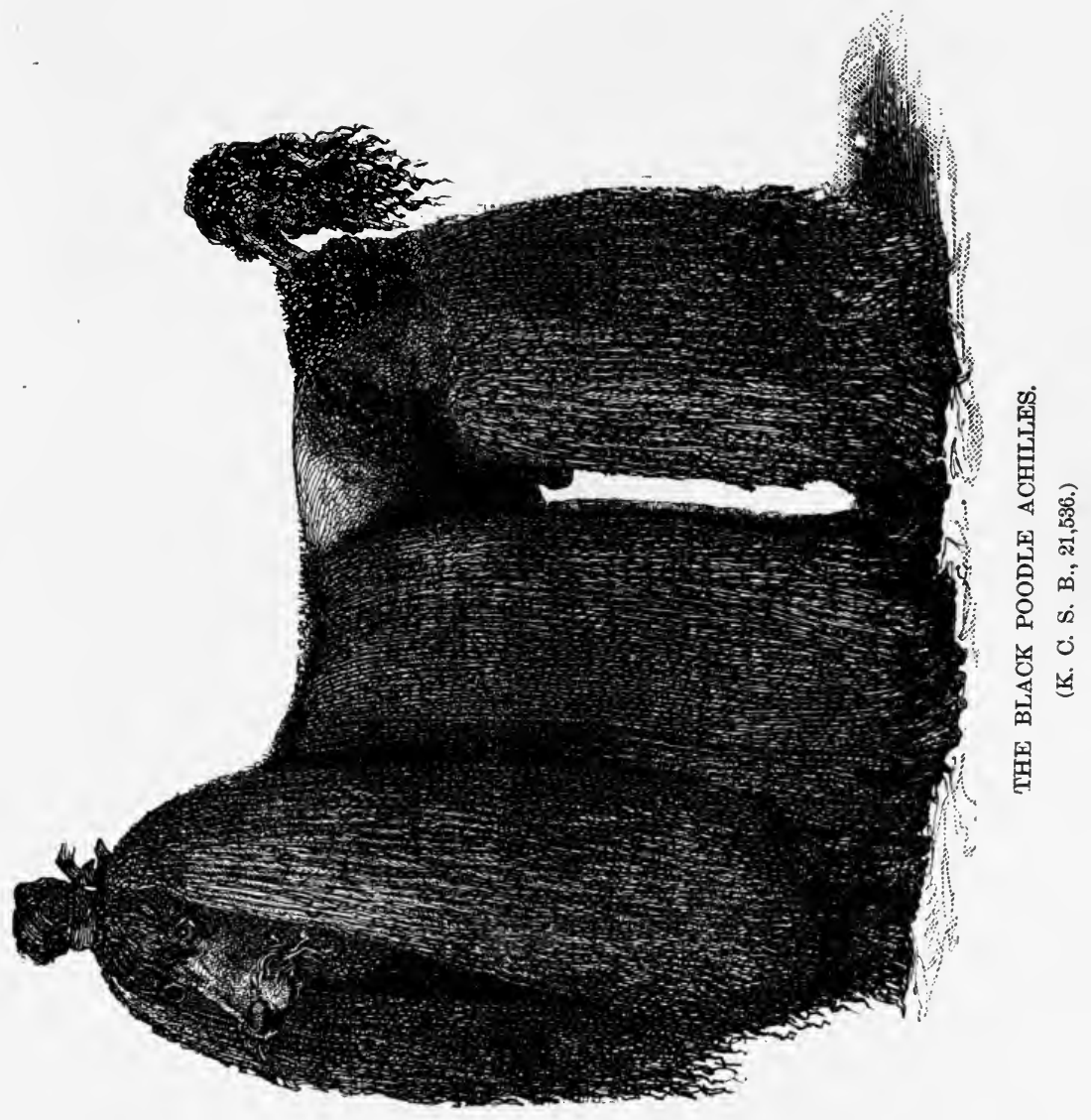


times a day is a good method of counter-irritation. When the acute stage is past and there is an abundant discharge, the treatment should be as for canker, though the powders referred to, carefully blown in, are even more needed than in canker. Constitutional treatment is also imperative in many cases.

When very chronic, the internal ear itself may become affected, though this is fortunately rare.

The disease, unless checked, will lead to the loss of the small bones, perforation of the drum-head (very common), and considerable deafness.

Deafness, to a certain extent, as a result of the last disease, is almost sure to be present, though not always readily observed. Old dogs, whose powers are all failing, are more or less deaf also, though less frequently than old men. There is a tendency in all white dogs, as bull terriers, to congenital deafness. A dog may be deaf in only one ear, but when born deaf usually both ears are defective. In testing for deafness the trials should be so conducted that the dog may not be able to perceive actual concussion of the earth, waftings of the air, or notice other signs which might attract his attention through sight or smell. It is well to make comparative tests on other dogs at the same time under the same circumstances. Deafness may be due to accumulations of dirt, wax, or both together, in the ears. After this has been softened by dropping oil into the ears for a couple of days, they should be well syringed with warm soap-suds.

Polypus of the ear is apt to arise from long-continued discharges from the ear, the result of inflammation (otorrhcea). When a discharge does not yield in a moderate 
period to treatment, a careful examination of the ear should be made with a speculum in a bright light. If a polypus is discovered and it can be reached with a forceps, snare, etc., its immediate removal is indicated, the base being cauterized with nitrate of silver or carbolic acid if possible, and the whole finally destroyed by repeated astringent applications (powders).

\section{DISEASES OF THE EYE.}

The visual apparatus consists of a series of refracting bodies which bring rays of light emanating from an object to a focus on the expansion of the optic nerve (retina) in the form of a clearly defined image, which so influences the nerve of vision that certain parts of the brain are affected, and "seeing" or "vision" results.

The principal refracting body is the crystalline lens. The essential apparatus (crystalline lens and retina), so far as the globe of the eye is concerned, is protected by a firm whitish outer tunic, lined within by a vascular (bloodsupplying) covering supporting the retinal expansion of the nerve of vision.

The main refracting body is supported in position by a ligament (suspensory ligament), the foldings (ciliary processes) of the vascular, pigmented coat (choroid), and the vitreous humor.

Light is admitted through the clear outer cornea, which is set into the rest of the globe as a watch-glass into its case. At the junction of this cornea and the firm outer coat (sclerotic) hangs, in front of the lens, a colored (pigmented) circular muscular curtain (iris) with the power to vary in size under the stimulus of light reflexly, so that 
the greater the quantity and intensity of light, the smaller the central opening ( pupil) in the curtain.

The globe of the eye is set in a bony socket, moved by several muscles, protected by the eyelids, eyebrows, eyelashes, and washed over with the secretion of a small gland

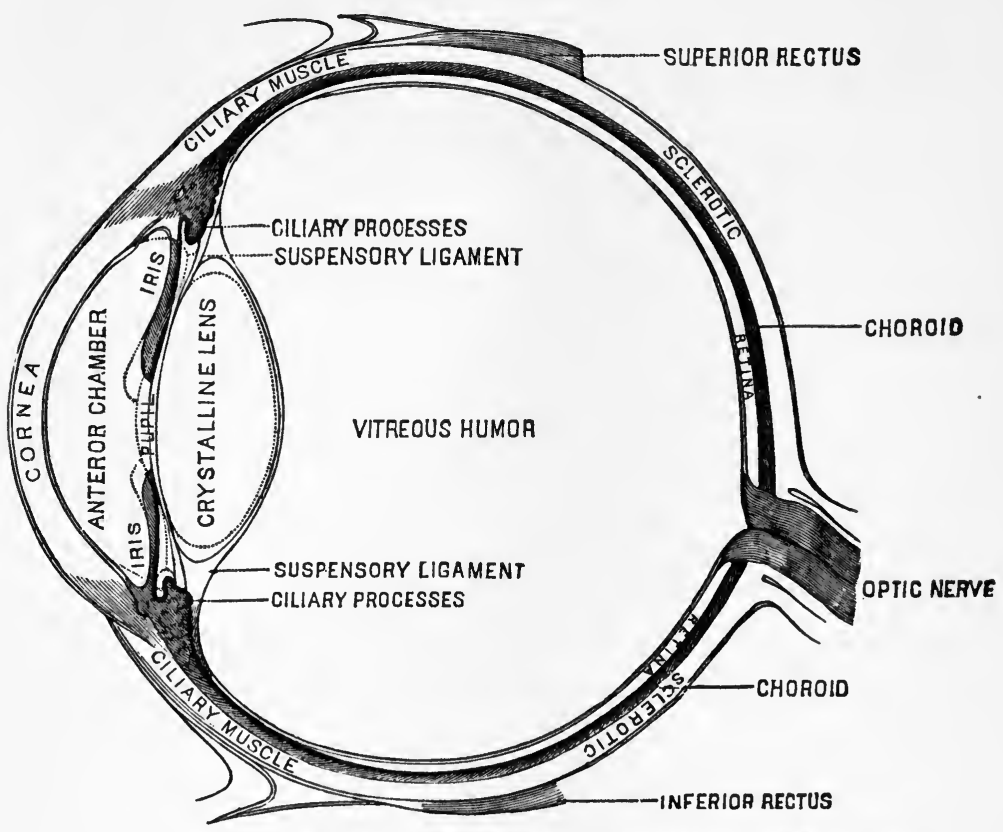

Fig. 23.-Section of Human Eye, somewhat diagrammatic (after Fuint).

(lachrymal) situated in the outer part of the socket. The secretion, when it has served its purpose, is carried away by the lachrymal duct into the nose.

In the dog, a third eyelid (membrana nictitans) is present at the inner corner of the eye, but is not so well developed as in herbivora, etc., though more prominent in some breeds, as bloodhounds. 
The gland of Harder is placed in connection with it, and secretes a protective oily matter.

It is important to remember the conjunctiva, a mucous membrane extending over the front of the ball, reflected on the inside of the eyelids, and terminating at their edges. It is very thin and transparent over the cornea.

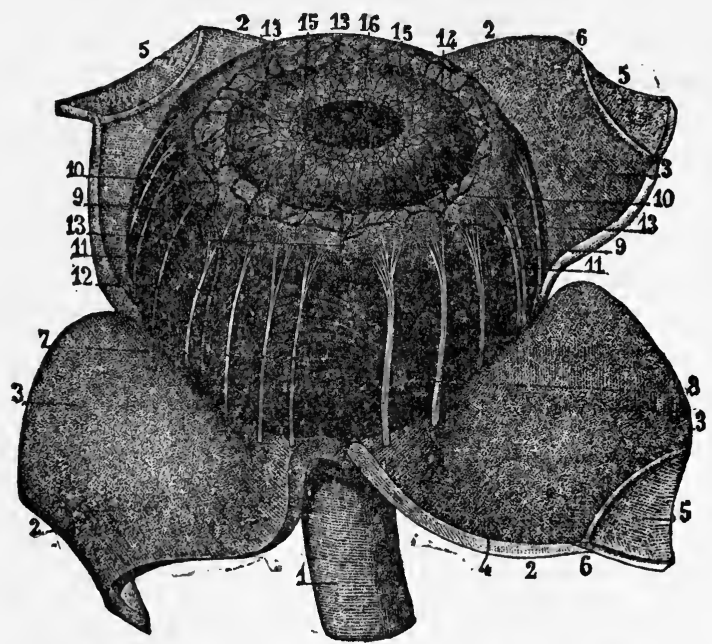

Fig. 24.-Eye Partially Dissected (AFTer SAPPey).

1. optic nerve ; $2,3,4$, sclerotic dissected back so as to uncover the choroid coat ; 5 , cornea, divided and folded back with sclerotic coat ; 6 , canal of Schlemm ; 7 , external surface of choroid, traversed by one of the long ciliary arteries and by ciliary nerves $; 8$, central vessel, into which the vasa vorticosa empty $; 9,10$, choroid zone ; 11 , ciliary nerves; 12 , long ciliary artery ; 13 , anterior ciliary arteries ; 14 , iris ; 15 , vascular circle of iris ; 16 , pupil.

While it is possible that any part of the eye may be the seat of disease, affections of certain regions are very uncommon, and it would serve but little purpose to give a complete account of all the diseases of the eye that have occurred at any time.

The eyelids, eyebrows, eyelashes, lachrymal apparatus, 
third eyelid ("haw"), and lachrymal ducts are more especially the protective apparatus of the eye, and affections of some of these parts are common.

Diseases of the Protective Apparatus of the Eye.-Not infrequently, especially after distemper, the eyebrows and eyelids are affected with a troublesome eczema, which must be treated on the general principles that apply to that disease.

Occasionally, particularly in neglected, ill-fed dogs and after distemper, the edges of the lids also tend to inflame and remain in a condition of chronic irritation, leading to exudation, scabs, loss of eyelashes, etc.

The condition does not always yield readily to treatment. The lids should be bathed with warm, soothing lotions, as boric acid and laudanum, dried, and anointed with vaseline, while attention is paid in every way to the general health and the surroundings.

If this simple treatment is not effective, it may be necessary to apply a mercurial ointment, either the red oxide-of-mercury ointment (pink ointment), three grains to one drachm of vaseline, or, better, the officinal nitrate-ofmercury ointment (citrine ointment), one drachm to one ounce of vaseline.

As these are very irritating to the eye, they should be confined to the lids. All mercurial ointments kill parasites which occasionally attach themselves to the edges of the lids. When such preparations are used it is most important that no other dog get near the patient, as he might lick them off and be poisoned with mercury, which in the dog happens readily and is very fatal. 
Inflammation and Abscess of the lachrymal gland now and then occur in the dog, and, when it does, should be treated on the general principles that govern other inflammations. It is important that no secretions be pent up.

The Lachrymal Ducts also may become the seat of inflammation or catarrh, giving rise to swelling, so that the tears are not carried off, but run over the cheeks.

If possible, after soothing treatment in the acute stage, a probe should be introduced and the duct opened up. A cutting operation, as slitting up the duct, may be required. Altogether they are most unsatisfactory cases to deal with, and the practitioner must be guided by the indications in each instance.

The haw, or third eyelid, may inflame and greatly enlarge. This condition, when acute and of short standing, may be treated with soothing and astringent lotions; and very often these will reduce the structure to a natural size within a moderate period. If not, it must be seized with forceps, drawn out, and snipped off, the dog being under the influence of an anæsthetic, as in nearly all other operations on the eye, so that nicety in results may be attained and accidents may not occur from the struggling of the animal. The application of cocaine may render an anæsthetic unnecessary.

Conjunctivitis, or inflammation of the mucous membrane of the eye.-The eyes in the dog, more than in any of our domestic animals, reflect the condition of the constitution, especially the state of the digestive and respiratory tracts.

There are all degrees of abnormality in the conjunctiva, from simple injection or redness, with little or no 
discharge of any kind, to the extreme redness, swelling, and purulent discharge of ophthalmia.

We have very often to deal with a catarrh of the conjunctiva akin to that of the nose during and after distemper as well as from general disorder of the digestive tract or the economy as a whole.

This catarrh may be regarded as a conjunctivitis, which, according to the symptoms, may be acute, subacute, or chronic, and is to be considered apart from ophthalmia.

Diagnosis.-In influenza the discharge is nearly always thin, especially for some days. In the catarrh of distemper, etc., it is thin at first, but soon becomes mucopurulent.

Ophthalmia.-The local symptoms are very severe, especially in the worst form, the lids being swollen (oxdematous), the conjunctiva very red, thickened, tender, and the seat of a copious purulent discharge. It is a violent inflammation of the mucous membrane, affecting more or less the whole eye sympathetically (reflexly, etc.).

There is pain, intolerance of light (photophobia), febrile symptoms, and general disturbance. Damp, dark, unhealthy kennels, bad feeding, etc., are predisposing causes.

There is difference of opinion as to how far purulent ophthalmia is contagious or infectious. However, it is practically better to assume that it is very liable to attack other dogs in the kennel, and accordingly to remove the sufferer to a quiet, comfortable, but somewhat darkened, place by himself.

Treatment.-The indications are to allay pain and irritation both by local and constitutional measures. 
The disease can not be aborted, but its severity may be mitigated and complications may be prevented.

The dangers are that adjacent structures may take on an inflammatory condition, and that abscesses and sloughing, or loss of structure, may result. Ulcers of the cornea are common after this disease.

Cleanliness, in the medical or surgical sense, can not be too much insisted on in all such diseases-i. e., all discharge must be frequently removed.

This had better be done without actual contact of the hand as much as possible, as the eyelids are extremely tender.

Warm water may be allowed to trickle from a sponge into the eyes, or, better, from a piece of cotton or lint, which, if brought in contact with the eyes at all, should be frequently renewed. The water should be as warm as can be borne comfortably. In the intervals a hot fomentation, medicated with belladonna if the pain be severe, may be laid over the eyes, but not long enough to retain much secretion before washing is resorted to again. Warm water may be poured into the eyes from a little kettle or teapot in a gentle stream.

A few drops of the officinal solution of atropine may be dropped into the eye two to three times a day, taking care that it does not run into the dog's mouth (poisonous).

The application with a camel's-hair brush of a solution of nitrate of silver, of a strength of ten to twenty grains to the ounce of water once or twice daily, has been found generally useful. For a lotion to be used more frequently, the following is recommended, and is useful in many catarrhal conditions of the eye : 


$$
\begin{aligned}
& \text { B. Zinci sulph.............. gr. xvj; } \\
& \text { Morph. sulph............... gr. iv ; } \\
& \text { Aquæ................ ad } \xi \text { iv. }
\end{aligned}
$$

Ft. mist.

Sig. : Apply several times daily as a lotion to the eyes. Sometimes boric acid, ten grains to the ounce of water, answers better than the sulphate of zinc.

The colorless fluid extract of golden seal, one part in six or eight of water, may be combined with other astringents, as sulphate of zinc, though this mixture is better adapted for ordinary forms of conjunctivitis.

An excellent prescription for this and other forms of inflammation of the eye and ear is Goulard's extract of lead (or Goulard's water) combined with morphia or opium in water, thus :

Bu Goulard's ext. plumbi......... 3 ss.; Ext. opii liquid.............. $\xi$ ss.; Aquæ.................. ad $\xi$ iv.

The quantity of the first ingredient may be double for use in the ear. The patient should be given abundance of bland, nutritious food.

If he does not sleep, and is very restless, Dover's powder combined with bromide of potassium is indicated.

Counter-irritation to the back of the head and neck will be found serviceable in all acute inflammations of the eye and ear.

Ulcers of the Cornea are apt to result from this and some other conditions. They are very slow to heal, and prevention is much better than cure.

The use of atropine and stimulating lotions and ointments has answered best. 
One of the most useful remedies is the yellow oxide-ofmercury ointment recommended for granular lids below. A small quantity of calomel dusted over the ulcers often does good.

Granular Lids.-A condition resulting from long-continued irritation of the mucous membrane, with more or less prominent elevations on the inside of the lids. These are a source of no little irritation to the cornea, and the eye as a whole.

Treatment.-At first a gentle application of a smooth crystal of sulphate of copper, and, immediately after, washing over the everted lids with a camel's-hair pencil dipped in water.

The upper lid is easily everted with a little practice by placing a rather small pencil or pen-handle over it and then seizing the edge of the lid and lashes and turning it back. The lower lid can readily be drawn from the eyeball or everted in a similar way.

A most useful application is an ointment made from the amorphous yellow oxide of mercury, one to three grains to one drachm of vaseline. A piece the size of a hemp-seed suffices for a single application.

The same treatment is excellent for opacities of the cornea, which are apt to result from granular lids or inflammation of the cornea itself.

The latter occurs during distemper, the whole cornea becoming cloudy or steamy in appearance. Generally it clears up without local treatment being specially directed to it.

Iritis.-Inflammation of the iris may occur independ. ently, or as a complication of other diseases of the eye. 
It is recognized by an alteration in the appearance and mobility of the structure. It assumes a dirty hue; the pupil may be contracted, or very irregular in shape.

Treatment.-Counter-irritation to the back of the head, atropine dropped into the eye frequently, and regulation of the general health.

Cataract is a whitish opacity of the crystalline lens, and may be either complete or partial. As the light is thus shut out, the eye is more or less useless.

It is rare in young dogs, but not uncommon in old ones.

The lens may be removed, as in man, but the sight is rather imperfect without glasses, which we fear even the most intelligent dog could scarcely be induced to wear.

If only incipient, attention should be paid to the general health by tonics, etc., to prevent its increase.

Amaurosis and Amblyopia are terms used to indicate blindness without obvious alterations in the structure of the eye.

In all such cases an ophthalmoscopic examination of the eye should be made by an expert.

The causation is obscure, but irritation from worms in the digestive tract, defective action of the liver, exhaustive diseases, etc., seem to be associated in some cases.

The presence of brain disease should be suspected in alterations of the pupils, squint, photophobia, loss of vision, etc., when other cause is not obvious.

The possibility of parasites lodging within the eye is not to be forgotten. The treatment of amaurosis must be in accordance with the cause and general condition of the animal. No local treatment is likely to be of any use. 
Dislocation (extrusion, protrusion) of the eyeball may result from violence, as fighting, etc.

If the parts are not clean they should at once be washed with an antiseptic solution, and, by gentle pressure, oiling well with vaseline, returned before swelling and inflammation have set in. If some time has elapsed, the eye should still be pressed back, if possible, before operative procedures are undertaken.

After replacement the head should be bandaged for a few days, cotton-wool being laid over the eye itself. If there is danger of inflammation, surgeon's lint dipped in the lead lotion referred to previously will tend to soothe. The dressing should, of course, be covered with impermeable material to keep the whole moist.

Squint can in some cases be remedied by operation, and it may be worth while if the dog be very valuable, though in most instances the services of an oculist will be desirable.

\section{DISEASES OF THE NERVOUS SYSTEM.}

The nervous system consists of nerve-endings, nervefibers, and nerve-cells. The cells alone are capable of originating influences (impulses), or modifying them when carried to them by the conductors or nerves. The nerveendings are specially modified cells adapted for receiving the stimulus from the outer world. All the sensory organs may be regarded as more or less complex combinations of nerve-endings. The principal centers are the brain and spinal cord, which in reality are groups or communities of organs, just as the alimentary canal is a group of organs, and we must expect to find localization and 


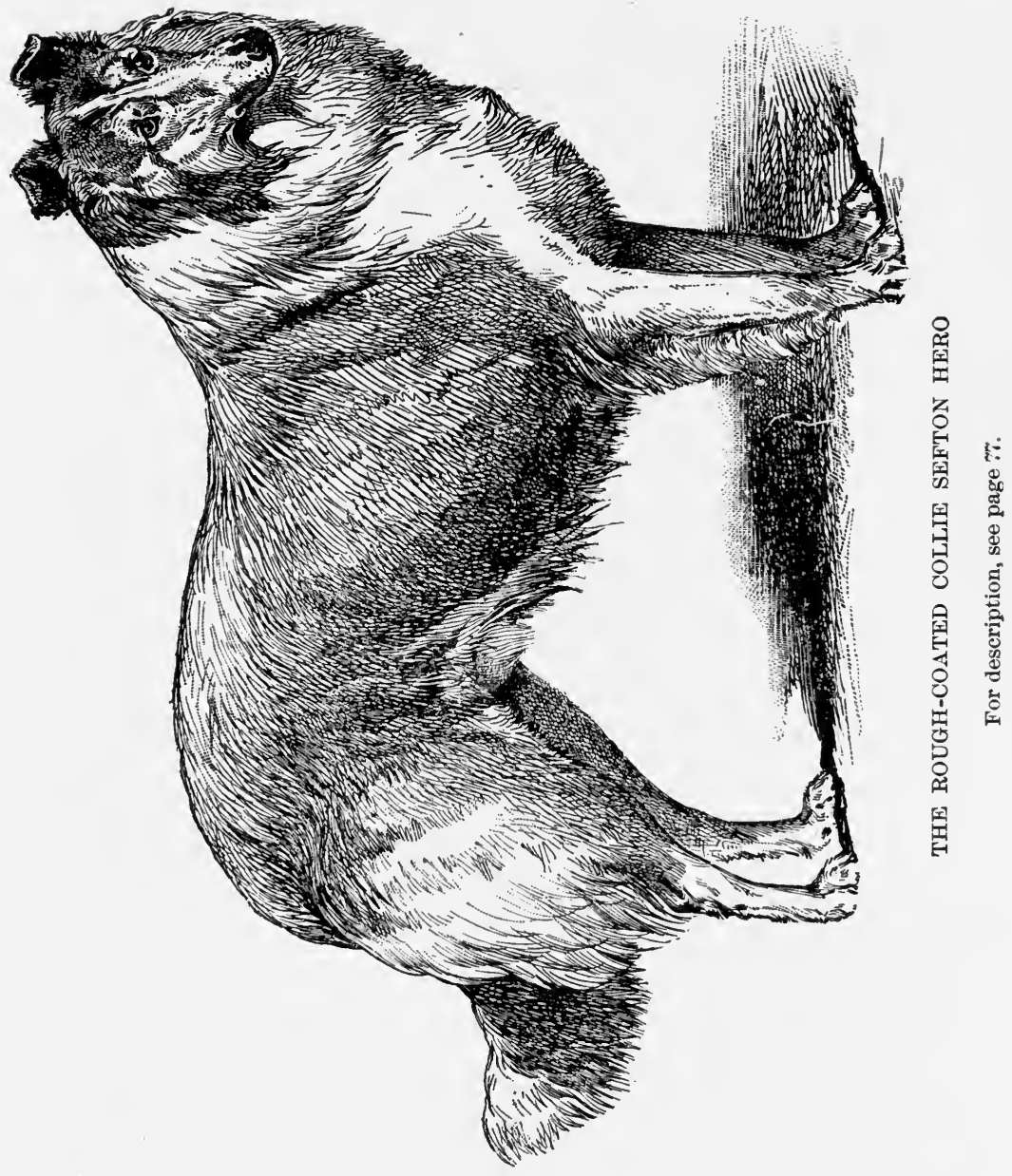



specialization of function in the spinal cord, and especially in the brain, as elsewhere.

We may compare the brain and spinal cord to the great collection of central offices of a vast telegraphic system, with the nerves as the conducting wires, and the nerve-endings as the outlying smaller, less important offices of the system. Another useful comparison, especially in understanding the functions of the cord and reflex action, is that of a battery representing the central nerve-cells, and the circuit as completed by the nerves and nerve-endings representing the wires.

The connection of every part of the body with the central nervous system and with the other regions, so that all the parts constitute a related (co-ordinated) whole, is one of the most important truths to be borne in mind by both physiologist and practitioner.

The nervous system in the dog is well developed, yet somewhat unstable; hence functional disease of this part is common.

Rabies (Hydrophobia).-This is the gravest of all the diseases of the $\mathrm{dog}$, both as regards the canine and human species, since it is invariably fatal, and is common to the dog and many other animals. The disease has been much misunderstood and dreaded by the non-professional portion of the public, though it is to the credit of dog-breeders that they have generally taken a sensible view of the subject.

Rabies has been treated at great length in some works, much useless speculation being indulged in up to within recent years, when the illustrious Pasteur put the subject on a more scientific basis. We have still a great deal to 
learn in regard to predisposing causes, and the real pathological lesion, if there be such visible by the microscope; while we are utterly in the dark as to any method of treatment that has the slightest effect when once the disease is established.

Rabies may be regarded as a specific disease of the nervous system leading to a fatal issue, and in the course of which all the various functions of the body may be more or less abnormal though the psychical changes are the most pronounced.

The cause is a virus or poison communicable by a bite from the affected animal owing to the poison being in the saliva. It is known that inoculation with the saliva will produce the disease.

Protection (immunity) against rabies has been produced by Pasteur by inoculations of the weakened (attenuated) virus obtained from the portion of brain next to the spinal cord (medulla oblongata).

The period of incubation or latency of the disease is more variable than in the case of any malady known to us. It seems to vary between a few days (ten to fifteen) and many months, if not even years.

The animals affected may show symptoms that vary sufficiently to warrant a division into two distinct formsthe excitable, furious, or maniacal, and the paralytic. It is to be borne in mind, as said before, that in this, as in all diseases, absolutely typical cases are rare, and the dog may be sick unto death with either form and not attract very marked attention. Death usually results in from two to ten days in the furious form, and in a much shorter period in dumb rabies. 
Pathology.-No absolutely characteristic post-mortem appearances are known. Evidently the changes are functional modifications of the brain-cells chiefly.

Symptoms.-These are principally expressed in the behavior and appearance of the dog. At first he may be very quiet, shy, sullen, inclined to hide away in corners; but sooner or later he is likely to show more or less excitement. The dog is profoundly altered in his psychic nature, and this is most evident to those who are accustomed to observe dogs, though in well-marked cases obvious to any one. He may seem more affectionate than usual, or the reverse. If a bitch, she may be sexually excitable, inclined to solicit attention from dogs of the opposite sex. Much stress must be laid on perverted appetite, the animal swallowing all sorts of foreign material -as sticks, stones, straw, even its own fæces and urine. The voice is altered to a short bark, often ending in a sort of howl or moan which is characteristic.

At this early stage the animal may or may not snap at objects or champ the jaws.

During the excitable stage, which may be well-marked or the reverse, the dog is prone to roam over wide tracts of country at a jog-trot, head down, tongue out, but not usually frothing at the mouth, with a dejected look and indifferent to what is about him, yet snapping at any animals that happen to come in his way. He may return to his home if not interfered with. The biting and snapping should not be regarded as deliberate, but as a sort of reflex action, or at all events as more or less unconscious. It is then the $\operatorname{dog}$ is most dangerous to other animals. A sort of bluish tinge to the mucous membrane of the mouth may 
appear, and should assist in diagnosis. He will not usually eat, and for this reason, and because of the general dis-

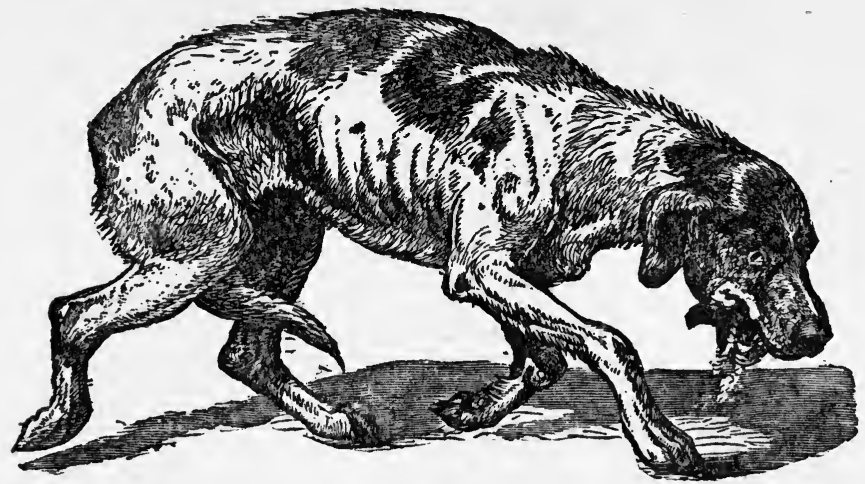

Fig. 25.-Representation of a Dog affected with Rabies (after Sanson).

turbance, sleeplessness, etc., he rapidly loses flesh. His eyes, altered in expression from the first, get more abnormal, and his whole appearance is extremely haggard. The excitement may periodically result in convulsive paroxysms, death resulting in one of these, or from the exhaustion that follows them.

Diagnosis.-Discrimination lies between epilepsy, or fits of various kinds, arising from the heat of the sun as dogs run the streets, neuralgia, toothache, meningitis, excessive fright, acute ear disease, parasites in the nose or brain, the distress of dogs lost in a large city, of bitches deprived of whelps, etc.

If the dog has been bitten and symptoms of a suspicious character follow, he should be isolated at all events and kept under observation. The bark of the rabid dog is very characteristic, and careful examination and observation should enable one to distinguish between the dis- 
turbance arising from real pain or mental distress and the altered behavior of rabies.

"Fear of water" is a pure hypothesis so far as the $\operatorname{dog}$ is concerned, nor, in the absence of paralysis, is there necessarily any difficulty in swallowing from spasm of the muscles concerned: The history and the entire assemblage of symptoms must be the basis for diagnosis.

The paralytic form of rabies (dumb rabies) is more insidious in its attack. There is not usually any excitement, but very soon after the onset of the disease, manifested by listlessness, the muscles of mastication become paralyzed, so that the lower jaw drops. There is no maniacal stage.

These forms do not constitute distinct diseases, and both may occur at the same time in the one kennel. In a word, the variations in the disease rabies are wholly de-

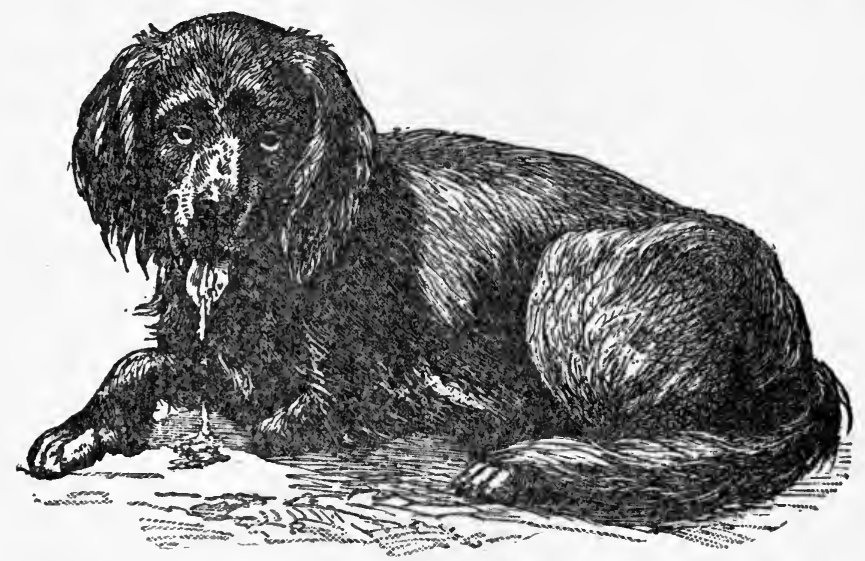

Fig. 26.-Representation of a Dog suffering from Paralytic Rabies (aFter Sanson).

pendent, so far as known now, on the amount of the poison introduced into the animal, and on the latter's individual peculiarities of constitution. 
Dumb rabies seems to be more prevalent in hounds kept in packs than in other varieties of the dog.

Treatment.-The disease can not be conveyed by the digestive tract, so that there is no danger in sucking a wound to extract the poison, provided the lips, etc., are free from cuts or abrasions-i. e., so long as they are protected by the natural covering of epithelium.

Sucking the wound, a handkerchief twisted tightly beyond the wound to prevent the return of blood as much as possible into the general circulation, and especially vigorous and prompt use of the actual cautery, in the form of a red-hot iron or the solid stick of nitrate of silver, constitute the best treatment. It is a good thing to carry the latter always in the vest-pocket, in view of emergencies of different kinds. In the ease of man, the subject should be at once subjected to the Pasteur treatment, which has undoubtedly produced marvelous results.

The dog should, if possible, be treated in the same way; but if the disease has actually developed itself and the diagnosis is certain, a painless death for the animal is the clear indication.

The rabid dog should be not only confined in a suitable place, but secured by very strong and reliable fastenings. But as all animals bitten do not become rabid, it is not necessary to kill a dog bitten by a rabid animal at once, for he may wholly escape; and instances are given of dogs repeatedly bitten that never took the disease-in fact, in this, as in other maladies, some animals enjoy a natural immunity; but in any case secure isolation is imperative.

Convulsions, Epilepsy, Fits, Apoplexy.-All the normal movements of the body are the result of harmonious or 
co-ordinated functional activity of the neuro-muscular mechanism-i. e., of the nerve-centers, nerves, and muscles. In a fit or convulsion this is not the case; the movements are irregular, purposeless, and generally are injurious, and always wasteful of the energies of the animal.

Epileptiform convulsions are due to an irregular discharge of the nerve-cells, which are in a highly unstable condition; they are independent of the will, occur during unconsciousness, are not dependent on a stimulus from without, but usually on no stimulus that we are able to trace, or else upon some tumor, etc., of the brain.

They occur unexpectedly, last a variable period, the spasms are usually either of the nature of one prolonged muscular contraction (tonic), or from the first or following on the other variety they consist of alternate contraction and relaxation (clonic). The dog usually froths at the mouth, and may bite the tongue. Epilepsy may be hereditary, or due to injuries to the head which have resulted from severe concussion, new growths, to the irritation of worms, etc., though it is better to speak of the disturbance in such cases as convulsions which may be epileptiform in character and reflex, as they certainly are when due to teething and worms.

Fits, then, may arise from teething, from worms, indigestion, and a variety of causes, such as exhausting diseases, nursing puppies to the point of debility, or the virus of certain diseases, as distemper.

Treatment.-During the fit nothing can usually be done but to prevent the animal injuring himself as far as possible, and from escaping when deranged mentally. If 
the fits be due to a recognizable cause-as worms, overfeeding, etc.- this must be removed of course.

Habitual epilepsy had better be treated with bromide of potassium conjoined with some bitter. Sometimes small doses of iodide of potassium prove useful. In all cases of fits special causes of excitement must be removed.

As the purpose of treatment is to obviate the tendency to irritability of brain-cells and often excess of blood in the head, bromide of potassium will be worth a trial in most cases of convulsions.

The body should be kept warm and the head cool.

It is often well to hold a dog quiet and soothe him, and wet the head. In no case should one dog be allowed to see another in a fit, as it may induce a like condition, or produce at least a shock, if it does not cause an attack upon the victim. Dogs at shows sometimes grow very excited. They should be removed to a quiet place, or fits may result; cold to the head, and bromides, are also indicated. If in any case of fits such measures do not suffice, the dog may then be placed in a warm bath, the head being kept cool.

However, on account of the reaction and the danger from cold, this is not to be done unless other measures fail. The convulsions of strychnine poisoning and all forms of fits, when the stomach is very irritable, may be treated by rectal injection of twenty to thirty grains of chloral hydrate. In extreme cases, from whatever cause, when death is threatened by a succession of fits, a little chloroform and ether in equal parts may be cautiously given by inhalation.

After fits dogs should always be kept in a rather dark, quiet place, free from all excitement for a while. 


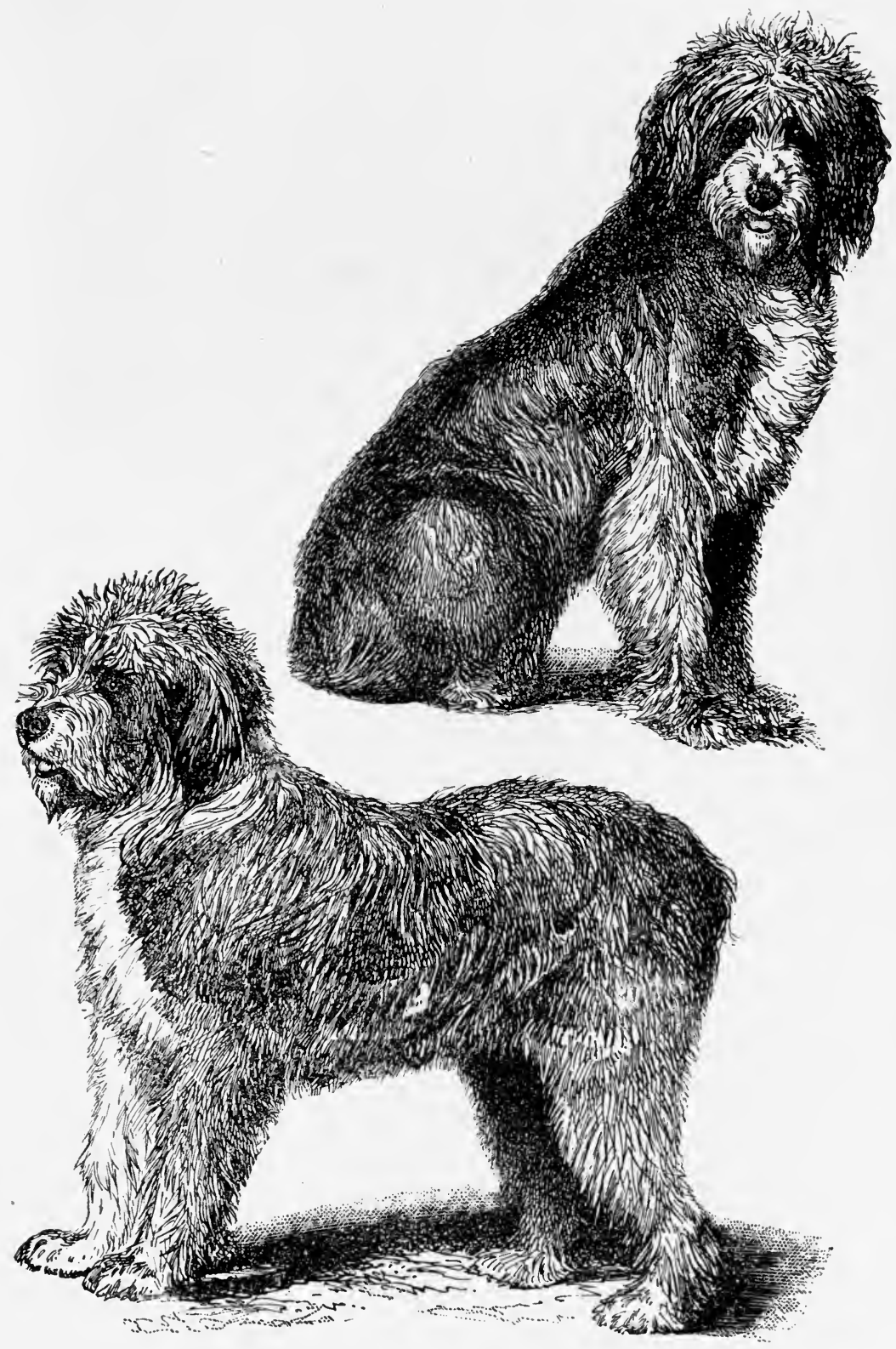

THE BOB-TAIL SHEEP DOGS GRIZZLE BOB AND DAIRY MAID,

For description, see page $\tau 8$. 

Vertigo, or dizziness, is apt to occur in dogs, that are overfed, when taken a-field. They may reel, sit down dazed, or fall over, without usually losing consciousness. Generally attention to the digestive tract, and exercise gradually increased, remedy this state of things.

Apoplexy is a term that has been used for a sudden attack, with loss of consciousness, possibly convulsions, the former not being of brief duration, as in epilepsy, but more lasting.

The causes are as in the preceding-excitement, etc.

Diagnosis.-It differs greatly from epilepsy. Usually convulsions are not prominent; the loss of consciousness is long-continued, or, in fatal cases, permanent, with stertorous (loud snoring) breathing, pupils altered, either contracted or dilated, and more or less paralysis of one or both sides of the body.

Causation.-Generally pressure, due mostly to hæmorrhage within the brain, is the cause.

Treatment.-No means are known except operation of removing the blood-clot, and in dogs more than in men the location of the clot is difficult.

We must just wait in the hope that the blood-clot will be absorbed. The treatment is "expectant"-i. e., there is no routine treatment, but symptoms must be combated as they arise.

Paralysis.-Paresis is the term used for a certain degree of loss of voluntary control of the muscles; $p a$ ralysis, for complete loss. The muscles may still contract reflexly, but not at the command of the will. The defect may be in the brain, spinal cord, nerves, or the muscles themselves. 
Paralysis, more or less complete, often arises from worms; and when there is no obvious cause for a lameness in a dog, it is well to suspect worms. The author had a cocker spaniel that for some days was lame in one hindleg. Treatment on suspicion of a sprain, etc., proving useless, she was dosed for worms. Four tape-worms were expelled, and the leg weakness at once disappeared.

When paralysis is due to disease of the brain it is always on the side of the body opposite to the injury (lesion).

Paralysis very often follows distemper, and may be progressive.

Treatment.-As recommended under "Apoplexy," when the brain is involved.

If due to a tumor of any kind that can be localized, or if due to pressure from bone driven in, etc., operation is to be considered.

The paralysis from a bruise or that which follows distemper is well treated by counter-irritation and massage. After all acute symptoms have subsided, small doses of iodide of potassium for a couple of weeks, or, it may be, syrup of the iodide of iron, are worth trial.

Later, nux vomica or strychnine, in very minute and gradually increasing doses, may be useful, with such additional treatment as each case seems to call for.

Meningitis. - This term implies an inflammation of the coverings (meninges) of the brain or spinal cord. It may be either spinal, cerebral, or both combined.

The general pathology is much as in inflammation of other membranes, as the pleura, but, from the peculiar confined condition of the brain, the pain is intense, and 
naturally the brain partakes in the disturbance, so that the psychic symptoms are very pronounced.

Causation.-This is often obscure, but it may be the result of blows, wounds, ostitis, great heat, extreme cold, etc.

Symptoms.-Intense pain in the head, acuteness of all the senses at first, extreme sensitiveness over the whole body (hypercesthesia) perhaps, restlessness, greatly altered expression, mental aberration, passing on to delirium, mania, and finally stupor (coma).

Diagnosis.-This affection is liable to be mistaken for rabies, but there is no need to make such an error. In this disease vomiting is common; not so in rabies. The temperature is much elevated in most cases of meningitis, but little in rabies; the voice is high-pitched, the animal snaps, etc., but he does not tear up things abont him, or show a tendency to bite other animals; there is not the peculiar bark and howl combined, as in rabies.

The animal suspected of rabies should never be killed off-hand, as it may be a mere temporary excitement from which he is suffering. It is well to handle all such animals with thick gloves, so that biting may not occur, especially as the imagination of man is so active and can induce false rabies (lyssophobia), which may end fatally.

The prognosis in acute meningitis is bad.

When spinal, there is generally great tenderness over this region, and spasms, or possibly, in the later stages, paralysis-which also occur in cerebral meningitis. Squint, alterations in the pupils, etc., are not uncommon.

Treatment.-Counter-irritation to the back of the head and nape of the neck, or, in spinal meningitis, along each 
side of the spine. Over the main portion of the head, cold constantly applied in the form of cloths dipped in ice-water and often changed, or the ice-cap; bromide of potassium given frequently; the bowels well opened; the bladder relieved by a catheter, if the urine be retained, etc. But the cold applications and bromides must be the chief reliance in the acute stage.

After effusion, iodide of potassium, good food, counterirritation, etc., are indicated. If there be convulsions at any stage, in addition to the above belladonna may be tried.

If the heart be vigorous, chloral hydrate may be combined with bromide of potassium at the outset, but not continued, as it depresses the heart dangerously.

When subacute or chronic the disease is difficult to recognize, and the diagnosis is got at by a process of exclusion. Stupidity, drowsiness, alteration of disposition, twitchings, etc., should arouse suspicion. The history may throw light on the case.

The treatment should be as for the later stages of the acute form.

Hydrocephalus_" large head," "water on the brain," etc.-may occur in puppies owing to an excess of the fluid of the ventricles of the brain, possibly related to chronic inflammation. The prognosis is bad, though iodide of potassium, tonics, etc., may be tried.

Tetanus is a dreadful and generally fatal disease. It is due to an irritable condition of the nerve-centers, now believed to be caused by specific germs, in most if not all cases, which results in more or less constant discharges from the motor-cells of the brain and spinal cord, giving 
rise to tetanic or constant contraction of the muscles. The germs enter the system through some open wound, though it is not always possible to trace the chain of events. It is, fortunately, not common in the dog.

When the muscles of mastication are involved it may be impossible to give either food or medicine by the mouth.

Treatment.-Perfect rest, quiet, sedatives, and nutriment. Chloral hydrate, if necessary, by the rectum or by hypodermic injection, nutrient enemata, and, later, stimulants. Opium hypodermically may also be tried. The prognosis is very bad. Death may result from exhaustion, or from suffocation owing to failure of the respiratory muscles. Anti-toxic serum from immunized animals is now on trial.

Chorea.-We do not know the essential pathological condition underlying those irregular, more or less constant, muscular movements that go by the name St. Vitus's dance, megrim, chorea, etc. These irregular, involuntary discharges of the motor-cells may apparently be due to many causes.

Usually only certain groups of motor nerve-cells, and consequently only certain groups of muscles, are affected. The movements may or may not cease during sleep. Generally there are no febrile symptoms, and the animal's health may seem to be otherwise perfectly good.

It is certainly associated with the presence of worms in the intestinal tract in some instances, but it most frequently is a sequence of distemper. It may also follow on nervous shock from fright, as when a dog is thrown into water; against which, and against plunging rashly into a bath-tub without any warning, we wish to protest. 
In the dog the disease is certainly mostly of a func. tional character-i. e., no lesion can usually be discovered even with the microscope, as has been proved by careful autopsies and microscopic examinations instituted at the author's own suggestion. The poison of distemper weakens the cells, and they discharge irregularly and without the normal stimulus of the will-power.

Except when due to worms, etc., the prognosis is bad. Few cases following distemper ever wholly recover.

Treatment.-Apart from attention to the general health, only two or three drugs seem to have been of any use whatever. The disease has proved practically incurable.

We prefer to commence with small doses of iodide of potassium, in case there may be any morbid growths pressing on the nerve-centers. Counter-irritation might be worth a trial-i. e., over the part of the cord corresponding to the affected muscles.

Nux vomica or strychnine and arsenic are the drugs in which most confidence is placed. Some administer them together. It is a good plan to give one in the morning and the other in the evening.

Upon the whole, freshly prepared liquor arsenicalis does very well. It may be mixed with the animal's food, but never given on an empty stomach. Commencing with, say, three drops in water, after a few days the dose may be gradually increased to ten; then, after a brief cessation from dosing, begin again, say, with five drops, and increase in the same way to fifteen, and so on till twenty or thirty drops, in the case of large dogs, may be reached. The other remedies may be pushed in a similar manner, but not to very large doses. 
Arsenic should always be stopped when the constitutional symptoms of its action-as reddened eyes, whitish tongue, nausea, etc.-show themselves. The same applies to strychnine and nux vomica. Any stiffness or tendency to spasms demands an immediate withdrawal of these drugs. Phosphates and cod-liver oil may do good in very mild cases.

When both paralysis and chorea follow distemper the case is nearly hopeless, and the animal may soon, in spite of care, become so wretched that it is kindness to chloroform him to death.

Hyoscyamin in small doses may be tried, but with no great degree of hopefulness, in pure chorea.

Injuries to the Brain.-In consequence of violent blows, falls, etc., there may be concussion, or, if rupture of a blood-vessel or fracture of the skull, compression of the brain.

It is difficult, if not impossible, to distinguish these when they do not occur together, as is commonly the case.

Bleeding from the nose, and especially from the ears, is suggestive of fracture of the base of the skull.

Unconsciousness, alteration in the mobility or size of the pupils, either as compared with each other or with the normal, points to compression.

The symptoms of compression from a blood-clot or other cause have been already dwelt on (see "Apoplexy"). They may be sudden, or gradually increasing to the point of complete paralysis, coma, and death.

Treatment.-Little can be done but meet the indications as they arise. If possible, keep the bowels and bladder free, administer nourishment or stimulants, and await 
the results of Nature's intervention. As before remarked, if there be depressed bone, it should be elevated by operation (trephining).

Affections of the Nerves.-The nerves are occasionally the seat of painful tumors (neuromata, etc.), giving rise, it may be, to sudden or more or less continuous pain, muscular twitchings, etc.

Whenever an animal holds any part of its body more or less rigidly, walks gingerly, or utters loud cries now and then, the case calls for special examination. Recently a dog fell under the author's observation with such symptoms. As the case seemed hopeless, he was chloroformed to death, when a careful examination revealed a tumor pressing on one of the nerves of the brachial plexus as it issued from the spinal column.

Neuralgia, or pain in a nerve, is to be suspected in a dog that cries out apparently with pain when colic, meningitis, etc., can be excluded, ard especially if he has bad teeth.

The treatment must depend on the cause. If a decayed tooth, it should be removed; if from cold or some constitutional defect, then attention to the digestive tract and to the diet will be the first consideration, with relief of pain.

If periodic, a good dose of quinine (three to seven grains), 'a couple of hours before the attack, is indicated.

A dose of Dover's powder internally, with counterirritation over the part affected, or a hypodermic injection of morphia in the same region, may be required. 


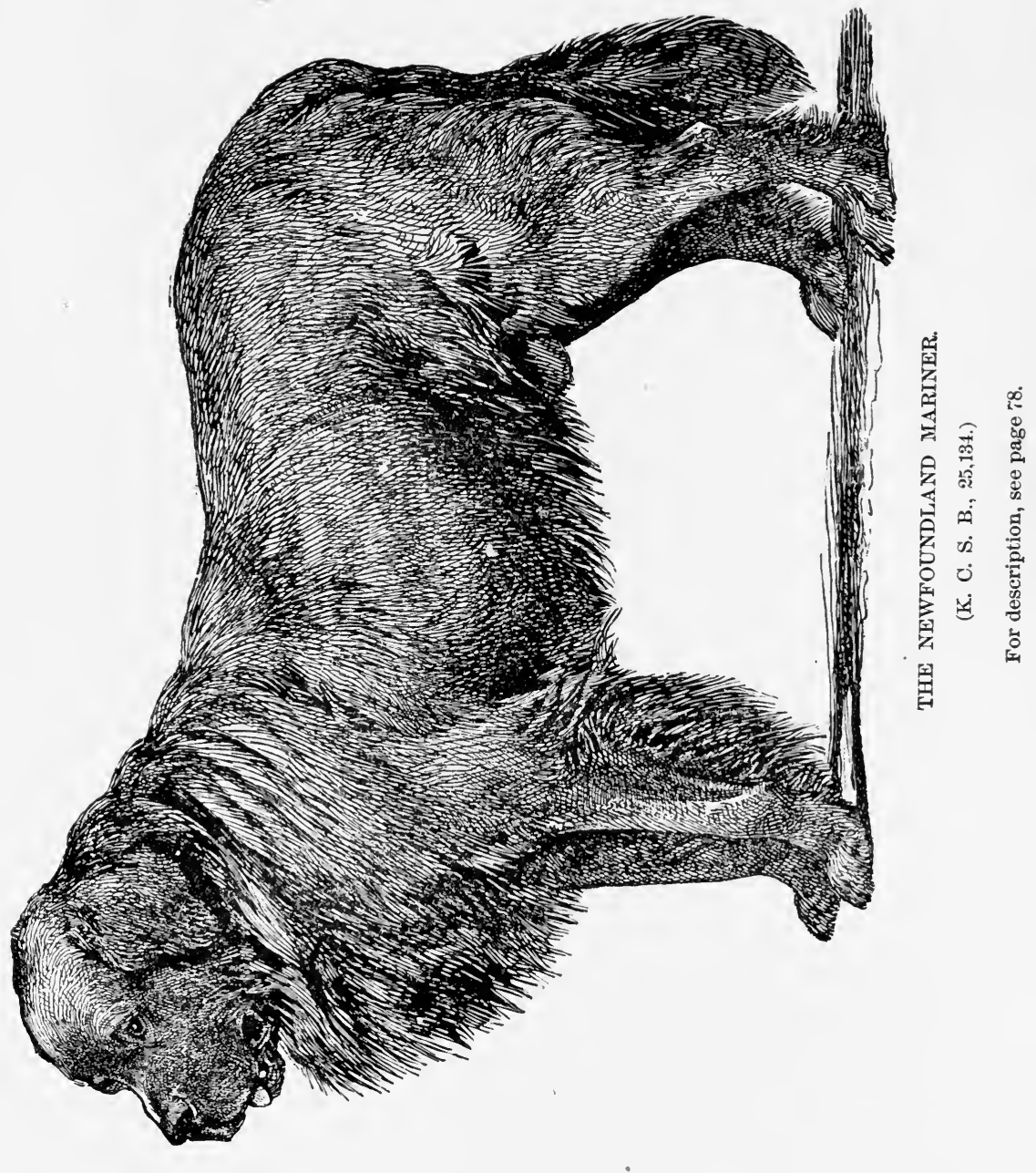





\section{DISEASES OF THE SKIN.}

The structure and functions of the skin have already (page 117) been considered, as well as the reasons why disorders of this region are so frequent in the dog. Distemper, parasites, and skin diseases are the bane of all large kennels of dogs, and with the greatest care they will occasionally occur, while in the absence of especial precautions a kennel may be demoralized if not destroyed. Diseases of the skin are not usually of themselves fatal, but they may so undermine a dog's constitution that he becomes the victim of some fatal malady.

We wish once more to insist on the close connection between derangements of the digestive organs and of the skin, to be explained reflexly as well as by the deterioration of the blood by poisons introduced from the alimentary tract through imperfections in the digestive processes.

Skin diseases may be divided into parasitic and nonparasitic, but in any case they all, sooner or later, become inflammation of the skin; and it is from ihis point of view that they are most profitably studied and treated.

Instead of considering the numerous phases of cutaneous inflammation as so many separate diseases, it is much more simple, rational, and, we think, practical, to consider the causes and treatment of inflammations of this great organ as a whole.

Causation.-Inflammation is a perverted nutrition (metabolism) of a part, and its symptoms are the same in the skin as elsewhere, but modified by the fact of exposure to the atmosphere, etc. The cause is external or internal irritation. 
The external sources of irritation may be parasitesvegetable or animal-or bedding that is old, damp, saturated with exhalations from the animal's body, or possibly urine or fæces.

The above may be direct exciting causes, but such are not essential to skin disease. Certain conditions of body predispose, and these arise from excessive or otherwise improper feeding, lack of exercise, or starvation, and general inattention to sanitary surroundings.

It is always to be remembered that pure-bred dogs are disordered by an environment in which a mongrel might do fairly well. So common a cause is overfeeding, that a certain form of inflammation of the skin has been called "surfeit" or blotch.

Of course the presence of parasites, by the itching some of them cause, leads the subject to scratch so much that this of itself suffices to explain the inflammation, altogether apart from their own biting and burrowing.

Pathological Condition and Symptoms.-As in other inflammations, there is heat, redness, pain or tenderness, and swelling; but these are present in very varying degrees in different cases. Perhaps the most typical form of inflammation is that known as eczema. A localized, swollen, more or less red, tender area, known as a pimple (papule), appears, which soon has its epithelial covering raised by exudation from the blood-vessels and becomes a vesicle, which may be filled with a clear, a turbid, or a purulent fluid. In the latter case it constitutes a pustule. These sooner or later burst; the fluid escapes, irritates the adjoining skin, and dries into more or less well-defined scabs. If the animal scratches, these may 
bleed or become ulcers, or they may run together, and large patches of skin may thus be involved in a common condition. - If this state of things continues, deep sores may form.

It may be that from the first the inflammatory condition may be somewhat different; there may be no vesicles, pustules, or exudations, but a redness of the skin with dry exfoliation of the epithelium in a sort of coarse dandruff. Such a condition is often termed pityriasis rubra, and may occur over the whole body.

Again, there may be an eruption of papules small and more readily felt than seen, each one being distinct and giving a "shotty feel," a condition known as prurigo.

Generally, in the less acute (subacute) forms there is little exudation, etc. Chronic conditions are marked by thickening, loss of flexibility, a tendency to crack, exten. sive loss of hair, etc.

Since the hair follicles may be involved, loss of hair is very common in all forms of skin disease. The exact course of the inflammation is determined not alone by the cause, but depends on whether the dog is long-haired or the reverse, the nature of the treatment, and his individuality.

More or less tenderness or actual pain, itchiness, irritability of temper, possibly restlessness, even to the point of sleeplessness in extreme cases, with corresponding failure in the general health, are common. However, in all such matters there is the greatest range of variability.

Diagnosis.-It is highly important to distinguish between parasitic inflammations of the skin and those not due to this cause. The principal diseases of the skin de- 
pendent on regetable parasites are ringworm (Tinea tonsurans) and favus.

Ringworm occurs in more or less circular, well-defined patches, from which the hair falls, and which are covered with a fine scurf.

Favus is characterized, after the earliest scurfy stage, by peculiar crusts of a sulphur-yellow color and a smell of mice. Beneath these, cup-shaped ulcers are found. In both diseases spores or branches (mycelium) of a vegetable growth (mold) may be discovered by the microscope.

Follicular Mange is caused by a sort of mite (Acarus folliculorum), which lodges in the hair follicles and seba-

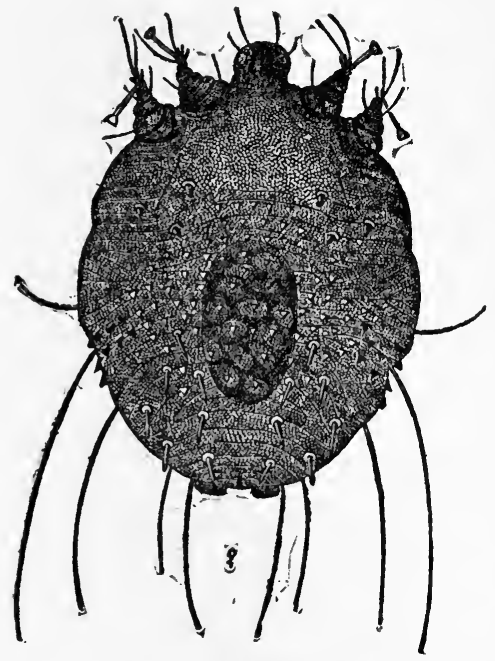

Fig. 27.-Sarcoptes Canis (Grrlach). ceous glands and sets up inflammation. It is likely that a vegetable, fungoid growth akin to that cansing ringworm is an additional source of the mischief.

Sarcoptic Mange, or dog itch, is due to a mite (Sarcoptes canis). The female, the larger, bores into the skin, there burrows, and lays a multitude of eggs that soon hatch out, the young running over the surface to repeat the story. The irritation gives rise to intense itehing, and an inflammation, with distinct small papules, surmounted by pointed (not flat, as in eczema) vesicles. 
This is very contagious-more so than the follicular mange; there is much more irritation, itching, etc.

The hair follicles are greatly affected in the follicular disease, and the scabs have a peculiar sort of moldy smell. Tenderness replaces itching. It is more common in young dogs.

In the early stages the diagnosis from eczema is not difficult; later, the microscope alone may decide.

Though nearly all skin diseases in the dog are popularly termed "mange," true itch is rare as compared with eczema, which is very common. When a skin disease rapidly spreads through a kennel, mange is to be suspected; though the possibility of several dogs being affected in a like way, from gorging, is not to be forgotten.

Follicular mange is apt to begin about the head.

If not soon cured, both become associated with eczema from irritation, when the diagnosis becomes more difficult, but generally possible by the help of the microscope.

Eczema is, in the larger proportion of cases, a constitutional disease, or the expression of a disorder within. All the forms of parasitic disease are essentially local, though, from the irritation they produce, the constitutior. soon suffers.

An investigation into the whole environment of the patients is always advisable, both for purposes of diagnosis and treatment. In a large proportion of cases the disease will turn out to be eczema, due to excessive or scanty feeding, improper diet, etc.

Is eczema contagious? One has only to observe the effect of the exudation on comparatively healthy skin to be convinced of its irritating effect. That the discharge can 
produce irritation and inflammation is certain, and in this sense it is contagious. It is better to act on this assumption and keep the dog pretty much to himself, and especially not allow others to sleep with him.

Sarcoptic mange is so extremely contagious, that when there are several dogs in a kennel all, or nearly all, will become affected; and it spreads rapidly over the body from a small beginning in separate vesicles that lead to a whitish line, the burrow of the insect. The irritation in mange is so great, that a dog may rapidly lose flesh and fall off in health generally. Follicular mange is also contagious.

Treatment.-The indications are to remove the cause, allay irritation, stimulate enfeebled parts of the skin, relieve the skin by acting on other parts, correct constitutional aberrations, etc.

Parasitic disease when due to animals is much more readily managed, follicular mange excepted, than when vegetable organisms are concerned. Prompt measures soon kill the dog-mite, break up its burrows, and destroy the eggs.

Suppose the case to be quite recent, very little inflammation of the skin yet present, and consequently few scabs, the dog should be well washed with soft soap, the rubbing and scrubbing being of the most thorough character.

An ointment the basis of which is sulphur will complete the work within a few days, so far as destroying the parasites themselves is concerned, but eczema may remain and require additional treatment.

In the management of all skin diseases, not only the remedy but its mode of application is of great importance. 
The Application of Remedies.-As the object of all local remedies is to affect the skin itself, it may be necessary, though not usually, to remore the hair from the diseased patches of skin by clipping as close as possible.

As to whether a lotion or an ointment shall be chosen, must depend on whether the dog has a long or a short coat, whether clipping away of hair is admissible, the stage of the disease, etc.

Both lotions and ointments should be applied as dressings when possible-i. e., the parts should be covered with cotton dipped in the lotions and evaporation prevented by impermeable material, or the cotton covering the parts smeared with ointment may be dipped in oil. This keeps the former from being rubbed or licked off. Moreover, when the limbs are affected, a bandage nicely applied is comfortable, and favors the circulation of the blood.

Such methods are not, however, always applicable, from the disease being very extensive or from some other cause.

As any oily substance applied to the skin naturally checks its proper functions, ointments should never be employed continuously, however suitable, but will always be found more useful if washed off every few days.

In using any ointment or lotion it is well to apply it over only a small part of the affected surfacc, to learn whether it is suitable or not; or two or three different applications may be compared in their effects; for a remedy that will help one case will only make another worse, and what is most useful at one stage of the disease will be harmful at another. Moreover, a lotion or ointment that may soothe when of a certain strength, will irritate when 
stronger. Before discussing special forms of skin disease further, a few of the principles that underlie treatment in general will now be considered.

Principles of Treatment. - Lotions are most efficacious in the early stages of inflammation, before there is exudation and the formation of scabs, or they may be used to soften scabs and soothe at the same time; however, some kind of oil or oily substance will best answer this purpose. In all cases, before applying an ointment, scabs should be removed, as they only tend to keep the application from the diseased skin.

Generally the very best way to begin all local treatment is by washing the dog, though, of course, the season and all the circumstances must be taken into the account.

Crusts or scabs may be softened by washing in water containing a little sodium carbonate (washing soda), which is soothing in itself. However, in general, oil applied to the skin, if scabs have formed, washing the animal in a couple of hours, or as soon as the scabs are moderately soft, with strong carbolic soap, will have a good effect, as carbolic acid allays irritation and favors healthy action of the skin. A little crude carbolic acid put into the washing-water-enough to make its presence perceptible to the hand-will serve the purpose, and is cheaper, some Castile soap being used to lather the dog. If the skin is very tender, eggs beaten up may replace soap. In all cases, when carbolic acid is used, the dog should be well rinsed with water not too cold.

Having got the subject ready for the application of some remedy, the next thing is to determine what one. Is the skin broken, or only red and tender? Are there 
ulcers? Is thickening and loss of hair prominent? etc., are among the questions to be considered. Ointments are more continuous in their action, unless lotions be applied, as suggested above.

The following hints as to the preparation and use of certain drugs are to be remembered: Glycerin, when pure, tar, turpentine, balsams, coal oil, etc., are all stimulating and unsuitable for the most acute form of a skin inflammation, though valuable in subacute and chronic forms. Sodium carbonate and bicarbonate, borax, acetate of lead, etc., are soothing in most cases.

The best basis for ointments is vaseline, as it does not readily become rancid. Belladonna, though an excellent sedative, is not in the case of the dog to be used in ointments, as it may be licked off and cause poisoning. Opium, though seldom required, is not so dangerous.

Itching may be relieved by the addition to ointments and lotions of alkalies, carbolic acid, and rarely opiates.

Sulphur, in powder, dusted through the hair down to the skin, is soothing; and dry oxide of zinc is useful when exudation is excessive.

In non-parasitic disease the internal treatment may be the more important of the two, as generally the cause of the trouble is to be traced to some disorder of the digestive organs. The state of the bowels should be especially attended to, and the diet. Sulphur, Epsom salts, cream of tartar, and bicarbonate of soda, are useful. Violent purging is usually not required. Often the liver is at fault, and the portal circulation sluggish; in this case one of the officinal compound cathartic pills at night, and a saline in the morning, may prove efficient. 
Sulphur has, besides its laxative effect, a good influence on the skin of the dog, and may be given day after day for a time with the food, or, combined with cream of tartar, in syrup.

Arsenic is never to be given in the acute form of skin disease, and when used, as pointed out before, the dose must be small at first, increased gradually, never given on an empty stomach or undiluted, stopped every now and then, and not continued when the digestion is poor or symptoms of irritation show, as evidenced by coated whitish tongue, red eyes, etc.

Arsenic is the most valuable constitutional remedy we possess in chronic cases when judiciously employed.

In cases that resist all ordinary treatment a few doses of calomel, small and speedily worked off by salines, may act well.

The general health of the dog is always to be considered. When very thin or debilitated, tonics and cod-liver oil are demanded.

Diet is, in eczema, of the utmost importance. In a large number of cases the $\operatorname{dog}$ is overfed. In such a case a fast of twenty-four hours will often be the very best treatment. In all cases a complete change of diet is desirable.

If the dog has been fed much on meat, let him have none for a while, but a diet of milk and bread or milk and wheat porridge. On the other hand, if he has been getting only starchy food, or an excess of it, a shange to meat alone will be the best natural medicine. The half-starred dog is very liable to eczema.

Very often a long walk, or a run of ten to fifteen miles 
after a horse, an exciting hunt in the woods continued to the point of weariness, and followed by spare feeding, will work wonders.

If constipation exists it must be overcome, and if by exercise and dieting, so much the better. The value of vegetables for this purpose is not to be forgotten.

If for any reason the sulphur ointment can not be used in sarcoptic mange, a lotion prepared as follows is cleanly and effective. It forms a good standing mixture for a kennel. It should not be kept very long, but made fresh every few weeks :

Unslaked lime, one pound; sublimed sulphur, two pounds; add two gallons of soft water; mix well and boil down to one gallon; let stand till cool; pour off, after standing some hours, the clear liquor; filter, if necessary. Apply frequently over the whole body with gentle friction.

\section{Special Formulas.}

For allaying irritation :

1. Salt-water baths, or bathing with vinegar and water.

2. Lotion of sodium carbonate or bicarbonate, or borax, of the strength of about ten grains to the ounce of water.

Some glycerin may be added, thus :

B Sod. biborat............... 3 jss.;

Glycerin................ $\xi \mathrm{ij}$

Aquæ camph ............. $\xi$ viij.

Ft. lot.

Especially useful in irritable, scaly, and papular eruptions. 
As a drying, soothing lotion:

B Zinci oxid.................... $3 \mathrm{ij}$;

Glycerin................ 3 ss.;

Aq. calc.................... $\xi \mathrm{ij}$

Aquæ................... ad $\xi$ viij.

Ft. lot.

Sig.: Apply as a lotion.

The lead lotion recommended before (page 309) is also excellent, but it is better to use morphia than opium, to avoid staining. It is not suitable for application over a large surface, for, while the dog is not readily poisoned with opium, his stomach is easily disordered by this drug.

In some cases the "black wash" (calomel and limewater) is valuable.

Prepared chalk in the form of ointment or wash, with or without lime-water, has also given good results.

By allowing water to stand over tar till it tastes strongly of this substance, a lotion suitable for the red unbroken skin may be made. For the eczema that attacks the face, especially the eyelids and eyebrows, some form of mercurial ointment may be demanded (see page 310). The liquor plumbi subacetatis may be combined with the tar-water.

Soothing ointments may be made of sulphur, oxide of zinc, borax, lead salts (acetate and subacetate), etc. These ointments as officinal preparations may be purchased ready-made. It may be wise to dilute them at times, or add alkalies, carbolic acid, or opiates.

The unguentum zinci (officinal) is a most valuable ointment for soothing and drying; but when parasitic disease is suspected the sulphur ointment should take its place. 
The former will be found very efficacious in eczema of the ear (canker).

Such a combination as the following will suit sarcoptic mange and many forms of eczema:

B, Sulphur. flor............... $\xi_{\text {ss. }}$;

Sod. carb............... 3 ss.;

Ol. pic. liq............... $3 \mathrm{ij}$;

Vaselin ................... 3 iv.

Ft. unguent.

Sig. : Apply freely once or twice daily.

Lard or vegetable oil may be substituted for the more expensive vaselin.

For mange (sarcoptic), especially after the first stage, and also for chronic eczema, with thickening; for eczema with a scurfy or scaly condition of skin, the officinal tar ointment, creasote, balsam of Peru, oil of cade, oil of tar, kerosene (coal oil), etc., are useful, properly combined.

As samples of combinations, we give:

Bi Sulph. flor................ $; \mathrm{j}$;

Bals. Peruv................. $\xi j$;

Vaselin....................

Ft. unguent.

Sig. : Apply twice daily for three days, then wash the $\operatorname{dog}$ thoroughly.

Tar ointment may be conjoined with sulphur ointment, one of the former, four to eight of the latter.

B Olei cad.................. z $\mathrm{zij}$;

Acid. acet................ $z^{\mathrm{ij}}$;

Acid. carbolic .............. 3 ss. ;

Olei olivæ.............. ad $\xi \mathrm{xvj}$.

Ft. mist. 
Apply freely twice a day, and wash the dog after three days.

This is an efficacious mixture for advanced cases, but disagreeable to the patient and to the one who applies it. For true mange its efficacy is increased, in the opinion of some, by the addition of sulphur.

B Balsam Peruv................ $\xi$ ss. ;

Vaselin.................... $3 \mathrm{ij}$.

Ft. unguent.

The balsam of Peru, dissolved in five to eight parts of alcohol, may of itself be painted on. The last four combinations are useful in itch (mange), and when thickening, cracks, etc., exist. The last two are excellent for cracked nipples. Balsam of Peru is rather expensive, though an excellent remedy.

Follicular mange is very difficult to cure. One of the most efficacious remedies is carbolic acid.

B Acid. carbolic................ $\xi$ ss.

Balsam. canadens.............. $z^{\mathrm{ij}}$;

Ft. unguent.

Sig.: Apply carefully, heating if necessary to render sufficiently liquid, with a camel's-hair pencil, in a thin layer over a portion of skin not to exceed two to four square inches at once, so that carbolic-acid poisoning may not follow. If necessary, muzzle the $\operatorname{dog}$ to prevent licking.

The mercurial ointments referred to before (page 305) may also prove useful, or the balsam of Peru.

Ringworm may be treated by frequent paintings over and around the affected area with tincture of iodine, St. George's paint (stronger than the former), or the appli- 
cation of mercurial ointments, etc., as in the last-mentioned disease.

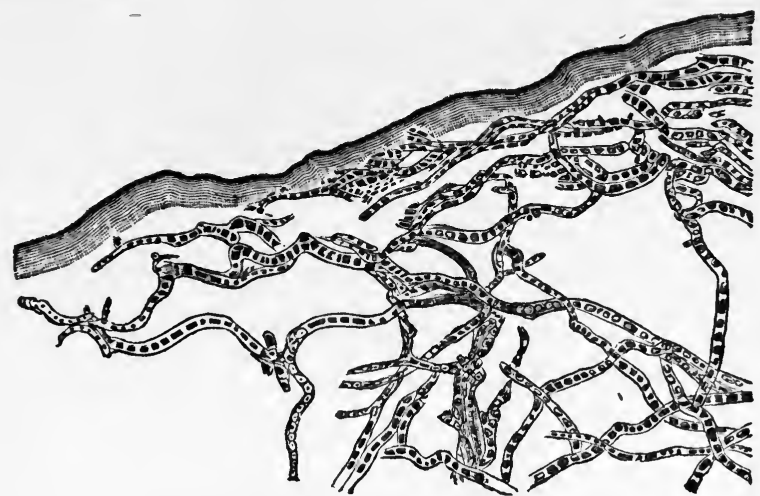

Tig. 28.--Tricophyton Tonsurans, the Vegetable Parasite causing Ringwork, Magnified 400 Diameters (after Payne).

After any of the contagious skin diseases, all with which the dog has been in contact, that can be destroyed without serious loss, should be burned; all collars, chains, dishes, etc., and the whole kennel, disinfected as well as thoroughly scrubbed (see page 379 ).

As an excellent kennel or office mixture for dogs requiring a saline, as frequently happens, and nearly always when eczema occurs, the author recommends the following, which may be kept constantly on hand :

B Magnes. sulph............ z

Ferri sulph.............. gr. xvj;

Acid. sulph. aromat......... $3 \mathrm{ij}$;

Spt. chloroformi .......... $3 \mathrm{ij}$;

Aquæ menth. pip .......... $\xi_{x v j .}$

Ft. mist.

Sig.: Give sufficient to move the bowels in the morning before food-say one to four teaspoonfuls in water. 
Of course, this is not a hard and fast formula, the most essential part being the saline, which is rendered more agreeable, and prevented from griping by some of the other ingredients. The whole is also somewhat of a tonic to the stomach and general system.

Frequently a dog is worried by great irritability of the skin, though there is no eruption or other obvious cause. In these cases a look at the tongue will often reveal a disordered digestion. Attention should be given to diet, etc. Sulphur, cream of tartar, and also bromide of potassium often prove useful. Phosphorus pills given after food ( $\frac{1}{100}$ to $\frac{1}{50}$ grain) are said to be helpful in some cases. A soda or salt bath is often followed by relief. A lotion of lead acetate is also very soothing.

Occasionally, as a result of skin disease or defect of nutrition of the hair follicles, the dog's coat almost all falls out, or unsightly bare patches result.

To stimulate the growth of hair, more blood and nervous energy are required in the skin; so that friction, massage, and stimulating applications are indicated.

Such applications as cocoa-nut oil, or a combination of this oil with coal oil and olive oil, in about equal parts, applied for a couple of days and then washed off, are helpful in many cases, especially if the $\operatorname{dog}$ is shedding his coat-as he naturally does in the spring and autumn-too slowly; or if the restoration of hair after its loss following suckling puppies is tedious. "Vegetable oil" (cotton-seed oil) is cheaper than olive oil, and answers well enough.

The above mixture is useful in true sarcoptic mange, especially if sulphur be added, also in chronic eczema. 


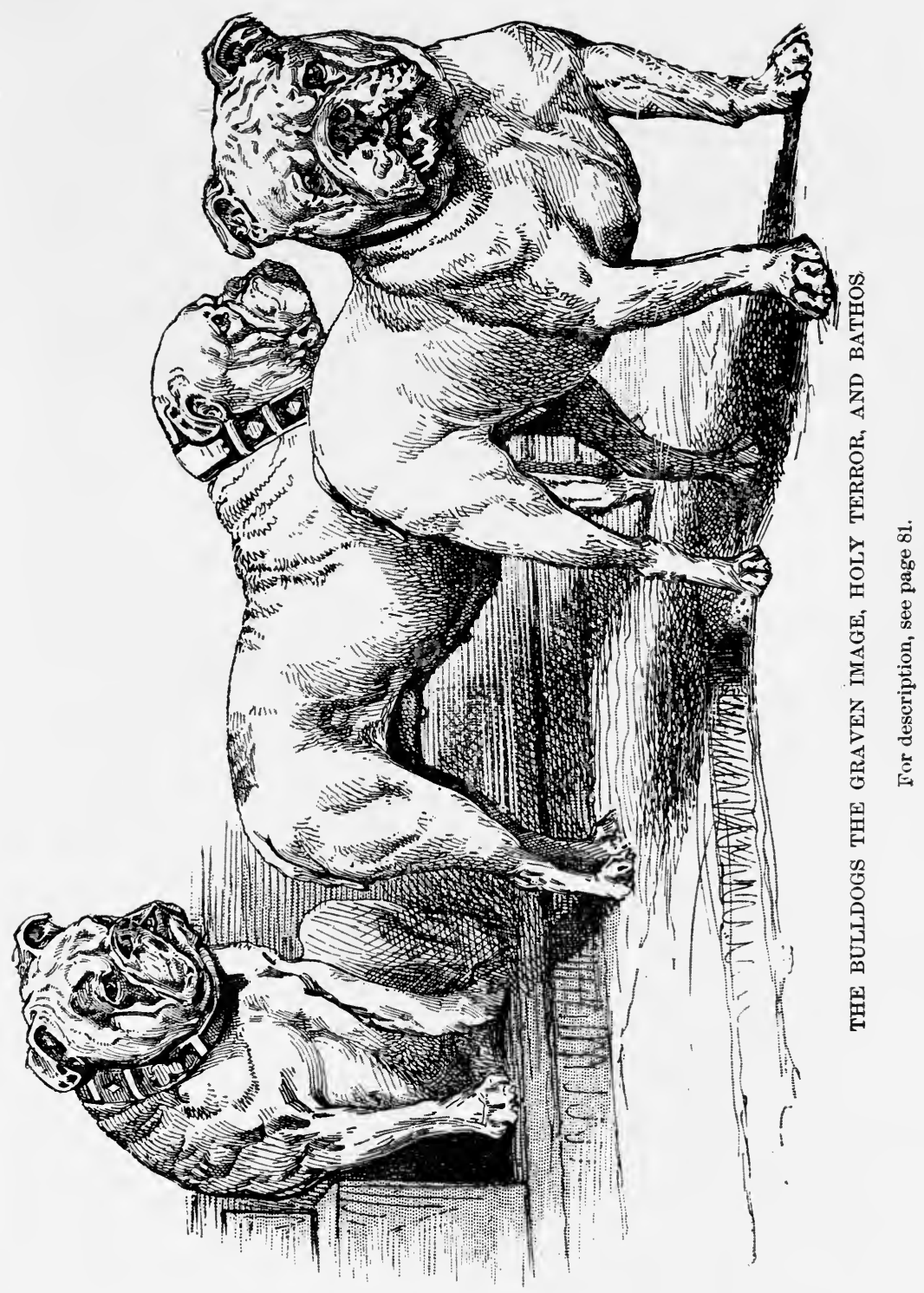


For bare patches, the following may prove of value:

B Sod. biborat................ $3 \mathrm{j}$;

Tinct. capsici............... $3 \mathrm{j}$

Glycerin .................. $z \mathrm{ij}$

Aquæ.................. ad $\xi \mathrm{vj}$.

Ft. mist.

Sig. : Apply with friction two to four times daily.

After a while the quantity of tincture of capsicum may be increased. A very light application of glycerin has also been found useful in recent cases.

When skin disease in any form occurs between the toes, it may be necessary to wrap up the feet in medicated dressings and keep the patient quiet.

It is most important when true sarcoptic mange occurs to thoroughly disinfect the kennels and everything with which the dog comes in contact. The same precautions should be taken as after a visitation of distemper (see p. 379).*

\section{INTERNAL PARASITES OR WORMS.}

It is likely that the estimate that three quarters of the whole canine race are, at some time, infested by worms, and that they cause more deaths than all other causes together, is about correct. To understand their prevention and treatment, a brief account of their varieties and life-histories will be necessary.

It is true that every principal organ in the body may be the seat of some form of parasite. Some of these are, however, of such rare occurrence that they are mere pathological curiosities, and need not be here described.

* Modern skin specialists attribute more importance to vegetable parasites than ever before; hence the value of sulphur, etc. 
Practically we have to do with nematode, or round worms, and cestode, or tape-worms.

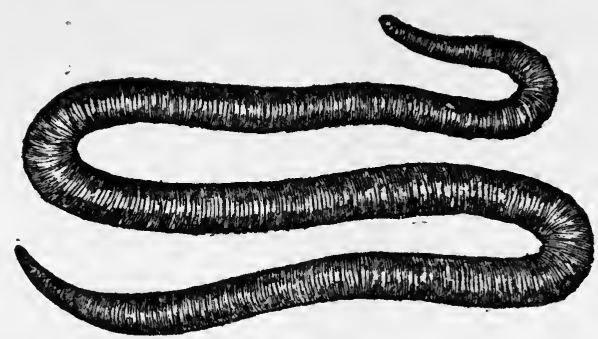

Fig. 29.-Eustrongylus Gigas (Cobbold).

This parasite is occasionally found of great size in the dog, especially in the kidney.

The principal round worm of the dog is Ascaris marginata, pale-red in color, round, tapering to each end, firm to the feel, the sexes distinct, propagated by eggs (ova) with great resisting power, and capable of maintaining their vitality for months, from one to eight inches in

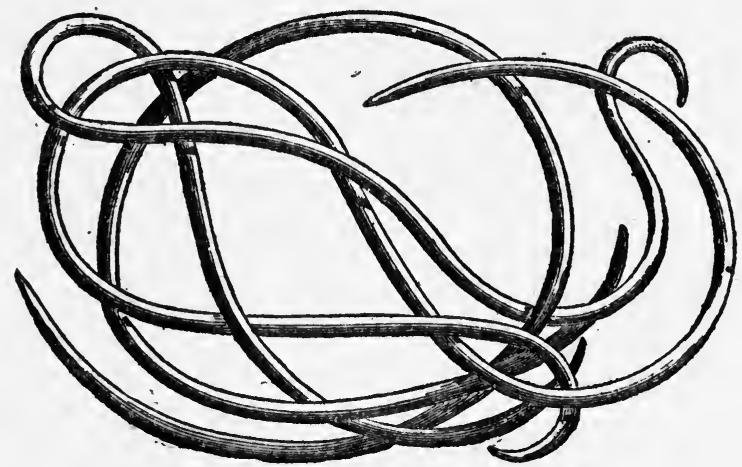

Fig. 30.-Ascarides (Stonehenge).

length, living in the small intestine, and moving about freely-i. e., not attached. Ascaris mystax also occurs.

The thread-worm, or oxyuris, is very small, similar in formation and mode of propagation to the preceding, lives 
in the large intestine, and may descend low down in the rectum.

The ova of round worms may be taken in with water, etc., or may hatch within the host, as the creature is termed that harbors them, possibly within the worm itself in some instances.

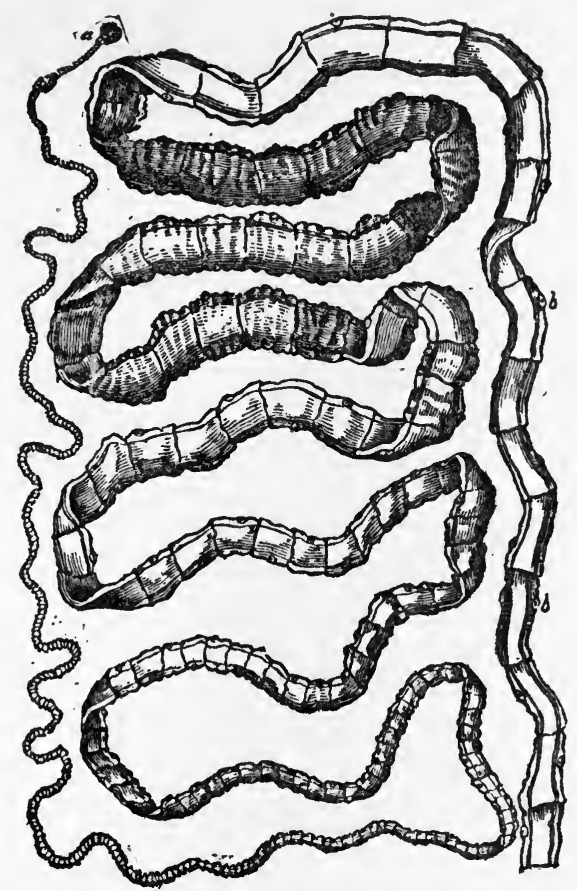

Fra. 31.-T Tenia Solium ('Stonehenge). $a$, head ; $b$, generative orifice.

The life-history and structure of the tape-worm is altogether different. Every tape-worm consists of a head which is usually provided with suckers, hooklets, or both, by which it attaches itself to the mucous covering of the intestines, of segments (proglottides) that are budded off 
from the head end, and which contain both male and female generative organs; so that a tape-worm is an example of an animal in which the sexes are combined (hermaphrodite). When each segment is perfect, it produces a vast number of eggs and drops away from the main colony. Those farthest from the head, being the oldest, come away first.

When these segments find their way into certain animals the eggs are set free by digestion of parts surround-

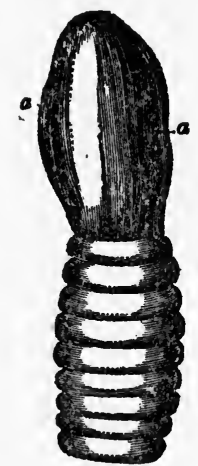

Fig. 32.-Head of BothRIOCEPHALUS LATUS MAGNIFIED (STONEHENGE).

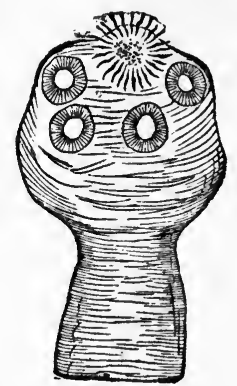

FIG. 33. - HEAD OF Tania Solium MAGNIFIED (AFT. ER Heller).

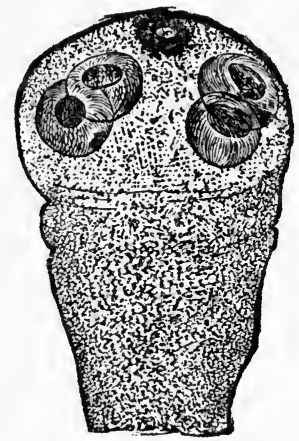

Fig. 34.-HeAd OF T正nia Mediocanellata MAGNIFIED (AFTER Heller).

ing them. The eggs hatch out into embryos, which undergo development up to a certain point, but do not become tape-worms in that species of animal but usually migrate from the alimentary canal into some other organ, commonly the liver, there forming often hydatids, or cysts, and proving fatal to their host. But when these hydatids, or immature tape-worms, pass into that particular species of animal suitable for their development they become tape-worms. 
The following are found in the dog: Toenia marginata, T. cucumerina, T. serrata, T. echinococcus, T. solium, and Bothriocephalus latus, the last two being common to man and the dog.

The first three are the most common: T. marginata, the intermediate host of which is the sheep, may attain a length of eight to ten feet; T. cucumerina, the most common, ten to twenty inches in length, with a very small head, the segments getting very gradually larger from before backward; $T$. serrata, intermediate host the hare and rabbit, twenty to forty inches in length.

To illustrate how tape-worm is propagated and how one animal may prove a source of disease to many, we may mention that a larval or immature form (Cconurus cerebralis) of a tapeworm exists in the sheep's brain. If this be taken into the dog's stomach it develops into a mature tape-worm, the eggs of which, if swallowed by the sheep in drinking-water,

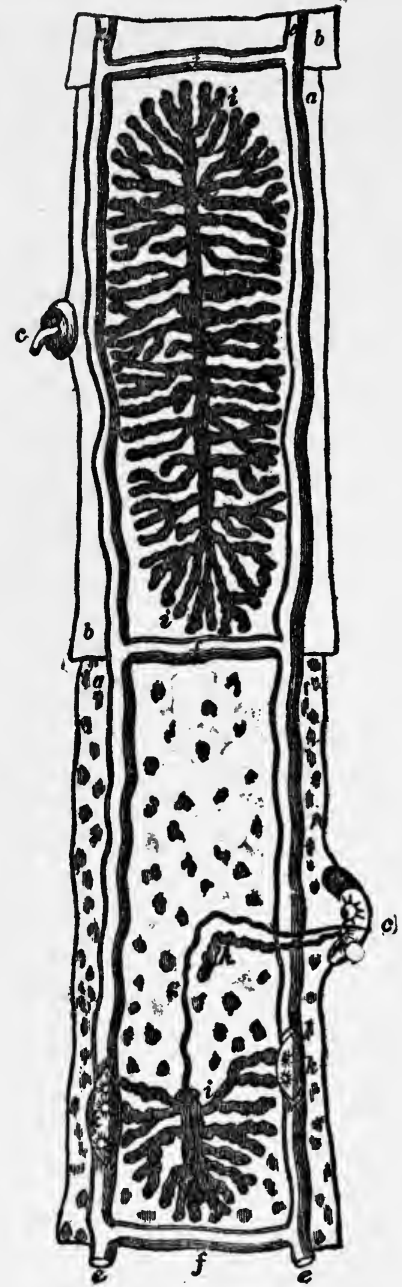

Fig. 35.-Tenia Solium (StoneHENGE).

$c$, generative orifice; $e$, water vascular canals ; $g$, ovarian duct; $h$, ovarian receptacle; $i$, branched ovarium. 
etc., become the larval form referred to above; and so the biological circle is completed.

Again, it is believed that the dog-louse (Trichodectes canis), more frequently, perhaps, the flea (Pulex canis), swallows the minute eggs of segments of the tape-worm ex-

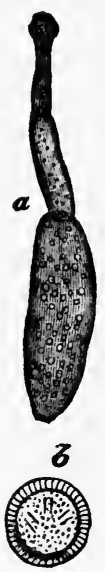

Fig. 36.-TANiA Echinococcus (AFTER BrISTOWE).

$a$, Tænia magnified 10 diameters ; $b$, ovum magnified 250 diameters. pelled from the dog and adherent to his hair and proves the intermediate host, while these parasites are again accidentally swallowed by the $\operatorname{dog}$; hence the vicious circle.

It is thus apparent that one dog with tapeworm may infect a whole kennel of dogs. All sorts of worms in the intestinal tract live on the digestive food by which they are surrounded. They may injure an animal, when numerous, by taking up the nourishment belonging to it; and by irritation, which has innumerable reflex effects that express themselves through every system of the body. As it is most important to beware of these symptoms, we instance some of them:

Digestive.-Colic, diarrhœa, constipation, vomiting, slimy stools of a peculiar wormy smell-it may be gray or bloodstained-capricious appetite or loss of appetite, bloating, etc.

Circulatory. - Blood impoverished, shown by pale gums, etc.

Cutaneous.-Harsh coat, skin eruptions, falling of hair.

Respiratory.-Dry, hot nose, cough. A special form of bronchitis may be caused by small worms in the bronchial tubes. 
Nervous.-Convulsions, twitchings in sleep, chorea, paresis.

The general economy suffers, as shown by emaciation, dullness, debility, etc.

Round worms are much more common than tapeworm, which is rare in puppies, from which the former are seldom absent in pure-bred dogs.

Diagnosis.-General lack of vigor, unthriftiness, with symptoms of imperfect digestion, especially bloating, should in a young dog suffice to lead to treatment for worms in the absence of any other obvious cause. Much attention to the anal region suggests thread-worms; marked emaciation, with a ravenous appetite, tape-worm. The segments may be seen at times in the stools.

Prophylaxis.-The prevention of worms has been alluded to under treatment of the brood bitch. Puppies get the eggs from their dam; but if one dog in a kennel has worms, it is easy to understand how they may be spread by dogs walking through the stools, licking each other, etc.

Milk can not convey the germs of worms except by their getting into it after it leaves the cow, which is not very likely; but milk does, in large quantity, tend to relax the digestive tract, produce an excess of mucus, and, in a word, favor an environment in the intestine suitable to the development of worms.

Continuous sloppy food for puppies is therefore a mistake.

Meals of dry biscuits, bread-crusts, etc., are beneficial in clearing out mucus and ova of worms and begetting a better tone in this region. 
Powdered charcoal, given with the food of puppies, in one-half to one-teaspoonful doses twice a day, occasionally, is both a preventive and a cure (vermicide). Every means that will produce a vigorous condition of the animal as a whole, and the intestinal tract especially, will be useful.

Treatment.-This may be divided into preparatory and medicinal. The object of treatment is primarily to expel the worms; hence it is important that remedies shall reach them readily, and find them in a somewhat famished condition.

It is always desirable to allow the subject to fast-if a weaned puppy, eight to twelve hours; if a dog over nine months, from sixteen to twenty-four hours. There will be no harm done, and possibly something gained, especially in the case of tape-worm, by giving a dose of castor oil several hours before the anthelmintic proper.

The following are the principal remedies recommended for the round worm: Santonine, wormwood, calomel and jalap, pink-root and senna, kousso, hellebore, pomegranate bark, turpentine, areca nut, kameela or pumpkin, squash seeds, wormseed oil, etc.

For tape-worm: Areca nut, kousso, pomegranate, turpentine, and oil of male fern.

An old and valuable remedy for round worms, and the safest and best of all, perhaps, for very young puppies, is wormseed oil. This, in dose of one to four drops, may be given to puppies of four to six weeks of age. It is well to combine the remedy with a drop of oil of aniseseed or oil of peppermint and a drop of turpentine, the whole to be well mixed with a teaspoonful of castor oil (for toy puppies a little less), warmed and floated on a little milk. 


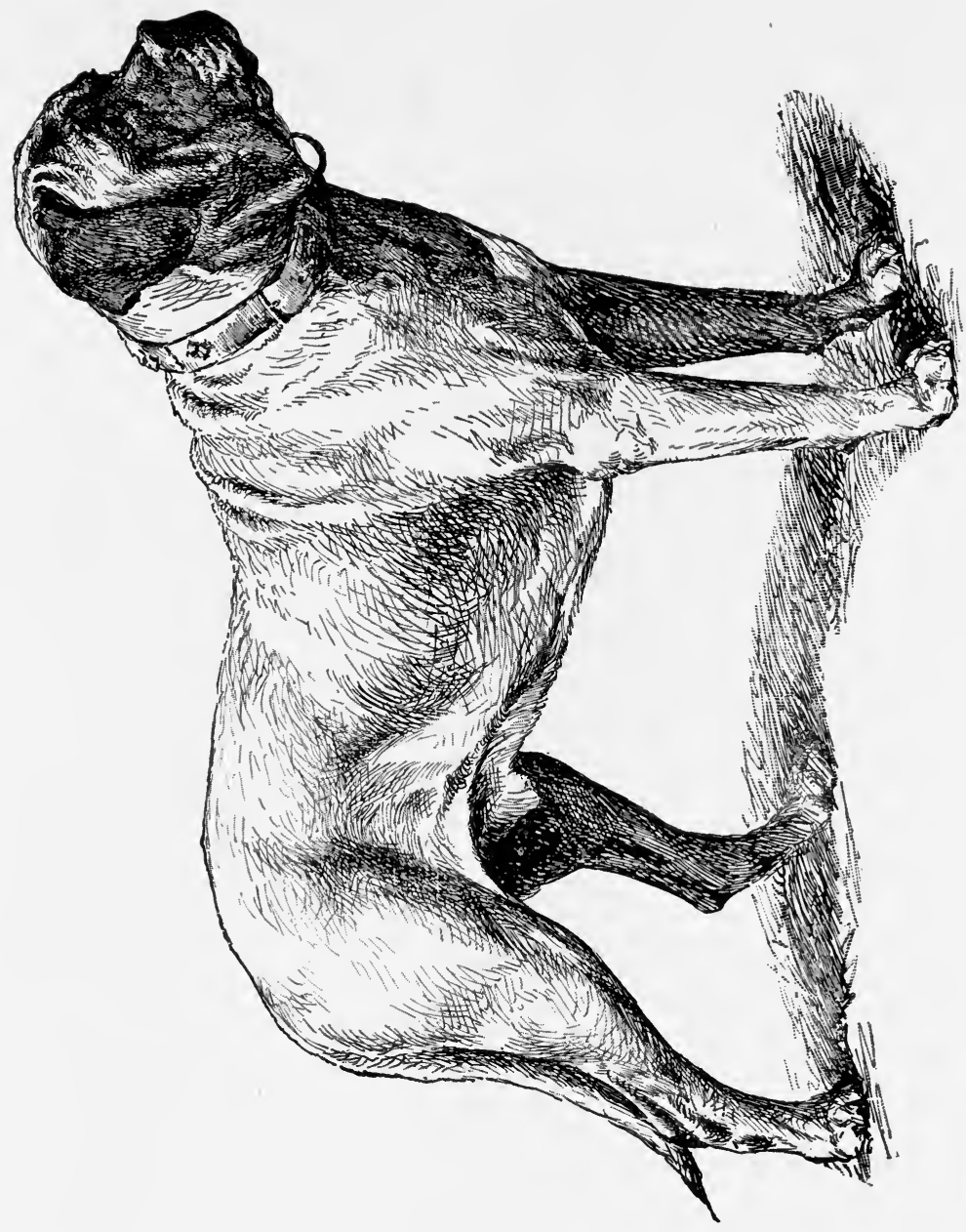

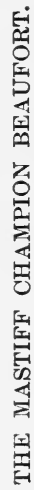



Kousso and pomegranate bark are not now often used.

Such remedies as powdered glass need be mentioned only to be condemned as dangerous.

Pink and senna. An extract of pink and senna combined is now to be had which is effective and tolerably safe. However, it acts very dissimilarly on different dogs, and should be used tentatively-i. e., the dose should at first be much smaller than is known to be generally safe.

It is one of the best remedies for puppies still sucking.

Three weeks of age is about the earliest at which any remedy may be used, and then only in urgent cases, as puppies bear drugging very badly. About five drops may be given three times daily for two to three days, and then a dose of oil to expel the dead worms. For older dogs one half to one teaspoonful may be given at a dose, and repeated. For very young puppies enough olive oil to relax may serve to expel worms.

Santonine. This remedy may be given alone to puppies in doses of one half to one grain, according to age, till three or four doses have been taken at intervals of an hour, then followed by castor oil; or santonine may be com. bined with the preceding in puppies over five weeks of age.

Turpentine is not usually required for round worms. Many object to its use altogether for the dog on account of its irritating effect on the kidneys and alimentary tract.

Given in small doses, it is certainly very irritating to the kidneys, and in a large dose it may set up gastritis or enteritis.

However, as vermicides, usually successful, fail with some dogs, it may be necessary to fall back on this remedy.

Even young puppies (two or three months) may take 
five to fifteen drops of turpentine with safety if given beaten up in egg, mucilage, or well mixed with castor oil, say a teaspoonful for ten drops of turpentine. It is important that it shall be quickly carried through the intestine.

Areca (betel) nut is, on the whole, the best anthelmin. tic we know. Some maintain that it is quite harmless, others that it is dangerous and never to be given. Both views are extreme. The author has used this remedy a great deal, and has never had one bad result. He has found it almost invariably efficacious for both the round worm and the tape-worm. It seems to be least certain and most dangerous with young puppies. $\mathrm{He}$ would never give it to a dog under five to six weeks, and to those under two months only with the greatest caution.

To very young puppies, about one grain to the pound weight of the dog is enough to try at first. Generally one grain and a half to the pound weight of the animal suffices, but, after four months of age, two grains is usually safe.

The author's plan is to fast the animal, give the freshly grated, dark-colored nut in gelatin capsules, and, after from three quarters to one hour and a half, according to the age of the dog, a large dose of castor oil, to make sure that the remedy is removed from the intestine. If there is not a movement of the bowels in half an hour, the dog is permitted to eat porridge and milk, which generally causes a motion.

Some dogs must be allowed out of the kennel, or they will suffer, owing to cleanly habits, before evacuating the bowels. It is the custom of some to combine santonine with areca nut, to which there is no objection. 
It is likely that the bad results that have followed the use of areca nut have arisen from neglect of some of the necessary precautions as to quantity and speedy purgation after the dose is given.

Some puppies seem to be such perfect breeding mechanisms for worms, and suffer so much from this pest, that it is almost hopeless work combating the evil. This condition is in some cases hereditary, and bitches that produce such offspring should be discarded as breeders.

After the use of worm remedies, especially areca nut or turpentine, the diet should be bland for a couple of days.

Pumpkin and squash seeds are excellent remedies and quite harmless, but rather troublesome to prepare. The hulled seeds should be gently stewed to a pulp, the fluid poured off, and given in teaspoonful doses. The pulp may also be given in larger quantity. It is especially a good way to dose puppies if they will take the preparation in their food; otherwise troublesome.

The best remedies for tape-worm are areca nut, oil of male fern, and turpentine.

The author would try the areca nut fairly first. If unsuccessful he would give later ten to thirty drops of the ethereal extract of male fern, shielded as recommended in the case of turpentine, and in half an hour, or earlier if the dog seemed much prostrated, a large dose of castor oil. This is severe treatment, and not justifiable except when the areca nut fails, as it seldom does. The worms passed should be examined carefully in water to ascertain that the head has been removed; otherwise reproduction of an entire worm is but a question of time. 
Thread-worms are easily destroyed by injecting into the rectum salt and water, vinegar and water, an infusion of quassia, etc., and retaining it there for a few minutes by holding the hand covered with a cloth against the anus.

It is highly important, to prevent the spread of worms, that all the excreta after dosing, even when no worms are seen, should be collected and buried deep, or, better, burned. When worms of any kind are obtained, the treatment should be repeated, but not till the dog has recovered from the last dosing.

\section{EXTERNAL PARASITES.}

Parasites are the great evil of canine existence; for if the $\operatorname{dog}$ is not killed by internal forms, he is worried by external ones, that may be so numerous and such constant companions day and night that his life is burdensome. Is it possible to prevent them?

Lice are the pest of puppies chiefly, and are most common about the head parts. Reference has been made to them already.

Fleas are divided into the common variety (Pulex irritans) and the sand flea (Pulex penetrans). The former bites, the latter bores, into the skin. Both are believed to undergo development not on the dog, but in sand, rubbish, etc.

The great difficulty practically is really not killing fleas and getting rid of those on the dog at the time, but in keeping him free; in fact, the former is quite an easy task comparatively. It is no exaggeration to state that there are surroundings amid which it is impossible to keep dogs clear of fleas for twenty-four hours; so that, in choos- 
ing the site for a kennel, and in all its arrangements the flea question should be kept prominently in view. On a sandy soil the sand-flea may prove extremely troublesome, and nothing but a conversion of the soil into another sort, or removal of the kennel, will suffice.

The removal of all rubbish, manure, old straw, spent or used sawdust, and the free use of wood ashes with lime below, will do much to keep down the flea pest. Coal ashes and loam together make a good, hard yard, which can be readily swept clean. All boxes used for sleeping places, and all cracks, should be frequently subjected to treatment with some of the agents that destroy these vermin. This subject has been dealt with in an earlier part of the work.

The agents and methods of destroying fleas are legion. Various powders, soaps, oils, acids, etc., are all efficacious, and the choice of the one or the other should depend on circumstances. It is to be remembered that insects breathe by pores, and that if these are filled up with oils, powders, etc., they must perish.

If a dog has but few fleas, the Persian or Dalmatian insect powder may be dusted through his coat conveniently from a little bellows, while he sits on papers to avoid loss, as the cost of this article is considerable.

When there are many dogs in a kennel badly infested with fleas this method will not prove of itself successful. The plan the author has found most satisfactory is the following: Cover the dog all over with a mixture of equal parts of cotton-seed oil and crude coal oil, and in half an hour wash the animal thoroughly with strong soap. In some cases simply washing in water to which some crude 
carbolic acid or cresol has been added suffices to kill, or nearly kill, the fleas.

In all cases the dog should be gone over with a fine comb and the vermin taken off and burned, for they have a way of reviving after washing that is astonishing.

Another plan that gives excellent results is to get the dog to stand over some clean boards, so that any fleas falling may be seen and trodden on; and with a shallow, flat dish containing coal oil at hand, pass a fine comb dipped in this fluid through the hair and rapidly rub off the fleas as caught into the shallow dish of oil.

But in any case, under certain unfavorable conditions, keeping dogs even moderately free from fleas is no light labor, and nothing but watchfulness and work will accomplish it.

The constant worry from fleas or lice may seriously derange a dog's health, or with the scratching produce eczema.

Lice can be easily destroyed by treating as for fleas, as recommended above, especially by the first method, but the comb will also be necessary, and in puppies with long ears freedom is secured only at the price of ceaseless vigilance.

Washing young puppies is to be avoided as a rule. Washing the head after treatment with oil, etc., will often suffice. However, with special care, washing is not the bane to puppies some would have us suppose. Of two evils, washing and lice, the former is much to be preferred. In the author's own kennel no unfavorable results have ever followed washing puppies with the precautions as to rapidly rinsing, drying, etc., he employs. 


\section{CONSTITUTIONAL DISEASES.}

Certain disorders affect some portions of the bcdy specifically, yet produce symptoms which are not referable to that region alone, but affect to a serious extent the whole economy, and hence are spoken of as constitutional. It must be admitted, however, that it is not easy to determine always how best to classify certain diseases; but the main thing is to grasp the condition of affairs by whatever name called.

Erysipelas.-Some would class this disease as an inflammation of the skin, and treat it under the head of "skin diseases." The constitutional symptoms are so pronounced we prefer to consider it a constitutional disease.

Erysipelas is an inflammation of the skin, with a strong tendency to spread, to attack the tissues beneath, to end in abscess or sloughing of parts, and attended by fever and prostration. It may attack the unbroken skin, but is particularly liable to occur around wounds, especially if patients with the disease are near. It is contagious and infectious, associated with and probably caused by a microbe, though certain constitutions are much more predisposed to it than others.

Symptoms.-Locally, heat, pain, redness, swelling, a peculiar tense, hard feel, with a dark tinge in the redness in some of the worst cases. Constitutionally, chill, nausea, fever, loss of appetite, prostration in bad cases, etc.

Treatment.-This must be both local and constitutional.

As to the local applications, practice differs much. Some paint with tincture of iron, or tincture of iodine; 
others use soothing lotions. Painting vigorously around but not on the seat of inflammation with tincture of iodine, with the application of the lead-and-opium lotion to the actually inflamed part, are the measures we are inclined to recommend.

All agree that constitutional treatment is essential. The bowels should be relaxed with salines. This is of great importance.

The food should be bland at first; later, highly concen. trated but easily digestible.

If there be much prostration, alcoholic stimulants are absolutely necessary, in small repeated doses.

The following has been found as useful as any internal medication :

B Tinct. ferri perehlor........... $3 \mathrm{v}$;

Potass. chlorat .............. 3v;

Glycerin ................. $\xi \mathrm{ij}$;

Aquæ.................. ad $\xi$ viij.

Ft. mist.

Sig. : Dessertspoonful every two to three hours.

After the acute stage, quinine and iron, or the citrate of iron and quinine, with perhaps cod-liver oil, may be needed.

The above remedy may be given in capsules when the $\operatorname{dog}$ is fractious, ten drops of the tincture of iron dropped on ten grains of powdered chlorate of potassium, allowing water or a little milk just after to dilute the medicine in the stomach.

The animal had better be isolated from others, and every attention paid to the surroundings, as the disease is a grave one. 
Diphtheria. - Fortunately, this fatal malady is very rare in the dog. It may possibly be communicated to him from the cat, from man, or the reverse. Its cause in the $\mathrm{dog}$, as it certainly is in man, is probably a specific germ; and certain conditions - as bad drainage, poor ventilation, debility, etc.-faw its spread. It usually attacks the throat (pharynx, larynx) or nose, and may extend from the one to the other, or downward into the windpipe. When fatal, it usually kills by exhaustion or suffocation in the acute stage, or later by paralysis, especially of the heart.

Symptoms.-Chill, fever which is not always marked, loss of appetite, debility, and symptoms referable to the parts affected, as difficulty in swallowing, possibly (if the larynx is attacked) great difficulty in breathing, etc.

Treatment.-The prognosis is grave, and treatment should be prompt, almost continuous, and both local and constitutional. The dog must be isolated; the air of his apartment had better be moist, and the ventilation perfect.

Sprays and lotions to the parts affected are called for, but should never be of a character to injure the mucous membranes.

Lime-water, lactic acid, carbolic acid, sulphurous acid, and peroxide of hydrogen are among the remedies most used.

The food should be easily digested but nutritions from the first. The constitutional treatment, in fact, may be very much as in erysipelas, but the medicine should be given in liquid form to get its local effect.

If suffocation is threatened, tracheotomy should be performed. 
Paresis or paralysis is apt to follow. Should it occur, reliance is to be placed on massage, nux vomica, strychnine, etc.

Exercise should be only gradually and cautiously allowed.

Dropsy.-Dropsy is a term usually applied to a condition associated with fluid in the abdomen. It is a symptom, and not a pathological condition, but is worthy of special reference.

It is due to some cause that gives rise to a very impoverished condition of the blood, or, as is more common, to pressure on or distention of the veins. The condition may be present in the thorax (hydrothorax), in the abdomen (ascites), or in the cranial cavity (hydrocephalus). Ascites is the more common, and is due to heart disease sometimes, but more frequently to some organic (structural) disease of the liver.

Symptoms.-These are made up of those due to the presence of the fluid and of those that are associated with the cause of the dropsy. There is usually debility, feeble pulse, loss of appetite, weak digestion, and probably difficult respiration or hurried breathing, etc.

Diagnosis.-This lies in the bitch between pregnancy and the disease in question. The pregnant animal is not sick or emaciated, the abdomen has not the even, tense feel of the dropsical subject, however many whelps may be within; besides, the mammary glands are usually enlarged. If there be a history of illness, the probability is that dropsy is the cause of the distended abdomen; but the matter may be settled by percussion. Dullness is always present, while a gentle tap at one part, as the animal lies 
on its side, will cause the perception by the hand held at a point opposite to this of a sort of wave or thrill, which will render the diagnosis certain.

Treatment.-The disease is often fatal, but the indications are to cause the absorption of the fluid and to improve the general health.

Unless the patient is very debilitated, purgation by calomel and jalap or elaterium may be tried.

Next, the use of iodide of potassium, or syrup of the iodide of iron, is indicated. Large doses of tincture of iron are also recommended. Digitalis is advocated by some.

Should the fluid not disappear within two weeks, tapping for its removal, which should be very gradual, may be tried. Similar treatment is to be adopted in hydrothorax. Treatment for hydrocephalus is generally unavailing.

Rickets.-Though the most obvious changes are in the bones, the disease is essentially constitutional.

The bones undergo a series of changes, which result in their becoming enlarged at the ends, less resistant, and consequently more apt to bend, so that deformities are common.

Of the bones, those of the limbs and head suffer oftenest. Along with this condition of the osseous system, the whole nutrition of the animal is at fault. Its appearance of general lack of vigor and unthriftiness, suggests that the best thing to do with the animal is to chloroform it; and so it is, in many cases.

Heredity has not been established as a cause-i. e., the condition has not come to the animal from a rickety (rachitic) dam or sire, or one of an otherwise unhealthy 
constitution, though possibly bad management of the dam when in whelp or during nursing, very many bitches not

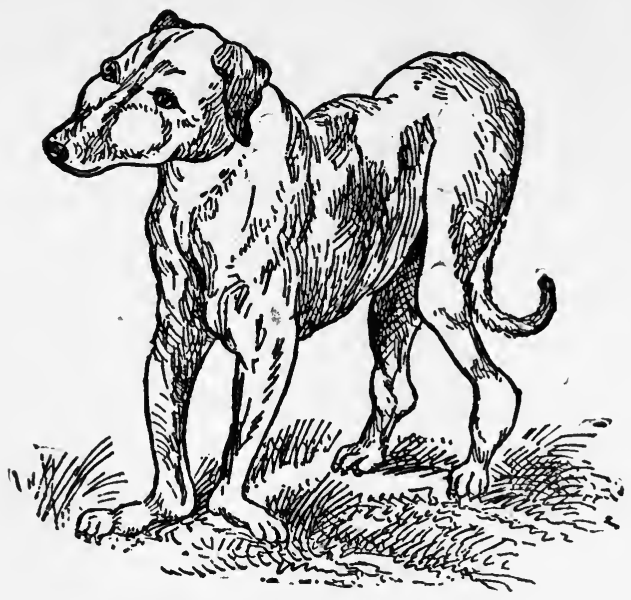

Fig. 37.-Rachitic Dog (HrLL).

being sufficiently fed at these periods, may give rise to rickets in the young. Unhygienic surroundings, as damp, dark, ill-ventilated kennels, food insufficient as to quantity or quality, etc., are undoubted causes.

Rickets has been experimentally produced in nursing puppies by removing them from the dam and giving them food they could not digest properly.

Treatment.-Everything possible should be done to improve the general health-sunlight, dry, warm, wellventilated kennels, and gentle exercise being essential. Lime-water, phosphate, bone-dust, cod-liver oil, iron tonics, etc., are all indicated. Grooming and massage are not to be forgotten. A diet varied and adequate is essential.

The puppies of large breeds of dogs often grow so fast that the weight of the body is too great for the limbs 
with their soft bones to bear; hence bending of the bones, relaxation of the ligaments, etc.

The craze for canine giants, and the habit of stuffing puppies to get size, at the expense of everything else, are to be condemned.

All puppies, whether of large or small breeds, should be regularly exercised after three to four months of age, by being taken into the fields or woods and kept in a condition that enables them to form bone and muscle, but should not carry, either now or at any period, a " mountain of flesh." Forced feeding, and neglect of exercise, etc., leads naturally to loss of stamina and the shortening of life.

When a puppy has this tendency to curvature of the bones, weakness of the joints, etc.,一a condition akin to rickets-good feeding and good management generally will suffice for an arrest of the evil, though treatment similar to that recommended for rickets will also be helpful.

Rheumatism.-Acute rheumatism may be regarded as an inflammation mostly of the joints, especially of the ligaments and related structures.

The cause has not been definitely ascertained, and, though cold, damp, etc., predispose, it is believed that the exciting cause is some poison produced within the body, possibly lactic acid.

Symptoms.-There are swelling and pain of the joints, difficulty in locomotion, anxiety lest the affected parts be moved and pain produced, elevation of temperature, disturbance of the digestion, etc. The disease is apt to shift from joint to joint. 
The subacute and chronic forms are more common in the dog.

Diagnosis.-The diagnosis lies between sprains and other injuries, colic, etc. In the acute form, when there is decided swelling without the history of any injury, when the temperature is a good deal elevated and the digestion deranged, the diagnosis is not difficult.

In any form of the disease the joints, if not tender to the touch, are so when moved, which often assists in a diagnosis.

The movements, attitude, etc., of a rheumatic dog are often characteristic.

In the subacute and chronic forms the health is not always greatly impaired.

Muscular rheumatism differs from that just described in not affecting joints, though in lumbago the ligaments as well as muscles of the loins are probably involved. The muscles are sore, stiff, and tender, if not positively painful.

Chest founder, or kennel lameness, affects more especially the muscles of the shoulders, chest, and fore-legs.

This form of rheumatism can generally be traced to damp, draughts, cold, etc.

Treatment.-In the acute form, alkalies and colchicum in frequent and rather large (ten to twenty grains) doses are still preferred by some; but with the majority salicylate of sodium is the favorite remedy. It is best given in gelatin capsules, every two or three hours, till pain, etc., is relieved; afterward in smaller doses at longer intervals. Some incline to phenacetin.

The animal should be made very comfortable, and, if 
pain be excessive, a dose of Dover's powder may be given-unnecessary, however, if phenacetin be used. The bowels should be free, and the food bland and readily digestible. It may be well to wrap up the joints in cottonwool. During convalescence, tonics, etc., may be needed.

In the subacute form the alkaline treatment may prove more successful.

In the chronic form, commoner in old dogs and in animals that go much into water, the treatment must be different. Counter-irritation will generally prove helpful, using tincture of iodine, St. George's paint, the iodine ointment, or red-oxide-of-mercury ointment in the proportion of, say, one to twelve of lard or vaseline, watching the effect so that actual blistering may not occur. Sometimes sedative liniments or ointments will answer a better purpose, such as the belladonna liniment, the chloroform liniment, or equivalent ointments. Dogs will not usually lick off these liniments, though they may the ointments. They are, moreover, often useful in all the other forms of rheumatism, including the muscular.

Internally, iodide of potassium, syrup of the iodide of iron, tincture of iron, etc., are of great value. At times a rheumatic affection, especially the chronic form, is very intractable, and renders the dog's life wretched.

Muscular rheumatism may be treated with hot fomentations, medicated with opiates (poppy-heads) or belladonna at first; later by counter-irritation in mild form. Little constitutional treatment is usually called for.

Distemper.-Distemper is an acute contagious disease that tends to run a definite course. It has been compared to typhoid and to typhus fever in man, and distemper or 
strangles in the horse. It is more like typhus than any of them, but the comparison is neither exact nor fruitful.

The disease is more apt to attack dogs under a year old, and pure-bred dogs, rather than others.

It is more fatal in the former, and especially in highly inbred animals, which is owing to their less stable nervous system and less resisting constitution generally.

As no specific is known for the disease, it remains the gravest acute malady that attacks the $\mathrm{dog}$, and between the ravages of distemper and parasites a large proportion of pure-bred puppies are annually carried off ; it therefore becomes important in the highest degree that the true nature of the disease and its prevention be well understood.

Causation.-Recent investigations and experiments, which it is hoped will be continued in different quarters, make it reasonably certain that a germ, possibly several germs, or, more likely, different forms of the one germ, are associated with distemper and constitute the essential cause of the disease.

Certain it is that there is a virus of some kind, that can be communicated from one animal to another, and which has great vitality-i. e., can long exist outside of the body without destruction, and communicate the disease when brought in contact with susceptible individuals. In this as in all similar diseases there are predisposing causes. Dogs do not equally at all ages and under all circumstances take distemper. We may say, then, that age, environment, condition of the constitution at the time of exposure, individuality, etc., are all important.

All dogs do not take distemper when exposed, and, as a rule, the older the dog the greater his chance of escape. 


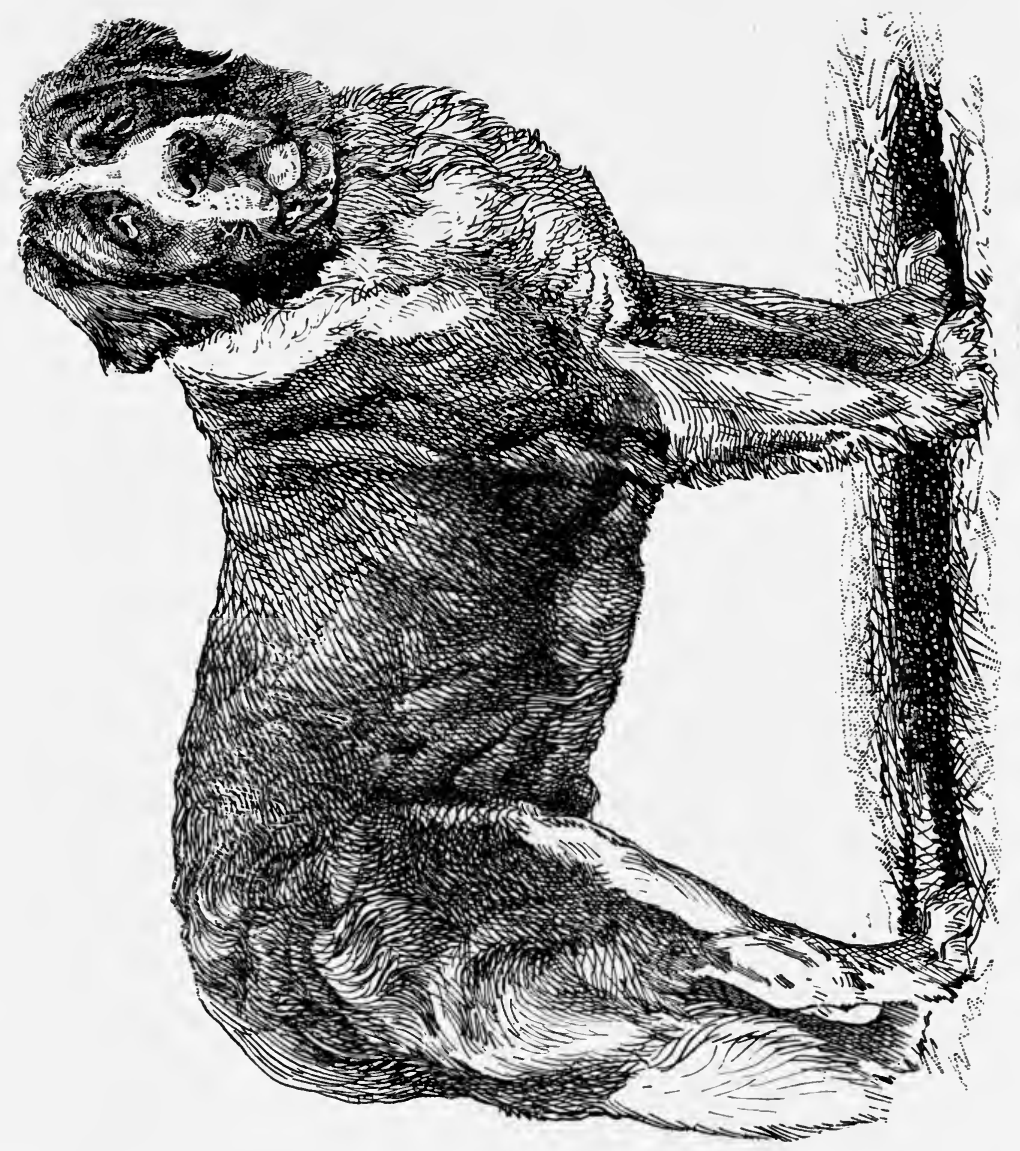

空 
Some dogs possess immunity from this malady, and rarely does the subject have the disease a second time.

It is possible, perhaps, that distemper can be conveyed through the air, but it is usually by contact with either an affected animal or with the poison (virus), which may be adherent to some inanimate body or the body of some dog that is not himself perhaps susceptible.

Anything that tends to lessen an animal's resisting power, as a sudden alteration in the environment, like a change of weather or of feeding, exposure to wet and cold, exhaustion, a long journey, the exciting and unnatural conditions of shows generally (see page 393), with the crowding together of large numbers of dogs that have lived under different conditions, etc.-all such favor the spread of the disease.

Prophylaxis, or prevention.-Much more can be done to ward off distemper than to cure it, and a consideration of the predisposing causes will suggest means of prevention.

It will be noticed that distemper is most rife in America during and after the fall shows in September and October. At this period many puppies are getting their second teeth, their constitutions are still very immature, and the nervous system-the great regulator of all vital processes-very unstable. It can not be doubted that shows favor the production of distemper, and must do so even when all precautions are taken; for the germs of the disease are so widely spread, that it would seem that all that is required for its propagation is a young animal with a somewhat temporarily lowered vitality.

Hence it follows that puppies should be kept at home, 
not sent to shows at all. Again, no dogs should be admitted from kennels in which distemper has existed so late as one month previous. Every exhibitor should be required to sign a paper to this effect, and that the whole kennel had been thoroughly disinfected and the dogs well washed after the disease had disappeared, and also before the show. All dogs should be washed two to three days before a show, and this should be repeated after each show. It can be so managed that neither their coats nor their health will suffer (see page 122).

Certainly it is unwise to allow any dog that has been away on a journey, or has mingled with a multitude of dogs, to return to his kennel without these precautions.

If puppies are sent to shows, the greatest care in all respects should be taken of them (see page 394).

It will be noticed that distemper is apt to break out in kennels during wet and cold or during muggy weather. When the animals are much confined the conditions are most favorable for the germs, or, at all events, least favorable for the $\operatorname{dog}$; hence the need of all precautions as to fresh air, cleanliness, etc. The digestive tract must be especially closely watched then. When dogs can not be exercised on account of the weather, an extra amount of grooming and massage, with less food and of a lighter kind, will prevent many kennel troubles.

It appears, then, that one of the seasons of the year at which dogs are most liable to take distemper also coincides with one of the show periods in America; so that there is, so far as many of the most valuable dogs are concerned, a double reason for the prevalence of distemper at that time. 
Symptoms.-Distemper shows so great a variety of symptoms that it will be judicious to give nearly all possible ones as they affect each system of organs of the body. It will not be feasible to enumerate all the combinations that occur, as these are simply endless.

Dullness, loss of appetite, vomiting, constipation usuually at first, possibly diarrhœa; elevated temperature, thirst, rapid pulse ; dry, hot nose, sneezing, chills, harsh or husky cough; soon a thin, irritating discharge from the eyes and nose; redness of the eyes (conjunctiva); later, a muco-purulent discharge from nose and eyes, and looser cough ; there may be twitchings, or fits of various kinds ; symptoms of meningitis, paralysis, emaciation-all of which show the effect of the poison on the nervous system.

The period of latency, or incubation, is from about four to sixteen days, during which the dog may seem to be nearly as well as usual, or rather dull.

Diagnosis. - When the nervous system is much affected the discrimination is between meningitis, fits from worms, teething, etc. But usually in distemper there is so much loss of flesh, prostration, etc., that the diagnosis is not difficult.

Whenever a dog rapidly loses flesh and falls off in his appetite, is dull, etc., especially if distemper is prevalent, this disease should be suspected and the animal isolated for further observation.

The harsh cough is rather characteristic. Those affections of the eyes associated with indigestion are not accompanied by fever. The thermometer is invaluable.

At times the attack is so sudden and so prostrating 
that the dog never rallies, and these resemble the worst cases of typhus fever in man.

The blood in some cases undergoes a rapid and fatal degeneration; in others the nervous system is completely overpowered. Such cases must soon end fatally. We do not think divisions of such a disease into varieties is wise for the inexperienced, as it is seldom that typical cases of each are found, and the observer is led to look for what does not exist in nature; hence we do not say that there are two varieties or types of distemper, the nervous and gastric or catarrhal.

The disease might with some propriety be termed a catarrhal fever, but even that term expresses only a part of the truth.

Prognosis.-Except in the very serere cases (lightning cases) just referred to, and when the nervous system is much affected, leading to fits, paralysis, extreme emaciation, etc., the prognosis as regards survival of the immediate action of the poison is good, provided complications do not arise. Most of the deaths from distemper are due to these. With marked emaciation and total refusal of food the prognosis is always very grave.

Complications.-Extensive or capillary bronchitis, especially in young puppies, pneumonia, either lobar or lobular, are not uncommon, and often end fatally.

Diarrhœa with blood or bile in excess is also another frequently fatal complication; while jaundice is generally an indication that death is not far off, as the retained bile soon poisons the whole system and disorganizes the blood.

Paralysis and chorea may occur early or more frequently after all the acute symptons have subsided. They 
are due to the effects of the poison on the nervous system. When both occur together, or the paralysis is marked or progressive, the prognosis is very bad.

There may be both paralysis and chorea witho: visible structural changes in the spinal cord or brain.

Ulcers of the cornea, inflammation of the cornea or the iris (rare), are apt to result if the eye symptoms are severe or neglected.

Skin eruptions, mostly of an eczematous character, very frequently follow, and especially about the head. They are not readily cured-sometimes almost beyond treatment.

Very often it will be kindness, after an attack of distemper when complications of a chronic character have arisen that render the dog wretched, to chloroform him to death.

Not a few dogs are left with digestive powers so weakened that they are always liable to get out of condition.

However, it is the aim of the medical expert to try to save, and only to recommend a painless death when the case is obviously hopeless or the subject very miserable, and after trial of remedies has been made and a chance left for the vis medicatrix naturce (nature's healing power) to assert itself.

It is not always easy to detect such complications as capillary bronchitis, lobular pneumonia, or even the lobar form of the disease at the outset. The temperature may be but little elevated. A chill should arouse suspicion, or any increase in the rate of the breathing.

The physical signs are often ill-marked. The author recommends that every patient be subjected at the outset of the disease to a very careful physical examination, espe- 
cially as regards percussion and auscultation of the chest, so that any departures from the existing state may be the more readily appreciated, for much depends on an early diagnosis of a complication and its prompt treatment.

Treatment.-Two extreme positions have been taken in regard to this disease-the one that there is some specific or means to cut it short, the other that all remedies, or at least all medication, is utterly useless.

It is true that distemper can not be aborted, but it is equally true that the patient may be put under conditions that favor his avoiding the rocks and quicksands and reaching a harbor of safety.

The sooner the notion that there is any specific for distemper known at present is abandoned, the better. The treatment of this disease may be resolved into providing an environment most favorable to healthy life generally, and the avoidance of complications; in other words, providing as good hygienic surroundings as possible, with suitable food, and meeting special conditions as they arise.

All who have written intelligently on distemper are agreed on certain points, such as that there is no specific for the disease; that careful nursing and feeding are of the highest importance; that strong purgatives are to be avoided; and that exercise is injurious.

The dog should, of course, be isolated from all companions, if possible in a separate building; he should be rendered comfortable, and especially guarded against cold. In many cases a blanket or chest-jacket will be useful, perhaps always in winter. This is of vital importance, as all sorts of chills are apt to aggravate symptoms and set up complications. 
As there is a pronounced tendency to wasting, nothing can be of greater importance than that every means shall be employed to feed to maintain the strength. Good feeding is half the battle, certainly in this disease. The author can not give any better advice than to feed much as in the case of a human being with a very capricious appetite.

At the outset, if there is a troublesome cough and tendency to retching, an emetic of fifteen to twenty grains of sulphate of zinc with a teaspoonful of wine of ipecac, for an ordinary-sized puppy of six months or over, may do good. The bowels had better be unloaded, and sulphur is about the best remedy, or sulphur and cream of tartar; castor oil or syrup of buckthorn will do; but no strong medicine should be given to open the bowels.

As the fever may be decided for a few days $\left(103^{\circ}\right.$ to $106^{\circ}$ Fahr.), the importance of plenty of fresh air and a nutritious but unstimulating diet can be appreciated.

However, if a dog will not take milk, milk and eggs, rice and milk, rice pudding, bread and milk, or such like, he may have a little beef or mutton cut fine or grated. This may act as a tonic to his disordered digestive organs, and do more for him than any medicine; but the first stage is not the time for feeding on meat largely.

Those who believe in antipyretics will give them at this stage. For our own part we would not, as a rule, but would save the stomach of the dog as much as possible, lest it give out and pave the way for a fatal issue.

One or two large doses of quinine, which we always combine with bromide of potassium, as it renders it much less exciting to the dog, may do good-e. g., five to eight 
grains of quinine with fifteen to twenty grains of the bromide. Many like to give a fever mixture, such as the following:

B Tinct. aconit. $\operatorname{rad} . . . \ldots \ldots \ldots . . . . .3$ jss. ;

Spt. eth. nit................ $\xi_{3}$; ;

Ammon. mur............... 3 jss.;

Pot. chlorat............... 3 iij;

Syrup. aurant............... $z_{j}$;

Aquæ................. ad $\xi$ iv.

Ft. mist.

Sig.: Teaspoonful every two hours, till the pulse is slowed and the temperature lowered.

Some recommend dissolving chlorate of potassium in the dog's drinking-water. We do not indorse this plan, as we think a drink of good, cold, pure water has a valuable tonic effect itself.

The value of bromide of potassium, in the earlier stages of the disease, in quieting the animal, favoring sleep, etc., has not, we think, been fully appreciated. Phenacetin is soothing and antipyretic and might replace quinine.

So far as giving medicine is concerned, the author is guided very much by the state of the dog's digestion and his general condition. If there is much prostration, a feeble pulse, distaste for food, etc., the above-mentioned remedies seem to him to be contra-indicated, while small doses of quinine and carbonate of ammonium, or perhaps alcoholic stimulants, with liquid food, will serve a good purpose.

Alcoholic stimulants are injurious in the early stage, as a rule. Aconite must be watched in any case, on account of its depressing action on the heart. When 


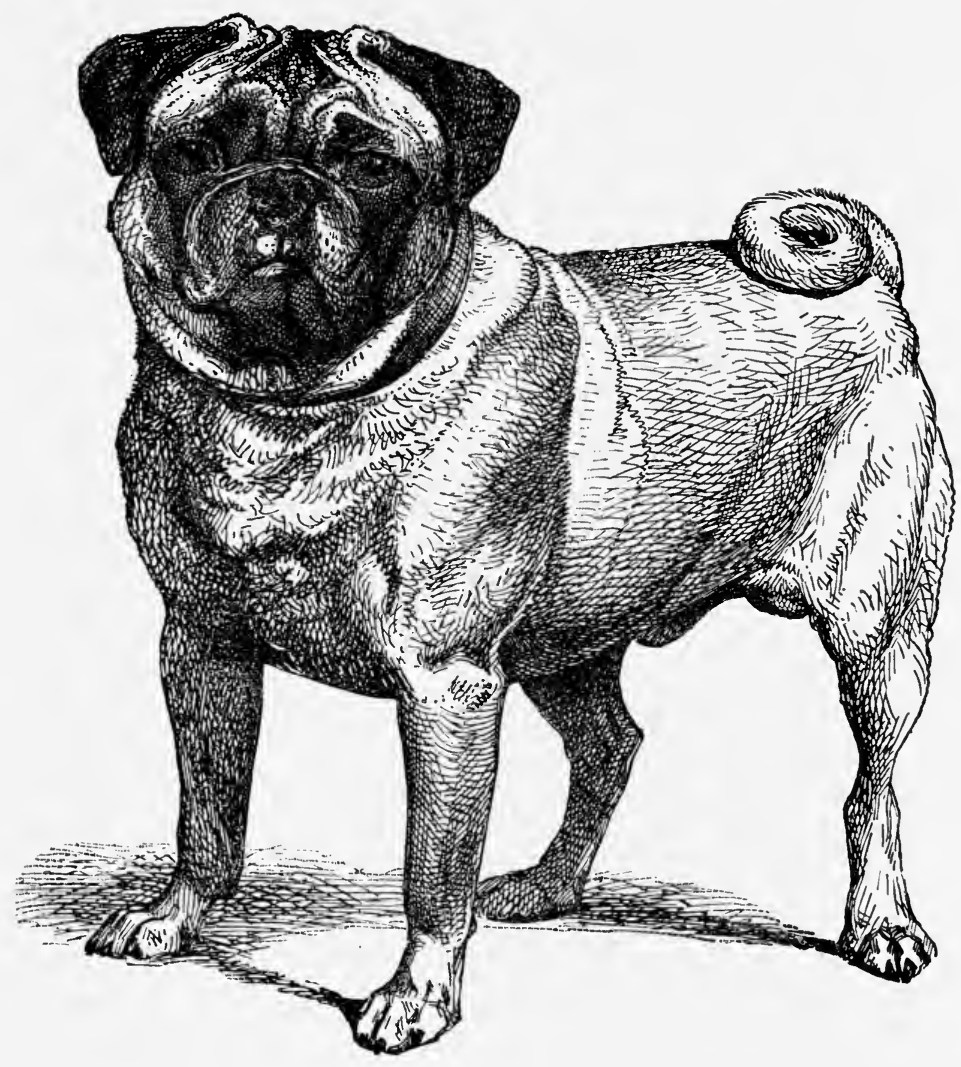

THE PUG CHAMPION LORIS.

(K. C. S. B., 17,567.)

For description, see page 90 . 

the pulse is rapid and full, it is often a most valuable remedy, but again at times it seems to fail utterly to reduce the heart's action, or it proves too depressing. If it does not meet expectations after half a dozen doses, it had better be discontinued. Hyposulphite of sodium is highly valued by some experts.

Our own plan of medication is sometimes after this fashion, though our belief in its efficacy is not very strong.

After one to two large doses of quinine and bromide of potassium, we inclose in gelatin capsules No. 00 chlorate of potassium, bromide of potassium, and three to five grains of hyposulphite of sodium, all powdered fine, and some quinine (one to two grains); in this put three to five drops of tincture of aconite (if Fleming's, only one half to one drop); give this to the patient, and then offer him a drink of water, and, if he will not take this, a little milk. By this method we know that the dog gets every particle of his medicine, which is always an uncertainty when given in liquid form, not to mention the worry arising from the unpleasant taste, etc.

However, such treatment must not be routine, or continued regardless of symptoms or for an indefinite time, as we have already endeavored to point out.

When the dog has passed the acute or febrile stage, he must be treated according to the condition in which he is found. If his appetite is poor, vegetable bitters, especially nux vomica, are indicated. The citrate of iron and quinine will, in such and most cases, be found an admirable remedy. As soon as his stomach will bear it, cod-liver oil beaten up with milk, or eggs and milk, will be most useful. All dogs should be so fed as to build them up, and given tonic 
treatment, as it is impossible to say whether chorea or paralysis may not follow, often long after, apparently mild cases. On this the author can not too strongly insist, and he believes the subject has not received the attention it deserves. Comparatively few dogs, in fact, die during the acute stage of the disease; and as such complications as chorea and paralysis are scarcely ever recovered from, it is all the more important to attempt to prevent them.

The treatment of the various and numerous possible complications of distemper is given under the different diseases, elsewhere in the volume.

A word of warning as to the eyes. They do not usually receive the attention they deserve during the earlier stages of the disease.

From the first they had better be treated as recommended under "Ophthalmia" (see page 308). It is all-inportant to soothe the conjunctival irritation and keep the discharge well washed away, otherwise ulcers of the cornea, eczema of the lids, and a weakened condition of the eyes that may trouble the patient for months, if not for the rest of his life, may result. The edges of the lids should be kept smeared with a little vaseline, and if to this a small quantity of powdered iodoform be added, so much the better. The ordinary zine ointment is also useful.

As a soothing lotion the following will perhaps serve better than any other:

B Acid boracic............... 3 ss.;

Ext. belladon. fl............. 3 ss.;

Ext. opii liq.............. $3 \mathrm{j}$;

Aquæ................ ad $\xi i v$.

Ft. mist. 
Sig. : Apply to the eyes, after they have been cleansed with warm water, frequently, being careful that none enters the dog's mouth.

Prevention of the spread of the disease and disinfection are of vital importance. There are many ways of accomplishing this. The plan we are most inclined to is the following:

1. Have a small separate kennel or hospital into which cases of suspected distemper may be put for observation.

2. House all distemper cases during the whole course of the illness in a separate kennel.

It is preferable to have both of these comfortable but cheap structures, that may be burned when they have been used a good deal, or, better, after each outbreak, if extensive.

No dog should be allowed to mingle with others, however well he may seem, so long as he has any discharge from nose or eyes, and never before from four to eight weeks have elapsed. After the nose and eyes have been specially disinfected by washings or injections of a suitable liquid, the animal should be well washed all over, the water being medicated with carbolic acid, cresol, etc.

If the kennels that have been used as hospitals can not be burned, they should be disinfected, and this should be of the most thorough kind, not relying on one method alone.

The walls and floors may be washed and scrubbed in the ordinary way, and afterward with a strong solution of carbolic acid, corrosive sublimate, or chlorinated lime, some hydrochloric acid being added to the water; then let chlorinated lime be laid upon the floors, the building tightly closed, and diluted hydrochloric acid sprinkled on 
the lime. The person who undertakes this will not have a pleasant task, and speedy escape will be necessary.

After this has gone on for many hours, the building may be aired, again sealed, and sulphur burned in it, the fumes being retained for six to eight hours. Then, after lime-washing all over or repainting, but little danger of contagion exists. Of course, all vessels, etc., that have been near the patient must be equally well disinfected.

\section{SURGERY OF THE DOG.}

It is lamentable that even yet much of the surgery, so called, of the lower animals consists of cruel blisterings and cuttings, anæsthetics not being used, while both the instruments and the method of operating are of a very primitive character and quite unworthy of the present age.

Our treatment of the subject of surgery must be brief, for the same principles apply as in the case of the other domestic animals and of man. The reduction of dislocations, and especially the setting of fractures and all cutting operations, should be undertaken only by those who have the requisite expert knowledge and skill.

However, we would remind the veterinary student and practitioner that the dog probably feels pain more acutely than any of our domestic animals, and that more than any other is he capable, by reason of his intelligence, of cooperating, or passively assisting, in surgical operations when not of a nature requiring an anæsthetic.

It is possible for one with but little anatomical knowledge to become so familiar with the natural feel of the joints, etc., of the dog that fractures and dislocations may 
be diagnosed, while the treatment of cuts not requiring stitches, and of some other accidental injuries, is simple.

We remind the reader of a few of the principles of surgery of more importance.

Any injury to an animal, whether from chemical or mechanical violence or from heat, is apt to be followed by inflammation with its attendant evils, as constitutional disturbance, possibly abscess, ulceration, sloughing, erysipelas, and blood-poisoning (septicamia). Hence the importance of attending to all injuries at once.

Fortunately, repair of tissue is more rapid in the dog and other of the lower animals, and shock or reaction less, than in man.

A few words on some of the commoner accidents and a few of the operations to which the dog must occasionally be subjected may now be offered, but first of all in regard to the use of anæsthetics.

Anæsthesia.-Collapse may take place suddenly during the inhalation of chloroform, and from this the dog may not be recovered, so that special care is necessary. Anæsthetics are rendered much safer if the dog be given half an hour previously, either by the mouth or hypodermically, a good dose of morphia. Most dogs are very much frightened when an anæsthetic is about to be given. Morphia renders them comparatively indifferent.

Many minor operations can be well enough done with no further assistance, the animal feeling little or no pain.

Ether, under proper precautions, is fairly safe for the dog, and some anæsthetic should be given, rather than subject the animal to severe and especially to prolonged pain.

Pain is injurious to the dog for the same reason that 
it is to ourselves, by causing depression, and disturbance of the nutrition generally; while it is too much to expect of a $\mathrm{dog}$, as it is of a child, that it should comprehend the purpose of the operation, except in the vaguest way at best; hence its future management may be very difficult. Dogs are ready to forget pain that has been followed by plain relief, but not cruelty. Anæsthetics had better be pushed rapidly to complete anæsthesia. The operation should be done as quickly as possible and the anæsthetic then removed, so that recovery may be rapid. A mixture of ether and chloroform, or of alcohol, ether, and chloroform, will be found on the whole the most satisfactory, though always demanding care in its use; but in every case the anæsthetic should be managed by one who is an expert, and he should give his whole attention to this, and not watch the operation or anything else. Dogs do not bear prolonged anæsthesia of any kind well.

Antisepsis.-Within the last twenty years surgery has been revolutionized by the use of methods to prevent putrefaction or kindred processes due to germs and other causes in wounds.

It is now regarded as highly important that all instruments, and the hands of the operator, be rendered surgically clean-i. e., free from germs as well as all else that can set up the processes referred to; and as a result, wounds made by the surgeon himself in operating heal directly (first intention) very frequently, and abscesses and the other evils referred to as the results of inflammation are rare.

Antiseptic dressings are commonly employed. There is no reason why the dog should not receive at the hands 
of the man that operates on him all the care given to a human heing. What is worth doing at all is worth doing well, and the individual who rightly comprehends his calling will act accordingly when operating on so noble a creature as the dog.

Formerly solutions of carbolic acid in water and in oil were much used. They are still in voguc, though weak solutions of corrosive sublimate are now preferred by many.

For disinfecting instruments that have been well washed with soap and water, one-to-twenty carbolic acid or one-to-five-hundred corrosive sublimate will answer.

For dressings, one to forty or one to eighty of the former or one to two thousand of the latter is strong enough.

Various dry antiseptic dressings can now be purchased ready-made at chemists' shops. Carbolic oil is not the best dressing for wounds in dogs.

Cuts.-When slight and recent, it is only necessary to make sure that no foreign bodies-as dust, hair, etc. - are in the wound, and that it is protected by some simple, wellfitting covering. No irritating "salves," ointments, etc., should be applied. Avoid all sources of irritation, the air included, and Nature will do the rest. It is needless to remark, that after all injuries the parts should be kept as nearly at absolute rest as possible. If the wound be large and gaping, it will be advisable to bring the edges together with stitches of silk thread. It is not usually necessary to give an anæsthetic, but it may be advisable to give a hypodermic injection of morphia. The instruments (needles, etc.) should be suitable in size, shape, and sharp- 
ness, and the operator skilled. A bandage should be so applied that very slight pressure will be exerted.

When antiseptic dressings are not employed, boric acid and a little iodoform may be sprinkled over the wound. The latter keeps off flies, and both greatly assist the healing process.

Wounds of mucous membranes-i. e., those of the mouth, throat, vagina, etc.-may be dangerous from hæmorrhage, and should receive prompt attention. Cold and pressure are usually successful in arresting bleeding; indeed, these are the best methods of controlling hæmorrhage when the injured blood-vessel can not be secured by a ligature, and may often supersede ligatures.

Sprains and Bruises.-These are common in so active and spirited a creature as the dog. The danger is at first inflammation, and, later, weakening of parts; in fact, a sprain may lead to a permanent weakness.

The treatment indicated is rest, cooling lotions, as the lead-and-opium wash, iced cloths, etc. If inflammation has actually set in, hot fomentations, medicated with opium or belladonna, may be better. After this stage, and to encourage a return to a natural condition, any kind of a stimulating application-e. g., ammonia, soap, or turpentine liniment-will be useful, with suitable rubbing, massage, graduated exercise, etc.

Usually after the acute stage bruises do not give much trouble unless abscesses form. The treatment is much as for sprains.

Burns and Scalds.-When large, these are always liable to be followed by serious consequences.

The indication is to allay pain by opiates internally, 


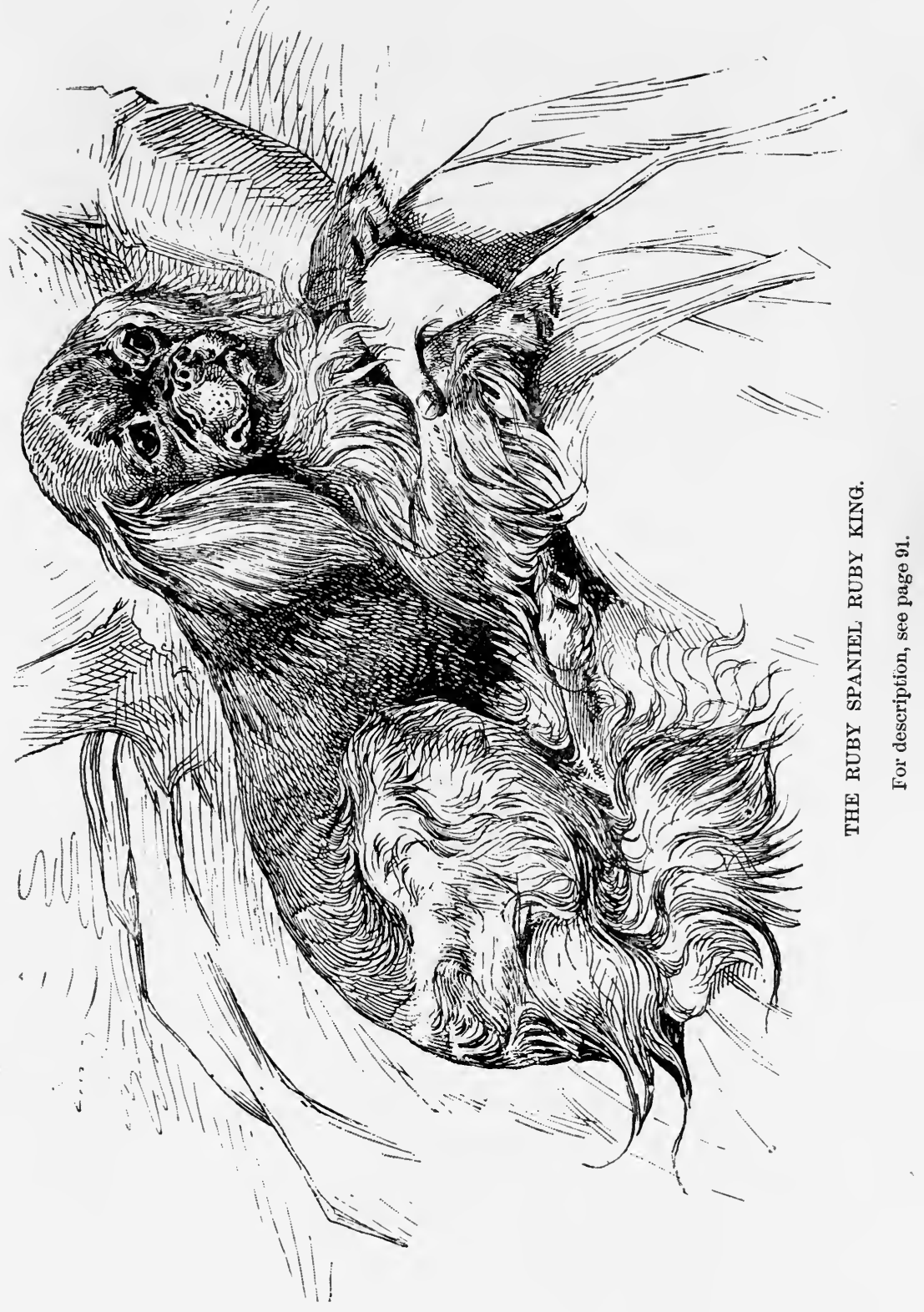



and exclusion of the air externally by some covering applied over the seat of injury.

Scalds are usually worse than burns. Covering the part with dry bicarbonate of sodium, solutions of the same, even dry flour if the former is not at hand, with oil, vaseline, etc., all serve to protect the part and so to soothe. An old and favorite remedy is a mixture of lime-water and linseed oil or olive oil, in equal parts. As the dog bears opiates well, a little of the fluid extract of opium may be added to the dressings at first, but should not be continued.

Should suppuration follow or abscesses form, poultices may be required after evacuation of the pus by incision in the latter case.

It is very important to maintain the strength, and in severe cases to administer alcoholic stimulants.

Fractures and Dislocations. - The increased movement, the crackling or grating (crepitus) of the ends of the broken bone, and the extreme tenderness, usually suffice for a diagnosis of fracture.

The sooner a dislocation is reduced or a fracture set, the less likely is inflammation to follow. After a dislocation has been overcome it is always necessary to bandage the part and insist on absolute rest.

A dog will not often walk on a fractured leg, but he should not be allowed to run freely on account of the risk of injury to it. Of the various dressings for fractured limbs, splints and bandages, starch, glue, and plaster-ofParis bandages, the latter will usually be found the best, for very soon the dog can go about without fear of fresh injury, displacement, or other source of danger. It will 
generally be necessary to get swelling reduced before they are applied. They may be prepared by sprinkling the powder evenly over an ordinary bandage and rolling it up tightly. When applying, water enough to wet moderately will suffice, and some allowance must be made for contraction in hardening. The patient must be watched, and kept quiet till the dressing is dry. An ordinary bandage should be first applied, and a little cotton-wool put between the plaster bandage and the limb at the upper and lower ends, to prevent undue pressure of the sharp edges.

After union is established an ordinary bandage may be worn for a little while, and the dog allowed to exercise only in the yard for a time. Compound fractures-i. e., those with the skin broken-require especial care, and antiseptic dressings are essential.

Cutting Operations.-If serious, these should be done under anæsthetics or morphia (cocaine may suffice in some cases), and with every preparation and all antiseptic precautions. It is not usually necessary to anæsthetize before opening an abscess unless deep seated, but the knife used should be very sharp and the incision decided.

Tumors may require removal if they press on vital parts, grow rapidly, are unsightly, or if small but malignant-i. e., injurious to the health of the animal and very apt to involve adjacent parts.

In any cutting operation of this kind the question of hæmorrhage is to be carefully weighed. About the neck and breast there is considerable danger of bleeding. On the other hand, some tumors may be "shelled out," when superficial, with little trouble or danger. 
Castration and Spaying.-It is impossible to predict what effect on the physical and psychic nature of the dog these operations may have. After either, the subject may be little more than a useless, animated mass of flesh, unworthy the name of "dog." The author would not allow any dog he owned to be thus operated on, nor could he be induced to perform it except when the parts are diseased; and he hopes the time is not far distant when every reputable veterinary surgeon will take the same view of the case, and absolutely refuse to thus run the risk of destroying the dog as a dog merely to gratify the whim of some owner who wishes to shirk his responsibility. Every man should either not keep a dog at all or treat the animal as a dog. A spayed or castrated dog can not win a prize on the bench. Both operations are simple, and with due precautions they may be safely undertaken when really required, but always antiseptically. Before the testicles are severed the spermatic cords should be each secured with a stout ligature, to prevent hæmorrhage. The same applies to the ovarian tubes.

Umbilical Hernia.-This affection arises from incomplete closure of the abdominal walls, allowing the intestine to fall into the sac of distended skin. When small, it is likely to disappear in puppies. If large or growing worse, operation is demanded. The animal is to be anæsthetized, the sac opened, and the edges of the abdominal parietes brought together by strong sutures after the gut has been returned within the abdomen. The skin is to be separately sutured and covered with antiseptic dressings. It is well to keep the dog quiet for a couple of days, and to cover the wound with a firm pad and bandage. 
Other forms of hernia are rare, and must be treated according to the indications in each case.

\section{POISONING.}

The poisoning of dogs is occasionally accidental, but more frequently intentional, to the disgrace of human nature. Happily, the official poisoning of dogs not licensed is now rare, though municipal blundering in the control of dogs is still common enough.

The proper method to destroy dogs that are impounded is by the lethal chamber-i. e., by inhalation of carbonic-dioxide gas. When a single dog is to be killed for any reason, it can be easily and painlessly done by causing the animal to inhale chloroform without any admixture of air. The dog may be laid on his side, the legs quietly bound together, and a sponge, cotton wool, etc., placed in a towel formed into a cone, on which about half

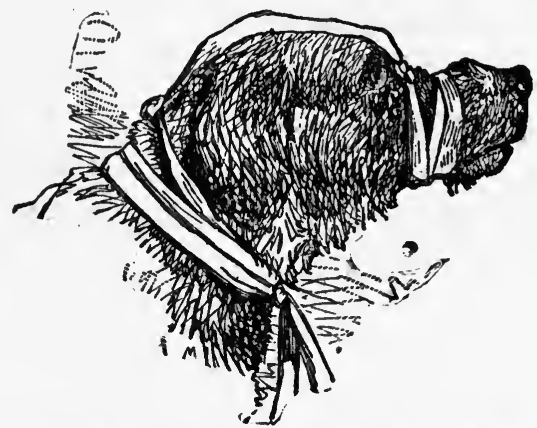

Fig. 38.-Method of controlling a Dog by a Tape, etc. (Mayeew).

an ounce of cheap chloroform has been poured, the whole being suddenly clapped tightly over his muzzle. In a few moments he will cease to struggle, but the cone may be left in position for some time longer. 


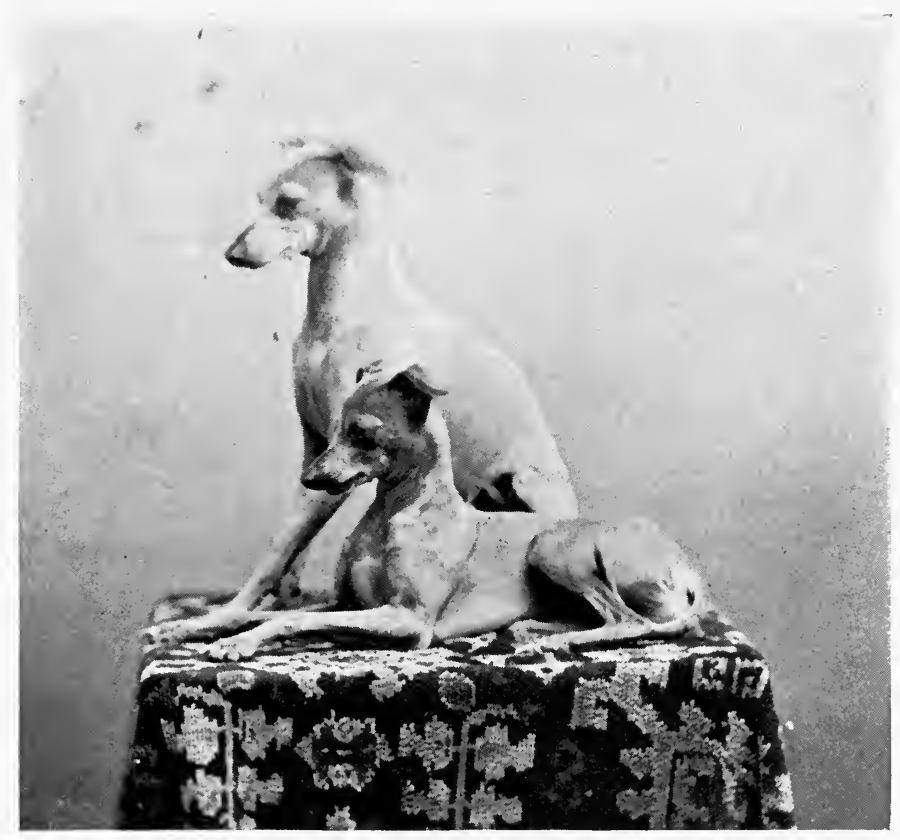

THE ITALIAN GREYHOUNDS WINKS AND IDIOM.

For description, see page 92. 

The commonest means of the "poison fiend" are strychnine, arsenic, pounded glass, and compressed sponge. Arsenic and strychnine can be purchased in the

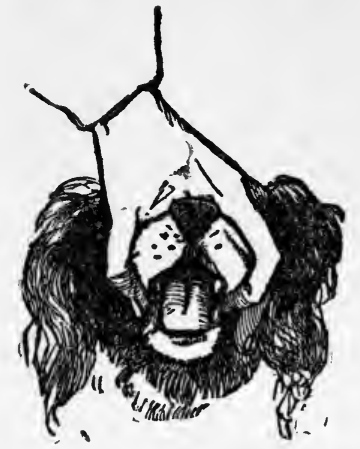

Frg. 39.-Administration of Medicines * (Mayhew).

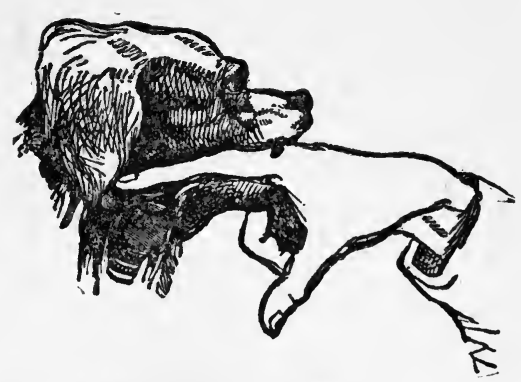

form of small pills, which may be pushed into little pieces of meat and dropped in the dog's way. Strychnine when undisguised, from its bitterness, will not be readily taken; but, as dogs bolt their food, even the crystals may be in. serted in a pellet of meat, butter, etc., and the deadly dose be swallowed. Occasionally dogs roaming the woods find poison laid out for wild animals.

Dogs are not infrequently poisoned by "rough on rats" (arsenic) or other similar vermin poisons, and extreme precautions should be observed, for it is to be remembered that the fatal poisoning of a dog is far more effectually secured by a moderate than a large quantity of the agent. The stomach may at once reject a large amount, while a smaller portion is likely to be retained long enough to accomplish the fatal purpose. Many a

* This cut was accidently omitted from the section on the Administration of Medicines, page 195 . 
dog has been saved from death by poison owing to the readiness with which the canine race vomit.

Dogs should not be allowed to pass through fields in which Paris green (arsenic) is distributed to kill potato bugs.

Puppies occasionally, though less frequently than children, are poisoned by the phosphorus of matches.

Chronic poisoning from protracted dosing with arsenic used for skin disease, chorea, etc., may occur.

Arsenic should never be administered continuously, and never longer than two weeks, without periodical intermissions in its use.

The practice of drugging dogs with arsenic, etc., to keep them in "show condition" can not be too highly condemned. Such dogs are apt to become so dependent on the drug that their health quite breaks down without it.

Practically, cases resolve themselves into strychnine and arsenical poisoning.

The diagnosis is not usually difficult to make out.

Strychnine causes pain, twitchings, possibly vomiting and purging, but in fatal cases always characteristic tetanic convulsions-i. e., there is prolonged spasm of the muscles, with more or less frequent relaxation. They are powerful and continuous enough to kill the dog by exhaustion, or to suffocate him by prolonged spasm of the muscles of respiration, or there may be paralysis of the same muscles, which leads to death in a similar way.

Arsenic and many corrosive substances cause gastritis and enteritis; hence the burning thirst, vomiting, purging, etc., the dog usually dying from exhaustion or collapse. 
Treatment.-The object should be, of course, to get rid of the poison as soon as possible, so that it may act neither locally nor constitutionally; hence emetics, immediately after the poison has been swallowed, are always indicated unless the animal is already vomiting freely. For this purpose fifteen to twenty grains of sulphate of zinc, with a teaspoonful of wine of ipecac soon after, will usually prove the best. If this is not at hand, baking soda or washing soda dissolved in lukewarm water, or given in pills, may answer the purpose; also mustard in water. But every kennel should be provided with certain preparations against poisoning, such as laudanum, zinc sulphate, wine of ipecac, olive oil, calcined magnesia, lime-water, tincture of iron, bicarbonate of sodium, chloral hydrate, stimulants, etc. Very commonly the poison will have been absorbed before the dog is noticed; then the object must be to prevent the further local effects and keep the animal from sinking. Of course, expert assistance should always be sought, but in the mean time something may be done by an intelligent person.

Except in phosphorus poisoning, which is rare, oil may always be given; also calcined magnesia or limewater, as they are harmless and protect the stomach mechanically, which may be said of powdered charcoal and some other substances, as white of eggs, milk and flour, etc.

In strychnine poisoning an effort should be made to neutralize the effect of the agent on the spinal cord and brain. Bromide of potassium and chloral hydrate are the best physiological antidotes. Either may be given in twenty-grain doses, and, if they can not be administered by the mouth or retained in the stomach, they should be 
injected in solution in only a small quantity of water, well up into the bowel, and prevented from returning. The dose may be repeated, if necessary, till at least a drachm has been taken. Hypodermic injections of chloral are valuable.

The best antidote for arsenic is the hydrated oxide of iron, which can be quickly prepared by adding baking soda or washing soda to diluted tincture of iron so long as there is any effervescence-i. e., till the neutral point is reached. This may be given freely, say a tablespoonful every ten minutes.

When an animal's strength is failing, aromatic spirits of ammonia, carbonate of ammonium, or alcohol in repeated doses, are demanded.

In poisoning by mercury, little can be done to allay the symptoms, which are those of gastritis and enteritis, with corrosion of the mouth. The indications are to maintain the strength of the patient, as in other cases. If he survives the acute attack the mouth should be treated with astringent washes. Of course, the stomach should be protected mechanically, as in other cases.

Carbolic-acid pcisoning is marked by twitchings; possibly convulsions, or great prostration. The animal should be kept warm, and stimulants given. The danger of poisoning from lotions, ointments, etc., containing carbolic acid is not to be forgotten; but as recovery is more frequent than in poisoning by many other agents, treatment is hopeful.

Stings. - This subject may be briefly alluded to under the head of "Poisoning," as the danger and pain of stings arise in great part from the poison introduced into the wound. 


Even a single sting is painful enough, and when very numerous an animal's life is endangered. The same applies, but still more forcibly, to snake-bites. In the case of stings the best application is warm water and ammonia, sufficient of the latter to be very decidedly tasted. To prevent collapse and relieve pain, opiates and aromatic spirits of ammonia, or, in grave cases, carbonate of ammonium, say five grains every half hour till the worst is over, may be tried. In snake-bite, alcoholic stimulants should be combined, and the wound should, if possible, be quickly bathed with warm water or carbolic acid or cauterized with the solid nitrate of silver, which we have before recommended to be carried in the vest-pocket in a suitable holder, which may be readily purchased in any first-class druggist's shop.

In the case of snake-bite, it is well to put a ligature in the form of a pocket handkerchief around the limb, if that is the part injured, above the wound, to prevent the return of the blood to the heart till attempts have been made to remove the poison (sucking the wound is the best method) or to prevent its absorption by cauterization of the part.

\section{SANITARY AND MEDICAL ASPECTS OF DOG SHOWS.}

The whole environment of a dog show is an unnatural one from almost every point of view. The removal from the accustomed surroundings of home; the journey in a crate, with its enforced confinement; the unusual excitement with its strain on the nervous system, from the time the dog leaves home till he returns; the noise, loss of sleep, often vitiated atmosphere; the possibly foul bed, 
draughts, extremes of temperature, lack of exercise, change in food and water, and a hundred things (one need not enumerate all)-put a strain on the dog that tries him sorely even if there be no actual contagion of disease present in the form of mange, distemper, dysentery, etc.

Naturally all this tells most on young dogs with their less stable constitutions. In fact, a bench show is no place for a puppy; all the conditions are against him.

But every dog should be inspected daily. Doubtful cases should be removed to a little hospital, which should be, but is not, attached to all shows lasting more than one day.

The medical expert should be the consultant in regard to food, water, ventilation, disinfection, and all that pertains to the health of the dogs. The superintendent of the show should be a man intelligent enough to see that all directions are carried out properly, and discerning enough to detect cases of possible sickness in the absence of the medical man.

If puppies are brought to a show at all they should receive special attention, and a grain of quinine night and morning, in a routine way, is justifiable and wise.

Early removal (second day) is provided for by many shows-which is the next best thing to the entire absence of puppies from the first.

Much may be done, and should be done, to mitigate the discomfort of the show-bench for the canine occupants. Shows are indispensable as educators of the public, but to the dogs themselves their attractions are few and their trials and dangers many.

The points that require special attention are food, 
water, ventilation, a suitable temperature, avoidance of draughts, exercise at least twice daily, and the opportunity to attend to the calls of Nature thrice daily, disinfection, etc. All dogs should be carefully examined by a medical canine expert before admission, especially in regard to skin disease and distemper. Doubtful cases should be detained in a separate building for more prolonged examination and observation, and the doubt should be given against the individual dog, rather than imperil the whole canine gathering when suspicion can not be removed.

But the duties of the medical expert do not end with the preliminary inspection, which, as a matter of fact, is often far from thorough. If it is found that many dogs have unhealthy stools (diarrhœa, etc.), the food should be specially examined. Food should never be left before the animals more than an hour at most. Sour food is like poison to dogs. Often the water does not agree; if so, it should be boiled and cooled quickly, and, if there be a sediment, only the clear liquid should be used.

In truth, however, there are many things that only an experienced canine medical expert can, strictly speaking, well provide against ; and it would pay shows to obtain the services of such people, when they can be secured, for almost the entire time while the exhibition lasts.

During transportation of dogs it is better that they be fed rather sparingly on such food as will not tend to relax the bowels, so that they may not be compelled to soil their boxes. All crates should have holes in the bottom, to allow urine to run through. After a long journey, a dose of castor oil, moderate feeding, and a good deal of exercise are indicated. 


\section{TABLE OF DOSES OF THE PRINCIPAL DRUGS}

MENTIONED IN THIS WORK, FOR AN ADULT DOG OF 30-50 POUNDS.

Drugs are arranged very much according to their uses.

\begin{tabular}{l}
\hline Name of drug. \\
\hline Castor oil. \\
Syrup of buckthorn. \\
Fluid ext. of cascara \\
sagrada. \\
Epsom salts. \\
Flowers of sulphur. \\
Cream of tartar. \\
Compound rhubarb \\
pill. \\
Compound cathartic \\
pill.
\end{tabular}

Sodium bicarbonate.

Calomel.

Gray powder.

Jalap.

Elaterium.

Areca nut.

Santonin.

Fl. ext. pink and senna.

Eth. ext. male fern.

Oil of turpentine.

\section{Dose.}

1-2 oz.

$\frac{1}{2}-2$ ó.

10-40 drops. 1-4 drachms.

1-3 drachms. 1-3 drachms. 1-2 pills.

1-2 pills.

1-2 drachms.

2-4 grs.

2-6 grs.

8-15 grs. $\frac{1}{25}-\frac{1}{15} \mathrm{gr}$.

1-2 grs.

1-5 grs.

$\frac{1}{2}-1$ drachm. 10-30 drops.

10-30 drops.
As a laxative.

Remarks.

As a laxative; may be added to castor oil or given alone.

As a laxative, better to add a little powdered ginger, tinct. of ginger, etc.

As a laxative, may often be given with food.

As a laxative.

One pill given after the principal meal acts as a stomach tonic.

At night, followed by a saline in the morning.

With or without cream of tartar or powdered rhubarb as a laxative.

Always to be followed after a few hours by a saline.

In doses of 1-3 grains good for puppies with deranged liver. Must watch carefully against salivation, as with all preparations of mercury.

Usually combined with calomel.

A powerful purgative, causing watery stools.

Vermifuge; to be given in doses of 1-2 grains for each pound weight of the dog. Followed by castor oil in $\frac{1}{2}-1 \frac{1}{2}$ hour.

For puppies 1-3 grains, according to age, 2-3 times a day for two days; then follow with castor oil.

Better for puppies in doses of 5-30 drops, according to age, and in same way as santonin.

Very powerful remedy for tapeworm. Only to be used after areca nut has been tried. To be given in white of egg, mucilage, or oil, and followed in $\frac{1}{2}-1$ hour by castor oil.

To be given if areca nut fails, and with same precautions as malo fern. 
Name of drug.
Tinct. opii (lauda-
num).
Tinct. opii co. (paregoric).

Dover's powder.

Fl. ext. opium.

Pil. plumbi cum opio (lead and opium pill).

Sulphate of morphia.

Spirits of chloroform.

Potassium cyanide. Tinct. hyoscyamus.

Tinct. conium.

Tinct. belladonna.

Ext. belladonna.

Dilute prussic acid.

Tinct. senega.

Wine of ipecac.

Syrup of Tolu.

Syrup of squills.

Tinct. of squills.

Tinct. of aconite.

Potassium acetate.

Potassium bromide.

Ammonium carbonate.

Aromatic spirits of ammonia.

Spirits of nitric ether.

Tinct. of digitalis.

Fl. ext. ergot of rye.

Sulphate of quinine. Sulphate of iron.

\begin{tabular}{|c|} 
Dose. \\
\hline 5-30 drops. \\
$\frac{1}{2}-1$ drachm. \\
5-20 grs. \\
$5-30$ drops. \\
1 pill. \\
$\frac{1}{8}-\frac{1}{2}$ gr.
\end{tabular}

10-30 drops.

$\frac{1}{20}-\frac{1}{15} \mathrm{gr}$. 10-30 drops. 10-30 drops. 3-10 drops.

$\frac{1}{8}-\frac{1}{2} \mathrm{gr}$. 2-6 drops.

15-40 drops. 3-10 drops.

20-60 drops. 20-60 drops. 5-20 drops. 2-8 drops.

5-15 grs.

5-40 grs.

3-8 grs.

20-60 drops. 20-60 drops.

3-15 drops.

15-60 drops.

As a sedative for relief of pain, etc.

Remarks.

$\begin{array}{lll}\text { " } & \text { " } & \\ \text { " } & \text { "6 } & \text { " }\end{array}$

Every 2-4 hours for diarrhœa.

For relief of pain.

For relief of pain. Good sedative in cough mixtures.

As a sedative in cough mixtures.

As a sedative.

"6 "6

The officinal solution is to be employed. Useful in vomiting, etc.

As an expectorant in chronic bronchitis.

Useful to render expectoration loose. In doses of 2-5 drops useful in diarrhœa and dysentery.

Useful in bronchitis, especially when chronic.

Useful in bronchitis, etc.
“
6

Valuable to quiet the heart's action in fever. Fleming's tincture is very strong; dose, $\frac{1}{2}-1$ drop.

As a stimulant to the kidneys (diuretic).

A most valuable sedative; good adjunct of opium.

Valuable diffusible stimulant in pneumonia, etc.

For like use.

Stimulant to the kidneys; antifebrile remedy.

As a cardiac tonic best given in small doses and often (2-3 hours). As a diuretic, in larger doses, watching well its action.

To increase the contractions of the uterus and arrest hæmorrhage therefrom. For the latter purpose the extract of mistletoe is preferable.

1-2 grs.

$\frac{1}{2}-2$ grs.
As a tonic ; 7-15 grains as an antipyretic to lower temperature.
As a tonic. 


Name of drug.
Tinct, of iron.
Citrate of iron and
quinine.
Tinct. of nux vomica.

Ext. of nux vomica.

Tinct. of quassia.

Tinct. of gentian.

Compound tinct. of gentian.

Compound tinct. of cinchona.

Tinct. of rhatany.

Tinct, of kino.

Oxalate of cerium.

Subnitrate of bismuth.

Pepsin.

Bichloride of mercury (corrosive sublimate).

Wine of colchicum.

Iodide of potassium.

Syrup of the iodide of iron.

Liquor arsenicalis.

Salicylic acid.

Salicylate of sodium.

Potassium chlorate.

Sodium hyposulphite.

Biborate of sodium (borax).

Boric (Boracic) acid.

Sulphate of zinc.

Acetate of lead.

Tannic acid. \begin{tabular}{|c|c} 
Dose. & \multicolumn{1}{c}{ Remarks. } \\
\hline 5-15 drops. & $\begin{array}{l}\text { Valuable in erysipelas, diphtheria. } \\
\text { etc. }\end{array}$ \\
3-8 grs. & $\begin{array}{l}\text { A most excellent tonic when the } \\
\text { mopent }\end{array}$
\end{tabular} appetite is poor, etc.

3-10 drops. Valuable vegetable bitter; also stimulant to nervous system.

1-1 gr. Good to combine with other reme-

$\left.\begin{array}{l}\text { 5-15 drops. } \\ \text { 5-15 drops. }\end{array}\right\}$ dies in pill form. 5-15 drops.

Mild vegetable bitter; suits a weak stomach.

5-20 drops. Tonic to stomach and system generally.

10-30 drops. Internal astringents. Useful in 10-30 drops. $\}$ diarrhœa.

$1-4$ grs.

3-10 grs.

1-5 grs.

$\frac{1}{40}-\frac{1}{20} \mathrm{gr}$.

8-30 drops.

1-4 grs.

Sedatives to stomach in vomiting.

\} Useful in gastritis, diarrhœa,

dysentery.

Assists digestion. Useful in certain forms of dyspepsia.

Given cautiously, it is a valuable alterative to the nutrition.

Useful in rheumatism (acute).

Useful alterative in rheumatism, etc. Dose to be small at first, gradually increased, and closely watched. Well to combine with a vegetable bitter.

20-60 drops. Alterative. Useful in debilitated dogs of a certain class; acts also as a tonic.

3-20 drops. Small dose at first; gradually increased; occasionally stopped ; never given on an empty stomach.

5-10 grs. Useful in mange as an ointment; also for foul sores.

5-15 grs. Best remedy known for acute rheu. matism.

5-10 grs. Valuable as a blood tonic, etc., in diphtheria, etc.

3-10 grs. Useful in distemper.

5-10 grs. to Useful as a lotion.

$1 \mathrm{oz}$. of water.

5-10 grs. to

1 oz. of water.

3-15 grs. to

$1 \mathrm{oz}$. of water.

3-15 grs. to

1 oz. of water.

3-10 grs. to

1 oz. of water.
(

66

$66 \quad 66$

666

$66 \quad 66$ 
TABLE OF DOSES OF THE PRINCIPAL DRUGS. 399

\begin{tabular}{|c|c|c|}
\hline Name of drug. & Dose. & Remarks. \\
\hline Fl. ext. of golden seal. & $\frac{1}{2}-2$ drachms & Useful as a lotion. \\
\hline Nitrate of silver. & $\left|\begin{array}{c}5-20 \text { grs. to } \\
1 \text { oz of water. }\end{array}\right|$ & Useful in purulent ophthalmia. \\
\hline Carbolic acid. & $\begin{array}{c}1-20 \text { or } 1-40 \\
\text { (of water). }\end{array}$ & $\begin{array}{l}\text { Valuable as a lotion to allay irrita- } \\
\text { tion, disinfect, etc. }\end{array}$ \\
\hline Listerine. & $\begin{array}{l}\text { 5-30 drops, } \\
\text { internally. }\end{array}$ & $\begin{array}{l}\text { Useful in dyspepsia with flatu- } \\
\text { lency. Some prefer it to car- } \\
\text { bolic acid in lotions, etc.; non- } \\
\text { poisonous. }\end{array}$ \\
\hline $\begin{array}{l}\text { Phenacetin, antipy- } \\
\text { rin, etc. }\end{array}$ & $2-10 \mathrm{gl} \cdot \mathrm{s}$. & To reduce temperature. \\
\hline Caffein. & $\frac{1}{2}-1 \mathrm{gr}$ & Stimulant. \\
\hline $\begin{array}{l}\text { Hydrochlorate of apo- } \\
\text { morphia. }\end{array}$ & $\frac{3}{40}-\frac{3}{20} \mathrm{gr}$. & Expectorant. \\
\hline
\end{tabular}


.

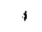

i

4
$\vdots$
4
4 


\section{N D EX.}

Abdominal organs, cancer of, 269. Abscess, perineal, 274. opening of, 386.

Absence of teeth in Turkish dog, 9. Acute cystitis, 278.

Acute laryngitis, 216.

Affections of the mouth, 247. of the nerves, 328 .

Airedale terrier, 56, 152.

Alimentary tract, diseases of, 244. structure of, 244.

Amaurosis, 311.

Amblyopia, 311.

Anæmia, 239.

Anæsthetics, 381.

Anatomy of the dog, 6 .

Anatomy and physiology of the eye, 302.

Aneurism, 242.

Animal body, 10.

Antisepsis, 382.

Anus, diseased condition around, 271. growths around, 274.

Apoplexy, 321.

Appetite, a capricious, 252.

Application to stimulate growth of hair, 344.

Arsenic, when to be used, 327.

Artificial selection, examples of, 60.

heat, 99.

Asthma, 230.
Autopsies, directions in making, 203.

Autopsies and morbid anatomy, 201.

Balanitis, 281.

Barrenness, 136.

Barzoi, 37.

Bassethound, description of, 43. illustration of, 52.

Beagle, description of, 41. illustration of, 48.

Bedlington terrier, 57, 160.

Bench-show form, 61.

Black Newfoundland dog, 78, 328.

Black-and-tan terrier, 50, 88.

Blain, 250.

Blood, diseases of, 237.

Bloodhound, description of, 38. illustration of, 40 .

Blood-vessels, diseases of, 242.

Bob-tailed sheep dog, description of, 78.

illustration of, 320 .

Brain, disease, 311. injuries to, 327.

Breeding, 125.

Breeds of dogs figured on Egyptian monuments, 3.

Bronchitis, 221. capillary, 221. verminous, 222 . Bronchocele, 243. 
Brood bitch, care of the, 135 . after whelping, care of the, 148 .

Bulldog, description of, 81 . illustration of, 344 .

Bull-terrier, description of, 55 . illustration of, 136.

Burns and scalds, 384.

Calculus, renal, cystic, 279 .

Cancer of abdominal organs, 269.

Canker, 296.

Capricious appetite, 252.

Care of the brood bitch, 135. after whelping, 148.

Care of the dog's skin, 117. of the stud dog, 134.

Castration, 387.

Cataract, 311.

Catarrh, nasal, 232.

Causes of disease, 182.

Characteristics of the dog, psychic, 15.

Chesapeake Bay dog, 74.

Chest jacket, 226.

Chlorate of potassium, 228.

Choice of puppies, 145.

Chorea, 325.

Chronic cystitis, 279. hepatitis, 268.

Classification of dogs, 18.

Cleanliness, 143.

Clubs, 22.

Clumber spaniel, $\mathbf{7 1}, \mathbf{2 4 0 .}$

Clydesdale terrier, 58.

Cocker spaniel, 69, 224.

Colic, 256-260.

Collie, the rough, description of, 77 . illustration of, 312. the smooth, description of, 77.

Color varieties, 92.

Common pathology, 213.

Complications incident to parturition, 288.

Composition of milk, percentage, 153.

Conjunctivitis, 306.

Constipation, 149, 254.

Constitutional diseases, 359.

Convalescence, 215.

Convulsions, etc., 318.

Cornea, opacities of, 310 . inflammation of, 310.

Crossing of dogs, 5 .

Cuts, 383.

Cutting operations, 386.

Cuvier's classification, 18.

Cystic calculus, 279 .

Cystitus, acute, 278. chronic, 279.

Dachshund, description of, 43. illustrations of, 56,60 .

Dalmatian, description of, 74 . illustration of, 280.

Dandie Dinmont terrier, the, 56 .

Darwin on the dog, 4 .

Deafness, 301.

Deerhound, description of, 36. illustration of, 16.

Degeneration of the liver, 268.

Description of disease, 206.

Determination of age, 171 .

Dhole, the, 19.

Diagnosis, 190. in influenza, 307 .

Diarrhœa, 253. of enteritis, 263.

Diet and care of the sick, 198. in eczema, 338 .

Differential diagnosis between colic, gastritis, etc., 260. of meningitis, 323 .

Digestive organs, functional disorders of the, 251. inflammatory affections of, 257 .

Dingo, 19.

Diphtheria, 361.

Discharges from the genitals, 294 .

Diseased condition around the anus, 271 . 
Diseases of the alimentary tract, 244.

of the blood and circulatory system, 237. of the blood-vessels, 242 .

of the ear, 295.

of the eye, 302 .

of the genital organs, 280 .

of the lymphatics and of certain glands, 243.

of the nervous system, 312 .

of the protective apparatus of the eye, 305.

of the respiratory organs, 209.

of the skin, 329.

of the skin, application of remedies, 335.

of the skin, diagnosis and varieties, 331.

of the skin, pathological condition and symptoms of, 330 . of the skin, principles of treatment, 336.

of the urinary system, 275 .

of the veins, 242 .

Disinfection, 200.

Dislocation of the eyeball, 312, 385.

Disposition and stamina, 133.

Distemper, 367.

causation, 368.

complications, 372 .

diagnosis, 371 .

nature of, 368.

prevention of, 369 .

prognosis, 372 .

symptoms, 371 .

treatment, 374 .

Dog, the, in health, 1.

absence of teeth in Turkish, 9 .

anatomy of, 6.

classification of, 18.

development of, 171 .

in disease, 178.

intelligence of, 16 .
Dog, the, normal temperature of, 184.

origin and history of, 1.

physical constitution resembling man's, 17.

psychic characteristics of, 15.

structure compared with man, 7.

wild and half reclaimed, 19.

zoölogical position of, 6 .

Dog shows, 393.

Dogs figured on Egyptian monuments, 3.

hunting by scent, etc., 38 .

hunting chiefly by the eye, etc., 34.

in health, management of, 94 .

Domesticated dogs, 38.

Dose, rule for, 194 .

Draughts, 214.

Dropsy, 362.

Drugs and their administration, 192.

Duke-Rhæbe blood, 68.

Dumb rabies, 318.

Dysentery, 261.

Ear, diseases of, 295.

Eczema, 333.

English greyhound, description of, 34. illustration of, 10.

Enteritis, 260.

Environment, 6.

Epileptic form, convulsions, 319.

Ergot of rye, 291.

Erysipelas, 359.

Esquimau dog, description of, 80.

Excretion, 117.

Exercise and occupation, 114.

and training of puppies, 161 .

of puppies, 169.

External parasites, 356.

Eye, diseases of, 302.

lotion, 309. 
Favus, 332.

Feeding, 101.

the nursing bitch, 149.

packs of hounds, etc., 111.

puppies, 156.

toy dogs, 112.

summarized, 113.

Fever, 187.

post-partum, 291.

Field form, 61.

Fissure of the nipple, 293.

Fistula in ano, 274.

Fits, 319.

Fleas, 356.

Follicular mange, 332.

Food in the mouth, 13.

Foodstuffs, 102.

Foster-mother, 147.

Foxhound, description of the, 39.

Fox-terrier, the, 48.

illustrations of, 64,72 .

Fractures and dislocations, 385.

Functional disease of the liver, 266.

disorders of the digestive organs, 251.

Gastritis, 260.

General principles of disease, 178.

Genital organs, 280.

Goitre, 243.

Goitre (bronchocele), 243.

Granular eyelids, 310.

Great Dane, 43.

Greyhound, English, description of, 34.

illustration of, 10.

Greyhound, Italian, description of, 92.

illustration of, 388.

Grooming, 123.

Grooming for the skin, 159.

Growths around the anus, 274.

Gun-shyness, 168.
Hæmorrhage, 294.

Hair, loss of, 331.

Harrier, 41.

Haw, inflamed, 306.

Heart disease, 240.

Hepatitis, 267. chronic, 267.

Hernia, 387.

Hints as to formulæ and administration of medicine, 234.

History of the dog, 1.

Housing of dogs, 96.

Hydrocephalus, 324.

Hydrophobia, 313.

Hyperæmia, 182.

Hypertrophy, 241.

Inbreeding, 132.

Incubation of rabies, 314.

Inflamed haw, 306.

Inflammation, 181.

and abscess of the lachrymal gland, 306.

of the middle ear, 300 .

of the tongue, 250 .

of the womb, 285.

Inflammatory diseases, 212.

affections of the digestive organs, 257.

Influenza, 215.

Injuries to the brain, 327 .

Instruments and the ear, 298.

Intelligence of the dog, 16 .

Internal parasites and worms, 345 .

Intestinal obstruction, 270 .

Intussusception, 205.

Irish terrier, 49, 80.

water spaniel, 72, 256.

Iritis, $\mathbf{3 1 0}$.

Irregularities of the bowels, 253.

Irritability of the skin, 344 .

Italian greyhound, 92, 388.

Jaundice, 266.

Kennel mixture, 343. 
Lachrymal ducts, gland, 306.

Laryngitis, 216.

Laverack strain of setters, 68 .

Lice, 353.

Life-history of worms, 348.

Liver, functional diseases of, 266. degeneration of, 268. organic affections of, $26 \%$.

Llewellin strain of setters, 68.

Local affections of the nasal passages, 232.

Lock-jaw (tetanus), 324.

Loss of hair, 344.

Lotion for the ear, 299.

Loup-Loup dog, 78.

Malpresentations, 289.

Maltese terrier, 58.

Mammary glands, 292.

Management of dogs in health, 94 . of puppies, 158.

Mange, follicular, 332. sarcoptic, 332.

Mastiff, description of, 83. illustration of, 352.

Mating, 131.

Meningitis, 322.

Method of studying the dog in disease, 189. administration of medicine, 195 .

Metritis, 285.

Mexican hairless dog, 93.

Milk as food, 106. in relation to worms, 351. percentage composition of, 153. secretion of, 144. teeth, 173.

Morbid growth, 284.

Mouth, affections of, 247.

Nasal catarrh, 232.

Nephritis, 279.

Nerves, affections of, 328.

Nervous system, structure and functions, diseases of, 312.
Neuralgia. 328.

Newfoundland, black, description of, 78.

illustration of, 328. other varieties, 79.

Normal temperature of the dog, 184.

Obstruction, 254, 270.

Ophthalmia, 307.

Organic affections of the liver, 267.

Origin and history of the dog, 1.

Otitis media, 300.

Otterhound, 42.

Ozæna, 234.

Paisley terrier, 58.

Paralysis, 321.

Paralytic form of rabies, 317 .

Paresis, 321.

Pariah, the, 19.

Parturition, complications incident to, 288.

Pasteur's inoculations, 314 .

Pastoral dogs, etc., 76.

Pathology in respiratory diseases, 213.

Pedigree in breeding, 132,

Percentage composition of milk, 153.

Percussion and auscultation, 219.

Perineal abscess, etc., 274.

Period of gestation, 137.

Peritonitis, 262.

Perverted appetite in dogs, 315.

Pharyngitis, 251.

Physical constitution resembling man's, 17.

Physiology of the dog, 11 .

Piles, 272.

Plethora, 240.

Pleurisy, 217.

Pneumonia, 222.

Pointing instinct, 59. 
Poisoning, 388.

Polypus, 301.

Pomeranian, the, description of, 78.

Poodle, description of, 75. illustration of, 300.

Post-partum fever, 291.

Preparation for whelping, 140.

Presence of a fifth toe in large breeds, 9 .

Prevalence of disease, 206.

Prognosis in respiratory diseases, 213.

Prolapse of the rectum, 271. of the vagina, 284.

Prophylaxis in respiratory diseases, 213.

Psychic characteristics of the dog, 15.

Pug dog, description of, 90. illustration of, 370.

Pulse, the, 187.

Puppies, exercise and training of, 161.

feeding, 156.

management of, 158.

rearing, 150 .

washing, 160 .

weaning, 152 .

Quality, 26.

Rabies (hydrophobia), 313. dumb, 318. incubation in, 314. paralytic form, 317 .

Rearing of puppies, 150.

Rectum, prolapse of, 271 .

Regions, anatomical, of the dog, 26. illustration of, 29.

Relative prevalence of disease, 208.

Remedies and their modes of use, 192.
Renal calculus, 279.

Respiration, 212.

Retention of urine, 276.

Retrievers, 73, 264.

Retrieving, $16 \%$.

Reversion, 131.

Rheumatism, acute, 365 . chronic, muscular, 367.

Rickets, 363.

Ringworm, 332.

plant causing, 343.

Rough collie, 77, 312.

Russian wolfhound or barzoi, 32,37 .

St. Bernard, description of, 86 . illustration of, 368 .

Salivary glands, 248.

Salivation, 251.

Sarcoptic mange, 332.

Schipperke, the, 92, 392.

Scotch terrier, the, 53, 104.

Secretion of milk, 144 .

Sense organs, 14.

Setter and pointer form, 62 .

Shedding of the teeth, 175 .

Sheep dogs, 76.

Skin, care of the, 117.

diseases of, 329.

grooming, 159.

structure and functions of, 117.

Skye terrier, 53, 120.

Spaniels, 69.

the clumber, $71,240$.

the cocker, $69,224$.

the English water, 73.

the field, 69, 216.

the Irish water, $72,256$.

the toy, $91,384$.

Spasms, 319.

Spaying, 387.

Specialism in breeding dogs, 22.

Spitz, the, 78.

Sprains and bruises, 384 .

Squint, 312.

Standards, 21. 
Standards, further considered, 25. summary of views on, 32 .

Stings, 392.

Stonehenge's classification, 18.

Structure of dog compared with man's, 7.

Stud dog, care of the, 134.

Summary of views on standards, etc., 32.

Surgery of the dog, 380 .

Table of doses of drugs, 396 .

Tape-worms, 346.

Teeth, the, 249.

diseases of, 249.

milk, 173.

shedding of, 175 .

Temperature of whelping apartment, 143.

normal, of the dog, 184 .

Terriers, general physical and psychic characteristics of, 45. Airedale, 56, 152.

Bedlington, 57, 160.

black-and-tan, 50, 88.

bull, 55, 136.

Clydesdale, 58.

Dannie Dinmont, 56.

fox, $48,64,72$.

Irish, 49, 80 .

Maltese, 58.

other breeds of, 55 .

Paisley, 58.

Scotch, 53, 104.

Skye, 53, 120.

Welsh, 56, 144.

white English (see-black-and $\tan ), 50,88$.

Yorkshire, 52, 96.

Tetarus, 324.

Tongue, inflammation of, 250 .

Tonic treatment, 236.

Toy dogs, 89.

Toy spaniels, description of, 91 .

illustration of, 384 .
Treatment of fits, 319.

Treatment of the bitch after conception, 137.

Tuberculosis, 231.

Tumors, 386.

Typical animal, a, 26.

Ulcers of the cornea, 309 .

Umbilical hernia, 387.

Urinary system, diseases of the, 275.

Urine of the dog, 275.

Urine, retention of, 276.

Use of instruments, the, 290.

Vagina, prolapse of, 284.

Vaginitis, 284.

Variations, 9.

Venous congestion, 182.

Ventilation, 139.

Verminous bronchitis, 222.

Vertigo, 321.

Vomiting, 251.

Vulvitis, 284.

Warts, 247.

Washing the dog, 122.

puppies, 152.

Watch-dogs and house-dogs, 80.

Weaning puppies, 152.

Welsh terrier, the, 56.

Whelping, 141.

Whippet, description of, 93 .

Wild and half-reclaimed dogs, 20.

Wild African dogs, 20.

American dogs, 20.

Wolfhound, Irish, description of, 36.

illustration of, 24 .

Wolfhound, Russian, description of, 37 .

illustration of, 32.

Womb, inflammation of, 285. 


\section{INDEX.}

Worms, 345.

diagnosis, 351.

kinds of, 348.

prevention of, 351.

round, 347 .

symptoms of, 350 .
Worms, tape, 346. treatment of, 352 .

Yorkshire terrier, 52, 96.

Zoölogical position of the dog, 6 .

(2) 


\section{TWENTIETH CENTURY TEXT-BOOKS.}

\section{TEXT-BOOKS OF ZOOLOGY.}

By David Starr Jordan, President of Leland Stanford Jr. University; Vernon Lyman Kellogg, Professor of Entomology; Harold Heath, Assistant Professor of Invertebrate Zoology; and George C. Price, Associate Professor of Zoology in Leland Stanford Jr. University.

\section{Animal Studies.}

A compact but complete treatment of elementary zoology, especially prepared for institutions of learning that prefer to find in a single book an ecological as well as morphological survey of the animal world. $12 \mathrm{mo}$. Cloth, \$1.25.

\section{Animal Life.}

An elementary account of animal ecology - that is, of the relations of animals to their surroundings. It treats of animals from the standpoint of the observer, and shows why the present conditions and habits of animal life are as we find them. It explains how the infinite variety of form and nature is the inevitable outcome of the struggle for existence. I2mo. Cloth, \$1.20.

\section{Animal Forms.}

This book deals in an elementary way with animal morphology. It describes the structure and life processes of animals, from the lowest, simplest, one-celled creations to the highest and most complex, discussing therewith the important subject of division of labor. I2mo. Cloth, \$1.10.

\section{Animals.}

This consists of "Animal Life" and "Animal Forms" bound in one volume, and groups the entire body of material needed for an elementary course in zoology in a handy and compact volume. I2mo. Cloth, \$1.80.

\section{Animal Structures.}

A laboratory guide in the teaching of elementary zoology. I2mo. Cloth, 50 cents.

$\begin{aligned} & \text { D. A P P L E TON A N D COM P A N Y, } \\ & \text { NEW YORK. } \\ & \text { BOSTON. }\end{aligned}$ CHICAGO.
LONDON.




\section{FRANK M. CHAPMAN'S BOOKS.}

\section{Bird Studies with a Camera.}

With Introductory Chapters on the Outfit and Methods of the Bird Photographer. By Frank M. Chapman, Associate Curator of Mammalogy and Ornithology in the American Museum of Natural His.ury. Illustrated with over 100 Photographs from Nature by the Author. $12 \mathrm{mo}$. Cloth, \$1.75.

Eird-Life. A Guide to the Study of our Common Birds.

Edition de Luxe, with 75 full-page lithographic plates, representing 100 birds in their natural colors, after drawings by Ernest Thompson-Seton. 8vo. Cloth, \$5.00.

Popular Edition in Colors. I2mo. Cloth, $\$ 2.00$ net; postage, I 3 cents additional.

Teachers' Edition. With 75 full-page uncolored plates and 25 drawings in the text, by Ernest Thompson-Seton. Also con. taining an Appendix with new matter designed for the use of teachers, and including lists of birds for each month of the year. I2mo. Cloth, \$2.00.

Teachers' Manual. To accompany Portfolios of Colored Plates of "Bird-Life." Contains the same text as the Teachers' Edition of "Bird-Life," but it is without the 75 uncolored plates. Sold only with the Portfolios, as follows:

Portfolio No. I.-Permanent Residents and Winter Visitants. 32 flates.

Portfolio No. II.-March and April Migrants. 3: p'ates.

Portfolio No. III.-May Migrants, Types of Birds' Eggs, Types of Birds' Nests from Photographs from Nature. 34 plates.

Price of Portfolios, \$1.25 each; with Manual, \$2.00.

The three Portfolios with Manual, \$4.00.

\section{Handbook of Birds of Eastern North America.}

With nearly 200 Illustrations, I2mo. Library Edition, Cloth, $\$ 3.00$; Pocket Edition, flexible morocco, $\$ 3.50$.
D. A P P L T O N
A N D
C OM PA N Y, NEW YORK. 



\section{UNIVERSITY OF CALIFORNIA LIBRARY}

\section{BERKELEY}

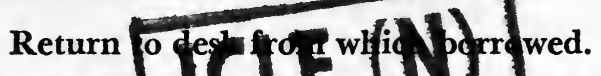

This book is DUK and last Uatestamped below.

$19 J u n 52 W \cdot N$ JUN 81952 LU

4 Jan'sith $X$

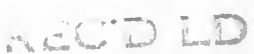

JAN 211957

$270 C+5 q$ AR REC. CIR DEC $6 \quad 1979$

LOAN DEPT.

MAY 30'67-8 PM

REC'D LD

NOV 281959 REC.CIR JUL 2180

JUN 021999

LD 21-95m-11,'50 (2877s16)476 
妁5 yo 20453

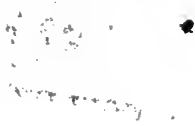

- t5

$\therefore$ 
